\title{
PHYSICS AND SAFETY ANALYSIS FOR THE NIST RESEARCH REACTOR
}

J. Carew, L. Cheng, A. Hanson, J. Xu, D. Rorer, D. Diamond

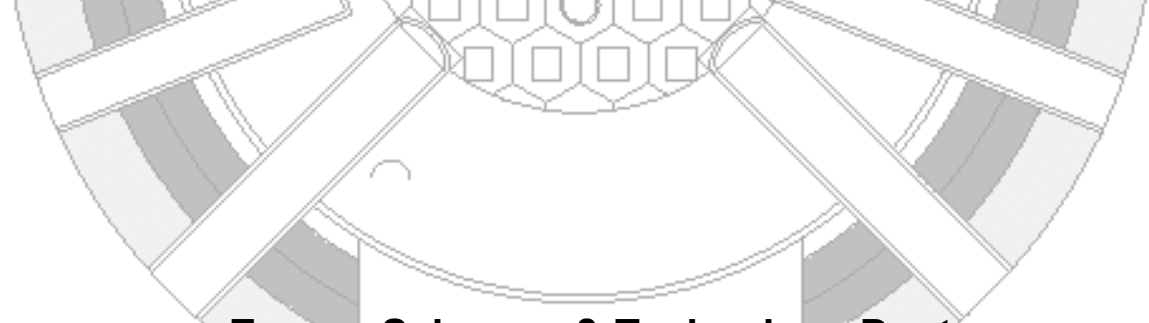

Energy Sciences \& Technology Dept.

Brookhaven National Laboratory

Upton, New York 11973-5000

Prepared for the

National Institute of Standards and Technology (NIST) 


\section{Technical Report BNL-NIST-0803}

\section{PHYSICS AND SAFETY ANALYSIS FOR THE NIST RESEARCH REACTOR}

Manuscript Completed: December, 2002

Date Published: August, 2003

Prepared by J. Carew, L. Cheng, A. Hanson, J. Xu, D. Rorer, D. Diamond

Brookhaven National Laboratory

Upton, NY 11973-5000

Prepared for

National Institute of Standards and Technology (NIST) 


\begin{abstract}
Detailed reactor physics and safety analyses have been performed for the $20 \mathrm{MW}_{2} \mathrm{O}$ moderated research reactor (NBSR) at the National Institute of Standards and Technology (NIST). The analyses provide an update to the Final Safety Analysis Report (FSAR) and employ state-of-the-art calculational methods. Three-dimensional MCNP Monte Carlo neutron and photon transport calculations were performed to determine the safety parameters for the NBSR. The core depletion and determination of the fuel compositions were performed with MONTEBURNS. MCNP calculations were performed to determine the beginning, middle, and end-of-cycle power distributions, moderator temperature coefficient, and shim arm, beam tube and void reactivity worths. The calculational model included a plate-by-plate description of each fuel assembly, axial mid-plane water gap, beam tubes and the tubular geometry of the shim arms.

The time-dependent analysis of the primary loop was determined with a RELAP5 transient analysis model including the pump, heat exchanger, fuel element geometry, and flow channels for both the six inner and twenty-four outer fuel elements. The statistical analysis used to assure protection from critical heat flux (CHF) was performed using a Monte Carlo simulation of the uncertainties contributing to the $\mathrm{CHF}$ calculation. The power distributions used to determine the local fuel conditions and margin to CHF were determined with MCNP.
\end{abstract}

Evaluations were performed for the following accidents: (1) the control rod withdrawal startup accident, (2) the maximum reactivity insertion accident, (3) loss-of-flow resulting from loss of electrical power, (4) loss-of-flow resulting from a primary pump seizure, (5) loss-of-flow resulting from inadvertent throttling of a flow control valve, (6) loss-of-flow resulting from failure of both shutdown cooling pumps and (7) misloading of a fuel element.

In both the startup and maximum reactivity insertion accidents, the core power transient is terminated by a reactor trip at $30 \mathrm{MW}$. The calculations show that both the peak reactor power and the excursion energy depend on the negative reactivity insertion from reactor trip.

Two cases were considered for loss of electrical power. In the first case offsite power is lost, resulting in an immediate scram caused by loss of power to the control rod system. In the second case power is lost to only the three operating primary pumps, resulting in a slightly delayed scram when loss-of-flow is detected as the pumps coast down. In both instances, RELAP5 results indicate that there is adequate margin to $\mathrm{CHF}$ and no damage to the fuel will occur, because of the momentum of the coolant flowing through the fuel channels and the negative scram reactivity insertion.

For both the primary pump seizure and inadvertent throttling of a flow control valve, the RELAP5 analyses indicate that the reduction in power following the trip is sufficient to ensure that there is adequate margin to $\mathrm{CHF}$ and the fuel cladding does not fail. The analysis of the lossof-flow accident in the extremely unlikely case where both shutdown pumps fail shows that the cooling provided by the $\mathrm{D}_{2} \mathrm{O}$ is sufficient to ensure the cladding does not fail. 
The power distributions were examined for a set of fuel misloadings in which a fresh fuel element is moved from a peripheral low-reactivity location to a central high-reactivity location. The calculations show that there is adequate margin to $\mathrm{CHF}$ and the cladding does not fail. 


\section{CONTENTS}

$\underline{\text { Page }}$

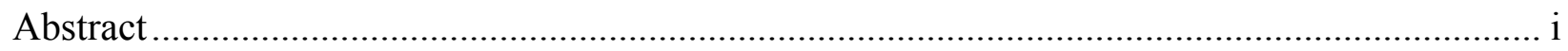

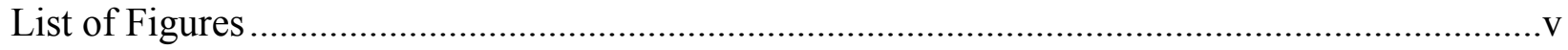

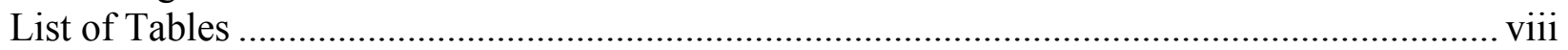

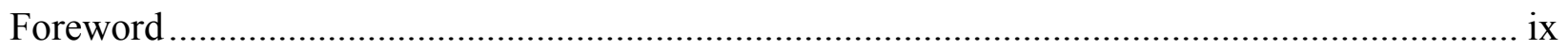

Acknowledgments....................................................................................................................

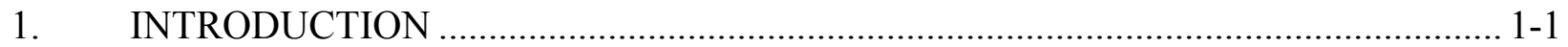

1.1 Background ................................................................................................ 1-1

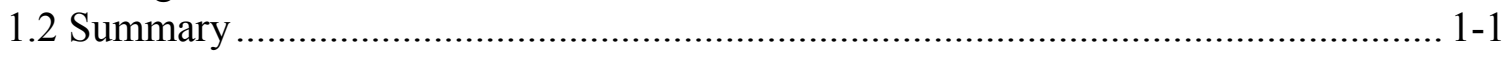

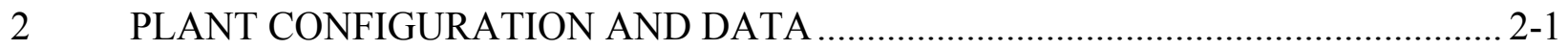

2.1 Description of the Core and Fuel ..................................................................... 2-1

2.2 Description of the Primary System ……………............................................. 2-3

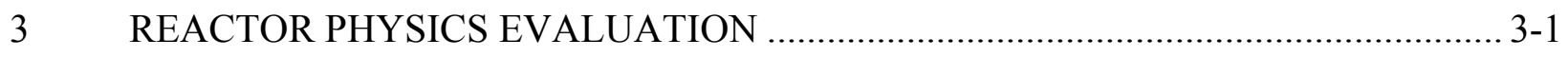

3.1 MCNP Reactor Physics Model …………………......................................... 3-1

3.2 Core Depletion Methodology …………………............................................. 3-2

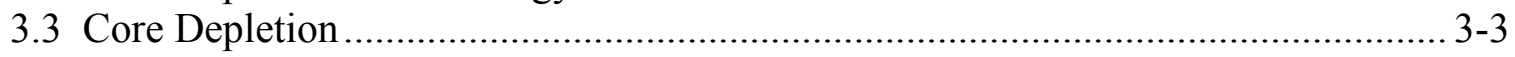

3.4 Steady State Power Distributions........................................................................ 3-4

3.4.1 Fuel Element Radial Power Distributions ...................................................... 3-4

3.4.2 Fuel Element Plate-Wise Power Distribution .................................................. 3-5

3.4.3 Fuel Element Axial Power Distribution...................................................... 3-5

3.4.4 Fuel Plate Transverse Power Density ........................................................... 3-5

3.5 Reactivity Effects................................................................................................ 3-6

3.5.1 Moderator Temperature Coefficient …………………................................ 3-6

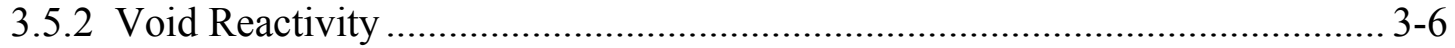

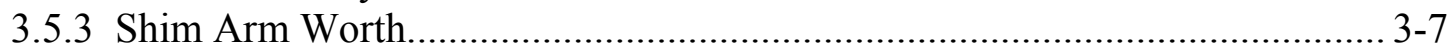

3.5.4 Regulating Rod Worth .......................................................................... 3-7

3.5.5 Beam Tube Reactivity.......................................................................... 3-7

3.5.6 Reactivity Associated with Upper Reflector Level ........................................ 3-7

3.5.7 Reactivity of Light Water Contamination.................................................... 3-8

3.5.8 Built-in Conservatism .......................................................................... 3-8

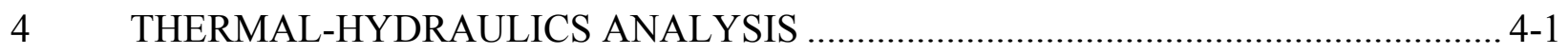

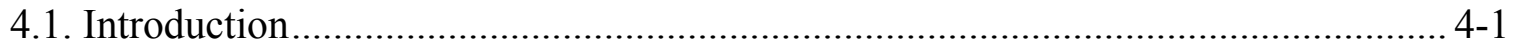

4.2 Methodology for Transient Analysis of the Reactor System................................... 4-1

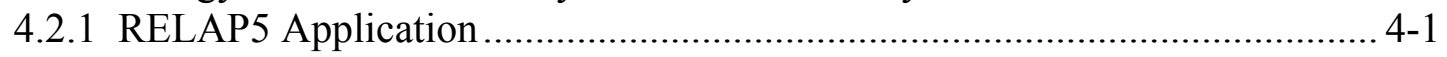

4.2.2 Modeling of the NBSR …………...................................................... 4-2

4.2.3 RELAP5 Input Data ............................................................................. 4-3 


\section{CONTENTS (cont'd)}

Page

4.3 Steady-State Thermal-Hydraulics Analysis ................................................. 4-8

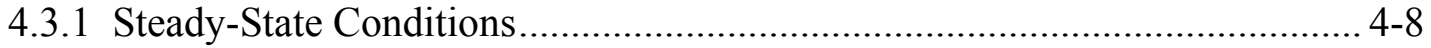

4.3.2 Core and System Predictions ................................................................ 4-8

4.4 Statistical Hot Channel Limits Analysis ....................................................... 4-9

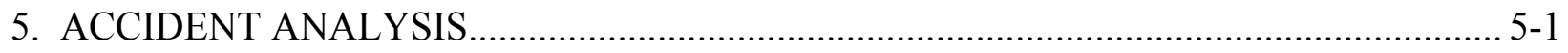

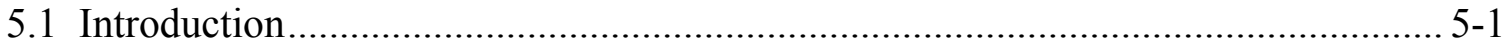

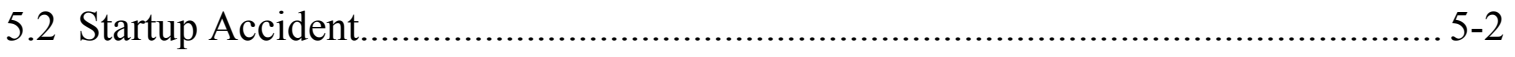

5.3. Maximum Reactivity Insertion Accident .................................................... 5-2

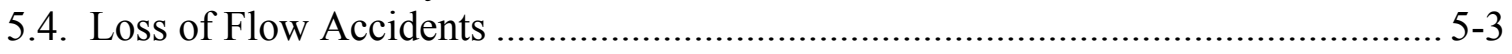

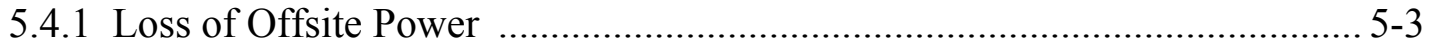

5.4.2 Loss of Electrical Power Feed to Primary Pumps ....................................... 5-3

5.4.3 Seizure of One Primary Coolant Pump...................................................... 5-4

5.4.4 Throttling of Coolant Flow to the Outer Plenum..................................... 5-5

5.4.5 Throttling of Coolant Flow to the Inner Plenum ...................................... 5-5

5.4.6 Loss of Both Shutdown Coolant Pumps ................................................... 5-6

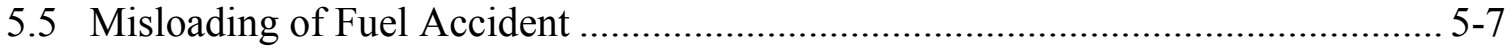

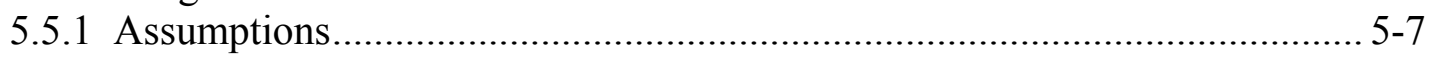

5.5.2 Radial Power Distributions ............................................................... 5-7

5.5.3 Safety Implications of a Misloaded Fuel Accident................................... 5-8

5.6 Heat Removal by Flow from the Inner Emergency Cooling Tank ......................... 5-9

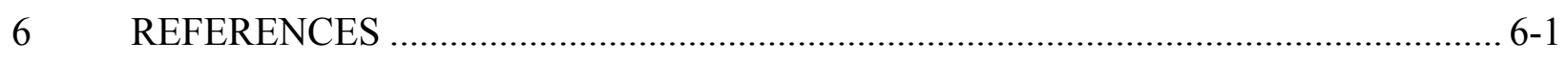

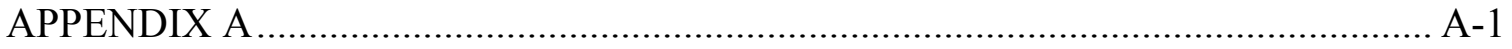

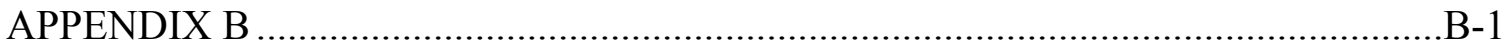

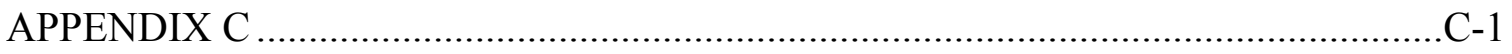

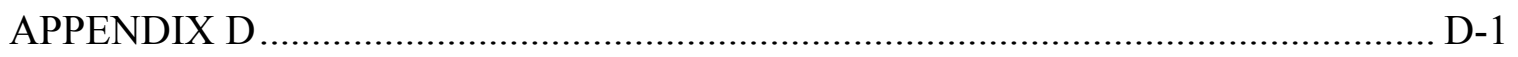

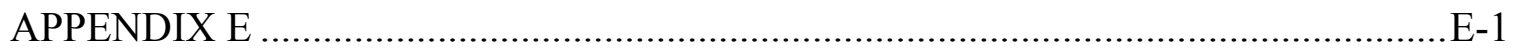




\section{FIGURES}

Figure No.

$\underline{\text { Page }}$

2-1 Vertical Cross-Section of the Reactor Vessel................................................2-6

2-2 Cutaway Isometric Drawing of Fuel Element …................................................ $2-7$

2-3 Detailed Cross-Section of Reactor Vessel at Mid-plane ........................................2-8

2-4 Dimensional Drawing of NBSR Fuel Element ....................................................2-9

2-5 Simplified Schematic of Primary Cooling System .............................................2-10

2-6 Exploded View of Plate Type Heat Exchanger ..................................................2-11

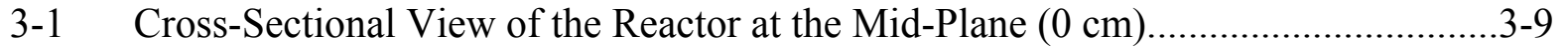

3-2 Cross-Sectional View of the Reactor at $-38.1 \mathrm{~cm}$ (-15 in) below the Mid-Plane .......3-10

3-3 MCNP Model of a Fuel Element ....................................................................... $3-11$

3-4 Fuel Designation Scheme and its Relation to the NBSR Fuel Element Positions.....3-12

3-5 $\quad{ }^{235} \mathrm{U}$ Inventory for Equilibrium Core at Startup, and Change in

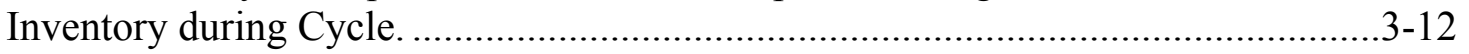

3-6 Actinide Inventory per Fuel Element as a Function of Irradiation Time for the 7-Cycle Fuel Elements..................................................................3-13

3-7 Actinide Inventory per Fuel Element as a Function of Irradiation Time for the 8-Cycle Fuel Elements ............................................................................... $3-13$

3-8 Relative Power Distribution for Each Fuel Element for the Core at Startup.............3-14

3-9 Relative Power Distribution for Each Fuel Element for the Equilibrium Core at Beginning-of-Cycle ............................................................................. $3-14$

3-10 Relative Power Distribution for Each Fuel Element for the Equilibrium Core at

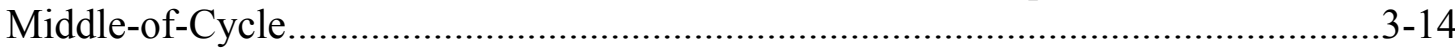

3-11 Relative Power Distribution for Each Fuel Element for the Equilibrium Core at End-of-Cycle.....

3-12 Percentage Change in the Fuel Element Power Levels for the Equilibrium Core from the Beginning-of-Cycle to the End-of-Cycle .............................................3-15

3-13 Relative Power Distribution per Fuel Element Plate for the Startup Core for the A-4 Fuel Element

3-14 Relative Power Distribution per Fuel Element Plate for the Startup Core for the E-2 Fuel Element

3-15 Relative Power Distribution per Fuel Element Plate for the Startup Core for the D-1 Fuel Element.

3-16 Relative power distribution per fuel element plate for the End-of-Cycle Core for the A-4 fuel element..

3-17 Relative Power Distribution per Fuel Element Plate for the End-of-Cycle Core for the E-2 Fuel Element.

3-18 Relative Power Distribution per Fuel Element Plate for the End-Of-Cycle Core for the D-1 Fuel Element .

3-19 Relative Axial Power Distribution for the Fuel Element in the A-4 Position in the Equilibrium Core at Startup..... 


\section{FIGURES (cont'd)}

Figure No.

Page

3-20 Relative Axial Power Distribution for the Fuel Element in the E-2 Position in the Equilibrium Core at Startup.

3-21 Relative Axial Power Distribution for the Fuel Element in the D-1 Position in the Equilibrium Core at Startup.....

3-22 Relative Axial Power Distribution for the Fuel Element in the A-4 Position in the Equilibrium Core at End of Cycle

3-23 Relative Axial Power Distribution for the Fuel Element in the E-2 Position in the Equilibrium Core at End-of-Cycle.

3-24 Relative Axial Power Distribution for the Fuel Element in the D-1 Position in the Equilibrium Core at End-of-Cycle.

3-25 Transverse Relative Power Distribution Along Each Fuel Element Plate.................3-22

3-26 Shim Arm Worth as a Function of Angular Position in the Equilibrium Core at Startup

3-27. Shim Arm Worth as a Function of Angular Position in the Equilibrium Core at End-of-Cycle

3-28. Reactivity Worth of the Regulating Rod as a Function of Relative Position (Percentage Withdrawn) in the Equilibrium Core at Startup.

3-29 Reactivity Worth of the Regulating Rod as a Function of Relative Position (Percentage Withdrawn) in the Equilibrium Core at End-of-Cycle

3-30 Core Reactivity as a Function of Upper Reflector Thickness Above Dump Level for the Equilibrium Core at Startup ....

3-31 Core Reactivity as a Function of Upper Reflector Thickness Above Dump Level for the Equilibrium Core at End-of-Cycle....

3-32 Shim Arm Reactivity Worth with the Upper Reflector Drained to the Dump Level for the Equilibrium Core at Startup

3-33 Shim Arm Reactivity Worth with the Upper Reflector Drained to the Dump Level for the Equilibrium Core at End-of-Cycle....

3-34 Reactivity Effect of $\mathrm{H}_{2} \mathrm{O}$ Contamination of the $\mathrm{D}_{2} \mathrm{O}$ Coolant ................................26

4-1 Simplified Loop Diagram of the NBSR Primary System .....................................4-11

4-2 Node Diagram of NBSR Reactor Vessel .......................................................4-12

4-3 Schematic of Coolant Channels in a Fuel Element...............................................4-13

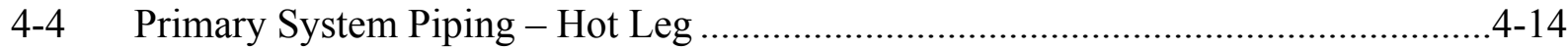

4-5 Primary System Piping - Cold Leg ............................................................. $4-15$

4-6 RELAP5 Model of NBSR Fuel Plate and Coolant Channel..................................4-16

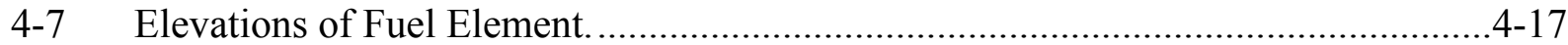

4-8 Primary Pump Performance Curves.................................................................4-18

4-9 Comparison of Pump Coastdown Calculation with Plant Data ................................4-18

4-10 Predictions of the Draining of the Inner Emergency Cooling Tank ........................4-19

4-11 Reactivity Worth of Shim Arms ....................................................................

4-12 Shim Arm Travel after Scram Initiation .......................................................4-20 


\section{FIGURES (cont'd)}

Figure No. $\quad \underline{\text { Page }}$

4-13 Lateral Power Distribution Across a Fuel Plate.................................................4-20

4-14 Relative Axial Power of Hot Fuel Element ..........................................................4-21

4-15 Coolant and Plate Temperature for Hot Channel in BOC Equilibrium Core ............4-21

4-16 Coolant and Plate Temperature for Hot Channel in EOC Equilibrium Core ............4-22

5-1 Startup Reactivity Insertion Excursion - BOC .................................................5-10

5-2 Startup Reactivity Insertion Excursion - EOC .............................................5-11

5-3 Maximum Reactivity Insertion Excursion - Equilibrium Core in Beginning of Cycle.

5-4 Fission Power Distribution Resulting from a Misloaded Fresh Fuel........................5-13

5-5 Comparison of Boiloff and Flow from Inner Emergency Cooling Tank..................5-14 


\section{TABLES}

Table No. $\quad \underline{\text { Page }}$

3-1 Determination of the Moderator Temperature Coefficient for the Four Cores .........3-27

3-2 Effects of Voids in the NBSR for the SU and EOC Conditions .............................3-28

3-3 Effects of Flooding of the Beam Tubes, the Cold Neutron Source and the Pneumatic Tubes for the SU Conditions...........................................................3-28

3-4 Effects of Flooding of the Beam Tubes, the Cold Neutron Source and the

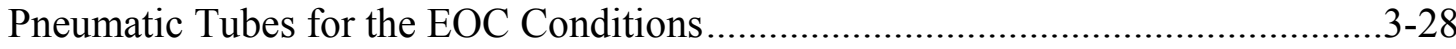

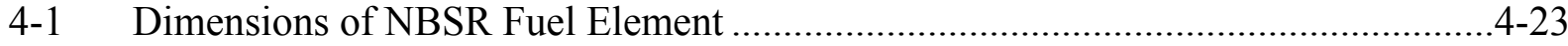

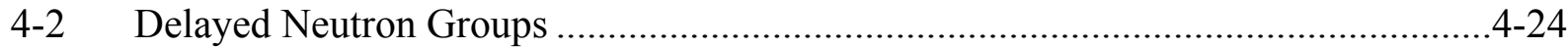

4-3 Dimensions of Various Coolant Channel Types in the Plated Region ......................4-25

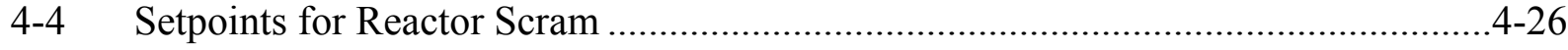

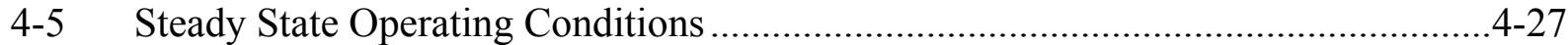

4-6 Steady State Core Thermal Analysis Results ......................................................28

4-7 Steady State Core Thermal Analysis Results .......................................................4-29

5-1 Reactor Response to Startup Accident.........................................................5-15

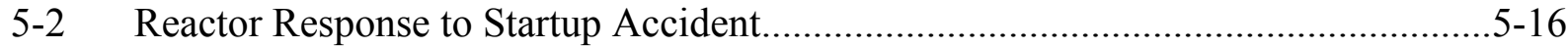

5-3 Reactor Response to Maximum Reactivity Insertion ......................................5-17

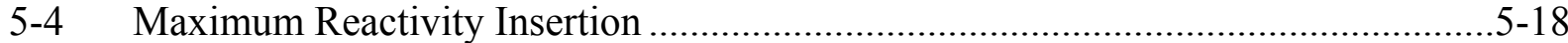

5-5 Transient Conditions at Hot Spot Following Loss of Commercial Power to Plant...5-19

5-6 Transient Conditions at Hot Spot Following Loss of Primary Pumps .....................5-20

5-7 Transient Conditions at Hot Spot Following Pump Seizure ..................................5-21

5-8 Transient Conditions at Hot Spot Following Pump Seizure ....................................5-22

5-9 Transient Conditions At Hot Spot Following Inner Plenum Flow Control Valve Throttling ..................................................................................5-23

5-10 Transient Conditions of Coolant Following Loss of Shutdown Cooling .................5-24

5-11 Transient Conditions of Fuel Plate Following Loss of Shutdown Cooling ..............5-25

5-12 Relative Assembly Power Due to Misloading of Fresh Fuel.................................5-26

5-13 Minimum Critical Heat Flux Ratio for the Misloaded Fresh Fuel ...........................5-27 


\section{FOREWORD}

The work presented in this report was completed in December 2002. Since that time, an improved MCNP model has replaced the one used for the analysis given in the report. The new model includes additional structural aluminum, including shim arm catchers and guides. The new geometrical model has an impact on the prediction of critical shim arm angle, makes power distributions slightly less peaked, and has an insignificant impact on differential quantities such as reactivity coefficients or control element worth. Hence, the safety analysis presented herein is either conservative relative to the new model or not significantly impacted. 


\section{ACKNOWLEDGMENTS}

The work documented in this report was performed under the auspices of the National Institute of Standards and Technology (NIST) and was funded by the NIST Center for Neutron Research. The program was monitored at NIST by Dr. Seymour Weiss, whose support of this work is greatly appreciated. The authors are also grateful to Drs. Menashe Gazit and Robert Williams of NIST for their cooperation, support and many valuable discussions during the course of this work.

The authors would also like to thank Ms. S. Monteleone for her help in preparing this report. 


\section{INTRODUCTION}

\subsection{Background}

The final safety analysis report (FSAR) for the NIST research reactor (NBSR) was documented in April 1966 [1] and supported the NBSR initial criticality in December 1967. The FSAR provided the required assurance that the consequences of reactor operation and the postulated accidents did not result in undue risk to the public. The 1966 analysis was updated in the 1980 Addendum-1 [2] to support the increase in NBSR power level from $10 \mathrm{MW}$ to $20 \mathrm{MW}$, which occurred in May of 1985. Further updates occurred in 1994 and 1998 [3, 4] that documented several major improvements to the NBSR physical plant and experimental facilities.

The analyses described in this report provide an update to analyses in the FSAR and use state-ofthe-art calculational methods to provide additional detail for the accident consequences and quantification of the conservatism in the original evaluations. The new analysis also takes into account recent changes in design of the cold source (although this does not make a significant change to any safety parameters.) The previous analyses which utilize a core physics description and/or a time-dependent integral description of the primary loop were reevaluated. In this updated analysis, detailed three-dimensional MCNP Monte Carlo neutron and photon transport [5] calculations were performed to determine the behavior of the key safety parameters for the NBSR. The core depletion and determination of the fuel compositions were performed with MONTEBURNS [6]. The time-dependent analysis of the primary loop was determined with the RELAP5 transient analysis code [7].

In addition to the evaluation of the core physics and accident analysis, the statistical analysis used to assure protection from critical heat flux (CHF) has been reevaluated using a full Monte Carlo simulation of the uncertainties contributing to the CHF calculation. This is more realistic than the previous FSAR analysis since it allows the variation of the individual uncertainty components to be random and independent, rather than making the extremely conservative assumption that all components are at their maximum values.

\subsection{Summary}

Detailed evaluations were performed for accidents involving

1) excessive positive reactivity insertions (startup withdrawal of rods, rapid withdrawal of large reactivity worth experiments, misloading of fuel elements), and

2) power-cooling mismatch accidents (loss of electrical power for primary pumps, pump seizure, closure of throttling valve, loss of both shutdown coolant pumps).

A detailed three-dimensional MCNP Monte Carlo model was used to calculate the NBSR core physics input for the accident analyses, including the beginning- and end-of-cycle power distributions, moderator temperature coefficient, as well as the reactivity worths of the shim arms, beam tubes and voids. This model included a plate-by-plate description of each fuel 
assembly, the water gap at the axial mid-plane, the beam tubes and the geometry of the shim arms. The power distributions were used to determine the local fuel conditions and the CHF ratios (CHFRs) during the transient.

The reactivity and flow transients were calculated using a detailed RELAP5 model. The model included the primary piping from vessel inlet to outlet, primary pump and heat exchanger, fuel element geometry and flow area, and flow channels for the six inner and twenty-four outer fuel elements. The initial operating parameters (flows, temperatures, power level and distribution, etc.) were assumed to be at their most limiting values or at the Limiting Safety System Setpoints (LSSSs). The NBSR reactor protection system logic was modeled and initiated a trip, after the appropriate instrumentation response delay, when the set point was reached. The limiting fuel temperature, CHFR and fuel enthalpy were calculated.

The results of these detailed calculations confirm the conservatism of the assumptions and corresponding predictions published in the previous versions of the FSAR. Even with the less conservative, more realistic values used in the current evaluations, there is adequate margin to $\mathrm{CHF}$ and no fuel damage is predicted for any of the accidents considered.

The details of these analyses are presented in the following sections. The NBSR plant data used to construct the MCNP and RELAP5 calculational models are given in Section 2. The MCNP physics models and the calculation of the key reactor physics safety parameters are described in Section 3. The NBSR thermal-hydraulics analysis and statistical evaluation of the CHFR at steady state are presented in Section 4. The assumptions made in developing the accident scenario and the consequences predicted for each accident are given in Section 5. 


\section{PLANT CONFIGURATION AND DATA}

The descriptive information and data set forth in this section were drawn from documents supplied by NIST [1 - 4].

The NBSR reactor is a heavy water moderated and cooled, enriched fuel, tank type machine designed to operate up to $20 \mathrm{MW}$ power. It consists of an aluminum vessel filled with heavy water which also contains the core of plate-type enriched fuel elements. These elements differ from the usual plate type elements by the inclusion of an unfueled gap separating the fueled sections of each plate above and below the midplane of the core.

Surrounding the vessel is the thermal shield (an iron/lead light water cooled structure), and an outer high density concrete biological shield, penetrated by various neutron beam tubes. These re-entrant beam tubes are welded to the reactor aluminum vessel, terminating in the vicinity of the vertical fuel gap. This design permits the extraction of highly thermalized neutron beams with a significantly reduced fast neutron component.

Another unique feature of the NBSR deign is the double plenum at the bottom of the vessel. These two independent concentric plenums permit the coolant flow to the inner and outer array of elements to be separately controlled.

A significant safety feature of the NBSR is the means for providing extensive heavy water emergency cooling. In addition to the usual overhead tank that can supply water either to the top or to the bottom of the elements, two inner structures within the reactor vessel retain heavy water in the event of a loss of water from the vessel. One of these structures supplies coolant flow to the elements and the other maintains water around the lower half of the core. It should be noted that the ability to feed emergency coolant to the lower plenum permits forcing water up through the elements.

\subsection{Description of the Core and Fuel}

Figure 2-1 shows an elevation drawing of the reactor. The core is contained in an aluminum tank $2.13 \mathrm{~m}(7 \mathrm{ft})$ in diameter and $4.88 \mathrm{~m}(16 \mathrm{ft})$ high. By the use of fuel elements with an unfueled center section (depicted in Figure 2-2), the core is split into an upper and lower section. Each of these fueled sections is $1.12 \mathrm{~m}$ (44 in) in diameter and $0.279 \mathrm{~m}$ (11 in) thick. The unfueled gap between the two fueled sections is $0.177 \mathrm{~m}$ ( $7 \mathrm{in})$. The overall dimensions of the core are $1.12 \mathrm{~m}$ (44 in) in diameter by $0.737 \mathrm{~m}$ ( $29 \mathrm{in}$ ) high. The fuel elements are supported by two grid plates $1.57 \mathrm{~m}(62 \mathrm{in})$ apart. The top of the lower grid plate is $0.229 \mathrm{~m}(9 \mathrm{in})$ below the bottom of the core and the bottom of the top grid plate is $0.610 \mathrm{~m}$ ( $24 \mathrm{in}$ ) above the top of the core.

The fuel elements are located on $0.177 \mathrm{~m}$ ( $7 \mathrm{in}$ ) centers in a hexagonal array. The relatively large spacing makes the NBSR a well-thermalized reactor, and at the same time makes it possible to introduce many in-core experimental facilities in addition to the beam holes and thimbles located in the reflector. The grid plates provide for 37 fuel element positions and four $6.35 \mathrm{~cm}(2.5 \mathrm{in})$ semi-permanent irradiation thimbles. Seven of the fuel positions are especially adapted for 8.89 $\mathrm{cm}(3.5 \mathrm{in})$ experimental thimbles, leaving 30 positions for fuel elements. A cross section of the 
midplane of the core is shown in Figure 2-3.

Cooling water enters through a double set of plenums at the bottom of the fuel, passes up through the fuel and into the reactor vessel, and then out through two outlet tubes in the bottom of the vessel. The inner six fuel positions and the G4 thimble are fed by one plenum and the remainder by a second concentric plenum.

The reactor is pressurized to approximately $996 \mathrm{~Pa}$ (4 inches of water) by means of a helium blanket. At $20 \mathrm{MW}$ the nominal inlet temperature of the $\mathrm{D}_{2} \mathrm{O}$ coolant is $37.8^{\circ} \mathrm{C}\left(100^{\circ} \mathrm{F}\right)$ and its outlet temperature is about $45.6^{\circ} \mathrm{C}\left(114^{\circ} \mathrm{F}\right)$. Since most of the neutron moderation is done in the $\mathrm{D}_{2} \mathrm{O}$ surrounding the fuel, rather than within the fuel element itself, the average moderating temperature is approximately the same as the coolant outlet temperature.

The side reflector is $0.508 \mathrm{~m}$ ( $20 \mathrm{in}$ ) thick and the top reflector thickness is determined by a 7.62 $\mathrm{cm}$ (3 in) overflow pipe which maintains a water level at about $3.00 \mathrm{~m}$ (118 in) above the top of the core. This large space above the core allows transferring of fuel elements to the fuel element transfer chute and shuffling of in-core elements.

There is another low level overflow pipe located at the upper grid plate elevation, concentric with the $7.62 \mathrm{~cm}$ ( $3 \mathrm{in}$ ) overflow pipe. This overflow is used whenever fuel elements are being transferred in a helium atmosphere (low water level). A third overflow, concentric with the fuel element transfer chute, serves as a moderator dump and can be used to drop the water level to $2.54 \mathrm{~cm}$ ( $1 \mathrm{in})$ above the core for emergency shutdown of the reactor.

The NBSR has two types of control rods. Primary control of the reactor is accomplished by use of four "semaphore" shim safety arms. Fine control is provided by the use of a single vertical regulating rod.

The four shim safety arms are each $2.54 \mathrm{~cm}(1 \mathrm{in})$ thick by $12.7 \mathrm{~cm}(5 \mathrm{in})$ wide and have a 1.32 $\mathrm{m}$ (52 in) poisoned length. The hollow interior is filled with helium and the $1.02 \mathrm{~mm}$. (0.040 in) thick cadmium poisoned volume is clad with aluminum on both the outside and inside. The arms pivot on hanger brackets just under the upper grid plate, with drive mechanisms penetrating the vessel through rotating leak-tight seals. The total reactivity worth of the four shim safety arms is about $26 \%$ and the worth of a single arm is about $6 \frac{1}{2} \%$.

The regulating rod consists of a solid aluminum cylinder, $6.35 \mathrm{~cm}(2.50 \mathrm{in})$ in diameter by 0.737 $\mathrm{m}$ (29 in) long. It is located in vertical thimble G6. The vertical drive mechanism is mounted in the top plug and is of standard commercial design. The volume of the regulating rod void combined with its aluminum structure as a poison is designed to make the reactivity worth approximately $0.6 \%$. 
As described above, the NBSR fuel elements are MTR plate type elements with a built-in water gap separating the upper and lower fueled sections of the plates (refer to Figure 2-2). Each of the two fueled sections consists of seventeen fuel plates. Two unfueled, curved outside plates and two side plates form a box section structure which surrounds the fuel plates. Figure 2-4 is an assembly drawing giving pertinent dimensions and tolerances.

All materials used in the NBSR fuel element contain less than $10 \mathrm{ppm}$ of boron and less than 30 ppm of cadmium. The fuel core is of a slug type, consisting of $\mathrm{U}_{3} \mathrm{O}_{8}$ mixed with an aluminum powder, with the uranium enriched to a minimum of $93 \%{ }^{235} \mathrm{U}$. The cladding and core materials are metallurgically bonded by hot rolling processes. The uranium content is about $1 \mathrm{gm} / \mathrm{cm}^{3}$. The

${ }^{235} \mathrm{U}$ content of each fuel plate core is $10.3 \pm 0.1$ grams, with 17 plates in the upper section and 17 plates in the lower section yielding a ${ }^{235} \mathrm{U}$ content for each fuel element of 350 grams.

The bottom adapter for each element is both an inlet nozzle and a valve. Coolant first enters the internal passage of the bottom adapter and flows up through an internal conical transition section to the lower portion of the box section. The coolant then flows through the channels between the fuel plates, and between the fuel plates and the outside unfueled plates, before exiting through the upper box section and out the top adapter. A small amount of coolant is also bypassed around the external surface of the lower nozzle to prevent any possibility of bulk stagnation. This bypass flow is possible only when the exterior conical section of the lower adapter is lifted off a mating conical seat in the lower grid plate. A $0.3 \mathrm{~mm}(.012 \mathrm{in})$ gap then exists between the nozzle and the hole in the grid plate. The element is spring loaded down by the latch mechanism which is described below. The lifting force necessary to achieve the bypass flow results from the hydraulic drag of the coolant on the fuel assembly. If flow should cease for any reason, the elements will drop down on the seats and so hold at least a portion of the bulk coolant in the hold-up pan which surrounds the core to mid-fuel height.

The upper adapter contains a spring-loaded cross bar which locks the fuel element into the grid plate structure. When the fuel element has been fully inserted through the upper grid plate into the lower grid plate, further downward pressure on the handling head causes the spring to compress and bring the cross bar down inside the upper adapter to a position just under the upper grid plate. The crossbar may then be rotated counterclockwise to engage into small notches in the bottom surface of the upper grid plate. The fuel element is thus locked between the grid plates. When flow exists, the spring is further compressed, and a gap is created between the bottom adapter of the fuel rod and its seat, allowing for small bypass flow to the hold-up pan. It is forced directly against the cross bar and seats the bar firmly into the grid plate notches.

\subsection{Description of the Primary Coolant System}

The primary coolant system, as shown in Figure 2-5, circulates heavy water through the reactor. This system is designed to transfer $20 \mathrm{MW}$ of heat from the core to the secondary cooling system, while operating at a nominal flow of $568 \mathrm{l} / \mathrm{s}(9000 \mathrm{gpm})$ with a reactor inlet temperature of $37.8^{\circ} \mathrm{C}\left(100^{\circ} \mathrm{F}\right)$ and an outlet temperature of $45.6^{\circ} \mathrm{C}\left(114^{\circ} \mathrm{F}\right)$. 
Four main coolant and two shutdown coolant pumps are arranged in parallel. From the discharge header of the primary coolant pumps, water passes through two main heat exchangers and a reactor inlet strainer. Then, for the equilibrium core at $20 \mathrm{MW}$, approximately $145 \mathrm{l} / \mathrm{s}$ (2300 gpm) of heavy water enters the inner plenum to cool the central six fuel elements, and the remaining $423 \mathrm{U} / \mathrm{s}(6700 \mathrm{gpm})$ is directed to the outer twenty-four fuel elements via the outer plenum. About $4 \%$ of the total flow in each plenum bypasses the fuel elements and cools the various in-core thimbles. The water passes up through the fuel elements and down the outside, leaving the reactor vessel through two $0.305 \mathrm{~m}$ (12 in) diameter pipes which join outside the subpile room. After passing through a venturi the water enters the pump suction header.

A portion of the $\mathrm{D}_{2} \mathrm{O}$ in the primary coolant system is diverted to the purification system by the $7.62 \mathrm{~cm}$ (3 in) reactor overflow line. Purified water is then normally returned to the primary system via the emergency cooling tank.

Thermal expansion and contraction of the $\mathrm{D}_{2} \mathrm{O}$ is absorbed by a $55,455 \ell$ (14,650 gallon) storage tank which also acts as a reservoir for $\mathrm{D}_{2} \mathrm{O}$ dumped from the core tank.

The main heat exchangers, HE-1A, HE-lB, and HE-lC are of a single pass and counter-flow design, fabricated of carbon and stainless steel using plate-and-frame construction. The basic unit of construction consists of two $8 \mathrm{~mm}(0.314$ in) thick stainless steel plates welded together forming a tall, thin chamber (called a "cassette") to contain the downward flow of primary $\left(\mathrm{D}_{2} \mathrm{O}\right)$ coolant. A set of grooved passages is provided for this coolant by stamping a herring-bone pattern of depressions in each plate before welding. Each heat exchanger has 132 cassettes stacked side-by-side, with nitrile gaskets sandwiched between them, forming 131 thin vertical volumes between the cassettes to contain the upward flow of secondary coolant. The stainless steel cassette plates thus form a barrier between the primary and secondary coolant, but allow the transfer of heat across the barrier. This arrangement is depicted in Figure 2-6.

Gasketed inlet and outlet orifices in each cassette allow all of the primary coolant chambers to be connected in parallel. Similarly, a set of gasketed ducts traversing each cassette at the top and bottom provide connected passages (external to the cassette chambers) serving as parallel inlets and outlets for all of the secondary coolant volumes between the cassettes. Two carbon steel pressure plates, one at each end of the gasketed cassette assembly, are clamped together by tightening bolts, compressing the nitrile gaskets and assuring a leak-tight seal. This design prevents mixing of the primary and secondary coolant; any leakage of either the primary or secondary coolant will be to the exterior surface of the heat exchanger.

Each heat exchanger has a design temperature of $93^{\circ} \mathrm{C}\left(200^{\circ} \mathrm{F}\right)$ at a design pressure of $1034 \mathrm{kPa}$ $(150 \mathrm{psi})$ and will transfer a heat load of $10 \mathrm{MW}\left(34 \times 10^{6} \mathrm{BTU} / \mathrm{hr}\right)$ to the secondary water system. Two heat exchangers are normally in service, with the third serving as an installed spare. Total allowable pressure drop on the primary and secondary sides is $34.7 \mathrm{kPa}$ (5.03 psi) and $41.2 \mathrm{kPa}(5.98 \mathrm{psi})$, respectively. 
The four main coolant pumps are single stage centrifugal units operating in parallel. They are of the shaft sealed type. Each pump motor is a single speed, $480 \mathrm{~V}, 3$ phase, $60 \mathrm{cps}$ unit having a rating of $100 \mathrm{~kW}(125 \mathrm{hp})$. At the required head, each pump is capable of supplying $190 \mathrm{l} / \mathrm{s}$ (3000 gpm), so that during normal power operation three pumps are required to maintain the required flow of $570 \mathrm{l} / \mathrm{s}(9000 \mathrm{gpm})$. The fourth pump serves as a spare.

Two $50 \mathrm{l} / \mathrm{s}$ (800 gpm) centrifugal pumps are installed in parallel with the main coolant pumps to provide forced cooling to the reactor during shutdown periods and in the event of a power failure to the main pumps. Each pump has a $6 \mathrm{~kW}(7.5 \mathrm{hp}) \mathrm{AC}$ motor and a like size DC motor connected to a single shaft turning at $1150 \mathrm{rpm}$. 


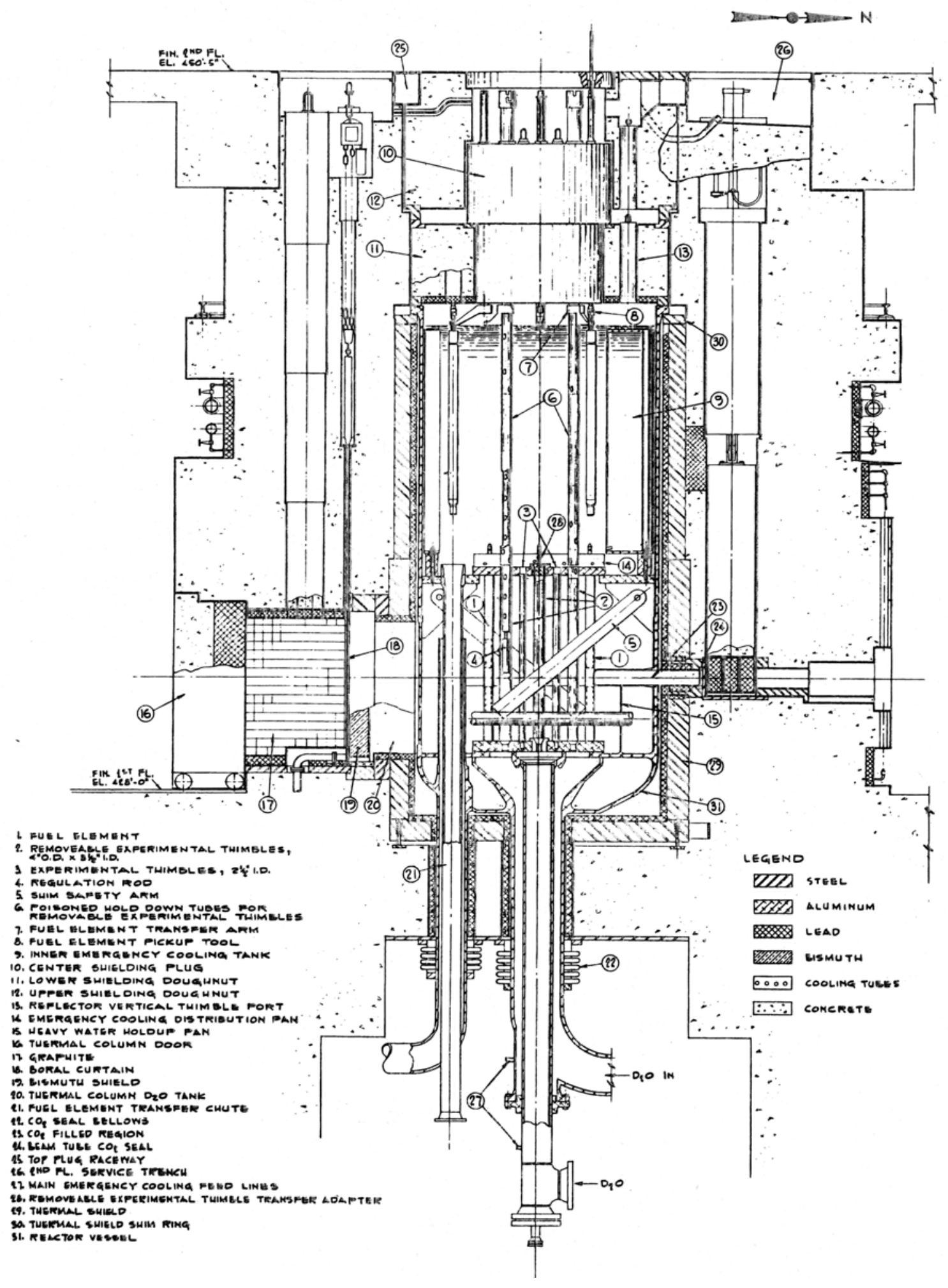

Figure 2-1. Vertical Cross-Section of the Reactor Vessel 


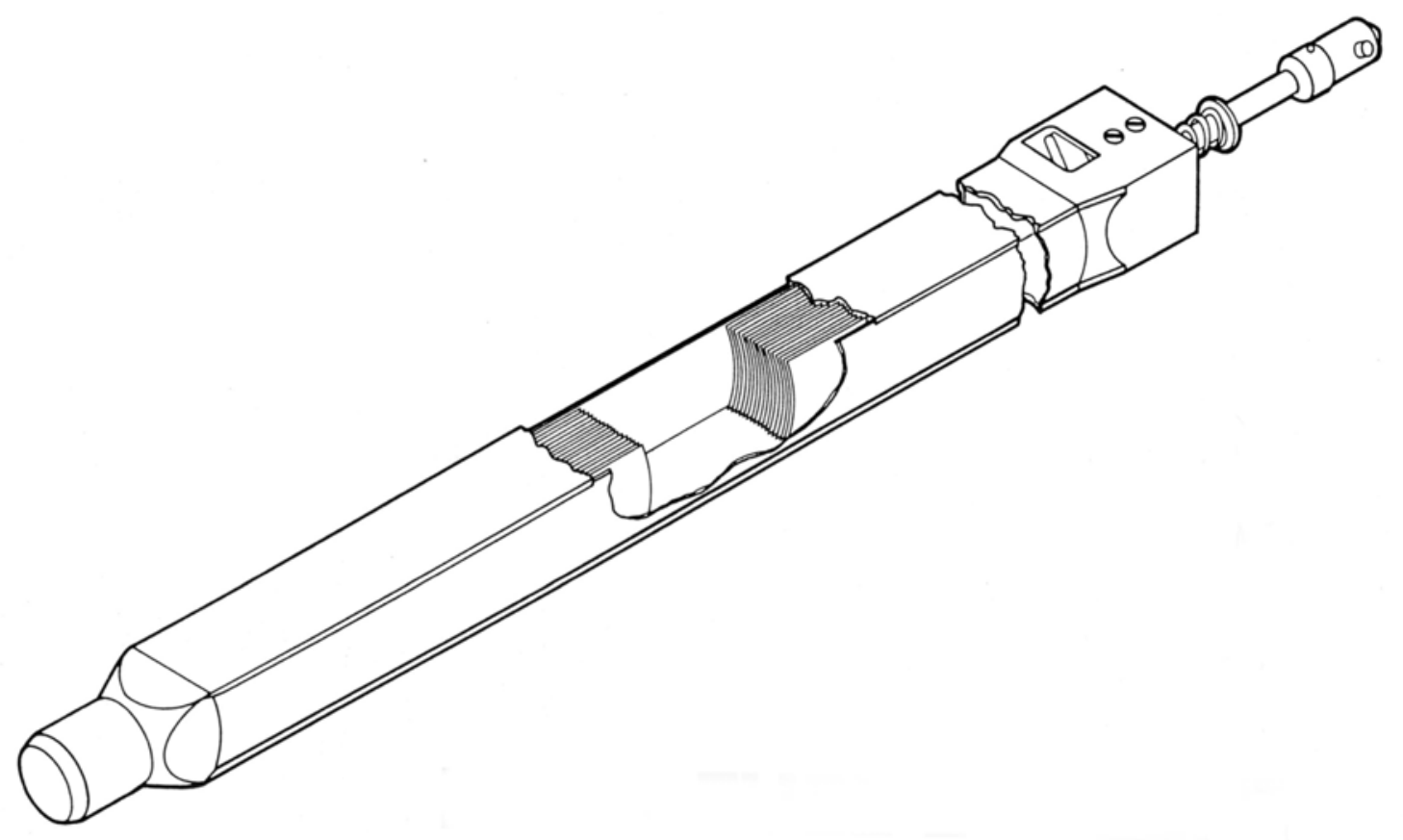

Figure 2-2. Cutaway Isometric Drawing of Fuel Element 


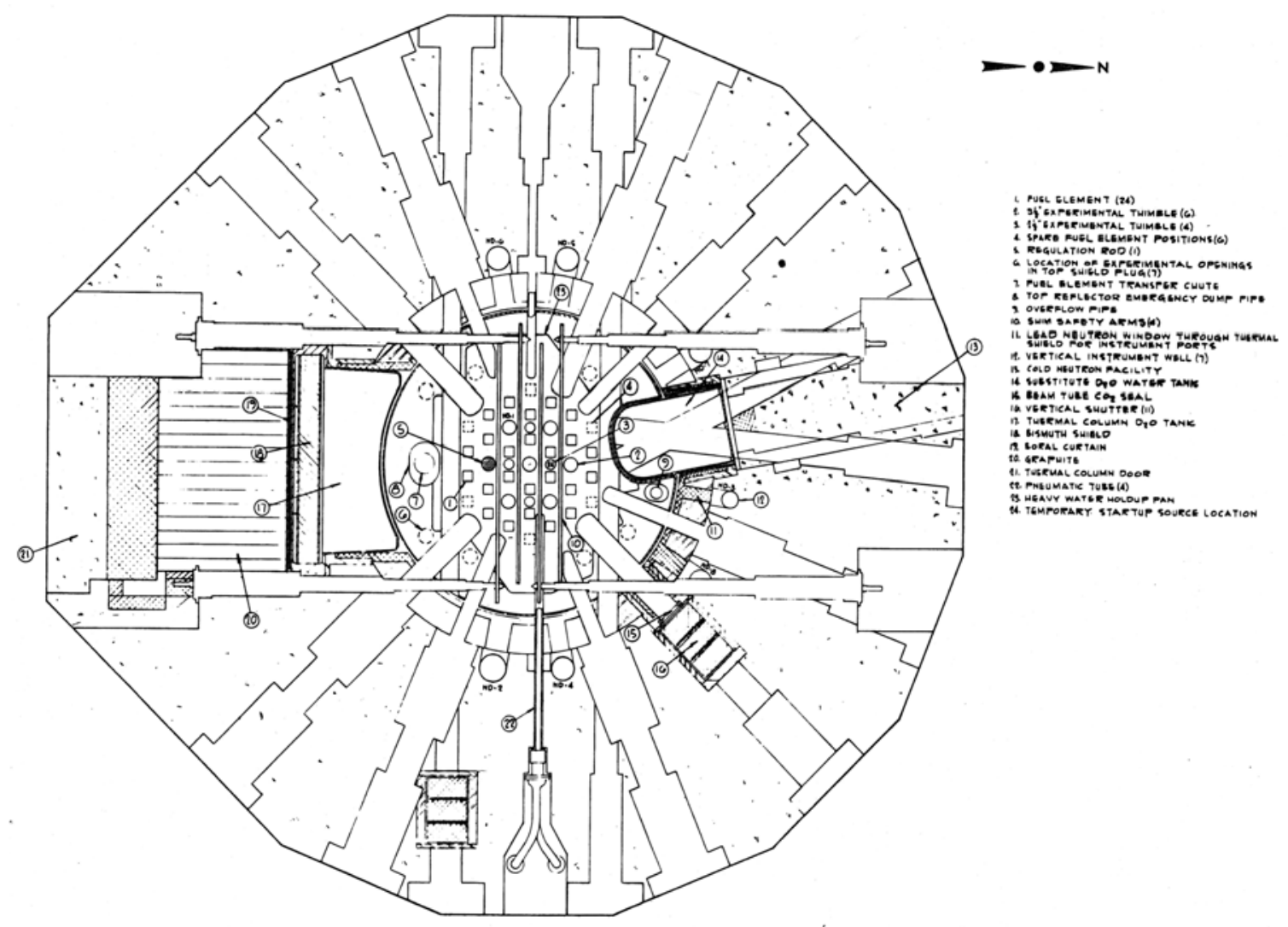

Figure 2-3. Detailed Cross-Section of Reactor Vessel at Mid-plane. 


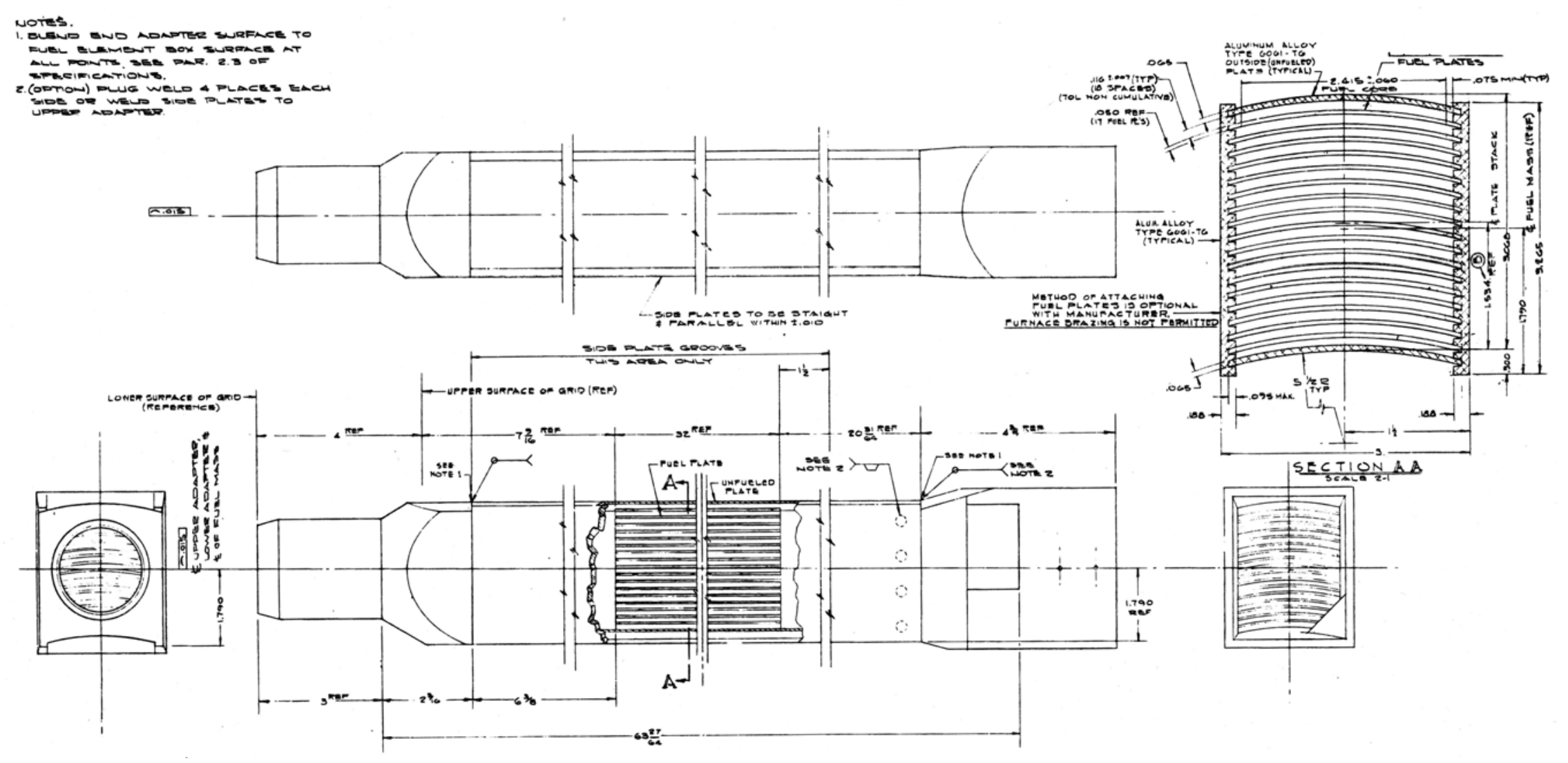

Figure 2-4. Dimensional Drawing of NBSR Fuel Element. 


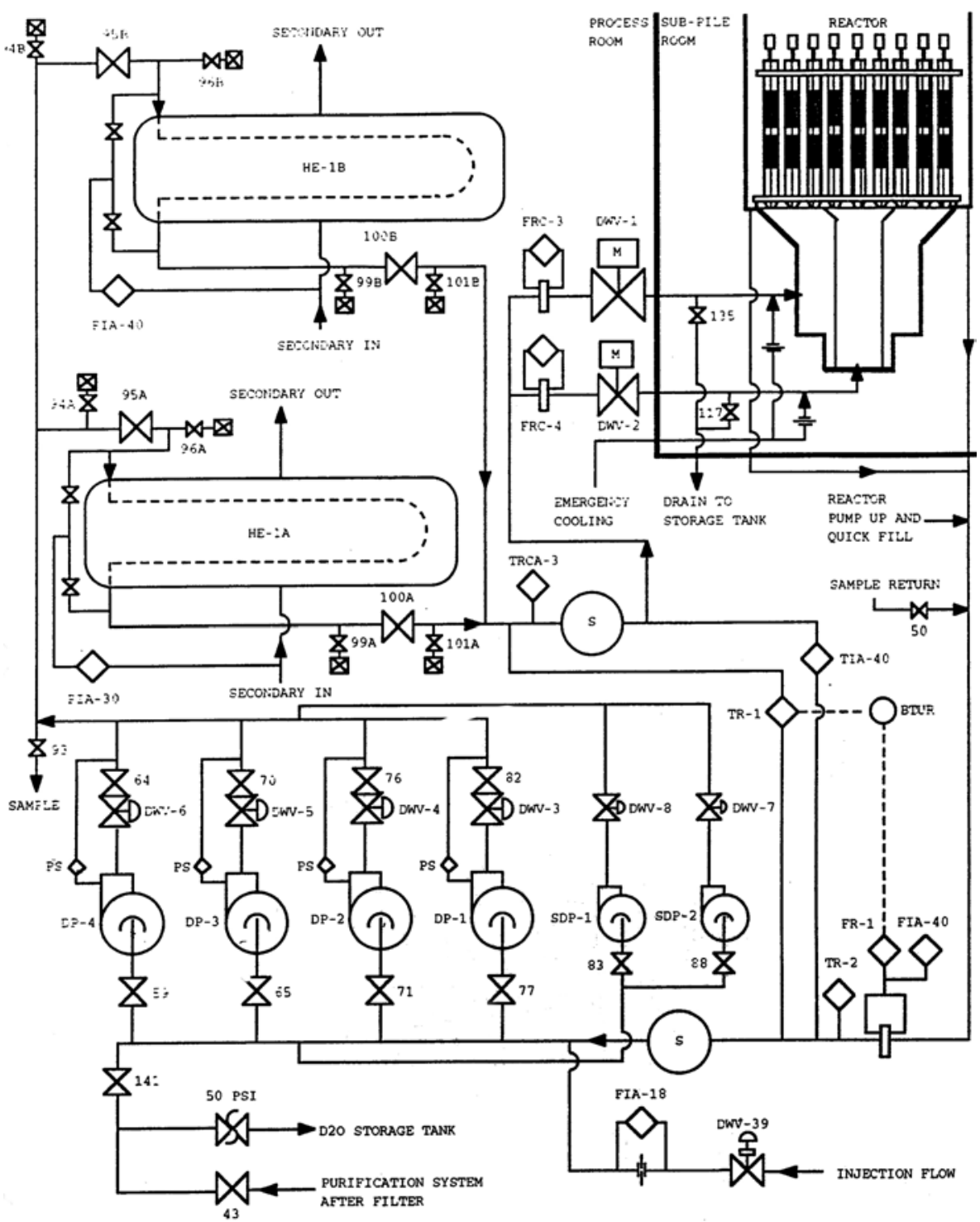

Figure 2-5. Simplified Schematic of Primary Cooling System 


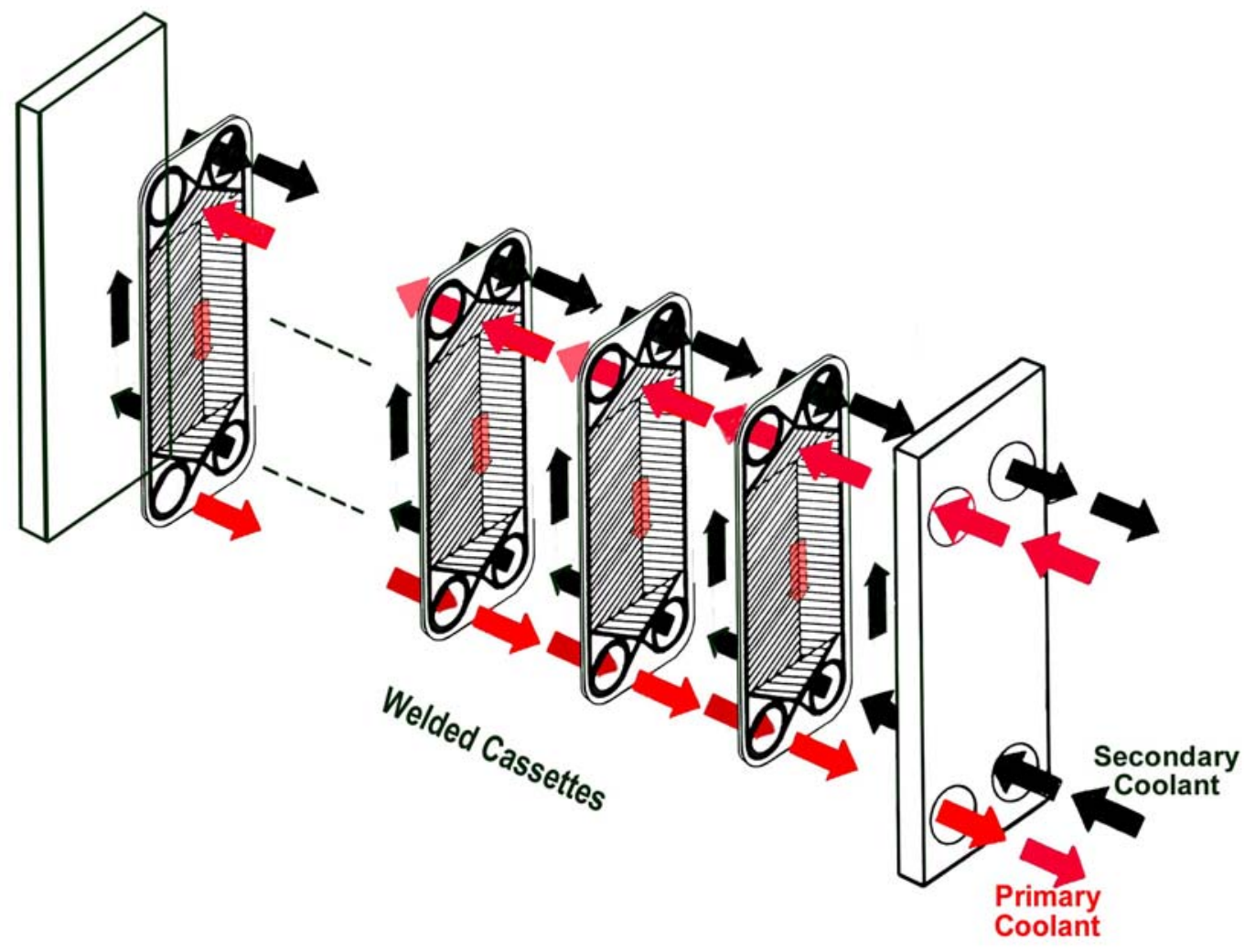

Figure 2-6. Exploded View of Plate Type Heat Exchange 



\section{REACTOR PHYSICS EVALUATION}

\subsection{MCNP Reactor Physics Model}

The calculation of the reactor physics parameters was performed with the MCNP Monte Carlo code. The model used in the evaluation is a slightly modified version of a model originally developed by R. Williams[8] at NIST. Figure 3-1 depicts the reactor cross section at the midplane $^{1}$, as modeled in MCNP. The boxes in the reactor core show the unfueled gap region of the fuel elements, consisting of the aluminum frames that are always filled with $\mathrm{D}_{2} \mathrm{O}$. Surrounding the boxes are hexagonal lines, which are simply computational divisions that do not represent any physical structures. Some of the hexagons are intersected by straight lines running east and west. These lines represent computational boundaries for the travel of the shim arms, and these areas are filled with the shim arms and $\mathrm{D}_{2} \mathrm{O}$. The core region is surrounded by an outer $\mathrm{D}_{2} \mathrm{O}$ region, followed by the reactor vessel region and then the biological shielding region. In the outer $\mathrm{D}_{2} \mathrm{O}$ region, four rectangles represent the segments of shim arms that intersect the mid-plane gap region when the shim arms are positioned at $18.5^{\circ}$.

Within the reactor core there are seven circular regions. The southernmost region represents an aluminum tube containing the solid aluminum regulating rod that displaces $\mathrm{D}_{2} \mathrm{O}$ as it is inserted. The other six circular regions represent the experimental thimbles which are aluminum tubes filled with $\mathrm{D}_{2} \mathrm{O}$. There are also nine radial beam tubes and three pneumatic tubes, two of which are the smaller tubes running horizontally east and west. The third pneumatic tube is located below the mid-plane at $-21.6 \mathrm{~cm}(-8.5 \mathrm{in})$, and runs horizontally between the M-4 and L-3 fuel element positions (refer to Figure 3-4). It is the only horizontal tube that traverses a fueled region of the core. The beam tubes and pneumatic tubes are all modeled as aluminum structures filled with a vacuum. North of the reactor core is the Cold Neutron Source (CNS), modeled as an aluminum structure filled with a combination of $\mathrm{D}_{2} \mathrm{O}$ and liquid $\mathrm{H}_{2}$, as well as $\mathrm{H}_{2}$ gas (which is modeled as a vacuum).

Figure 3-2 shows the cross section of the core at $-38.1 \mathrm{~cm}(-15 \mathrm{in})$, below the mid-plane of the core. This level is below the lower fueled section of the core, which ends at $-36.83 \mathrm{~cm}(-14.5 \mathrm{in})$. This figure shows the two tangential beam tubes that run east and west below the core. As with the radial beam tubes and pneumatic tubes, the tangential beam tubes are modeled as aluminum structures filled with a vacuum.

The four cadmium shim arms, which pivot from points above and to the east and west of the core, are modeled as rectangles. Referring to Figure 3-1, the northernmost shim arm pivots from the east side of the core, and the southernmost shim arm pivots from the west side. The two shim arms in between alternate their pivoting directions. Two of the beam tubes shown in Figure 3-1 have flattened surfaces on the tubes that allow for the motion of the shim arms through that region. When the shim arms are at the nominal $0^{\circ}$ position, they are fully inserted and the reactor is shut down. At the nominal $41^{\circ}$ position, the shim arms are fully withdrawn to the horizontal position (typical of end-of-cycle operation).

\footnotetext{
${ }^{1}$ The center of the gap in the reactor fuel is defined as being the reference point for all dimensions. The mid-plane of the reactor is the horizontal plane centered in the gap. Since this gap is $17.78 \mathrm{~cm}$ it ranges from $-8.89 \mathrm{~cm}$ to +8.89 $\mathrm{cm}$.
} 
The reactor is modeled by a column of $\mathrm{D}_{2} \mathrm{O} 200 \mathrm{~cm}(78.7 \mathrm{in})$ high, from $-100 \mathrm{~cm}$ to $+100 \mathrm{~cm}$. This height is smaller than the actual height of the reactor vessel and level of the $\mathrm{D}_{2} \mathrm{O}$, but neglecting the additional height of $\mathrm{D}_{2} \mathrm{O}$ results in an insignificant increase in the return of neutrons to the core. This will be shown later when the calculations of the reactivity of the column height are discussed. For convenience, the upper grid plate has not been included in the model. However, calculations have shown that that this approximation has a negligible effect on the power distribution and the core reactivity.

The fuel elements were modeled as a series of flat aluminum plates surrounded by $\mathrm{D}_{2} \mathrm{O}$, with the appropriate amount of fuel in the center of each plate. The model of the plates is shown in Figure 3-3. In this model the two endplates, which are solid aluminum and are parallel to the fuel plates, take up a volume larger than the actual aluminum endplates. However, the material composition in this region has been adjusted to account for the additional $\mathrm{D}_{2} \mathrm{O}$ in this region. The fueled region of the core ranges from $+8.89 \mathrm{~cm}(+3.5 \mathrm{in})$ to $+36.83 \mathrm{~cm}(+14.5 \mathrm{in})$ and from -8.89 $\mathrm{cm}(-3.5 \mathrm{in})$ to $-36.83 \mathrm{~cm}(-14.5 \mathrm{in})$, which is $27.94 \mathrm{~cm}(11 \mathrm{in})$ of fuel in each of the upper and lower regions of the core. The fuel element assemblies are continuous aluminum boxes that run from the lower grid plate to the upper grid plate.

Four core models with specific material inventories were developed for the analyses: a startup core (SU), the beginning-of-cycle equilibrium core (BOC), the middle-of-cycle equilibrium core (MOC), and the end-of-cycle equilibrium core (EOC). The methodology used for the development of the core-specific inventories is discussed in Section 3-2. For convenience, the critical shim arm position for the SU and BOC cores was assumed to be with the shim arms withdrawn to $18.5^{\circ}$. The values of $\mathrm{k}_{\text {eff }}$ with the shim arms at this position for these cores are 1.006 and 0.983 , respectively. In the calculation for the MOC core, the shim arms are assumed to be at $29^{\circ}$ and $\mathrm{k}_{\text {eff }}$ is 1.005 . For the EOC core, the shim arms are fully withdrawn to $41^{\circ}$ and $\mathrm{k}_{\text {eff }}$ is 1.029 .

\subsection{Core Depletion Methodology}

Because of the high burn-up and short, 38-day NBSR fuel cycle, an accurate determination of the fuel isotopic inventory is required. For $20 \mathrm{MW}$ operation, there are a total of 30 elements in the reactor. The initial inventory of a fresh element is 350 grams of ${ }^{235} \mathrm{U}$ as $93 \%$ enriched $U$ in $\mathrm{U}_{3} \mathrm{O}_{8}$, mixed with aluminum. The fuel mixture contains $32.74 \mathrm{wt} \%{ }^{235} \mathrm{U}, 2.46 \mathrm{wt} \%{ }^{238} \mathrm{U}, 6.36$ $\mathrm{wt} \% \mathrm{O}$, and $58.46 \mathrm{wt} \% \mathrm{Al}$. During each cycle, the fuel element inventory is reduced by approximately 30 grams of ${ }^{235} \mathrm{U}$. At the end of each cycle, the NBSR rotation scheme requires that four fuel elements are removed, the remaining 26 are moved to different locations, and four fresh, unirradiated elements are inserted. Consequently, after the initial core load, there is a mix of fuel elements that have received different levels of irradiation and burn-up.

Fourteen of the fuel elements will ultimately receive seven cycles of irradiation and sixteen will receive eight cycles of irradiation. In order to keep track of the different fuel elements (as required by MONTEBURNS)[6], a two-digit numbering scheme has been adopted. The first digit, being 7 or 8 , represents an element that will receive either seven or eight cycles of irradiation. The second digit, 1, 2, 3, 4, 5, 6, 7, or 8, signifies the present cycle of the particular element. For example, the 7-1 and 8-1 designations represent elements that are fresh and unirradiated, while 88 or 7-7 elements are in their final cycle and will be removed from the reactor after the present 
cycle. Each possible designation applies to two symmetrically located fuel elements in the core. The loading is shown in Figure 3-4. The two-digit fuel designation scheme is depicted on the left, while the current NBSR-defined fuel element designation scheme is on the right. (The "NBSR Loading" designations are derived from the original alphanumeric grid plate designation).

The fuel inventory was determined with the MONTEBURNS/MCNP/ORIGEN2 [15] computer programs. The inventory for the initial core was determined by R. Williams of the NBSR staff and was included as the initial estimate in the original NIST MCNP model. From that initial determination, the MONTEBURNS system was used to calculate the inventory of all elements after nine 38-day cycles. Eight thirty-eight day cycles were required for all of the elements to have inventories that were completely determined by the code system. Once this inventory was determined, another set of calculations of nine 38-day cycles was performed to ensure consistency between the sets of calculations.

Calculations of inventories were made for four cores: the SU core, the BOC core, MOC core and the EOC core. For the SU and BOC cores, the fresh fuel elements contain only ${ }^{235} \mathrm{U},{ }^{238} \mathrm{U}$, pure aluminum, and ${ }^{16} \mathrm{O}$. At the end of nine cycles, the inventory in each element then represents an EOC core. At this point the fuel is ready for shuffling to the next location, so every *1 (where * is a 7 or 8 cycle element) fuel becomes a $* 2$ fuel, every $* 2$ fuel becomes a $* 3$ fuel, and so forth. The 77 and 88 elements are removed and the 71 and 81 fresh elements are inserted. The EOC equilibrium inventory for the $* 1$ fuel becomes the BOC equilibrium inventory for the $* 2$ fuel, the EOC equilibrium inventory for the $* 2$ fuel becomes the BOC equilibrium inventory for the *3 fuel, and so forth. The SU core is identical to the BOC equilibrium core except the ${ }^{135} \mathrm{Xe}$ is decayed to ${ }^{135} \mathrm{Cs}$, the ${ }^{105} \mathrm{Rh}$ is decayed to ${ }^{105} \mathrm{Pd}$, and the ${ }^{149} \mathrm{Pm}$ is decayed to ${ }^{149} \mathrm{Sm}$. The MOC core was determined by evaluating the MONTEBURNS values after 19 days of irradiation, and the EOC core was determined using a 38-day MONTEBURNS evaluation.

MONTEBURNS uses MCNP to calculate the neutron spectra for each region. It then calls ORIGEN2 to calculate a set of one group cross sections for each material. ORIGEN2[15] then calculates the core inventory and MONTEBURNS rewrites the material files in MCNP. This process can be repeated during the cycle, so the depletion of a high burn-up core can be calculated over relatively small time steps, and not averaged over a complete cycle. The calculated burn-up is an output of the code. The results of the depletion and burn-up calculations are presented in the following section.

\subsection{Core Depletion}

The depletion and burn-up calculations were made starting with the SU core with 40 intermediate time steps per cycle, and running a set of nine 38-day cycles. The convergence of the calculated inventories was tested by calculating an additional nine cycles of reactor operation. The

${ }^{235} \mathrm{U}$ content was determined for each of the non-feed elements (those elements with less than $350 \mathrm{~g} \mathrm{of}{ }^{235} \mathrm{U}$ ) and averaged over the nine cycles. A total of $49 \%$ of the inventory values were within $1 \%$ of the average, $36 \%$ were within $1-2 \%$ and $15 \%$ were within $2-3 \%$. None of the concentrations deviated more than $3 \%$ from the average. 
The ${ }^{235} \mathrm{U}$ inventory of the $\mathrm{SU}$ core as a function of core position, as calculated with MONTEBURNS, is shown in Figure 3-5. Also included in this figure is the percent decrease in the ${ }^{235} \mathrm{U}$ content for each fuel element during a single 38-day cycle. The fuel elements in the two north corners of the core are the 8-1 fuel elements. At the end of this cycle, their ${ }^{235} \mathrm{U}$ inventory is $318 \mathrm{~g}$. In the shuffling, they will be moved to the two south corners of the core. The two 7-1 fuel elements are at the east-west corners of the core. At the end of the cycle, their ${ }^{235} \mathrm{U}$ inventory will decrease by $29 \mathrm{~g}$, for a balance of $321 \mathrm{~g}$. During the shuffle, they will be moved to the two inner locations on the north face of the core. By following the shuffling shown in Figure 34, and using the data in Figure 3-5, one can follow the ${ }^{235} \mathrm{U}$ inventory and its change throughout depletion.

The change in the fuel element ${ }^{235} \mathrm{U}$ and ${ }^{238} \mathrm{U}$ inventory, and the balance of the other actinides are shown in Figures 3-6 and 3-7 for the seven-cycle and eight-cycle fuel elements, respectively. These plots follow the actinide content of each fuel element as it is moved during the cycle-tocycle fuel shuffling, i.e., the plots follow the actinide inventory of a single element as a function of time.

During their life-time, the ${ }^{235} \mathrm{U}$ inventory of the seven-cycle and eight-cycle fuel elements is reduced by $216 \mathrm{~g}$ and $237 \mathrm{~g}$, respectively. As can be seen from Figures 3-6 and 3-7, the reduction in the ${ }^{238} \mathrm{U}$ content is small, approximately $1 \mathrm{~g}$, or $4 \%$. The bulk of the growth of "other actinides" in the fuel elements is dominated by ${ }^{236} \mathrm{U}$. This isotope represents approximately $96 \%$ of these actinides and builds to $33 \mathrm{~g}$ for the seven-cycle fuel elements and $36 \mathrm{~g}$ for the eight-cycle fuel elements. Nevertheless, because of the smaller ${ }^{236} \mathrm{U}$ fission cross-section, ${ }^{235} \mathrm{U}$ contributes $99 \%$ of the fission rate in any fuel element.

\subsection{Steady State Power Distributions}

Steady state power distributions are required to evaluate the heat flux and fuel temperatures at the limiting core locations. The detailed local power distributions are determined using the MCNP model and the final compositions described in the previous section.

\subsubsection{Fuel Element Radial Power Distributions}

The radial fuel element power distributions for the different cores were calculated with the threedimensional MCNP models. The fission energy for a given fuel element is the energy deposited in the fuel matrix. The calculated power levels were normalized so that the core average is unity. With this normalization, the actual power in a fuel element is the relative value multiplied by the total reactor power (20 MW), divided by the number of fuel elements in the core (30).

Figures 3-8, 3-9, 3-10, and 3-11 provide the power distributions for the SU, BOC, MOC, and EOC cores, respectively. The numbers on the left of each figure represent the normalized power for each element whose core positions are defined in Figure 3-4. The numbers on the right side of each figure are the statistical uncertainties in the power levels as calculated by MCNP. The differences between the SU and BOC power distributions of Figures 3-8 and 3-9 are due to the differences in the concentrations of the ${ }^{135} \mathrm{Xe},{ }^{105} \mathrm{Rh}$, and ${ }^{149} \mathrm{Pm}$ fission products. 
The differences between the BOC, MOC and EOC power distributions are due to differences in the fuel inventory and the shim arm insertion. For the SU and BOC distributions, the shim arms are inserted to $18.5^{\circ}$; for the MOC distribution they are at $29^{\circ}$, and for the EOC distribution they are at $41^{\circ}$. Following the progression of withdrawal from Figures 3-8 through 3-11, it is noted that the power is higher in rows 1 and 7 when the arms are partially inserted than when the arms are withdrawn. Likewise, the inner rows increase in power as the shim arms are removed. Figure 3-12 shows the percentage change in the fuel element power levels from BOC to EOC.

In addition to the shim arms, there are numerous beam tubes and the CNS around the core that will also affect the distribution because they introduce void regions near the core. In Section 3.5.3, the void reactivity is discussed and the effect of flooding the beam and pneumatic tubes is discussed in Section 3.5.5.

\subsubsection{Fuel Element Plate-Wise Power Distribution}

In order to determine the fuel element hot channels, the number of fissions in each fuel plate in the core was calculated with a core-wise normalization of unity. The relative plate-wise power distributions for the SU and EOC conditions are shown in Figures 3-13 through 3-18 for three selected fuel elements in the A-4, E-2, and D-1 positions (refer to Figure 3-4). It may be seen from Figures 3-13 to 3-15 that the shim arms suppress the power in the upper part of the core during start-up conditions. It is also noted that the highest fission rate occurs in the outermost plates of the elements.

\subsubsection{Fuel Element Axial Power Distribution}

The axial power distributions were determined by dividing each fuel element into 16 equally spaced axial segments ( 8 in the upper section and 8 in the lower section). MCNP was used to calculate the fission rate in each segment. The axial power distributions for the three fuel elements shown in Section 3.4.2 above are plotted in Figures 3-19 through 3-21 for SU conditions and in Figures 3-22 through 3-24 for EOC conditions.

In the SU condition, the shim arm suppresses the power in the upper section of the element. This is most pronounced in the A-4 element, which is close to a shim arm. The D-4 element is separated from the shim arm by one row of elements, and the suppression of power is not as great in the A-4 element.

It is evident from these figures that the power distribution increases in the segments closest to the gap at the core midplane and at the top and bottom of the fuel element. The axial peak power occurs at an axial segment either immediately above or below the central water gap.

\subsubsection{Fuel Plate Transverse Power Density}

In order to determine the peak temperature in the fuel plate, the power distribution has been determined along the lateral direction of the fuel plate (i.e., horizontal). This was accomplished by modeling a single element with reflective boundary conditions, and dividing each plate into 17 
equally spaced segments. MCNP was then used to determine the fission rate in each of the 289 segments of the fuel element (i.e., 17 segments in each of 17 plates).

The results of this calculation are shown in Figure 3-25. The lateral segment with the lowest power is in the center of the element plate " 0 " in Fig. 3-25, and the segments with the highest power are on the outside of the element plate "8" in Fig. 3-25, adjacent to the inter-element water gap. The power of only nine segments is given in the figure, since the fission power in the remaining plates is symmetric to those shown here.

\subsection{Reactivity Effects}

\subsubsection{Moderator Temperature Coefficient}

The calculation of coolant temperature effects is handled in two ways in MCNP: 1) through the density of the coolant and 2) through the thermal scattering kernel used to calculate the scattering cross sections. The density can be changed continuously, but the scattering kernel can be changed only discretely in increments of $100 \mathrm{~K}$.

The density component of the MTC was determined by calculating the change in $\mathrm{k}_{\mathrm{eff}}$ resulting from a change in the coolant density corresponding to an increase in temperature from the nominal operating temperature of $319 \mathrm{~K}\left(115^{\circ} \mathrm{F}\right)$ to $373 \mathrm{~K}\left(212^{\circ} \mathrm{F}\right)$. This temperature increase results in a $\mathrm{D}_{2} \mathrm{O}$ coolant density decrease from $1.0966 \mathrm{~g} / \mathrm{cm}^{3}$ to $1.0635 \mathrm{~g} / \mathrm{cm}^{3}$. The change in $\mathrm{k}_{\text {eff }}$ resulting from an increase in the scattering kernel temperature was determined by increasing the scattering kernel temperature from $300 \mathrm{~K}$ to $400 \mathrm{~K}$.

Results of these calculations for the SU, BOC, MOC and EOC cores are presented in Table 3-1. The first line (under each core) shows the results of the calculations for the base case (i.e., a density of $1.0966 \mathrm{~g} / \mathrm{cm}^{3}$ and a scattering kernel temperature of $300 \mathrm{~K}$ ). The second line for each case gives the results when the scattering kernel temperature was changed from $300 \mathrm{~K}$ to $400 \mathrm{~K}$. The third line shows the results when the density was reduced from 1.0966 to $1.0635 \mathrm{~g} / \mathrm{cm}^{3}$. The first column gives the density used for each case, the second column is the scattering kernel temperature, the third shows the calculated value of $\mathrm{k}_{\mathrm{eff}}$, the fourth gives the statistical deviation for the value of $\mathrm{k}_{\mathrm{eff}}$, the fifth shows the change in $\mathrm{k}_{\mathrm{eff}}$, in percent, the sixth gives the change per degree Kelvin and the seventh shows the change per degree Fahrenheit. Finally, there are two lines under the "combined" heading. The first line contains the results of the analyses when both the density and the scattering kernel temperature are changed in the MCNP model. The second line is the prediction obtained by using the results of the individual density kernel and scattering kernel analyses and summing them together. For all of the cases the MTC is negative.

\subsubsection{Void Reactivity}

The effect on the core $\mathrm{k}_{\mathrm{eff}}$ of introducing a uniform coolant void was calculated with the MCNP core model. The calculations were performed for the SU and EOC cores for two different void cases. In the first case, the six vacant irradiation thimbles (note that the seventh, southernmost thimble contains the regulating rod) are voided. In the second case, the moderator in all of the fuel elements is voided. The results of these analyses are shown in Table 3-2 and indicate that 
the voiding of the thimbles and voiding of the fuel elements both result in a negative reactivity effect.

\subsubsection{Shim Arm Worth}

The reactivity worth of the shim arms has been calculated for both the SU and EOC cores. The reactivity was calculated as a function of shim arm positions, i.e., from full insertion $\left(0^{\circ}\right)$ to full withdrawal $\left(41^{\circ}\right)$. The results of these calculations are presented in Figures 3-26 and 3-27 for the SU and EOC conditions, respectively. For the SU core, $\mathrm{k}_{\mathrm{eff}}=1.006$ when the shim arms are at $18.5^{\circ}$ and $\mathrm{k}_{\mathrm{eff}}=1.029$ for the EOC core when the shim arms have been withdrawn to $41^{\circ}$. When the shim arms are fully inserted $\left(0^{\circ}\right), \mathrm{k}_{\mathrm{eff}}$ is 0.88 for the SU core and 0.84 for the EOC core.

\subsubsection{Regulating Rod Worth}

The reactivity worth of the regulating rod has been calculated for both the SU and EOC cores. The worth was determined by calculating the $\mathrm{k}_{\mathrm{eff}}$ of the core as a function of rod withdrawal. The results of these calculations are presented in Figures 3-28 and 3-29 for the SU and EOC cores, respectively. The flattening of the reactivity curves at $50 \%$ withdrawal is due to movement through the $17.78 \mathrm{~cm}$ (7 in) gap in the fuel.

\subsubsection{Beam Tube Reactivity}

Detailed calculations of the beam tube and cold neutron source (CNS) reactivity have been performed for both the SU and EOC cores. The reactivity worth of the beam tubes was determined by replacing the void in the beam tubes with $\mathrm{D}_{2} \mathrm{O}$. The reactivity worth of the CNS was determined by replacing the liquid hydrogen and hydrogen gas with $\mathrm{D}_{2} \mathrm{O}$. The calculations were made for the following conditions: all tubes and the CNS were flooded simultaneously; only the CNS was flooded; all of the beam and pneumatic tubes were flooded; the nine radial beam tubes were flooded; the two tangential beam tubes were flooded; and the three pneumatic tubes were flooded. The results of the calculations are presented in Tables 3-3 and 3-4 for the SU and EOC cores, respectively. In all cases the flooding has a positive effect on the reactivity of the core. The CNS and radial beam tubes are located at the core mid-plane. Their combined worth is larger for the EOC core than for the SU core. This is due to the shim arms suppressing the flux in the upper half of the SU core. The pneumatic tubes are considerably smaller than the beam tubes and flooding them has a smaller effect.

\subsubsection{Reactivity Associated with Upper Reflector Level}

The upper reflector can be considered to be a safety feature since draining the reflector to the dump level (i.e., to the top of the fuel) results in the insertion of a substantial amount of negative reactivity. MCNP calculations have been performed to determine the core reactivity as a function of the thickness of the upper reflector for both the SU and EOC cores. The results of the analyses for the SU and EOC cores are shown in Figures 3-30 and 3-31, respectively. In these calculations, the base case is for a $65 \mathrm{~cm}$ (25.6 in) reflector thickness. Because of increased shim arm insertion and reduced flux in the upper regions of the SU core, the worth of the upper reflector is smaller than for the EOC core, where the shim arms are fully withdrawn. 
Calculations of the shim arm reactivity worth with the upper reflector drained to the dump level have also been performed. The results of these calculations for the SU and EOC cores are presented in Figures 3-32 and 3-33, respectively. In both cases, when the shim arms are fully withdrawn, the reactor is subcritical with the reflector drained.

\subsubsection{Reactivity of Light Water Contamination}

MCNP calculations have been performed to determine the reactivity effect associated with light water $\left(\mathrm{H}_{2} \mathrm{O}\right)$ contamination of the NBSR $\mathrm{D}_{2} \mathrm{O}$ coolant. In these calculations, the amount of light water in the heavy water coolant was increased and the core $\mathrm{k}_{\text {eff }}$ was calculated. The results of the calculations shown in Figure 3-34 for the SU core demonstrate that light water contamination of the NBSR coolant results in a substantial negative reactivity insertion.

\subsubsection{Built-in Conservatism}

The MCNP model that was used for this work did not include all of the interior structure that exists in the NBSR. The net result of including this structure in the calculation means the critical position of the shim arms is at a larger angle (more withdrawn). As was indicated earlier in this chapter, the shim arms force the shape of the power distributions when they are inserted. As they are withdrawn, the power distributions become less peaked. A limited set of MCNP calculations were performed on the model including the internal structures. In the present work, the maximum relative power peaking was 1.16. In the updated model, the maximum value was 1.11. The higher maximum values are used in the analyses of the hottest areas of the fuel (Section 5). This in turn will result in a smaller CHFR. 


\section{NORTH}

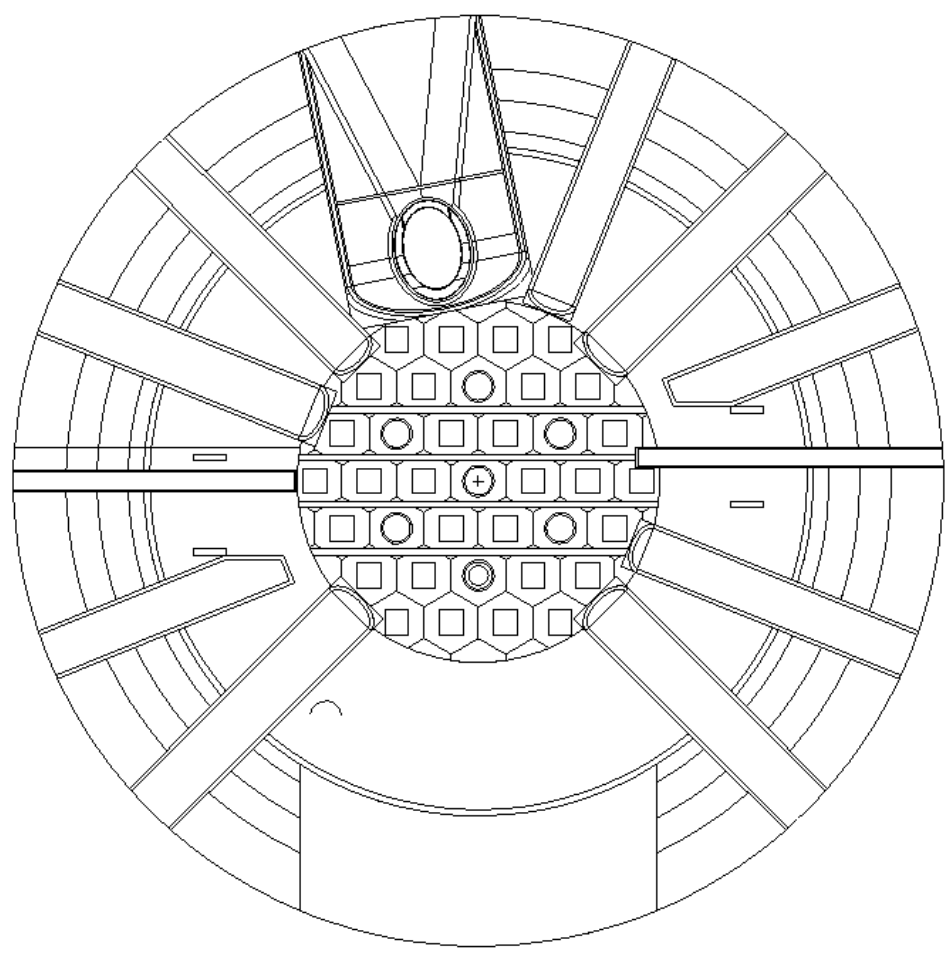

Figure 3-1. Cross-Sectional View of the Reactor at the Mid-Plane $(0 \mathrm{~cm})$. 


\section{NORTH}

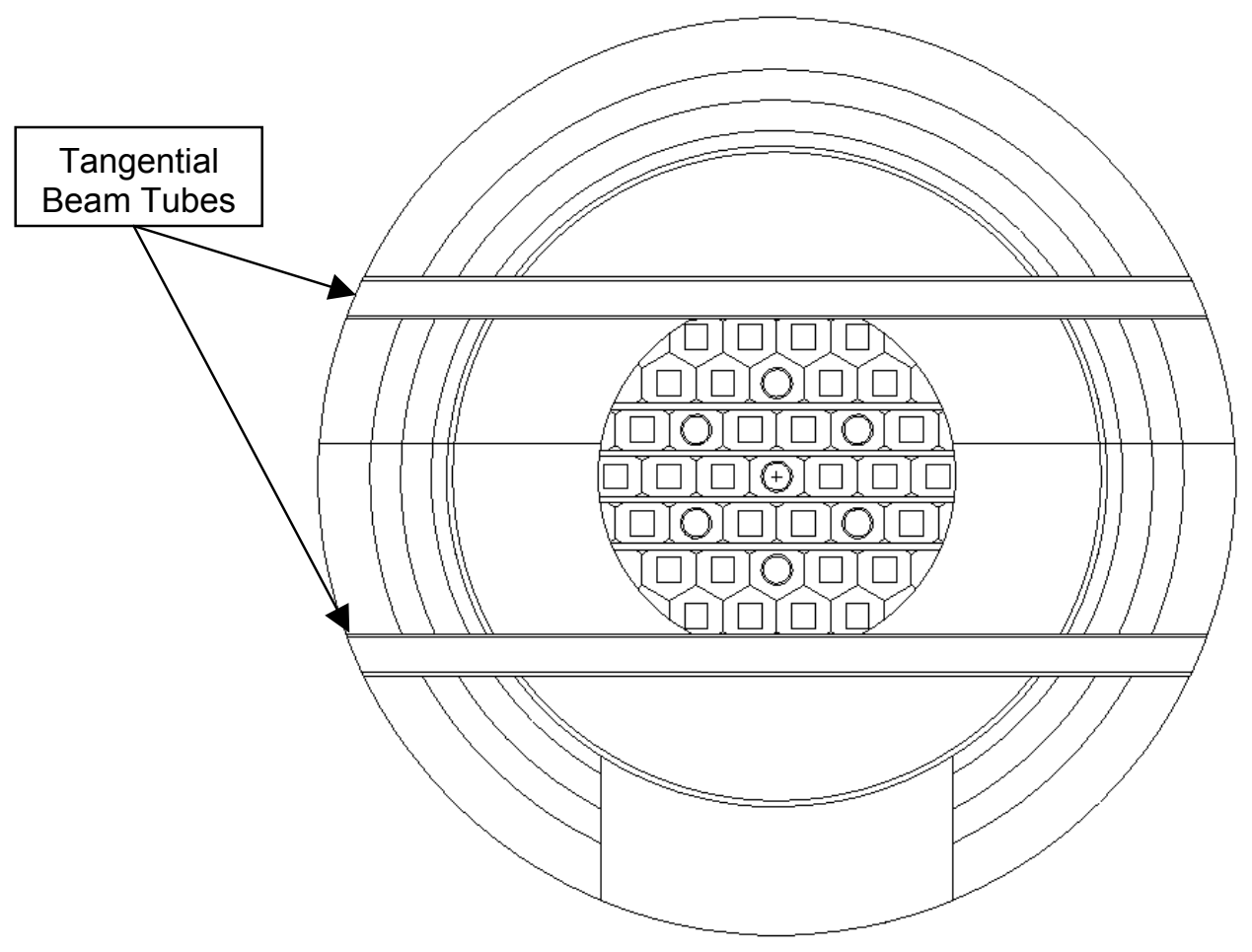

Figure 3-2. Cross-Sectional View of the Reactor at $-38.1 \mathrm{~cm}(-15 \mathrm{in})$ Below the Mid-Plane. 


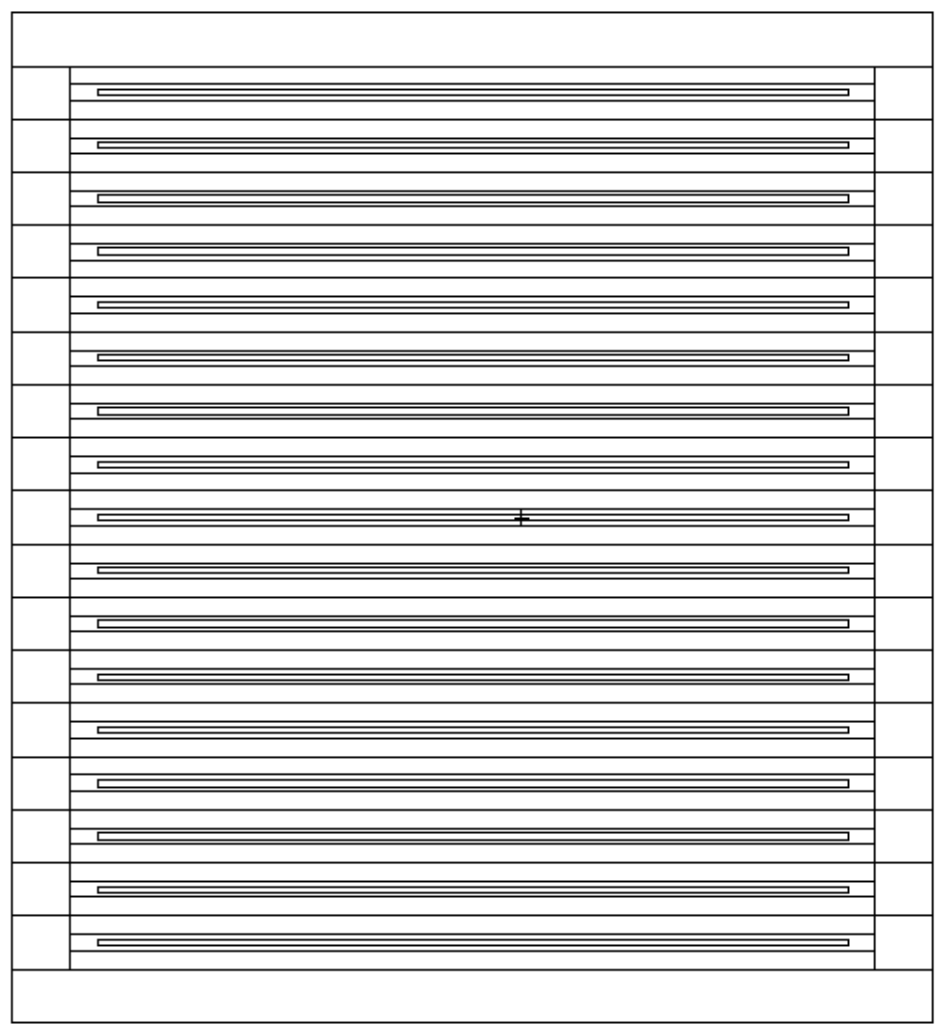

Figure 3-3. MCNP Model of a Fuel Element. 


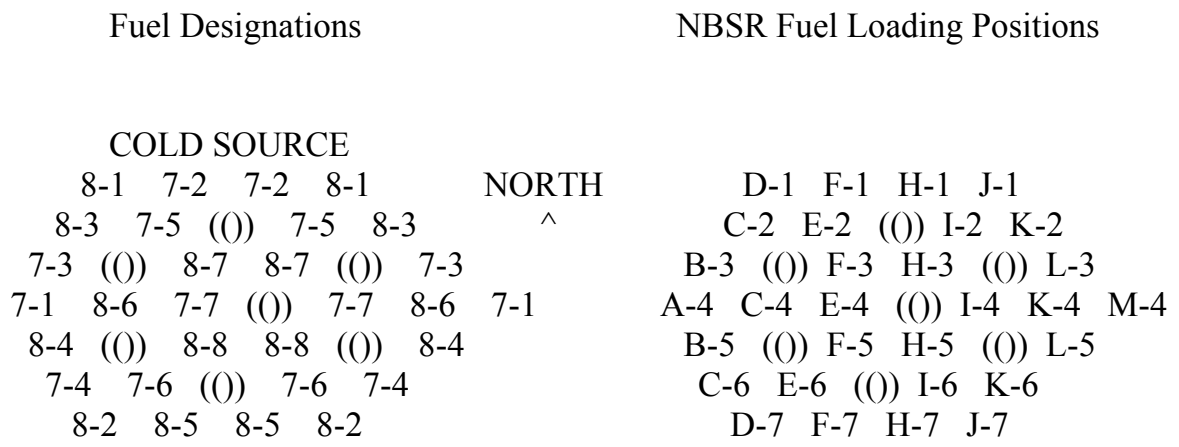

Figure 3-4. Fuel Designation Scheme and its Relation to the NBSR Fuel Element Positions. The $(())$ is used to represent the in-core thimbles.

\begin{tabular}{|c|c|}
\hline${ }^{235} \mathrm{U}$ content per fuel element (gra & Decrease in ${ }^{235} \mathrm{U}$ (grams) \\
\hline \multicolumn{2}{|l|}{ COLD SOURCE } \\
\hline $\begin{array}{llll}350 & 321 & 321 & 350\end{array}$ & NORTH \\
\hline $285 \quad 226(()) \quad 226 \quad 285$ & $29 \quad 30 \quad(()) \quad 30 \quad 29$ \\
\hline $286(()) \quad 170 \quad 170(()) 286$ & $\begin{array}{llllll}30 & (()) & 31 & 31 & (()) & 30\end{array}$ \\
\hline $350200 \quad 164 \quad(()) \quad 164200350$ & $\begin{array}{lllllll}29 & 30 & 30 & (()) & 30 & 30 & 29\end{array}$ \\
\hline $256(()) 139139(()) 256$ & $\begin{array}{llllll}31 & (()) & 26 & 26 & (()) & 31\end{array}$ \\
\hline $256196(()) 196256$ & $\begin{array}{lllll}30 & 32 & (()) & 32 & 30\end{array}$ \\
\hline $\begin{array}{llll}318 & 225 & 225 & 318\end{array}$ & $\begin{array}{llll}33 & 25 & 25 & 33\end{array}$ \\
\hline
\end{tabular}

Figure 3-5. ${ }^{235} \mathrm{U}$ Inventory for Equilibrium Core at Startup, and Change in Inventory during Cycle. 


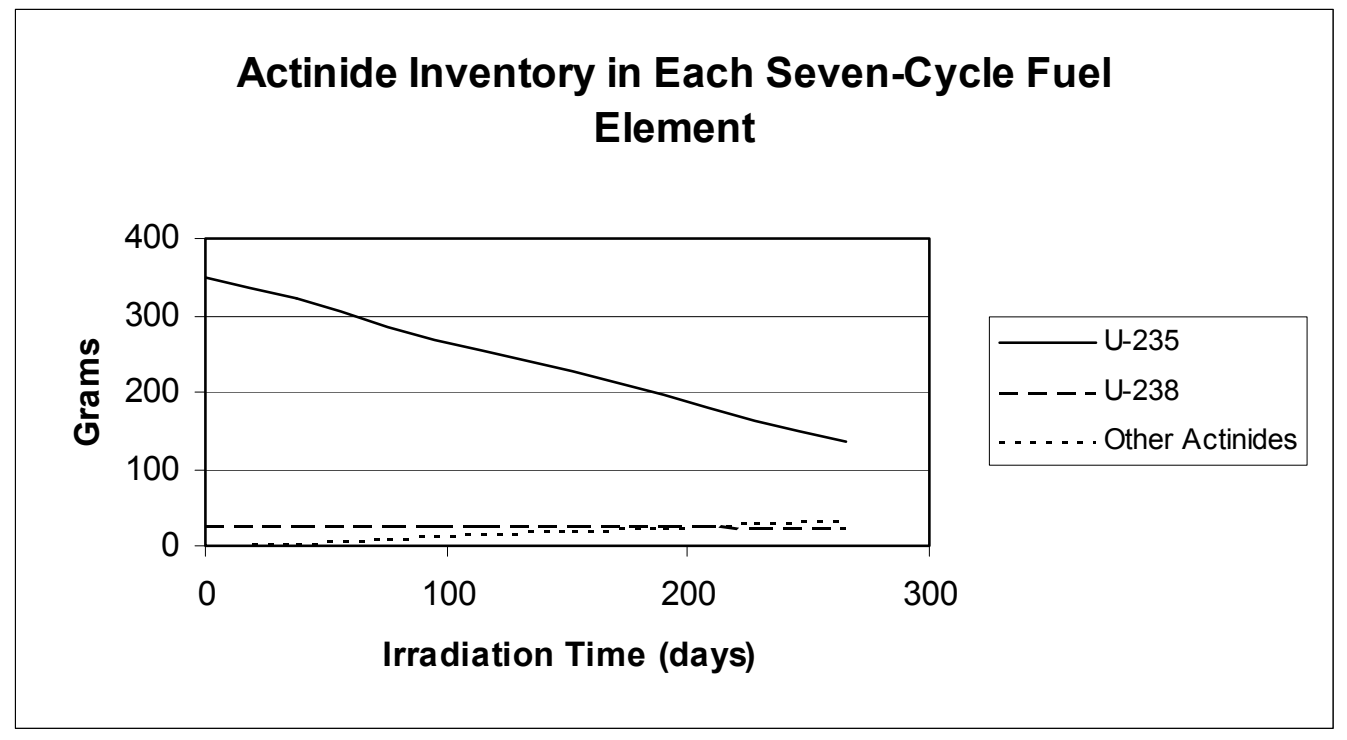

Figure 3-6. Actinide Inventory per Fuel Element as a Function of Irradiation Time for the 7-Cycle Fuel Elements.

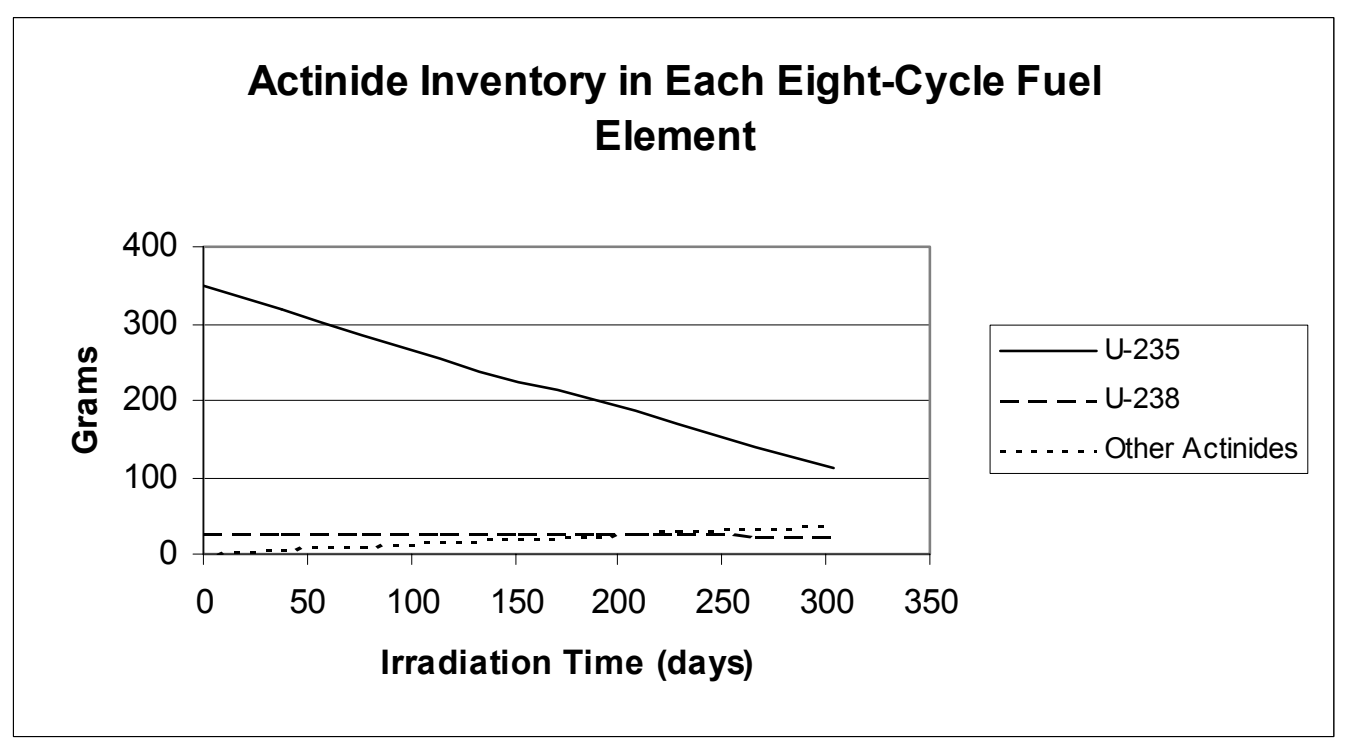

Figure 3-7. Actinide Inventory per Fuel Element as a Function of Irradiation Time for the 8-Cycle Fuel Elements. 


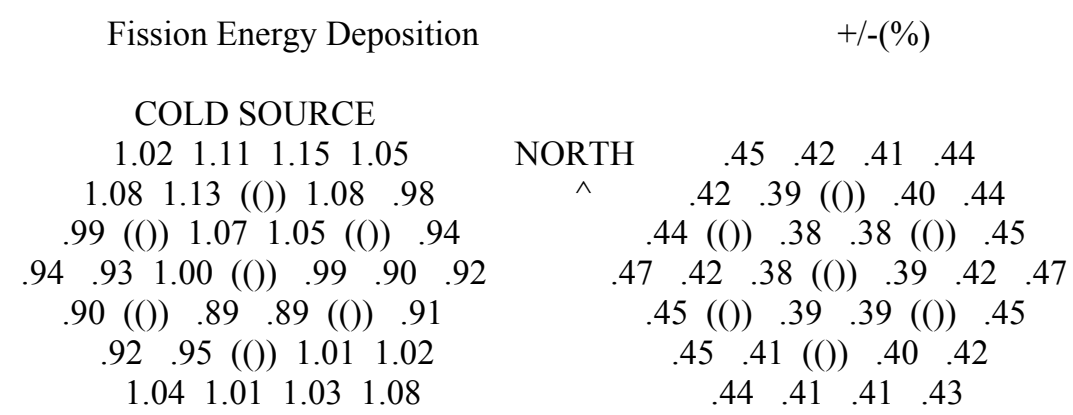

Figure 3-8. Relative Power Distribution for Each Fuel Element for the Core at Startup.

\begin{tabular}{|c|c|}
\hline Fission Energy Deposition & $+/-(\%)$ \\
\hline COLD SOURCE & \\
\hline $\begin{array}{llll}1.06 & 1.12 & 1.16 & 1.09\end{array}$ & $\begin{array}{llll}.45 & .42 & .41 & .44\end{array}$ \\
\hline $\begin{array}{llll}1.09 & 1.14(()) & 1.09 & .99\end{array}$ & $\begin{array}{lllll}.42 & .39 & (()) & .40 & .44\end{array}$ \\
\hline $.98(()) \quad 1.07 \quad 1.06(()) \quad .94$ & 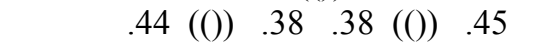 \\
\hline 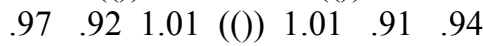 & $\begin{array}{lllllll}.47 & .42 & .39 & (()) & .39 & .42 & .47\end{array}$ \\
\hline 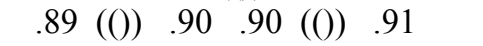 & 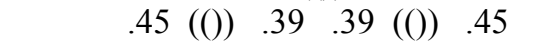 \\
\hline $\begin{array}{lllll}.89 & .93 & (()) & 1.01 & 1.02\end{array}$ & $\begin{array}{llll}.45 \quad .41 \quad(()) & .40 \quad .42\end{array}$ \\
\hline $\begin{array}{llll}.99 & .99 & 1.00 & 1.05\end{array}$ & $\begin{array}{llll}.45 & .42 & .41 & .43\end{array}$ \\
\hline
\end{tabular}

Figure 3-9. Relative Power Distribution for Each Fuel Element for the Equilibrium Core at Beginning-of-Cycle.

\begin{tabular}{|c|c|}
\hline Fission Energy Deposition & $+/-(\%)$ \\
\hline \multicolumn{2}{|l|}{ COLD SOURCE } \\
\hline $\begin{array}{llll}.92 & 1.05 & 1.10 & .99\end{array}$ & $\begin{array}{llll}.46 & .42 & .41 & .44\end{array}$ \\
\hline $1.031 .08(()) \quad 1.10 \quad 1.06$ & $\begin{array}{lllll}.42 & .39 & (()) & .38 & .41\end{array}$ \\
\hline $1.05(()) \quad 1.05 \quad 1.06(()) \quad 1.07$ & $.42(()) \quad .36 \quad .36(()) \quad .41$ \\
\hline $\begin{array}{llllll}.99 & .99 & 1.05 & (()) & 1.05 & .98\end{array}$ & $\begin{array}{lllllll}44 & .39 & .37 & (()) & .37 & .39 & .44\end{array}$ \\
\hline 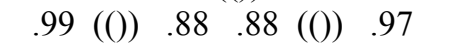 & 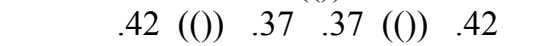 \\
\hline 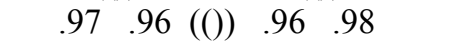 & $\begin{array}{lllll}.42 & .40 & (()) & .40 & .42\end{array}$ \\
\hline $\begin{array}{llll}.97 & .92 & .93 & .98\end{array}$ & $\begin{array}{llll}.44 & .42 & .42 & .44\end{array}$ \\
\hline
\end{tabular}

Figure 3-10. Relative Power Distribution for Each Fuel Element for the Equilibrium Core at Middle-of-Cycle 


\begin{tabular}{|c|c|}
\hline Fission Energy Deposition & $+/-(\%)$ \\
\hline \multicolumn{2}{|l|}{ COLD SOURCE } \\
\hline $\begin{array}{llll}.90 & .99 & 1.05 & .98\end{array}$ & $\begin{array}{llll}.46 & .42 & .41 & .44\end{array}$ \\
\hline $1.021 .05(()) \quad 1.071 .08$ & 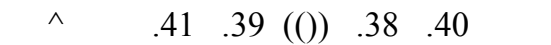 \\
\hline $1.07(()) 1.031 .04(()) 1.11$ & $\begin{array}{llll}.40(()) & .36 & .36(()) & .40\end{array}$ \\
\hline 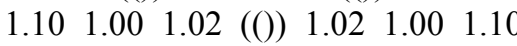 & $\begin{array}{lllllll}.42 & .38 & .36 & (()) & .36 & .38 & .41\end{array}$ \\
\hline $\begin{array}{lllll}1.03(()) & .89 & .89(()) & .99\end{array}$ & $\begin{array}{lllll}.40 & (()) & .37 & .37 & (())\end{array}$ \\
\hline $\begin{array}{llll}.99 & .94(()) & .93 & .97\end{array}$ & 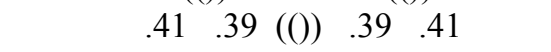 \\
\hline $\begin{array}{llll}.96 & .91 & .91 & .96\end{array}$ & $\begin{array}{llll}.43 & .41 & .41 & .43\end{array}$ \\
\hline
\end{tabular}

Figure 3-11. Relative Power Distribution for Each Fuel Element for the Equilibrium Core at End-of-Cycle.

$$
\begin{gathered}
\text { COLD SOURCE } \\
-15-12-9.5-10 \\
-6.4-7.9(())-1.8+9.1 \\
+9.2(())-3.7-1.9(())+18 \\
+13+8.7+1.0(())+1.0+9.9+17 \\
+16(())-1.1-1.1(())+8.8 \\
+11+1.1(())-7.9-4.9 \\
-3.0-8.1-9.0-8.6
\end{gathered}
$$

Figure 3-12. Percentage Change in the Fuel Element Power Levels for the Equilibrium Core from the Beginning-of-Cycle to the End-of-Cycle. 


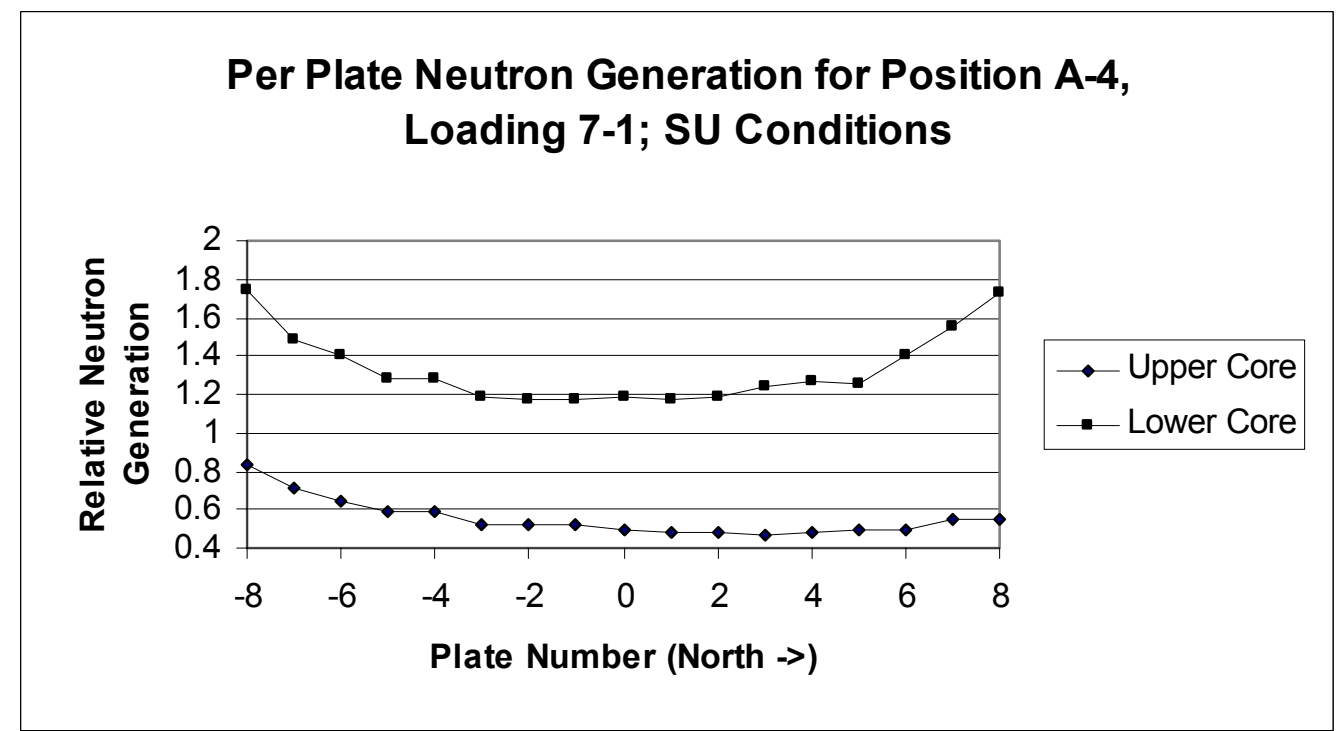

Figure 3-13. Relative Power Distribution per Fuel Element Plate for the Startup Core for the A-4 Fuel Element.

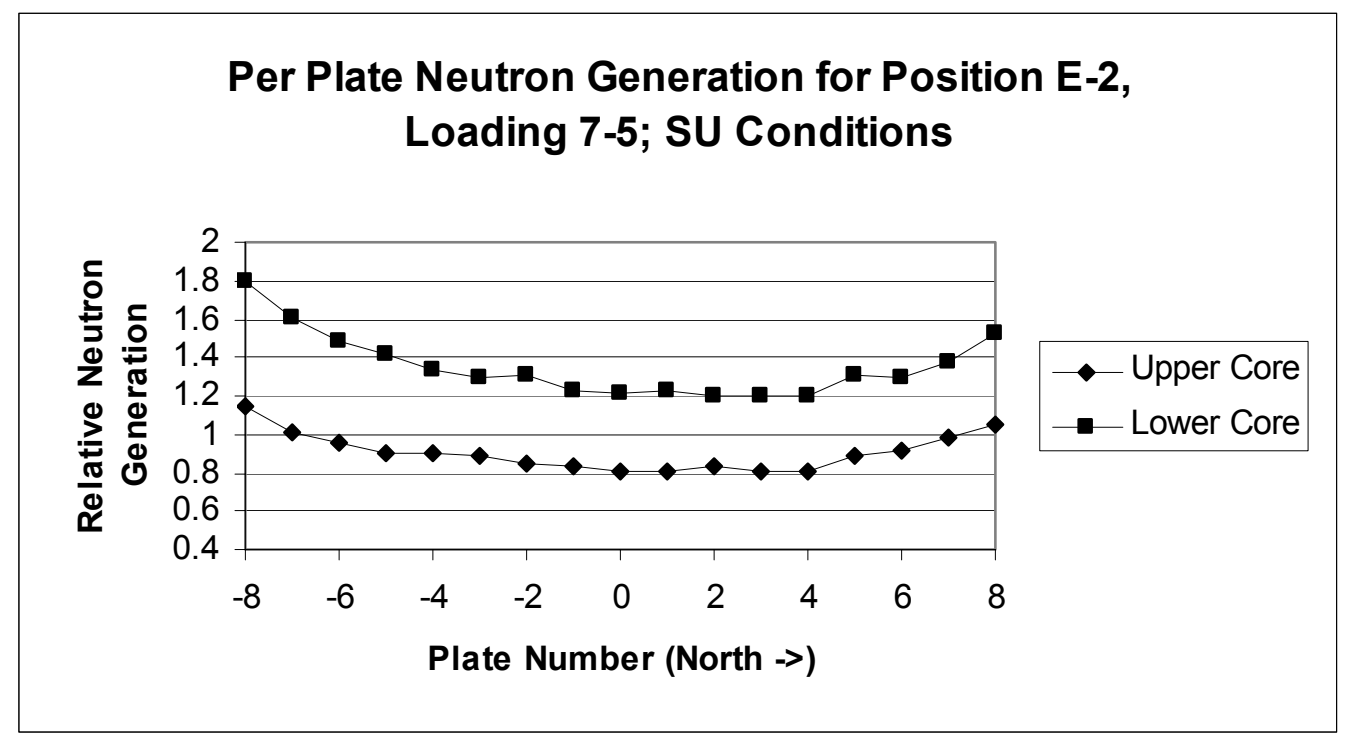

Figure 3-14. Relative Power Distribution per Fuel Element Plate for the Startup Core for the E-2 Fuel Element. 


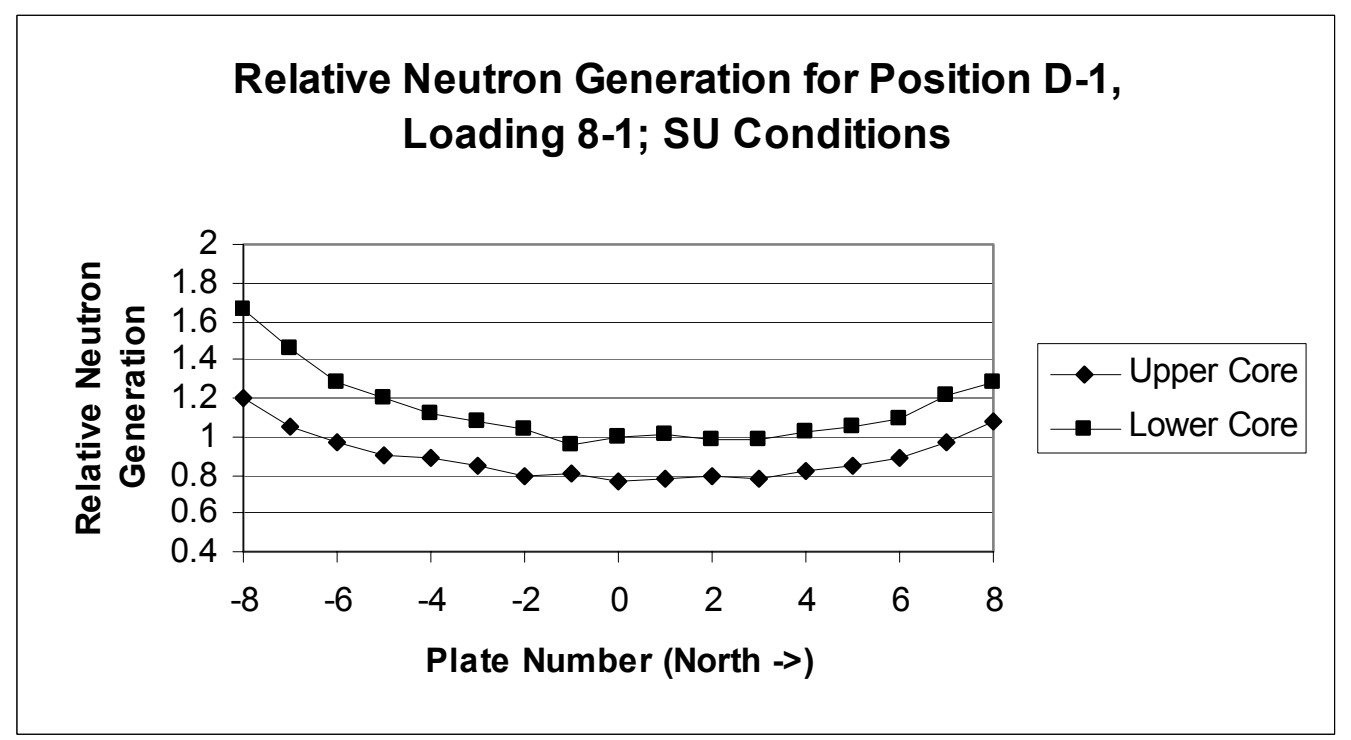

Figure 3-15. Relative Power Distribution per Fuel Element Plate for the Startup Core for the D-1 Fuel Element.

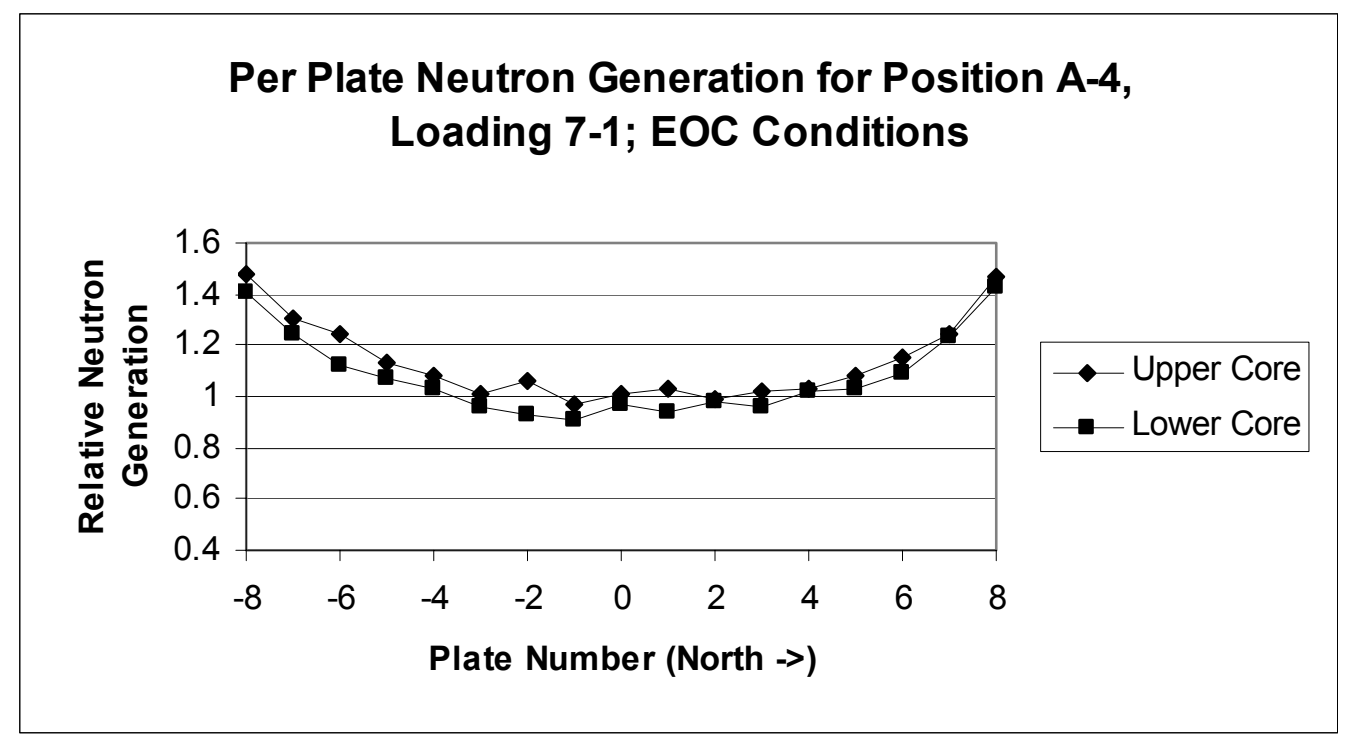

Figure 3-16. Relative power distribution per fuel element plate for the End-of-Cycle Core for the A-4 fuel element. 


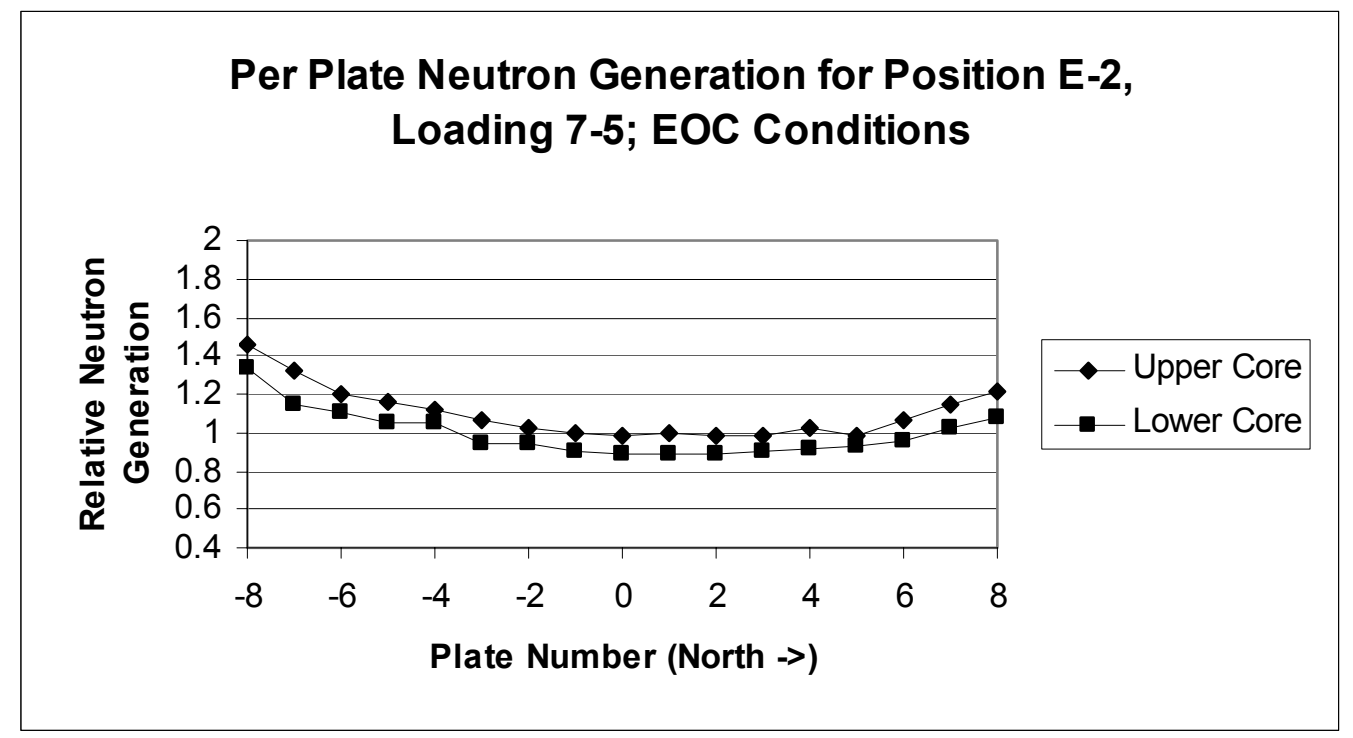

Figure 3-17. Relative Power Distribution per Fuel Element Plate for the End-of-Cycle Core for the E-2 Fuel Element.

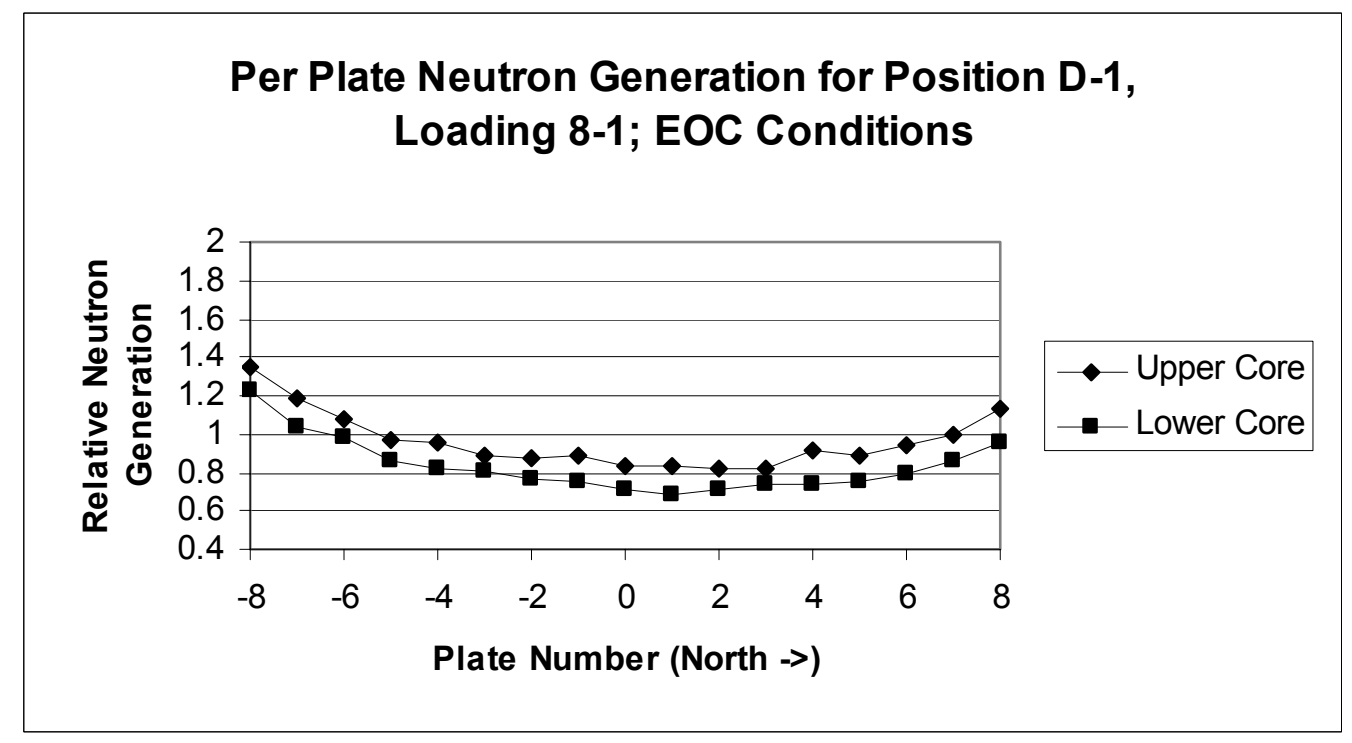

Figure 3-18. Relative Power Distribution per Fuel Element Plate for the End-Of-Cycle Core for the D-1 Fuel Element 


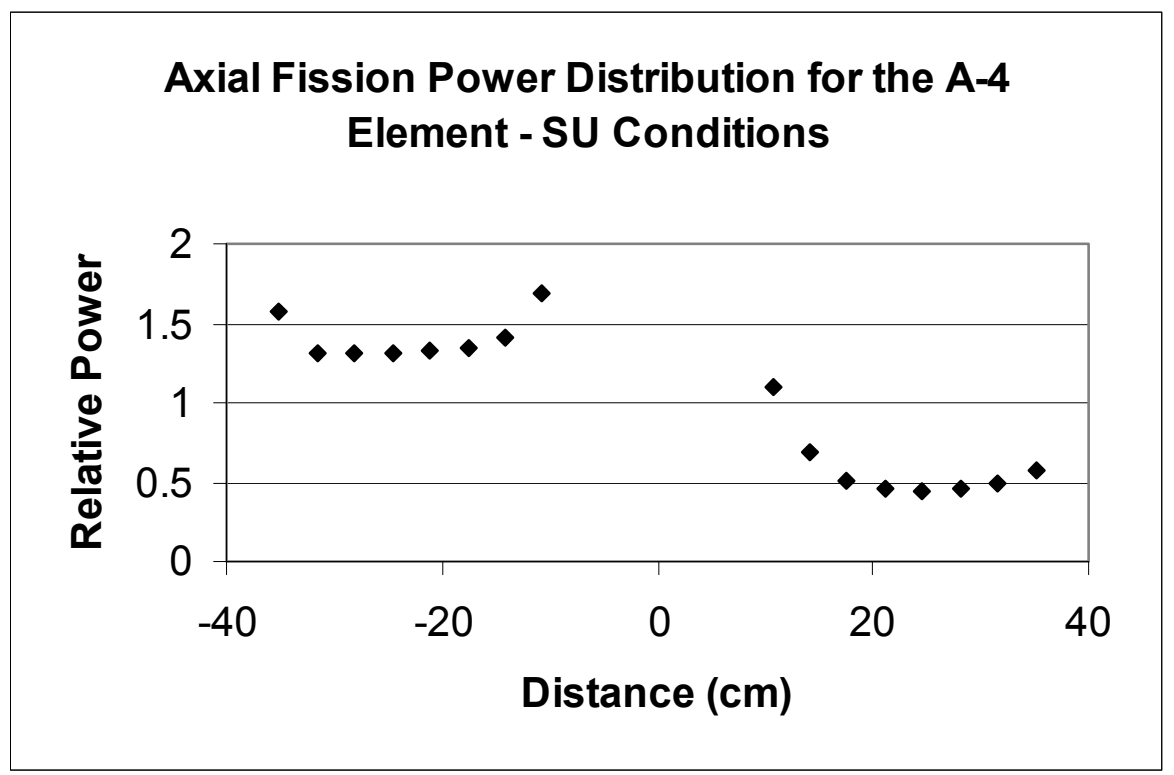

Figure 3-19. Relative Axial Power Distribution for the Fuel Element in the A-4 Position in the Equilibrium Core at Startup.

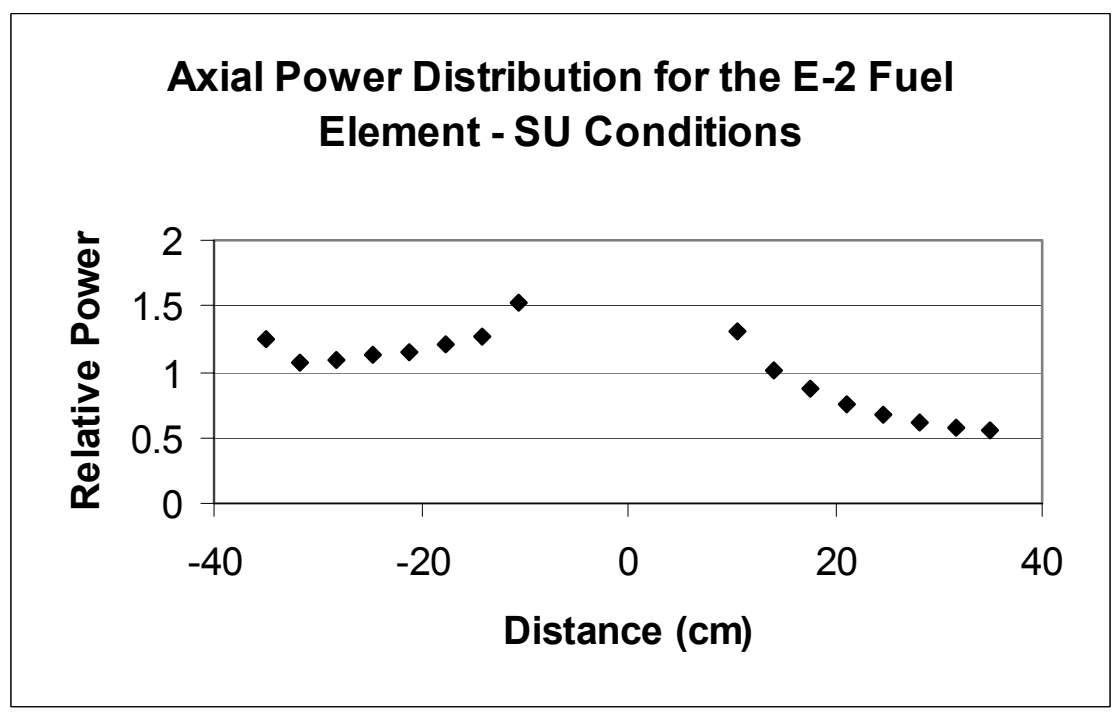

Figure 3-20. Relative Axial Power Distribution for the Fuel Element in the E-2 Position in the Equilibrium Core at Startup. 


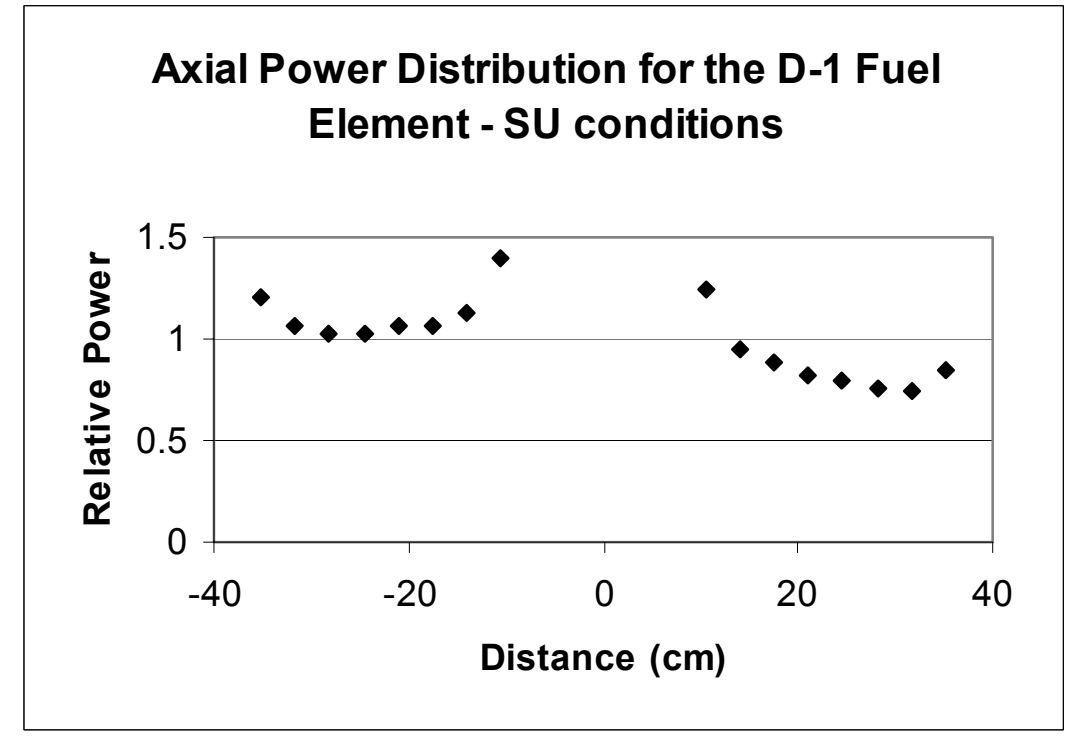

Figure 3-21. Relative Axial Power Distribution for the Fuel Element in the D-1 Position in the Equilibrium Core at Startup.

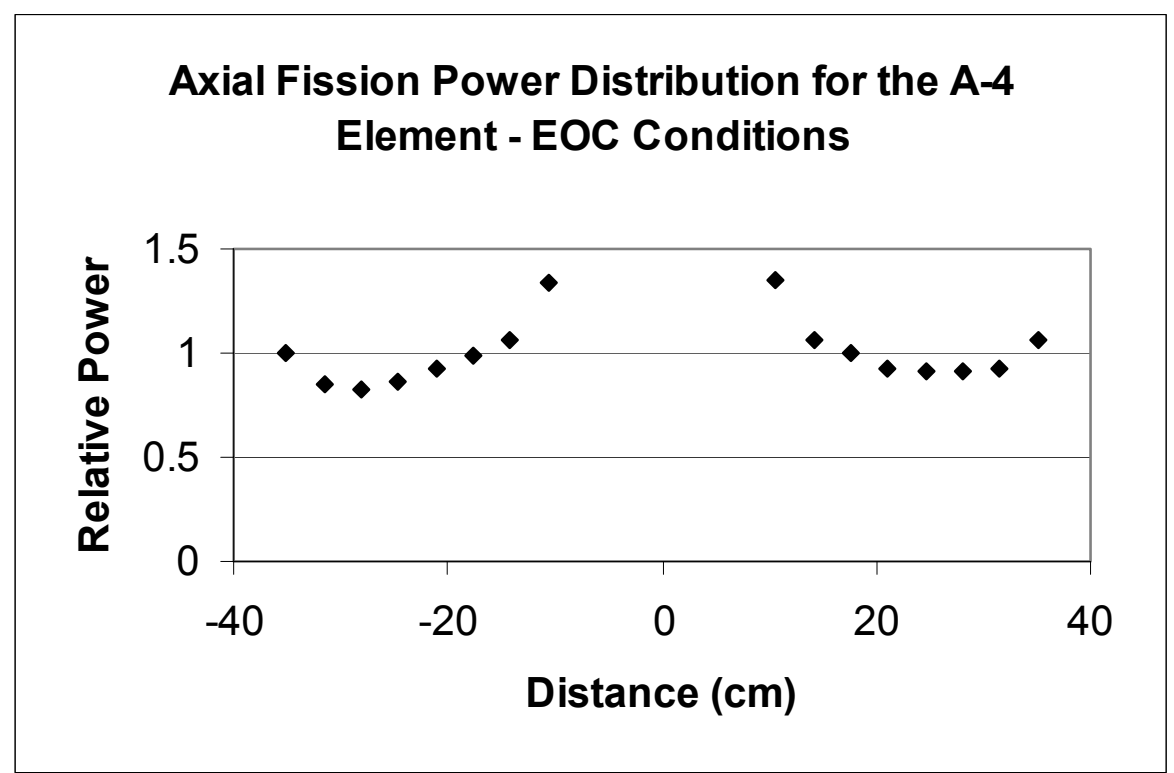

Figure 3-22. Relative Axial Power Distribution for the Fuel Element in the A-4 Position in the Equilibrium Core at End-of-Cycle. 


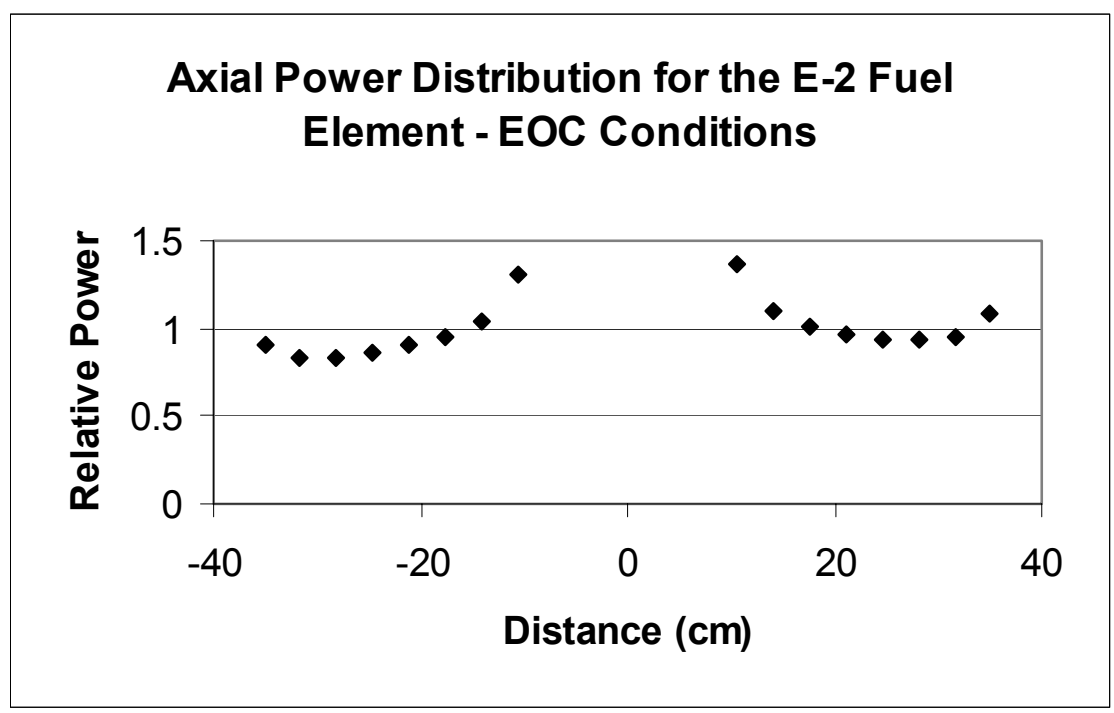

Figure 3-23. Relative Axial Power Distribution for the Fuel Element in the E-2 Position in the Equilibrium Core at End-of-Cycle.

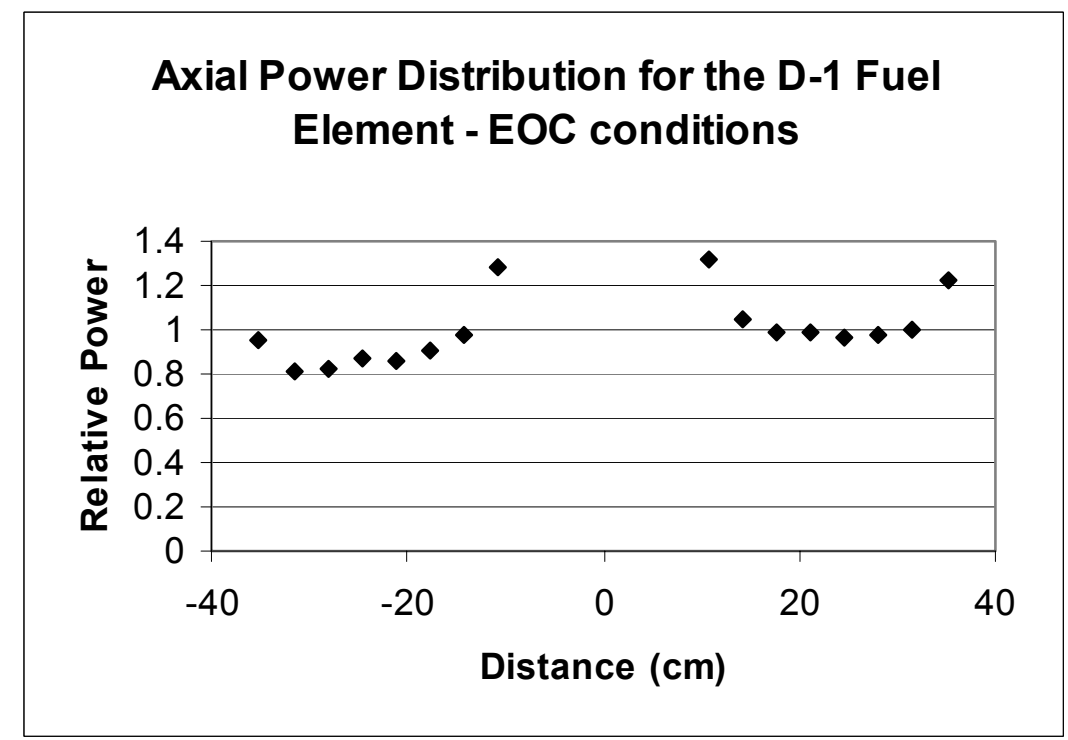

Figure 3-24. Relative Axial Power Distribution for the Fuel Element in the D-1 Position in the Equilibrium Core at End-of-Cycle. 


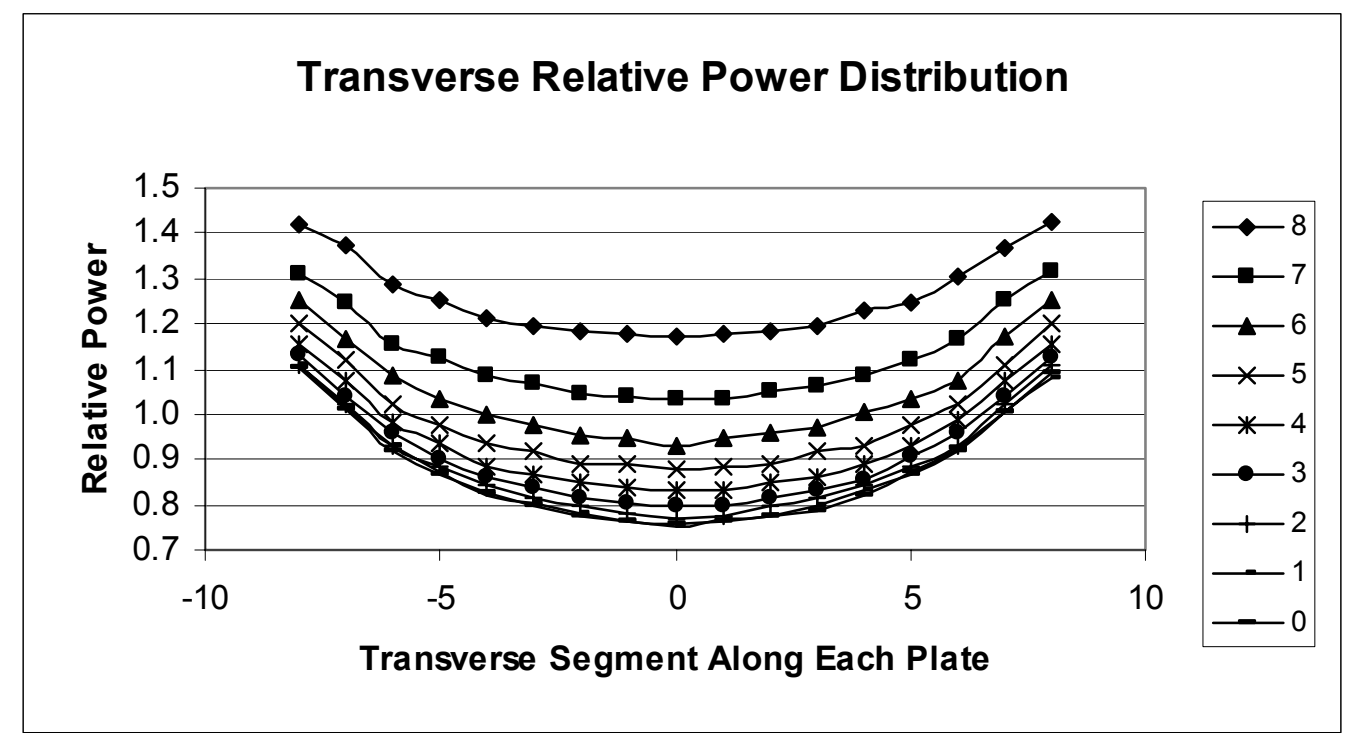

Figure 3-25. Transverse Relative Power Distribution Along Each Fuel Element Plate. Each curve corresponds to a specific fuel plate. The plates are numbered sequentially with Plate 0 located at the center of the element, and Plate 8 located at the outside of the element.

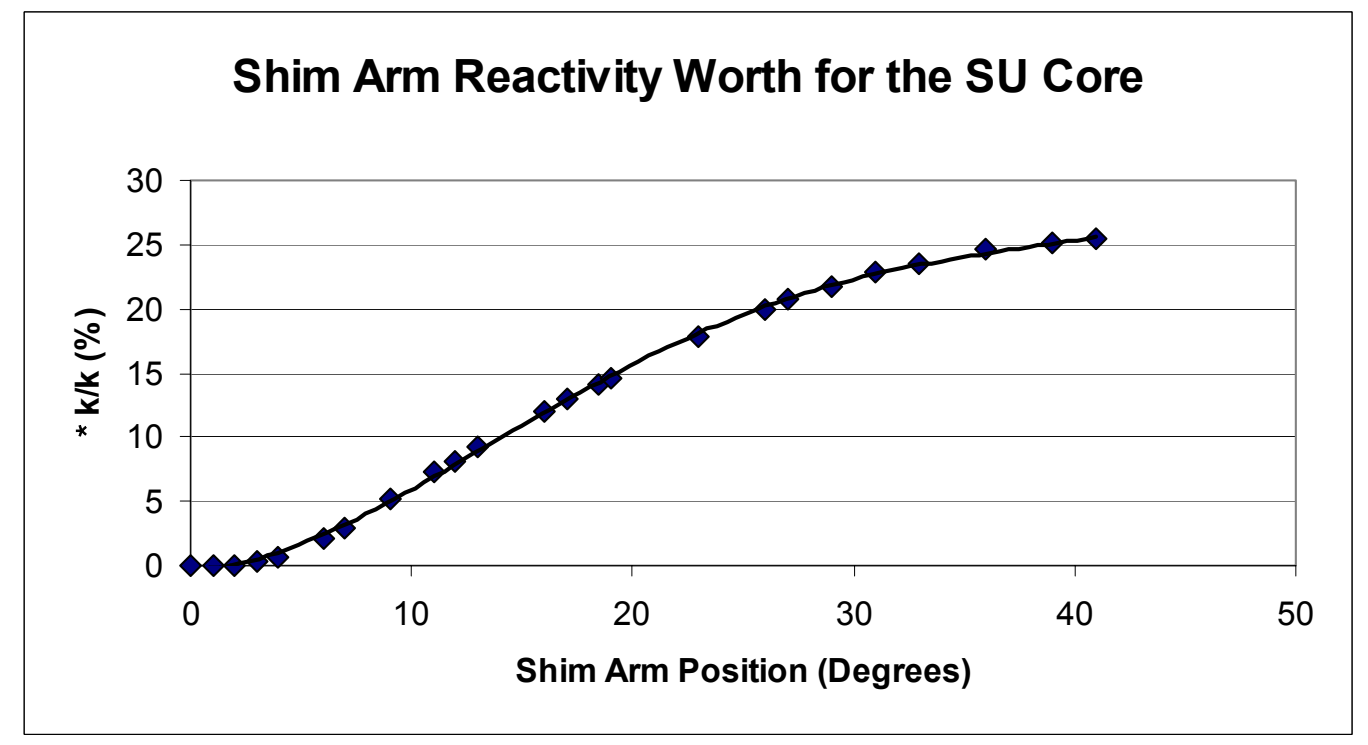

Figure 3-26. Shim Arm Worth as a Function of Angular Position in the Equilibrium Core at Startup. 


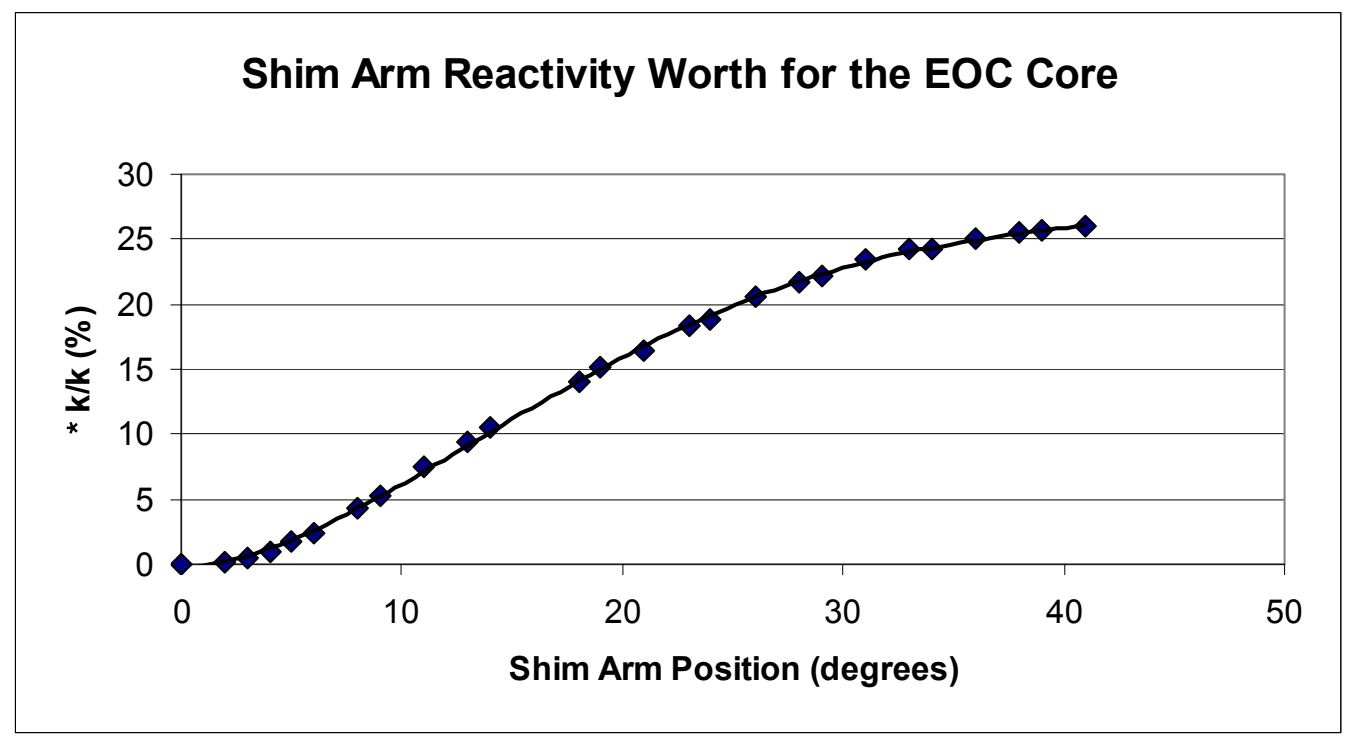

Figure 3-27. Shim Arm Worth as a Function of Angular Position in the Equilibrium Core at End-of-Cycle.

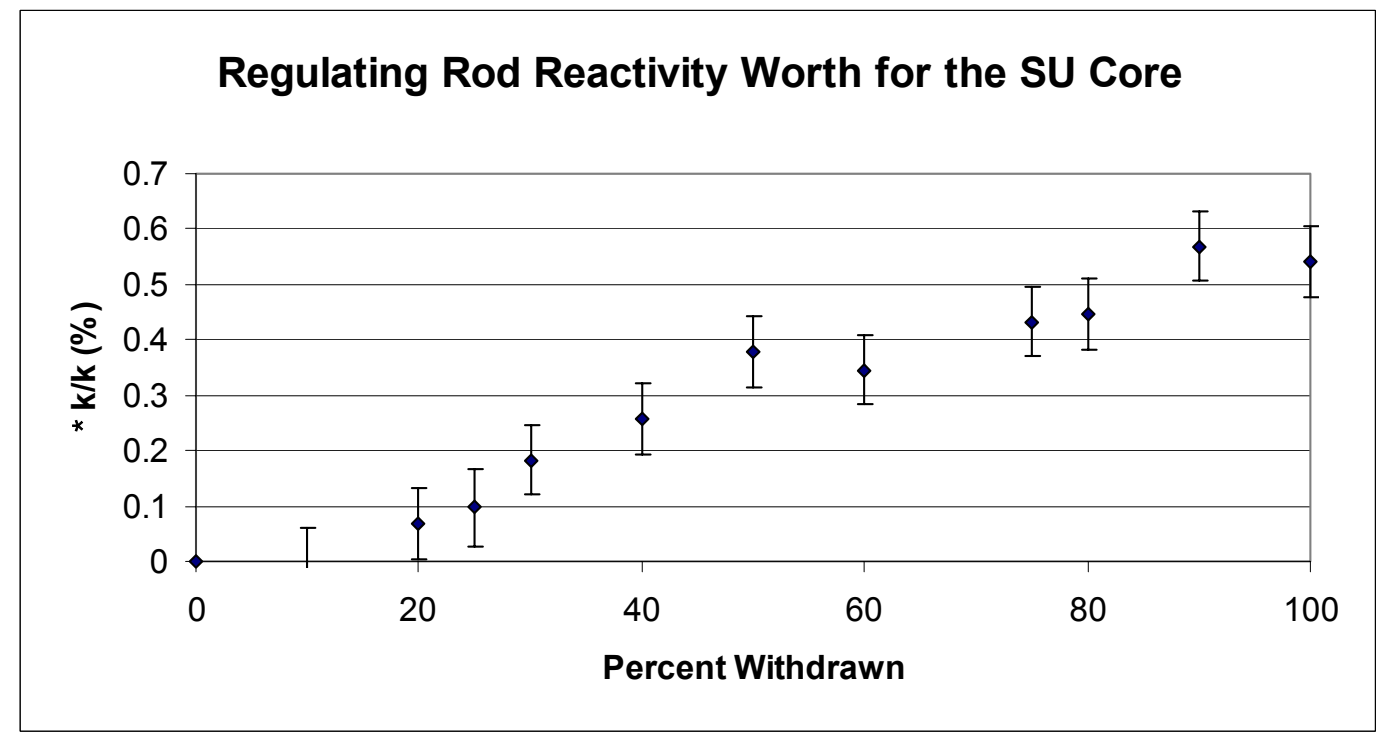

Figure 3-28. Reactivity Worth of the Regulating Rod as a Function of Relative Position (Percentage Withdrawn) in the Equilibrium Core at Startup. 


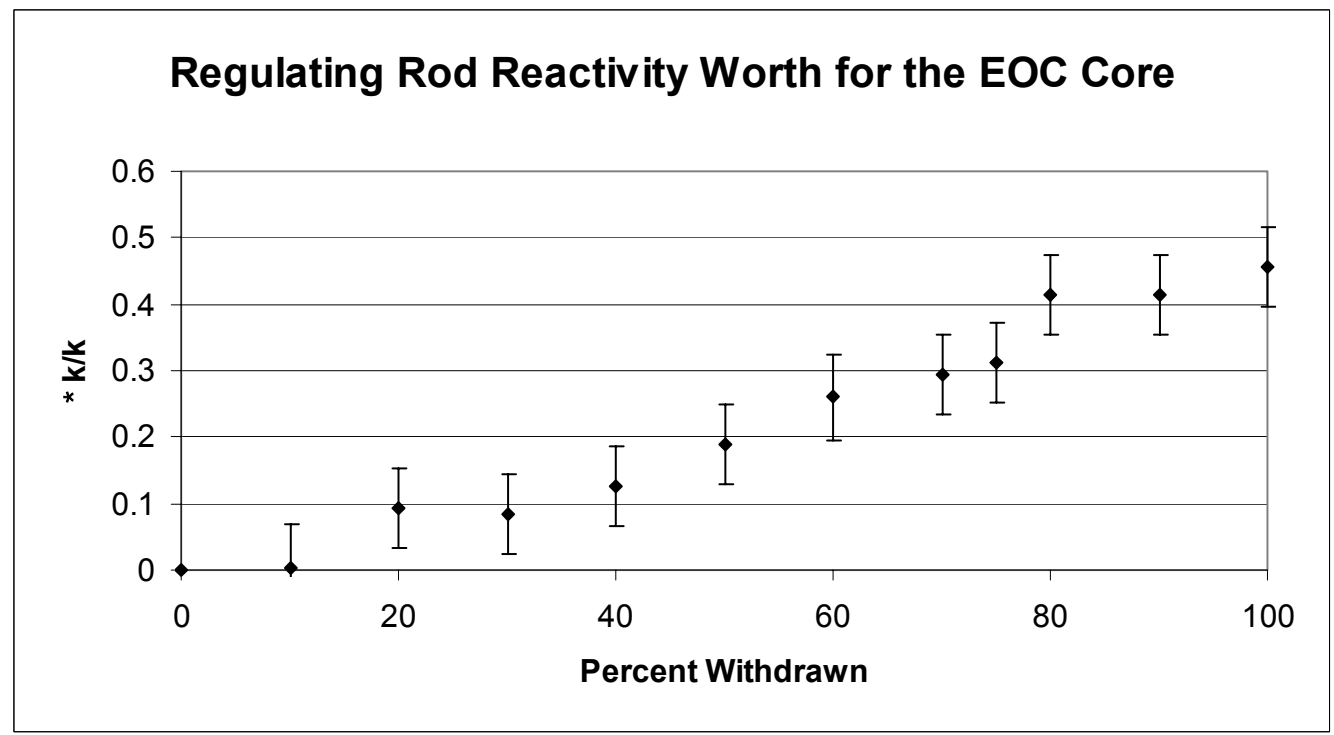

Figure 3-29. Reactivity Worth of the Regulating Rod as a Function of Relative Position (Percentage Withdrawn) in the Equilibrium Core at End-of-Cycle.

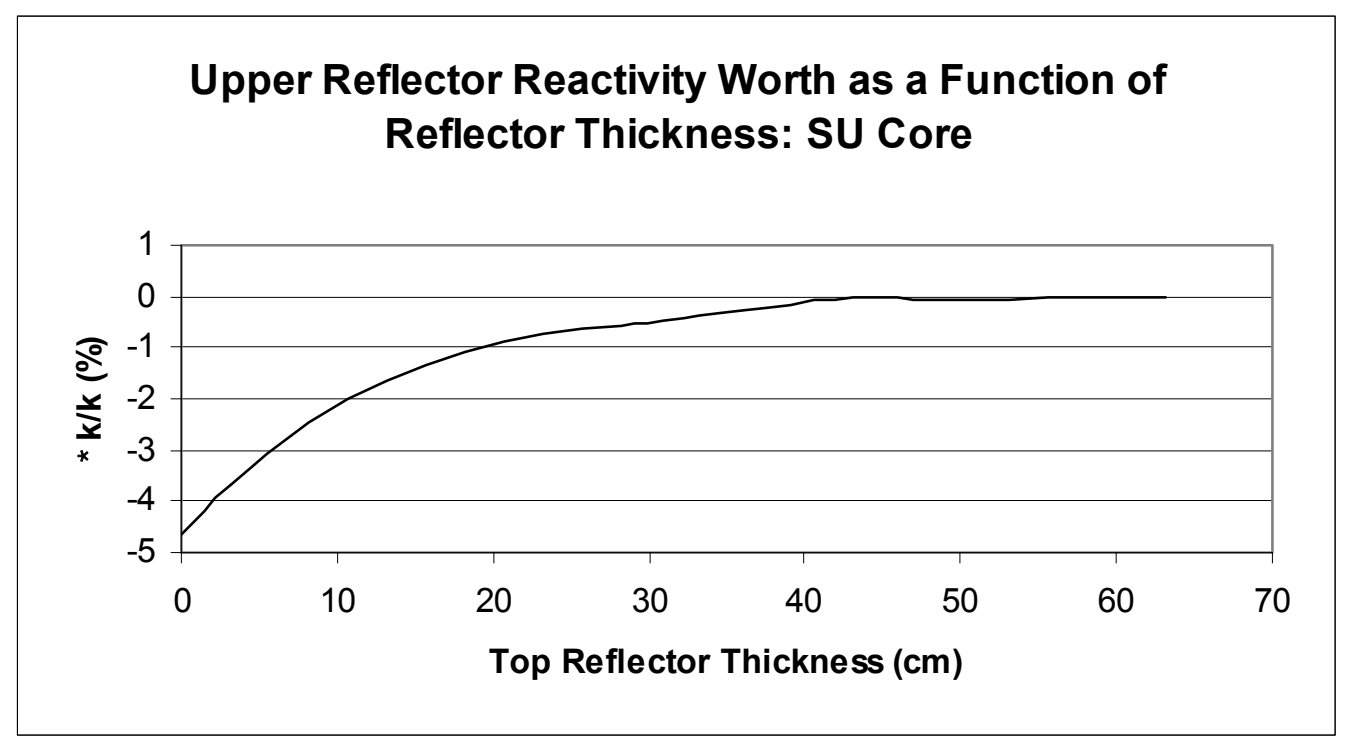

Figure 3-30. Core Reactivity as a Function of Upper Reflector Thickness Above Dump Level for the Equilibrium Core at Startup. 


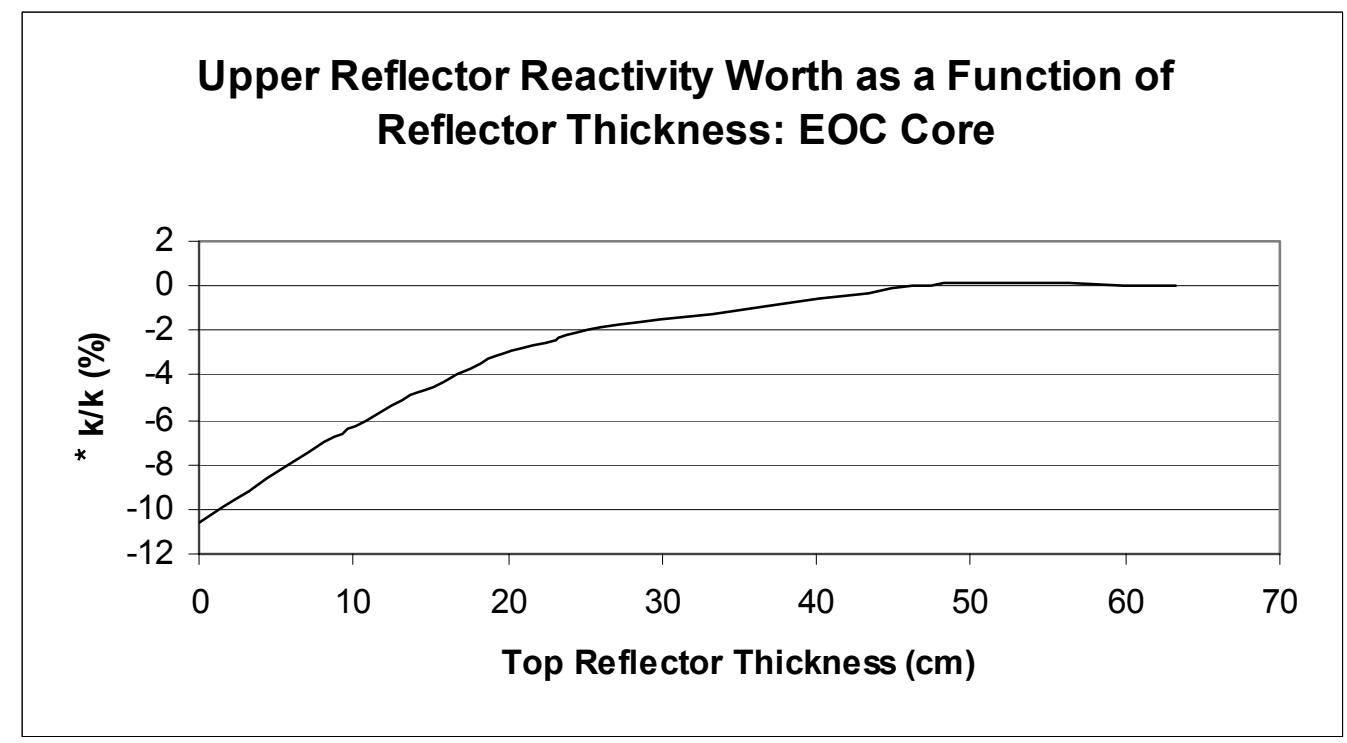

Figure 3-31. Core Reactivity as a Function of Upper Reflector Thickness Above Dump Level for the Equilibrium Core at End-of-Cycle.

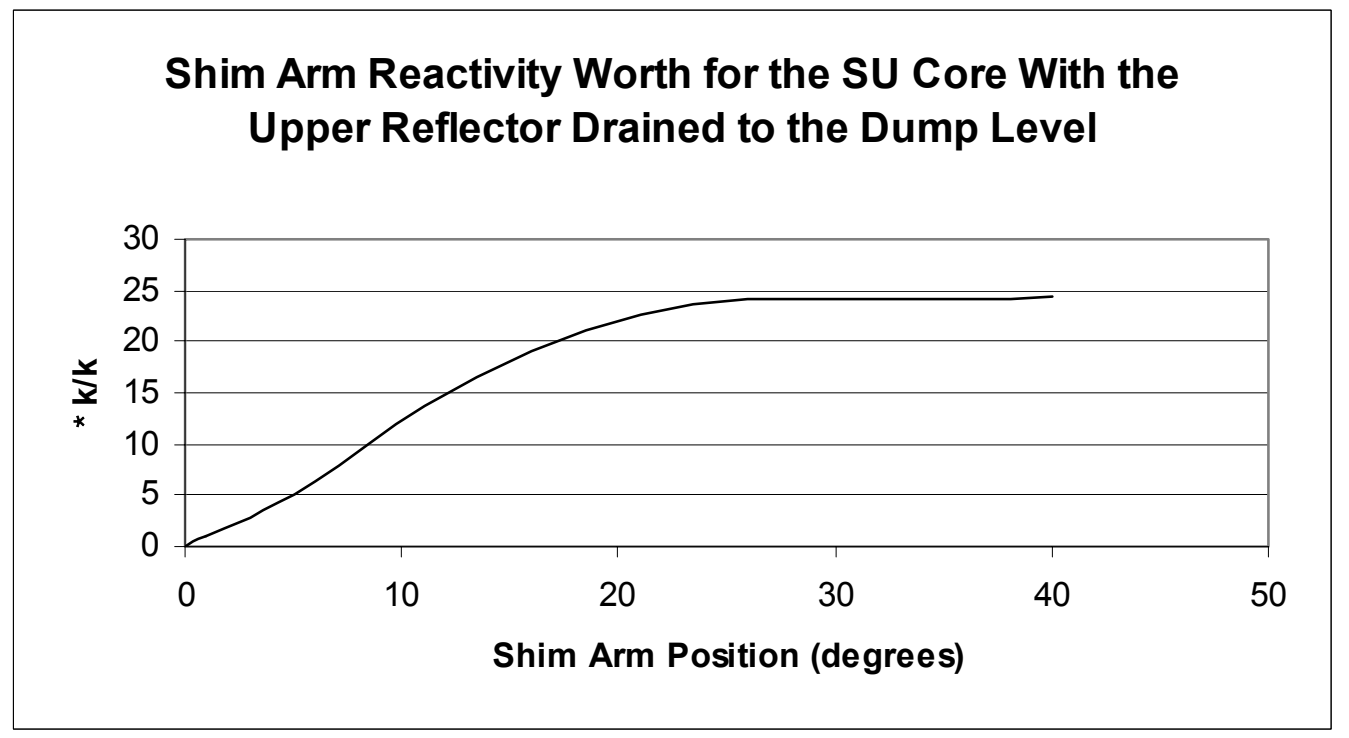

Figure 3-32. Shim Arm Reactivity Worth with the Upper Reflector Drained to the Dump Level, for the Equilibrium Core at Startup. 


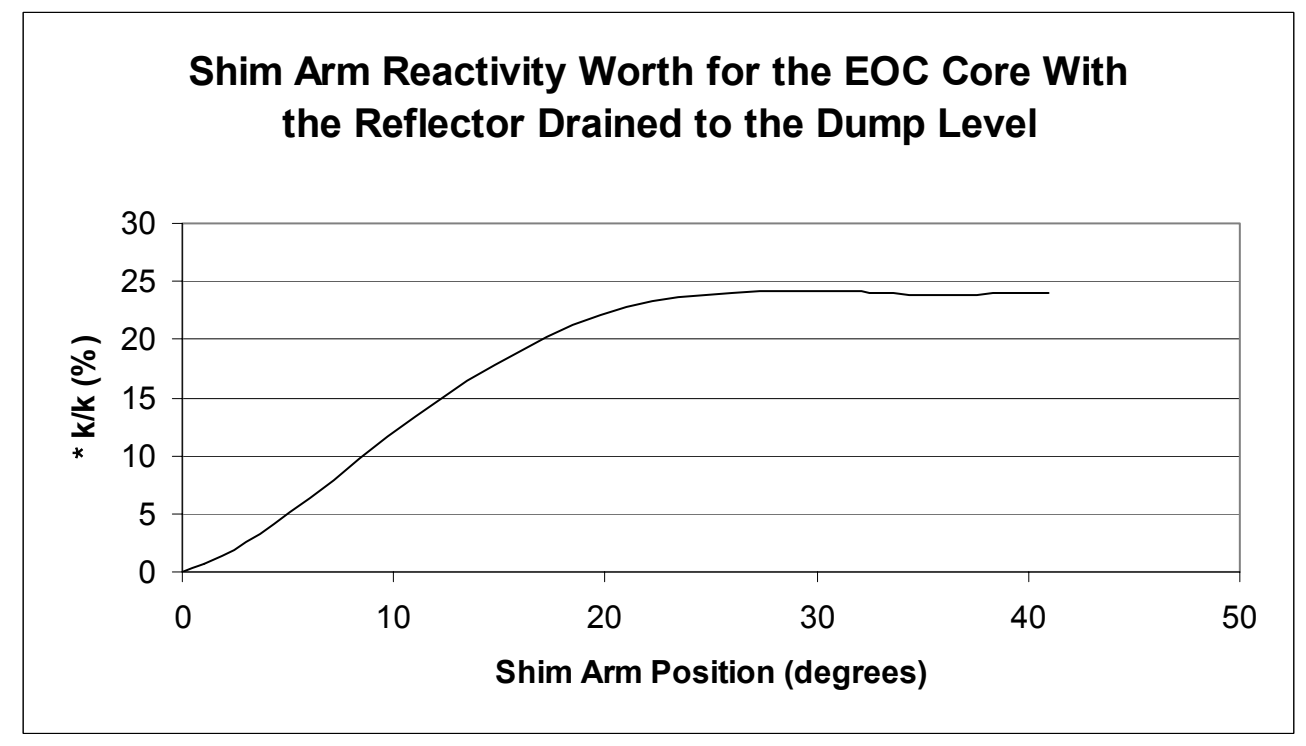

Figure 3-33 Shim Arm Reactivity Worth with the Upper Reflector Drained to the Dump Level, for the Equilibrium Core at End-of-Cycle.

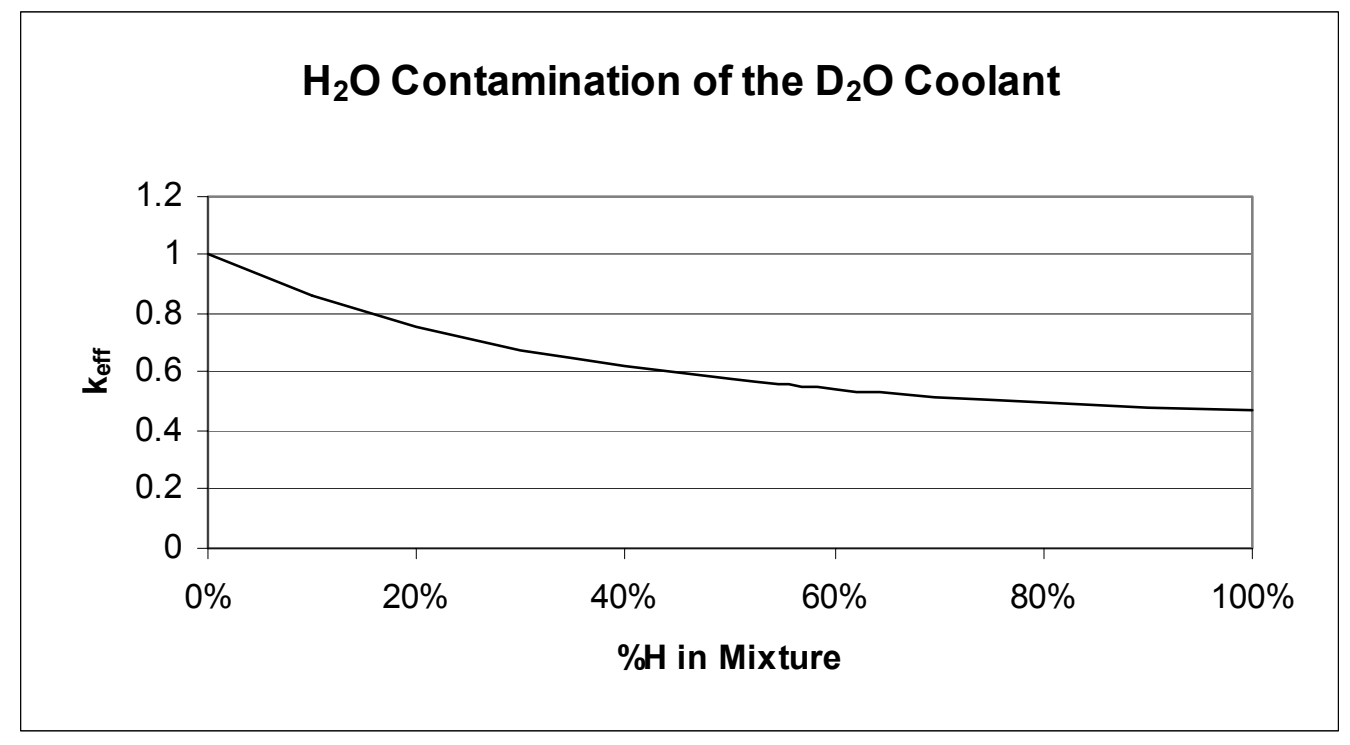

Figure 3-34. Reactivity Effect of $\mathrm{H}_{2} \mathrm{O}$ Contamination of the $\mathrm{D}_{2} \mathrm{O}$ Coolant. 
Table 3-1. Determination of the Moderator Temperature Coefficient for the Four Cores

\begin{tabular}{|c|c|c|c|c|c|c|}
\hline \multicolumn{7}{|c|}{ SU } \\
\hline $\begin{array}{l}\text { Density } \\
\left(\mathrm{g} / \mathrm{cm}^{3}\right)\end{array}$ & Scat. Kern. T & $\mathrm{k}_{\text {eff }}$ & $+/-$ & $* \mathrm{k} / \mathrm{k}(\%)$ & $* \mathrm{k} / \mathrm{k}(\%) / * \mathrm{~T}(\mathrm{~K})$ & ${ }^{*} \mathrm{k} / \mathrm{k}(\%) / * \mathrm{~T}(\mathrm{EF})$ \\
\hline 1.0966 & $300 \mathrm{~K}$ & 1.00643 & 0.00045 & & & \\
\hline 1.0966 & $400 \mathrm{~K}$ & 0.99726 & 0.00107 & -0.911 & -0.00911 & -0.00506 \\
\hline 1.06346 & $300 \mathrm{~K}$ & 0.99441 & 0.00049 & -1.194 & -0.02216 & -0.01231 \\
\hline \multicolumn{7}{|l|}{ combined } \\
\hline 1.06346 & $400 \mathrm{~K}$ & 0.98371 & 0.00077 & -2.257 & & \\
\hline 1.06346 & $400 \mathrm{~K}$ & prediction & & -2.105 & & \\
\hline \multicolumn{7}{|c|}{$\mathrm{BOC}$} \\
\hline Density & Scat. Kern. T & $\mathrm{k}_{\mathrm{eff}}$ & $+/-$ & $*_{\mathrm{k} / \mathrm{k}(\%)}$ & $*_{\mathrm{k} / \mathrm{k}(\%) / * \mathrm{~T}(\mathrm{~K})}$ & ${ }^{*} \mathrm{k} / \mathrm{k}(\%) / * \mathrm{~T}(\mathrm{EF})$ \\
\hline 1.0966 & $300 \mathrm{~K}$ & 0.98286 & 0.00046 & & & \\
\hline 1.0966 & $400 \mathrm{~K}$ & 0.97392 & 0.00045 & -0.910 & -0.00910 & -0.00505 \\
\hline 1.06346 & $300 \mathrm{~K}$ & 0.97146 & 0.00045 & -1.160 & -0.02152 & -0.01196 \\
\hline \multicolumn{7}{|l|}{ combined } \\
\hline 1.06346 & $400 \mathrm{~K}$ & 0.96301 & 0.00048 & -2.020 & & \\
\hline 1.06346 & $400 \mathrm{~K}$ & prediction & & -2.069 & & \\
\hline \multicolumn{7}{|c|}{ MOC } \\
\hline Density & Scat. Kern & $\mathrm{k}_{\text {eff }}$ & $+/-$ & $*^{*} \mathrm{k} / \mathrm{k}(\%)$ & $*_{\mathrm{k} / \mathrm{k}(\%) / * \mathrm{~T}(\mathrm{~K})}$ & ${ }^{*} \mathrm{k} / \mathrm{k}(\%) / * \mathrm{~T}(\mathrm{EF})$ \\
\hline 1.0966 & $300 \mathrm{~K}$ & 1.00482 & 0.00045 & & & \\
\hline 1.0966 & $400 \mathrm{~K}$ & 0.9974 & 0.00044 & -0.738 & -0.00738 & -0.00410 \\
\hline 1.06346 & $300 \mathrm{~K}$ & 0.99392 & 0.00045 & -1.085 & -0.02013 & -0.01118 \\
\hline \multicolumn{7}{|l|}{ combined } \\
\hline 1.06346 & $400 \mathrm{~K}$ & 0.98594 & 0.0007 & -1.879 & & \\
\hline 1.06346 & $400 \mathrm{~K}$ & prediction & & -1.823 & & \\
\hline \multicolumn{7}{|c|}{ EOC } \\
\hline Density & Scat. Kern. T & $\mathrm{k}_{\text {eff }}$ & $+/-$ & $*_{\mathrm{k} / \mathrm{k}(\%)}$ & $*^{*} \mathrm{k} / \mathrm{k}(\%) / * \mathrm{~T}(\mathrm{~K})$ & ${ }^{*} \mathrm{k} / \mathrm{k}(\%) / * \mathrm{~T}(\mathrm{EF})$ \\
\hline 1.0966 & $300 \mathrm{~K}$ & 1.02893 & 0.00044 & & & \\
\hline 1.0966 & $400 \mathrm{~K}$ & 1.02188 & 0.00044 & -0.685 & -0.00685 & -0.00381 \\
\hline 1.06346 & $300 \mathrm{~K}$ & 1.01878 & 0.00045 & -0.986 & -0.01830 & -0.01017 \\
\hline \multicolumn{7}{|l|}{ combined } \\
\hline 1.06346 & $400 \mathrm{~K}$ & 1.01149 & 0.00048 & -1.695 & & \\
\hline 1.06346 & $400 \mathrm{~K}$ & prediction & & -1.672 & & \\
\hline
\end{tabular}


Table 3-2. Effects of Voids in the NBSR for the SU and EOC Conditions

\begin{tabular}{|l|c|c|c|c|}
\hline & $\mathrm{k}$ & $+/-$ & $* \mathrm{k} / \mathrm{k}(\%)$ & $* \mathrm{k} / \mathrm{k}(\%) /$ liter \\
\hline SU Base Case & 1.00643 & 0.00045 & & \\
\hline SU with 5 thimbles voided & 0.98605 & 0.00043 & -2.025 & -0.254 \\
\hline SU with fuel elements void of $\mathrm{D}_{2} \mathrm{O}$ & 0.94913 & 0.00049 & -5.693 & -0.035 \\
\hline SU with fuel gaps void of $\mathrm{D}_{2} \mathrm{O}$ & 0.9938 & 0.01291 & -1.255 & -0.049 \\
\hline \multicolumn{5}{|l|}{} \\
\hline EOC Base Case & 1.02893 & 0.00044 & & \\
\hline EOC with 5 thimbles voided & 1.01384 & 0.00044 & -1.467 & -0.184 \\
\hline EOC with fuel elements void of $\mathrm{D}_{2} \mathrm{O}$ & 0.9798 & 0.00046 & -4.775 & -0.029 \\
\hline EOC with fuel gaps void of $\mathrm{D}_{2} \mathrm{O}$ & 1.02589 & 0.00042 & -0.295 & -0.012 \\
\hline
\end{tabular}

Table 3-3. Effects of Flooding of the Beam Tubes, the Cold Neutron Source and the Pneumatic Tubes for the SU Conditions

\begin{tabular}{|c|c|c|c|}
\hline & $\mathrm{k}_{\text {eff }}$ & $+/-$ & $* \mathrm{k} / \mathrm{k}(\%)$ \\
\hline SU Core base case - no flooding & 1.00643 & 0.00045 & \\
\hline All tubes and cold source are flooded & 1.03725 & 0.00046 & 3.06 \\
\hline \begin{tabular}{l|l} 
The cold source is flooded \\
\end{tabular} & 1.01098 & 0.00049 & 0.45 \\
\hline THE BEAM TUBES ARE FLOODED & 1.03005 & 0.00047 & 2.35 \\
\hline The radial beam tubes are flooded & 1.02403 & 0.00047 & 1.75 \\
\hline The tangential beam tubes are flooded & 1.01411 & 0.00047 & 0.76 \\
\hline The pneumatic tubes are flooded & 1.00822 & 0.00048 & 0.18 \\
\hline
\end{tabular}

Table 3-4. Effects of Flooding of the Beam Tubes, the Cold Neutron Source and the Pneumatic Tubes for the EOC Conditions

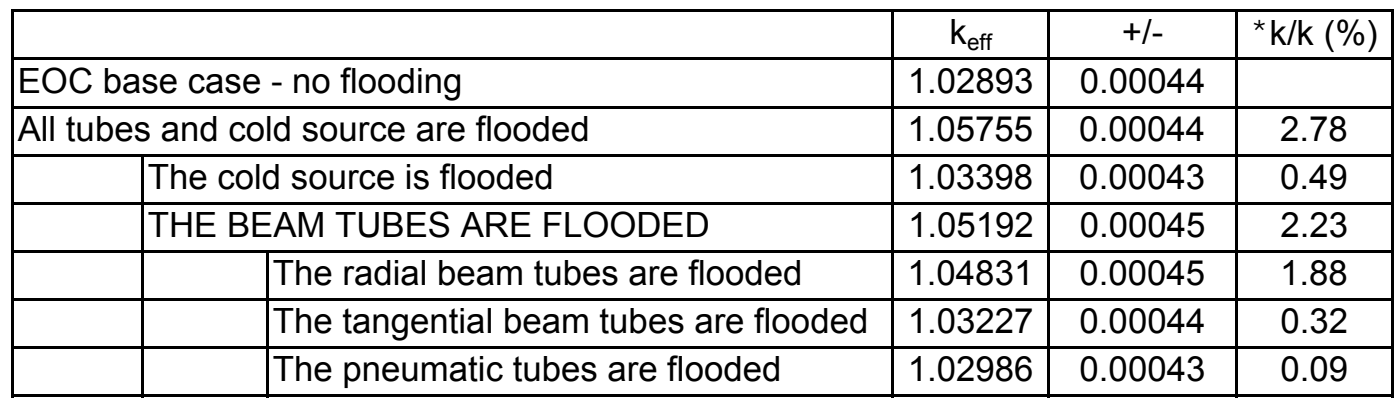




\section{THERMAL-HYDRAULIC ANALYSIS}

\subsection{Introduction}

The potential for fuel damage has been evaluated for various accidents and transients postulated for the NBSR. The criterion for fuel damage is based on the concept that overheating of the fuel plates is expected when the local heat flux of a fuel plate exceeds a certain critical value. The value of the critical heat flux (CHF) is generally associated with the phenomenon of boiling transition in which a sudden reduction in the heat transfer rate (from the heated wall to the coolant) results in a rapid increase in the wall temperature. The local heat flux in a fuel plate is a function of the reactor power and the power distribution in the core. Its value is determined from the reactor physics analysis presented in Section 3. The determination of the CHF for the NBSR in an accident or transient requires the evaluation of the thermal-hydraulics of the coolant. This is performed by using the computer code RELAP5/MOD3.2 [7]. The model for the NBSR is described in Section 4.2. The steady-state results for the NBSR are presented in Section 4.3.

For the purpose of analyzing postulated accidents/transients, the figure of merit for determining fuel damage is taken to be the minimum value of the critical heat flux ratio (CHFR) in the core during the course of the transient. In the analysis presented in Section 4.4 a relationship is developed correlating the nominal value of the minimum CHFR with the probability of the CHF being reached and fuel damage occurring. Using this statistical approach an acceptable nominal value of the minimum CHFR for the NBSR is chosen with the understanding that the value corresponds to a high probability of no fuel failure.

\subsection{Methodology for Transient Analysis of the Reactor System}

\subsubsection{RELAP5 Application}

RELAP5 is a light and heavy water reactor transient analysis code developed at the Idaho National Engineering and Environmental Laboratory (INEEL) for the U.S. Nuclear Regulatory Commission (NRC) [7]. It is capable of analyzing a wide variety of thermal-hydraulic transients in nuclear and non-nuclear systems involving mixtures of steam, water (light/heavy), noncondensables, and solute. RELAP5 is one of the most widely used system codes for analyzing reactor accidents/transients. The DOE research reactors ATR and HFIR used RELAP5 to analyze design basis accidents in their safety analysis reports (SARs). RELAP5 also has been applied to the HFBR, which is similar to the NBSR in many respects, especially with respect to the coolant (heavy water) and the geometry of the fuel element (MTR plate type).

RELAP5/MOD3, the current version of the code system, was developed with the objective of creating a code version suitable for the analysis of postulated accidents in water reactor systems, including both large- and small-break loss-of-coolant accidents (LOCAs) as well as a full range of operational transients. The hydrodynamic model in RELAP5 is a one-dimensional, transient, two-fluid model for flow of a two-phase steam-water mixture. The non-equilibrium transient two-fluid model is represented by the conservation equations of mass, momentum, and energy for each phase. The steam phase can contain non-condensable components and the water phase 
can have a solute component. Special process models are available to handle choked flow, abrupt area changes, and counter-current flow.

Metal components are modeled by heat structures with internal heat generation. Heat transfer within the structures is by one-dimensional heat conduction. A full boiling curve is implemented in the code for modeling heat transfer between heat structures and the coolant. Reactor power and decay power are calculated by a point kinetics model with reactivity feedback. In RELAP5 a hydraulic system is constructed by connecting fluid components, such as pipes, valves, pumps, etc., in series or in parallel. Geometric data and the initial thermodynamic state of the fluid are required for the interconnecting components. The initial flow rate is required at the junctions between two components. Heat structures are defined with the heat transfer surface facing the coolant in a hydraulic component. Time varying boundary conditions can be specified in terms of fluid flow rate or the thermodynamic state of the fluid. Control system components are available in RELAP5 to model system dynamic behavior such as component trips and the evaluation of system variables.

\subsubsection{Modeling of the NBSR}

The RELAP5/MOD3.2 model of the NBSR simulates the transport of heat and coolant in the primary system. The reactor vessel and the primary coolant loop are represented by a series of hydrodynamic volumes. Fuel plates in the core region are represented by heat structures. Fission and decay power are calculated by using the point kinetics model in RELAP5. A schematic diagram showing the main components of the NBSR primary system is shown in Figure 4-1.

The discussion of the NBSR model will be grouped into four sub-sections: the reactor vessel, the primary coolant loop, the secondary cooling loop, and fuel plates. A component number, as defined in the RELAP5 input deck, is used to identify each hydrodynamic volume modeled.

\subsubsection{Reactor Vessel}

The reactor vessel is divided into a number of interconnected hydrodynamic volumes. In addition, heat structures with internal heat generation are used to model the fuel plates. The inner six fuel elements are modeled as an inner group while the outer 24 fuel elements are modeled as an outer group. The inner group is divided into three different channel types, each with a different heating rate and flow area. The three types of channels are the hot stripe, hot element, and average element. The channel types are defined in Section 4.2.3. Similarly, the outer group is also divided into three channel types, and three additional channels correspond to average elements. The specific components that are used to define the reactor vessel model are described in Appendix A. Figure 4-2 is a block diagram showing the volumes representing the various parts of the reactor. Figure 4-3 is a schematic representation of the three types of flow channels. The hot stripe and the average element channel are similar in their composition of hydraulic volumes that constitute the flow path for the coolant in a fuel element. The hot element has two parallel flow paths in the upper and lower core. This arrangement is to simulate the effects of coolant mixing in the common flow areas of a fuel element. 


\subsubsection{Primary Coolant Loop}

Parallel flow paths in the NBSR primary coolant loop are modeled by combining them into a single effective flow path. This applies to the two outlet pipes from the reactor vessel, the three branches going into and out of the three primary pumps, and the two branches of the two primary heat exchangers. This simplification does not have a significant effect on the RELAP5 analysis since the parallel flow paths are thermally and hydraulically similar. Figures 4-4 and 4-5 depict the layout of the hot and cold leg of the primary coolant loop respectively. The specific components used to define the Primary Coolant Loop are described in Appendix B.

\subsubsection{Secondary Cooling Loop}

The secondary cooling loop is modeled simply as a once through circuit. At one end a source supplies the cooling water to the primary heat exchangers. After the heat exchangers the secondary coolant (light water) flows to a sink. The specific components used to define the Secondary Coolant Loop are described in Appendix B.

\subsubsection{Fuel Plates}

Rectangular heat structures are used to represent the NBSR fuel plates. Each channel type is associated with a different heat structure (the hot element has two heat structures for the two parallel flow channels in the core region). The power generated by fission and fission product decay is assumed to deposit in the fuel cermet with no direct heating of the coolant assumed. Direct heating tends to lower the local power peaking in the core region and thus neglecting this effect is conservative. Since each fuel plate is cooled on both sides it is then reasonable to model only the half thickness of a plate and double the width to give the correct wall heat flux. The cermet is modeled as a volumetric heat source and thermal energy is transferred by conduction in the fuel core (a half thickness of $0.0254 \mathrm{~cm}(0.01 \mathrm{in}))$ and the cladding (a thickness of $0.0381 \mathrm{~cm}(0.015$ in)). The fuel core of a NBSR fuel plate has a height of $27.94 \mathrm{~cm}(11 \mathrm{in})$ and a width (flattened plate) of $6.028 \mathrm{~cm}$ (2.3734 in). In the RELAP5 model, each NBSR fuel plate is assumed to have a heat transfer surface that has the same height but twice the width of the fuel core. Figure 4-6 shows the RELAP5 model of a NBSR fuel plate and the corresponding coolant channel. The assignment of power and axial power profile to each heat structure is discussed in Section 4.2.3.

\subsubsection{RELAP5 Input Data}

\subsubsection{Geometry}

Much of the RELAP5 input is for the dimensions of the hydrodynamic volumes. The geometric inputs for the NBSR are based on plant drawings and on-site walk-downs. Figures 4-4 and 4-5 summarize the dimensions of the primary loop piping. Elevations of the fuel element are indicated in Figure 4-7 and cross-sectional dimensions are summarized in Table 4-1. For simplicity, the lower and upper ends of a fuel element are assumed to be flush with the bottom of the lower grid plate and the top of the upper grid plate respectively. This approximation has a negligible effect on the results of these analyses, since in the lower core the $27.9 \mathrm{~cm}$ (11in) fueled region starts $22.9 \mathrm{~cm}(9 \mathrm{in})$ above the lower grid plate. The fuel region in the upper core ends $61 \mathrm{~cm}(24$ 
in) below the upper grid plate. The water level in the reactor is measured from the bottom of the lower grid plate. The core mid-plane corresponds to a level of $69.8 \mathrm{~cm}(27.5 \mathrm{in})$.

\subsubsection{Primary Heat Exchanger}

The two NBSR primary heat exchangers are combined into one unit. All heat transfer plates are lumped into a single rectangular plate with the appropriate total heat transfer area and a rectangular coolant channel on each side of the plate. Primary and secondary coolant flows countercurrently in the rectangular channels. A fouling factor is applied to the heat transfer surface to maintain a heat exchanger heat removal rate that agrees with the initial reactor power. The inputs for the heat exchangers are based on plant drawings and vendor specifications.

\subsubsection{Primary Pump}

The three primary pumps are lumped into one effective pump. The pump characteristics are developed from vendor diagrams. Figure 4-8 shows the pump head and pump efficiency as a function of flow in one pump. In RELAP5 the pump performance is specified in the form of 16 homologous curves, eight head curves and eight torque curves. As usual, vendor data are insufficient to define all 16 curves. For completeness, as required by RELAP5, the missing parts are filled in by data built into the code for a Bingham pump. The homologous curves are normalized to a rated flow of $140 \mathrm{U} / \mathrm{s}$ (2180 gpm) per pump that corresponds to the maximum pump efficiency as determined from the vendor data. This is equivalent to approximately $1 / 3$ the rated flow of one HFBR pump. Since the moment of inertia of the pump impeller and the motor shaft are unknown, the combined moment of inertia of three NBSR primary pumps is therefore assumed to equal to the moment of inertia of one HFBR pump (excluding the flywheel). The pump inertia is important in the calculation of the pump coastdown. Figure 4-9 provides a comparison between actual NBSR plant data and the RELAP5 prediction of pump coastdown. The differences during the first few seconds are believed to be due to the inertia of the flow instrumentation. The friction torque coefficient for the pump in the RELAP5 input has been adjusted to obtain good agreement with the data in the later part of the coastdown, which is most important in the transient analysis.

\subsubsection{Inner Emergency Cooling Tank Orifice}

It takes 30 minutes to drain the inner emergency cooling tank completely under gravity. The required orifice size was calculated analytically by applying the mechanical energy balance to the water in the tank with an orifice in the bottom. The corresponding initial mass flow rate through the orifice was also calculated analytically. A RELAP5 model of the inner emergency cooling tank was set up and the orifice was modeled as a junction with an abrupt area change. The orifice area was adjusted in the RELAP5 input until the initial orifice flow agreed with the analytical result. Using this orifice area, a RELAP5 calculation was performed to calculate the water level in the emergency tank as a function of time. The results of this calculation were then compared to an analytical solution. Figure 4-10 illustrates the excellent agreement between the RELAP5 results and the analytical solution. The performance of the inner emergency cooling tank in a postulated loss of coolant accident is discussed in Section 5.6. 


\subsubsection{Point Kinetics Input Data}

The RELAP5 reactor kinetics model calculates the total reactor power as the sum of fission power and fission product decay power. Fission power is calculated from the point kinetics model with the 14 delayed neutron precursor groups which are summarized in Table 4-2. The delayed neutron groups and the neutron lifetime (or the prompt neutron generation time, as used in RELAP5) are from the NBSR 9 Addendum 1 [2]. The effective delayed neutron fraction is 0.007574 and the neutron lifetime is $400 \mu \mathrm{s}$. The option selected to calculate decay heat in RELAP5 is to use the 1979 ANS Standard data for ${ }^{235} \mathrm{U}$.

In the present analysis, no credit is taken for the moderator density and temperature feedback. This is conservative since these negative reactivity feedbacks act in the opposite direction to the inserted accident reactivity and tend to reduce the transient power excursion.

The reactivity curve for the four shim arms as a function of position is shown in Figure 4-11. The shim arm travel as a function of time after scram is shown in Figure 4-12. The assumed scram motion of the shim arms is in the form of a nonlinear fit developed from measured data. A conservative time delay has been incorporated in the start of shim arm motion after the initiation of a scram. It is assumed that starting from any position the first $5^{\circ}$ insertion will take $240 \mathrm{~ms}$. The scram motion is described by the following relation:

$$
\Delta \theta=\mathrm{a}(\mathrm{t}-\delta)^{2}
$$

where $\Delta \theta$ is the shim arm travel in degrees, $\mathrm{t}$ is the time from scram initiation in seconds, and

$$
\begin{aligned}
& a=248.9 \\
& \delta=0.0983 .
\end{aligned}
$$

The above scram motion assumes that the shim arms remain stationary for the first $0.0983 \mathrm{~s}$ after a scram is initiated.

\subsubsection{Core Bypass Flow}

About $4 \%$ of the total primary flow bypasses the fuel elements. In RELAP5 the areas of the bypass flow junctions have been adjusted so that $4 \%$ of flow to the inner and outer plenums is bypassed. The bypass flow paths are blocked off (by trip valves J78 and J79) for the analysis of the loss of shutdown cooling accident. If allowed to stay open these flow paths could potentially be part of the return flow path for the internal recirculation.

\subsubsection{Core Flow Distribution}

The flow distribution between the inner and outer plenum is derived from actual plant measurements. At a primary flow of $560 \ell / \mathrm{s}(8700 \mathrm{gpm})$, the respective distributed flow values are $148 \mathrm{l} / \mathrm{s}$ (2300 gpm) and $412 \ell / \mathrm{s}$ (6400 gpm). This flow split is accomplished in the RELAP5 model by adjusting a junction loss coefficient in the outer plenum inlet pipe (Component 41). In simulating 
a flow control valve throttling accident, a motor valve is placed at the reactor inlet, replacing junction J50 (inner plenum inlet) or J51 (outer plenum inlet).

\subsubsection{Power Distribution}

The NBSR core has 30 fuel elements, each having an upper and a lower fueled region. A 15.24 $\mathrm{cm}$ (6 in) un-plated region at the core mid-plane separates the upper and lower core regions. Each core region has 17 fuel plates forming 18 coolant channels of identical dimensions. It is impractical to model individually all $1020(17 \times 30 \times 2)$ fuel plates and $1080(18 \times 30 \times 2)$ coolant channels in the 30 fuel elements. Instead, the 30 fuel elements are separated into two groups: 1) an inner core group of six elements which receives flow from the inner plenum and is located in the center of the reactor core, and 2) the remaining 24 elements in the outer core group, which receives flow from the outer plenum. Each group of fuel elements is represented by several idealized core channels. It is assumed in the NBSR model that the core channel flow paths are connected in parallel and the power to each channel is determined by the power distribution modeled by MCNP. Each core channel has heat structures representing the fuel plates in the lower and upper core region. A core channel may represent multiple fuel plates lumped together as an effective plate with an effective flow channel representing the flow through the plated and unplated regions.

In the NBSR model the inner and outer fuel element groups are each represented by three core channel types: the hot stripe, hot element and average element. A hot channel is identified from the power received by the coolant channels. Assuming energy generated in each fuel plate is divided equally to the coolant channel on each side of the plate, a channel power is calculated for each of the 16 interior coolant channels, i.e. channels bounded by two fuel plates. The hot channel is the coolant channel with the highest power (sum of the lower and upper core contributions). In order to account for the peaking of heat flux across the transverse span of a fuel plate, a hot stripe is defined as one of the channel types. Each fuel plate is divided conceptually into 17 vertical stripes (see Section 3.4.4) and the stripe with the highest power density is the hot stripe. Figure 4-13 shows the span-wise transverse (lateral) power distribution in the fuel plates as calculated in Section 3.4.4. The highest relative transverse (lateral) power factor is 1.27. Thus for any plate, the hot stripe will have a power density at most 1.27 times the plate average. Axial variation in power generation is specified by axial power factors. A set of axial power factor is determined for the hot element in the outer group (see Section 3.4.3) and this set is applied to all channel types. The hot element is defined as the fuel element that contains the hottest coolant channel. The relative axial power, normalized to the element average, is shown in Figure 4-14.

The characteristics of the three core channel types are discussed in the following paragraphs. The dimensions of the coolant channel types are summarized in Table 4-3.

\section{Single Channel Hot Stripe}

The single channel hot stripe has a power equal to 1.27 times the power of the hot channel. It is assumed that there are four channels having this power, to account for quarter core symmetry. It is also conservatively assumed that the flow area in the plated region is calculated with the

minimum gap size of $0.273 \mathrm{~cm}(0.107 \mathrm{in})$, rather than with the nominal gap. The other flow areas 
in the single channel hot stripe are reduced proportionally from their nominal values. The single channel hot stripe is depicted in Figure 4-3.

\section{$\underline{\text { Hot Element }}$}

This channel type has four parallel flow channels and is designed to simulate the effect of the common un-plated central gap region in a fuel element. The hot element is the fuel element that contains the hottest coolant channel in the group (inner or outer). Two parallel coolant channels in the lower core region share a common inlet section and exit to the common central gap. Two similar parallel coolant channels represent the upper core region. The parallel channels share the same non-plated regions in the fuel element. One of the parallel channels represents the hot stripe channel with one fuel plate and will be referred to here as the "multi-channel" hot stripe. The other channel represents the rest of coolant channels and plates in the hot element. It is important to note that the multi-channel hot stripe defined here differs from the single channel hot stripe defined in the previous paragraph, in that mixing in the central gap is allowed. The multichannel hot stripe and the hot element are also depicted in Figure 4-3.

\section{$\underline{\text { Average Element }}$}

The inner group has six fuel elements. An average element is used to represent all the fuel plates and coolant channels that are not part of the hot stripe or the hot element. The outer group has 24 elements and they are ranked according to their power rating. The first six elements with the highest power are grouped together, followed by the next six elements, and so on. A total of four average channels are formed and each represents an average element for the outer group. The first average element is different from the other three in that this first average element in the outer group is the equivalent of the average element for the inner group.

\subsubsection{Control Variables and Variable and Logic Trips}

In the RELAP5 code, control variables are functions defined in the input deck to calculate process parameters. Each control variable is identified by a number and an alphanumeric name. The more important control variables used in the NBSR transient analyses are listed in Appendix C.

The initiation of safety systems is defined in RELAP5 in the form of trip variables. Each trip is identified by a number. The NBSR input deck uses three types of trips. They are the pump trip, reactor trip and valve trip (open and close). A pump trip is usually initiated at time zero according to the accident scenario. A reactor trip or scram can be initiated by a number of conditions in the reactor. The reactor trips that have been modeled for the analysis of the NBSR accidents are the power and flow trips. Table 4-4 lists the scram values and the corresponding time delays as assumed in the RELAP5 model. A complete listing of the trips is provided in Appendix C. 


\subsection{Steady-State Thermal-Hydraulics Analysis}

\subsubsection{Steady-State Conditions}

The steady-state operating conditions are summarized in Table 4-5. This table shows the anticipated range and the design basis values that are used in the accident and transient analysis. In all cases the design basis value represents the conservative end of the range. For the thermalhydraulic analysis the primary flow is assumed to split between the inner and outer plenums at $148 \mathrm{l} / \mathrm{s}$ (2300 gpm) and $412 \mathrm{l} / \mathrm{s}$ (6400 gpm), respectively. This flow distribution is based on historic flow measurements that indicated a minimum flow of $6411 \mathrm{gpm}$ to the outer plenum, where the most limiting fuel element is located. The pressure of the cover gas above the core is only slightly above atmospheric and for simplicity all analyses are done with the assumption that the pressure in the cover gas region is constant at one atmosphere.

\subsubsection{Core and System Predictions}

Two key parameters of interest in the accident analysis are the fuel temperature and the CHFR. These two parameters provide a gauge for the effectiveness of heat removal from the fuel plates, and the condition of the fuel. Any imbalance between heat generation and heat removal will be directly reflected in these two parameters. With a non-uniform axial power distribution, as in the NBSR core, the maximum fuel temperature and the minimum CHFR do not always occur at the exit of the core. The matter is even more uncertain for the NBSR because of the upper and lower core arrangement in a fuel element. The location of the highest heat flux varies during the course of the fuel cycle as a result of shim arm movement and changes in the fuel burnup distribution. In the beginning of the cycle in an equilibrium core with the shim arms lowered, the lower core generally produces more power than the upper core. However, towards the end of the cycle when the shim arms are withdrawn, the upper core produces more power.

A steady state analysis of the NBSR core has been performed using the RELAP5 model described above with the initial conditions defined in Table 4-5. Four coolant channels are defined for the inner core fuel elements and seven coolant channels are defined for the outer fuel elements. Each coolant channel has a unique heat structure representing the fuel plates in the lower and upper core. Summarized in Table 4-6 are the maximum fuel centerline temperatures and the minimum CHFRs for all 11 heat structures corresponding to the 11 coolant channels for the BOC equilibrium NBSR core. Also listed are the coolant temperatures at the mid-core non-plated section and at the core exit. Table 4-7 provides these data for the EOC equilibrium core. It is noted that for all 11 heat structures the location of the maximum axial plate temperature coincides with the location of the minimum CHFR for each heat structure. Figure 4-15 shows the axial distribution of the fuel centerline temperature of the hot plate (heat structure 500) in the outer group hot element. The figure also shows the variation in coolant temperature including the effect of mixing in the unfueled midcore region. The temperature distribution has the same trend as the axial power distribution shown in Figure 4-14. In the case of an equilibrium core at the beginning of cycle, the axial power distribution peaks at the top of the lower core. Therefore the hot node (the node with the minimum CHFR) for each coolant channel is - starting from the inlet - the last heated node in the lower core. For both the inner and outer core, the hottest node is the node associated with the hot stripe in the hot element. Though the multi-channel hot stripe in the hot 
element and the single channel hot stripe have the same heat flux, the difference in the modeling of the non-plated mid-section of the fuel element resulted in the multi-channel hot stripe in the hot element having a slightly lower coolant mass flux. This is because the channel representing the hot element allows mixing with the remaining channels in the central gap, while the single channel hot stripe allows no mixing. Furthermore, because of the inner plenum/outer plenum flow split, on the average each fuel element in the outer core receives less flow as compared to the elements in the inner core. Consequently, the hot node of the multi-channel hot stripe in the hot element for the outer core group is the hot spot for the whole core. The CHFR at the hot spot is 2.98. For the inner group of fuel elements the minimum CHFR is 4.87. At the end of cycle, power peaking shifts to the upper core. Figure 4-16 shows the plate and coolant temperatures in the EOC hot channel (heat structure 400). For an EOC core, the hot spot is located at the bottom of the upper core. The CHFR at the hot spot is 3.76. At EOC, the minimum CHFR for the inner group of fuel elements is 5.58. Details of the calculation of the CHFR are discussed in Section 4.4 .

An examination of the core exit coolant temperature clearly shows the effect of coolant mixing in the non-plated mid-section of a fuel element. This is evident by comparing the exit temperatures of the single channel hot stripe (no mixing) and the multi-channel hot stripe in the hot element (with mixing). The mixing of coolant has the effect of lowering the core exit temperature by several Kelvin.

Except where noted in the discussion of the accident progression, the accident analyses indicate that the location of the hot spot for all transients analyzed in Section 5 remains the same throughout the duration of the analysis.

\subsection{Statistical Hot Channel Limits Analysis}

A statistical analysis was performed in order to account for the effects of uncertainties in the hot channel variables (i.e., CHFR, coolant temperature rise, fuel plate temperature drop and fuel plate local heat flux), and to determine the probability of exceeding local limits. This statistical analysis determined the cumulative probability distribution function (PDF) for each of the hot channel variables. The analysis accounts for the uncertainty in each parameter used in the determination of the hot channel variables, either by a random sampling of the parameter or by applying a conservative bias to the parameter. The probability distributions were determined using a direct Monte Carlo simulation of the uncertainty propagation. The details of this analysis, together with the definition of the hot channel variables, are described in Appendix D.

The Bernath correlation [9] was used to determine the CHF. The parameter uncertainties were sampled from normal distributions having standard deviations based on estimates of the uncertainty in the individual parameters. For each hot channel variable, the PDF was used to determine the limiting value such that there was a $95 \%$ probability of not exceeding this value. For the CHFR, the $99.9 \%$ value was also determined. The Monte Carlo sampling was shown to be adequate by increasing the number of samples by a factor of two and observing that the change in the limit values was $\leq 0.5 \%$. From Table D-3, it is seen that the $95 \%$ limits (expressed as a ratio of the nominal value to the random (or limit) value) determined by the statistical analysis for full power operating condition are: CHFR, 1.435; coolant temperature rise, 1.164; fuel plate 
temperature drop, 1.283; and local heat flux, 1.333 . The $99.9 \%$ limit value determined for the CHFR is 1.911. 


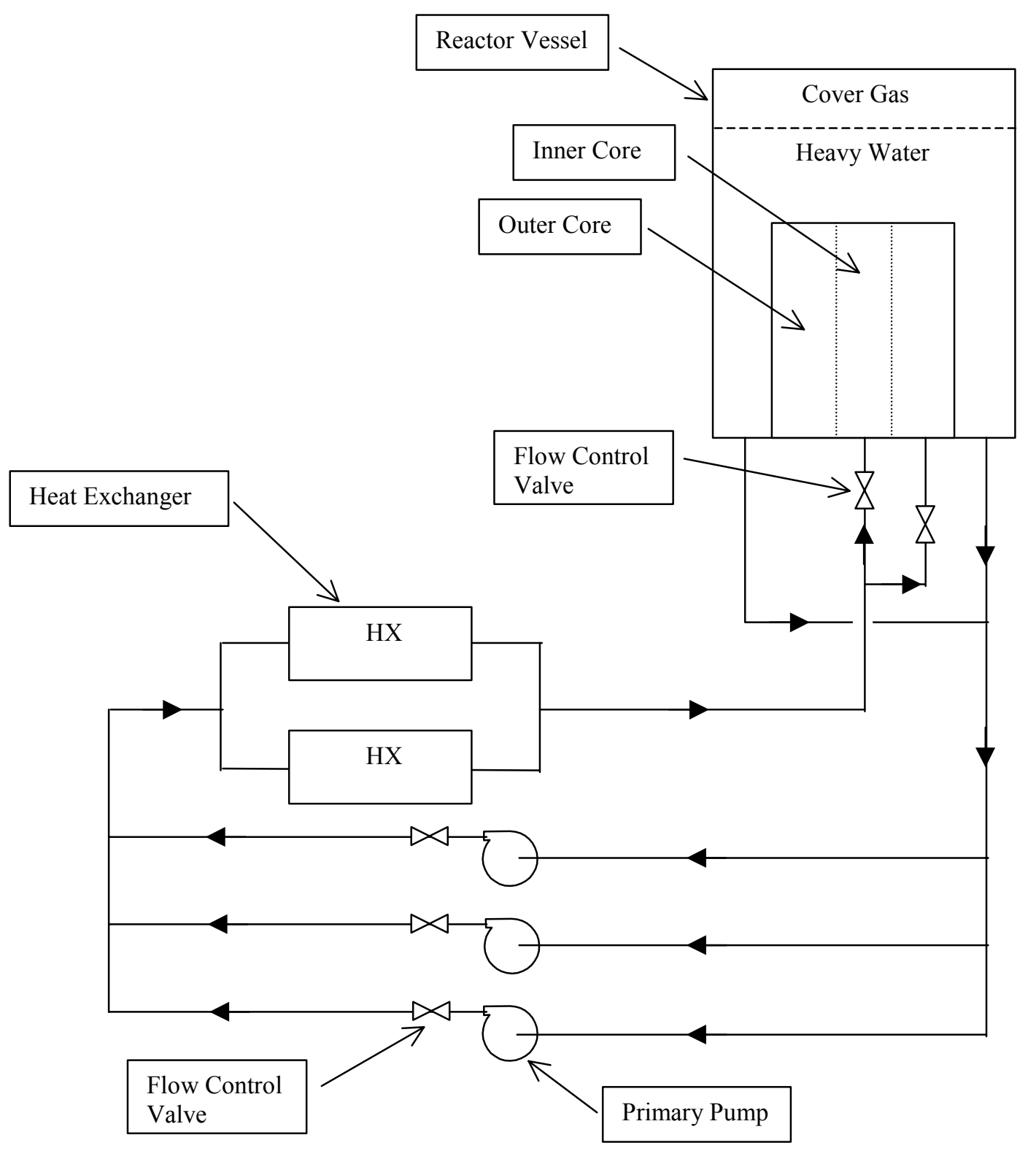

Figure 4-1. Simplified Loop Diagram of the NBSR Primary System. 


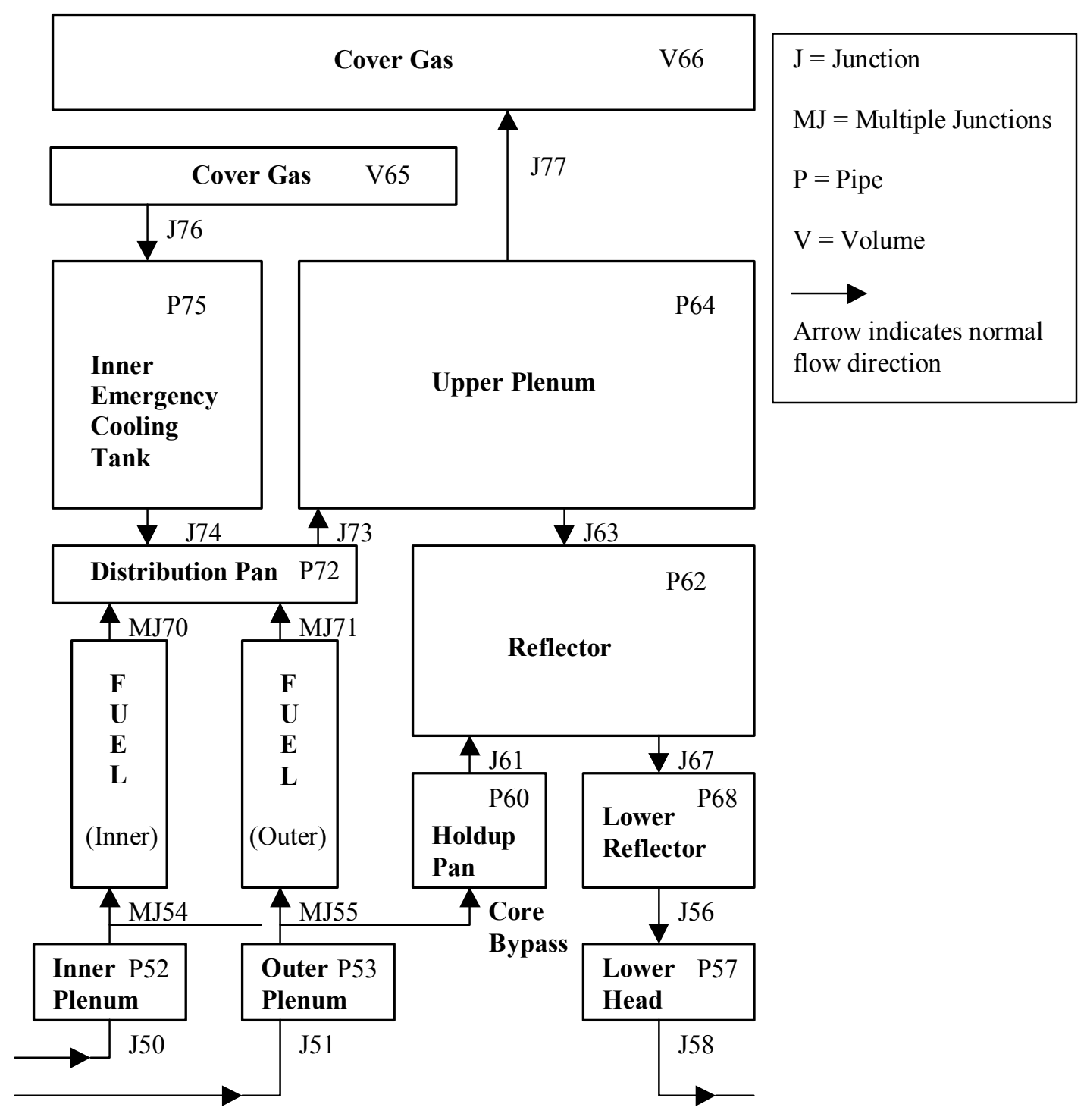

Figure 4-2. Node Diagram of NBSR Reactor Vessel. 


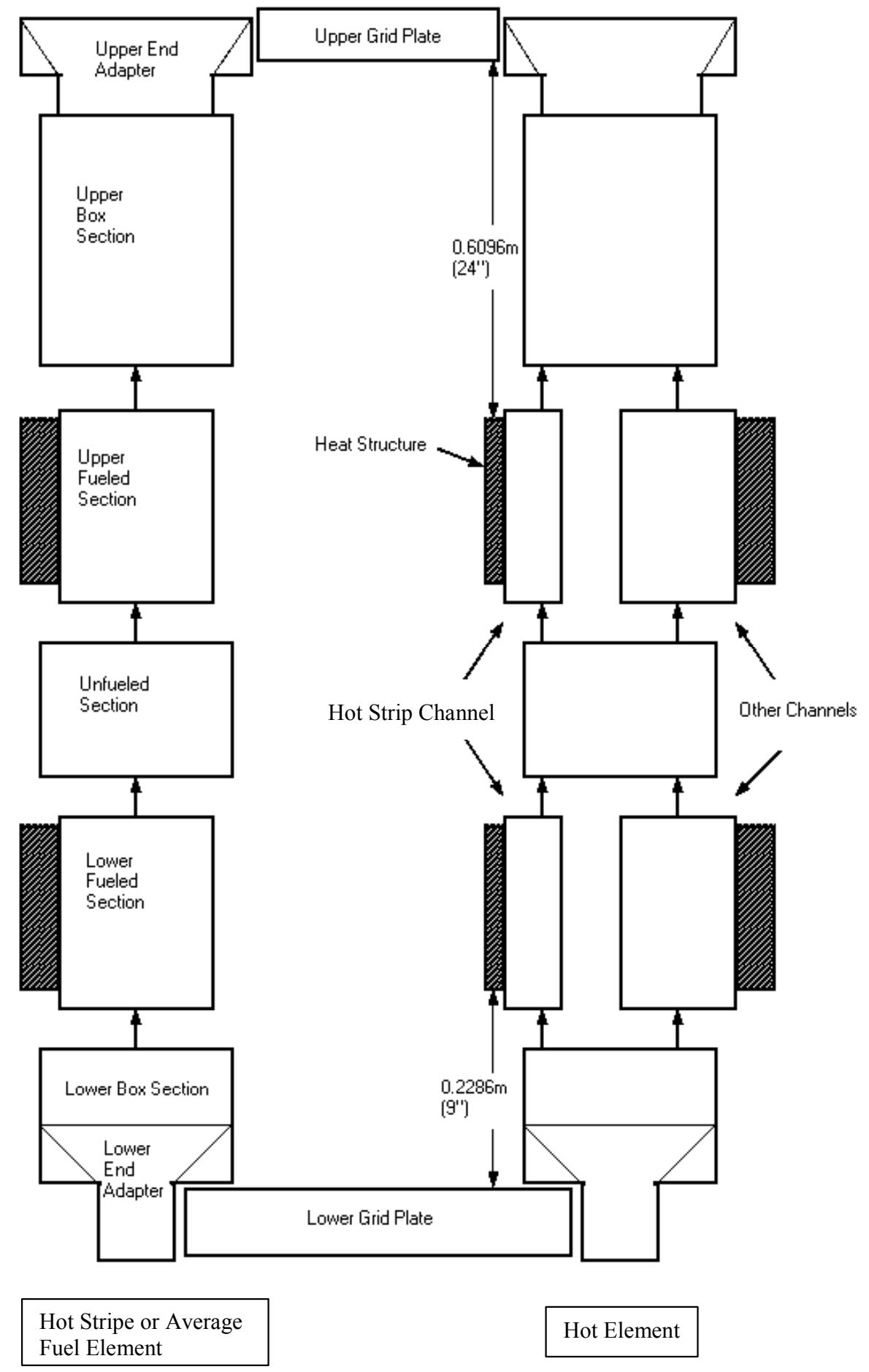

Figure 4-3. Schematic of Coolant Channels in a Fuel Element. 


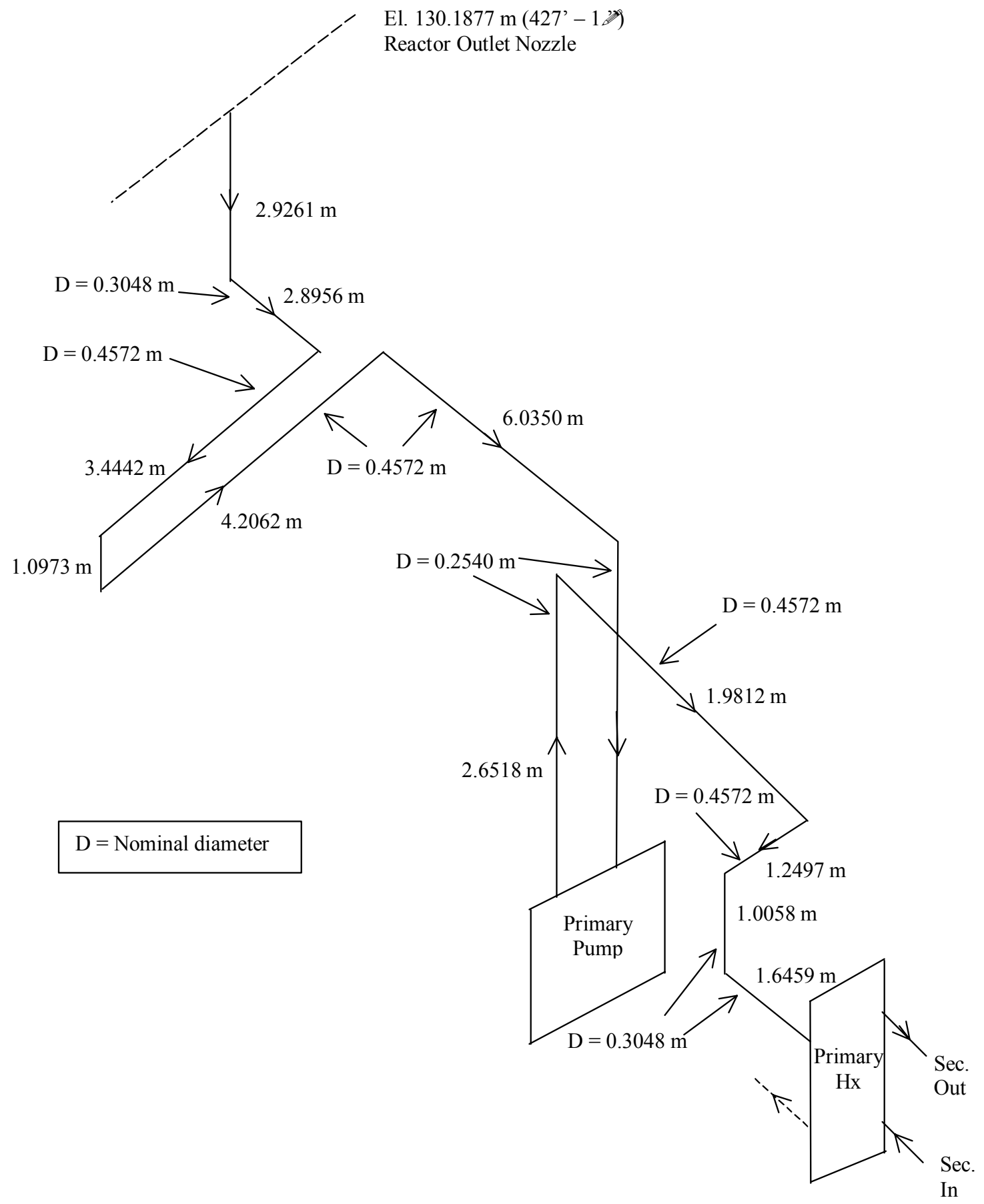

Figure 4-4. Primary System Piping - Hot Leg. 


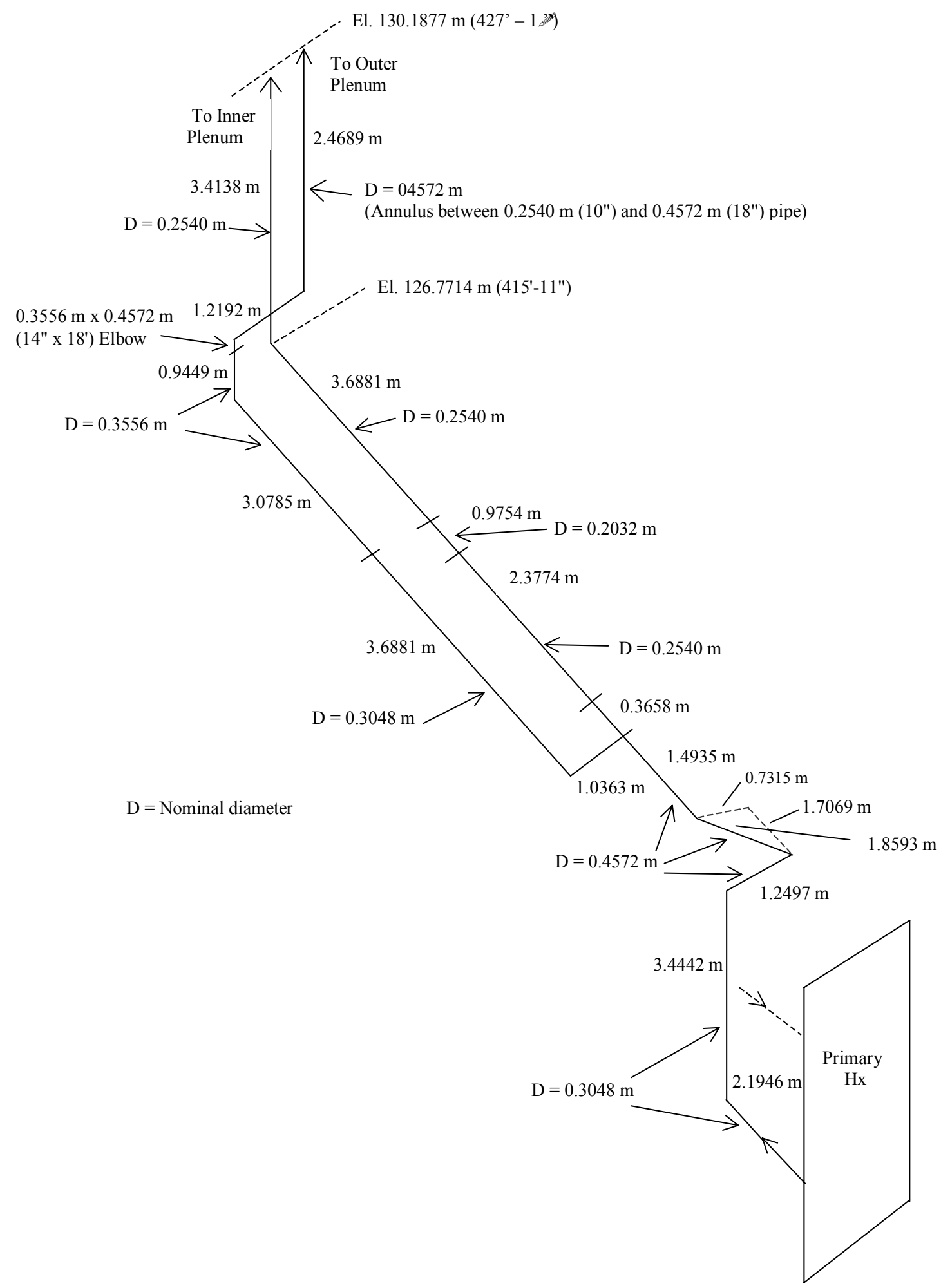

Figure 4-5. Primary System Piping - Cold Leg. 


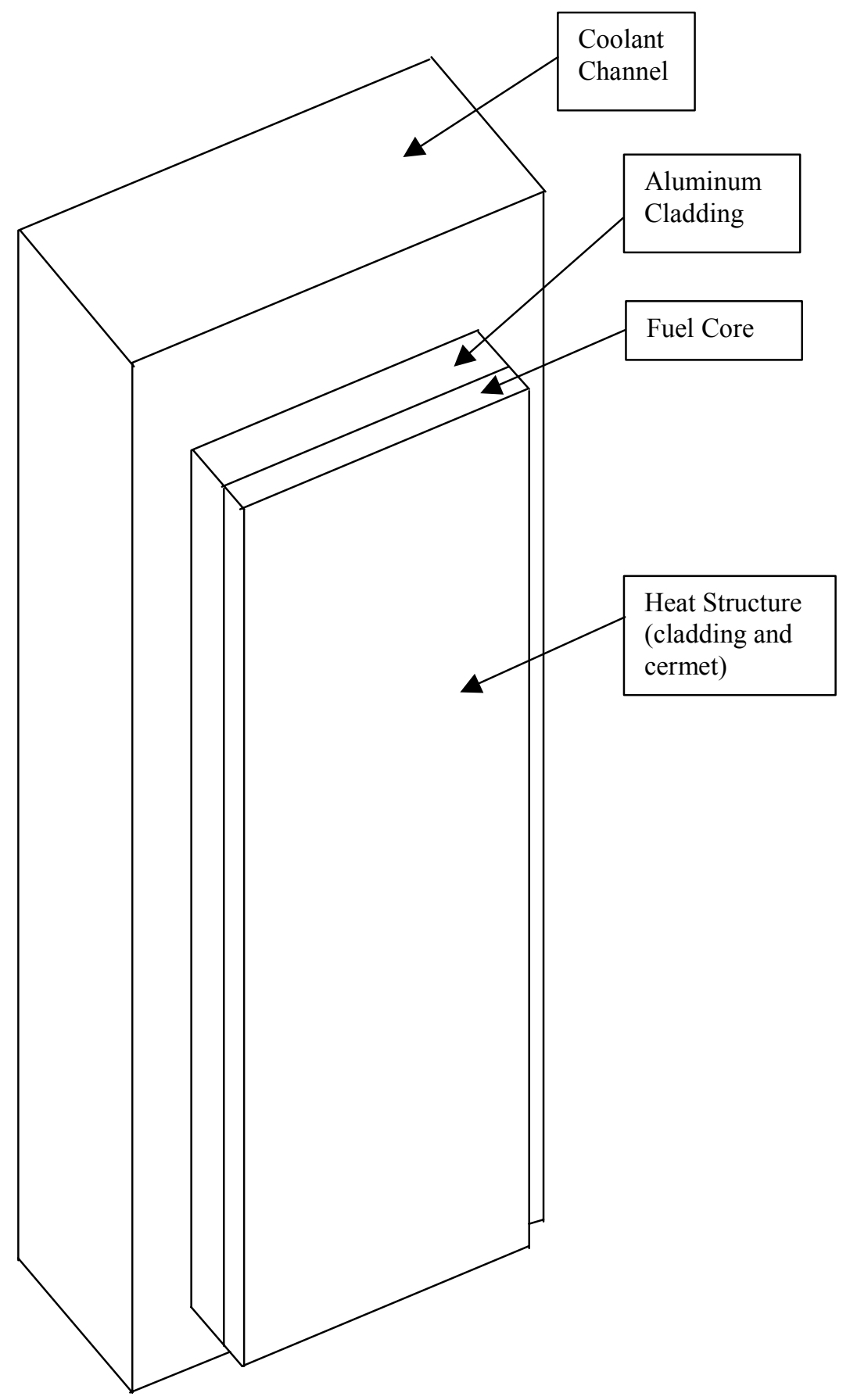

Figure 4-6. RELAP5 Model of NBSR Fuel Plate and Coolant Channel. 

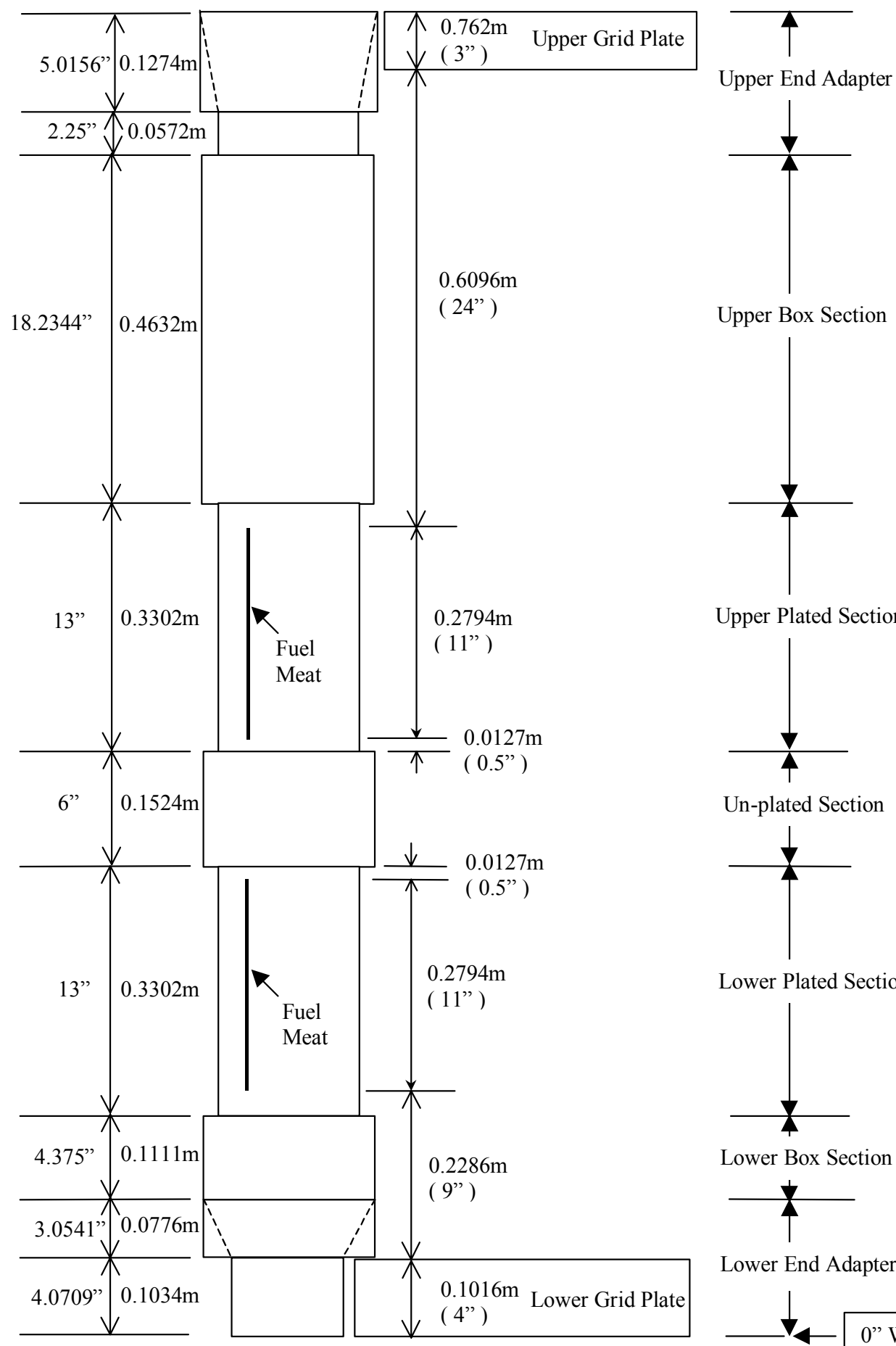

Upper Box Section

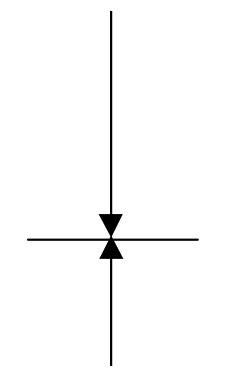

Upper Plated Section

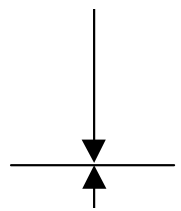

Un-plated Section

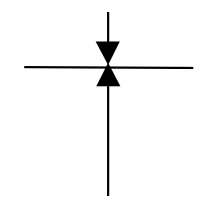

Lower Plated Section

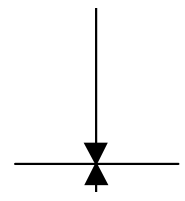

Lower Box Section

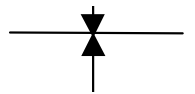

Lower End Adapter

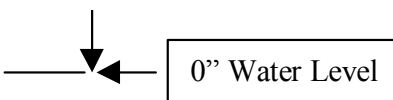

Figure 4-7. Elevations of Fuel Element. 


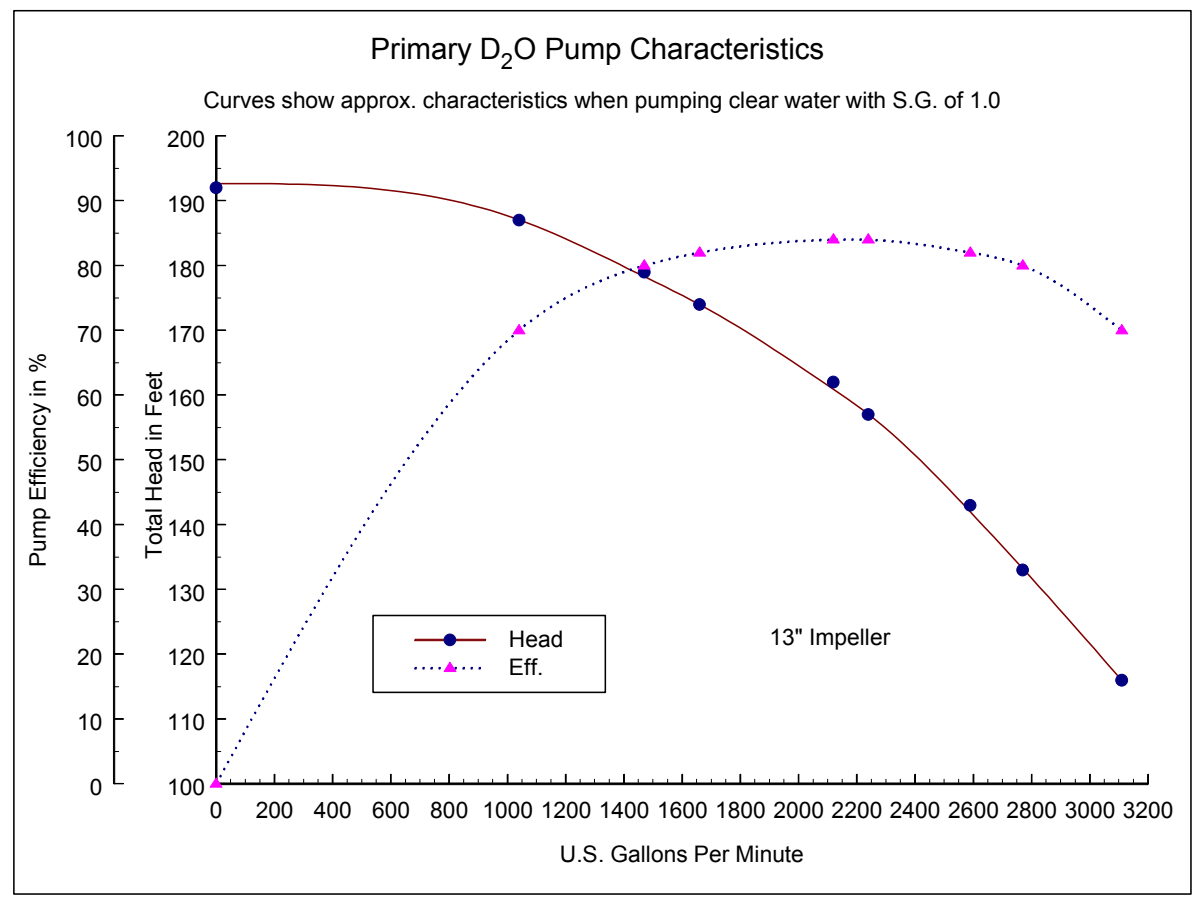

Figure 4-8. Primary Pump Performance Curves.

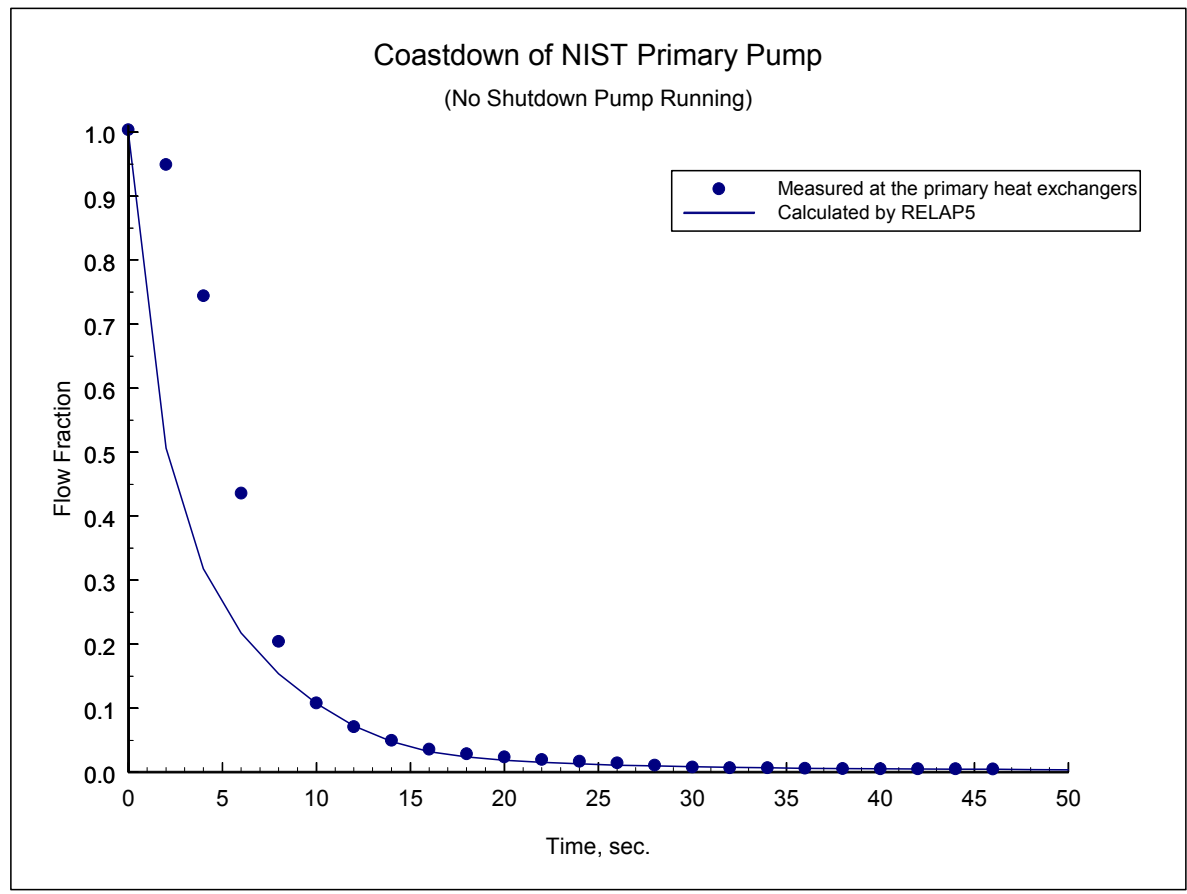

Figure 4-9. Comparison of Pump Coastdown Calculation with Plant Data. 


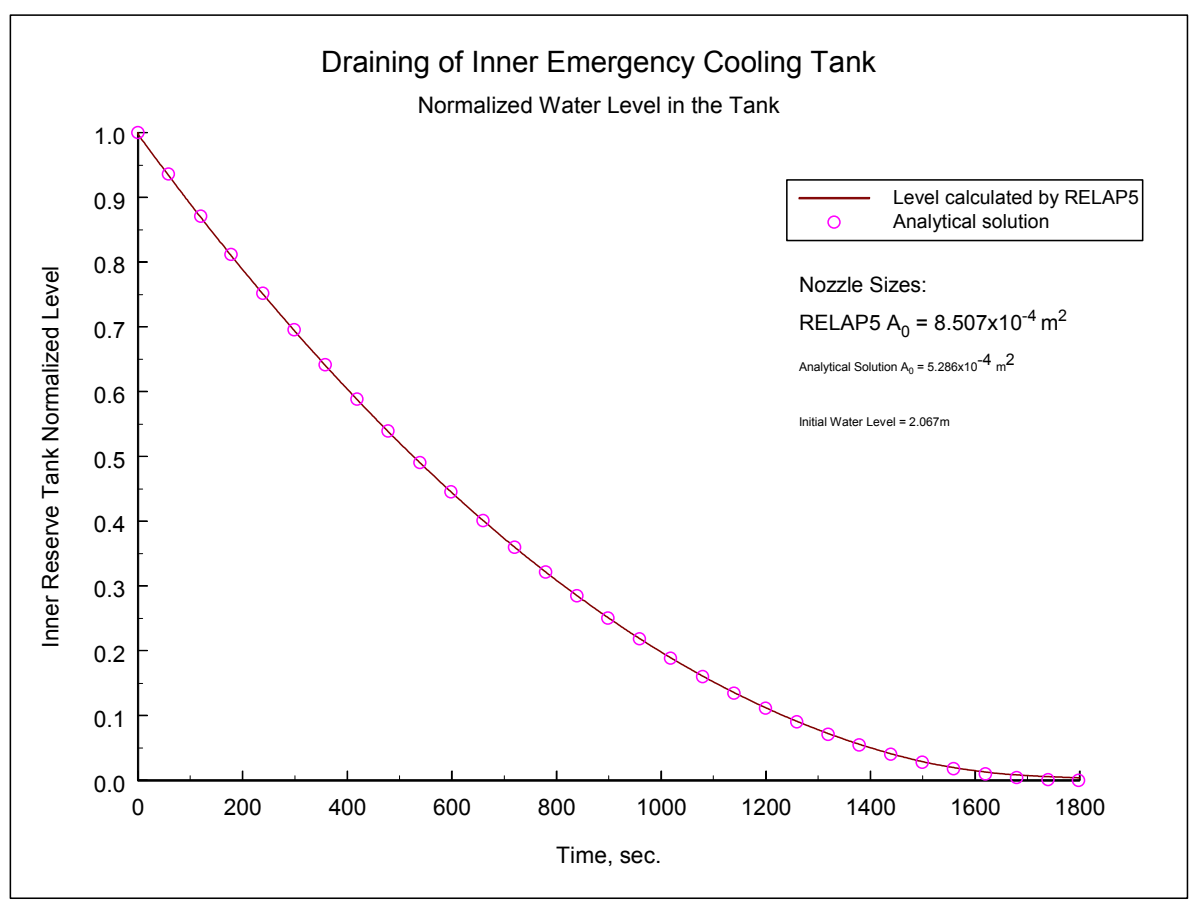

Figure 4-10. Predictions of the Draining of the Inner Emergency Cooling Tank.

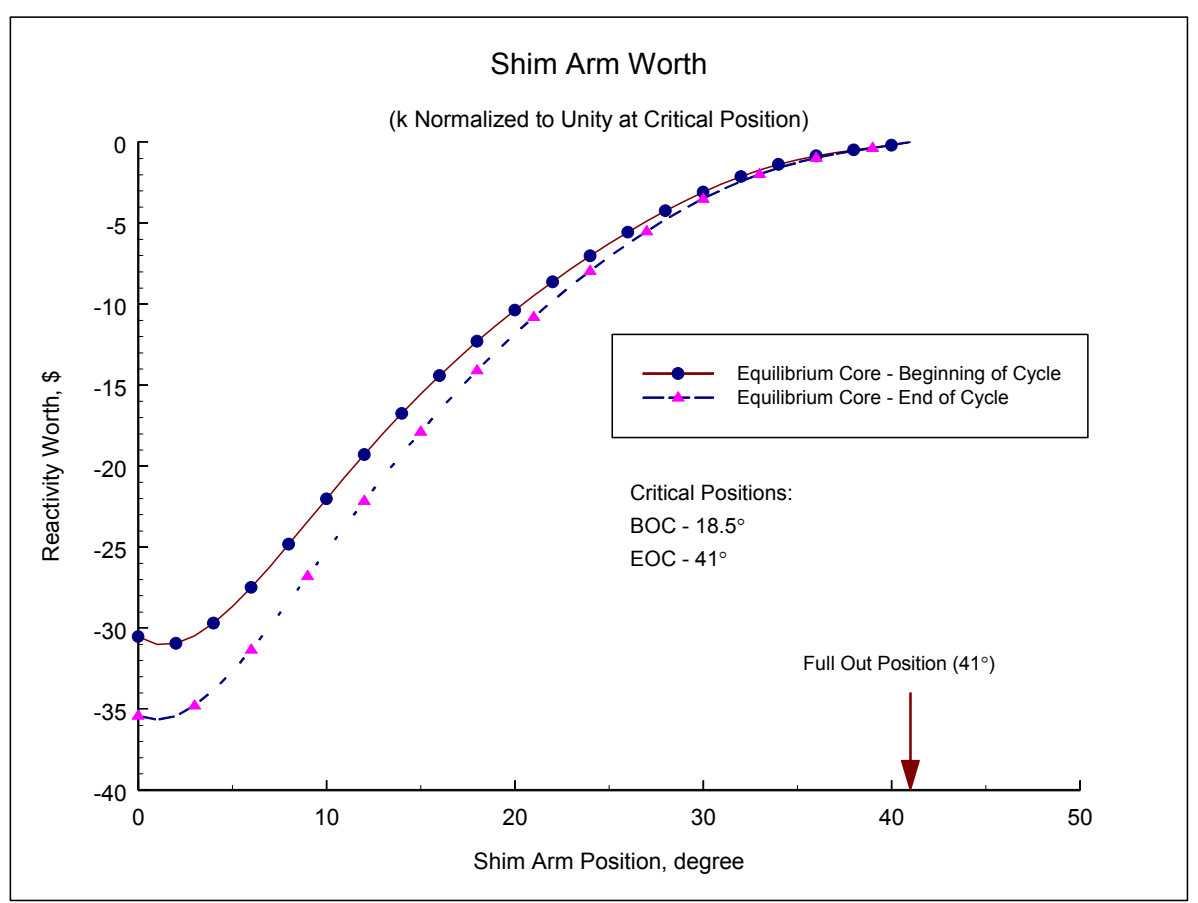

Figure 4-11. Reactivity Worth of Shim Arms. 


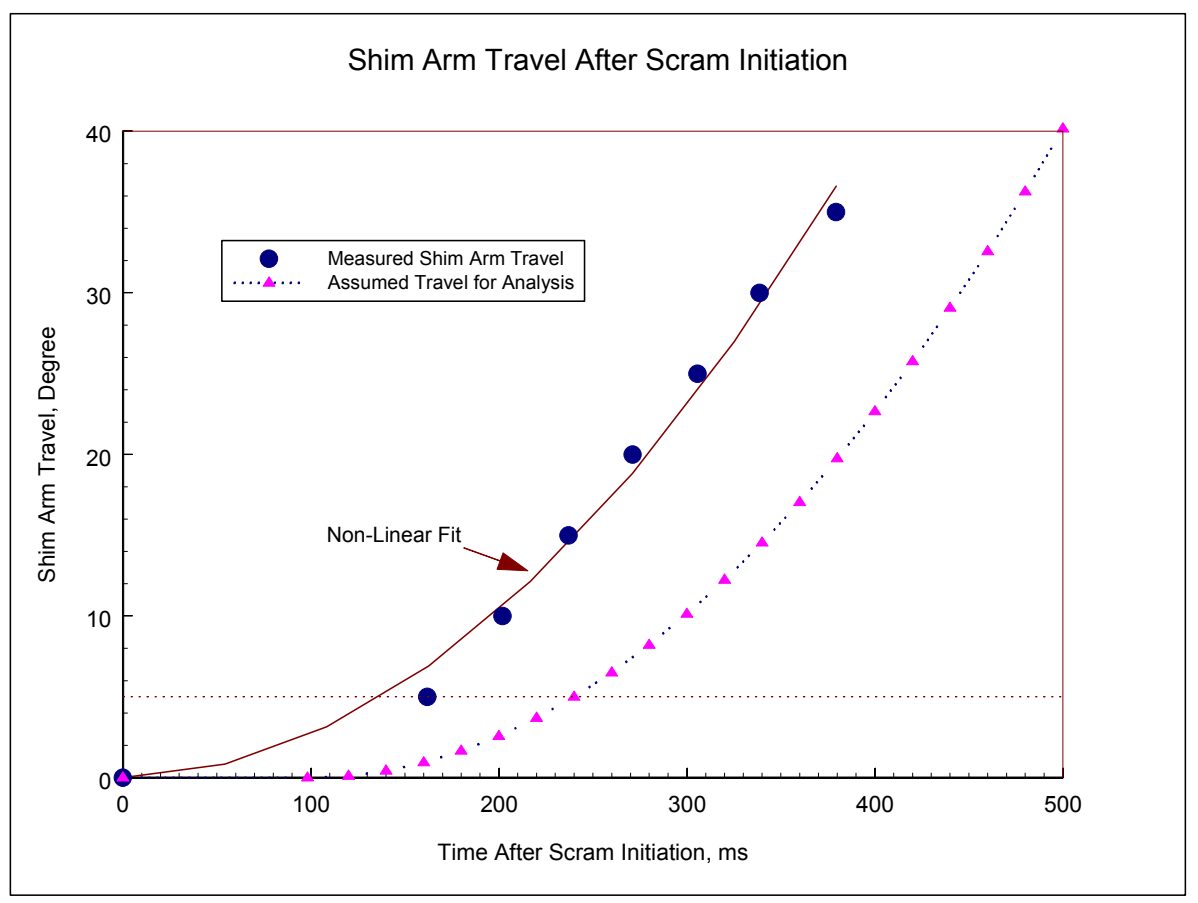

Figure 4-12. Shim Arm Travel after Scram Initiation.

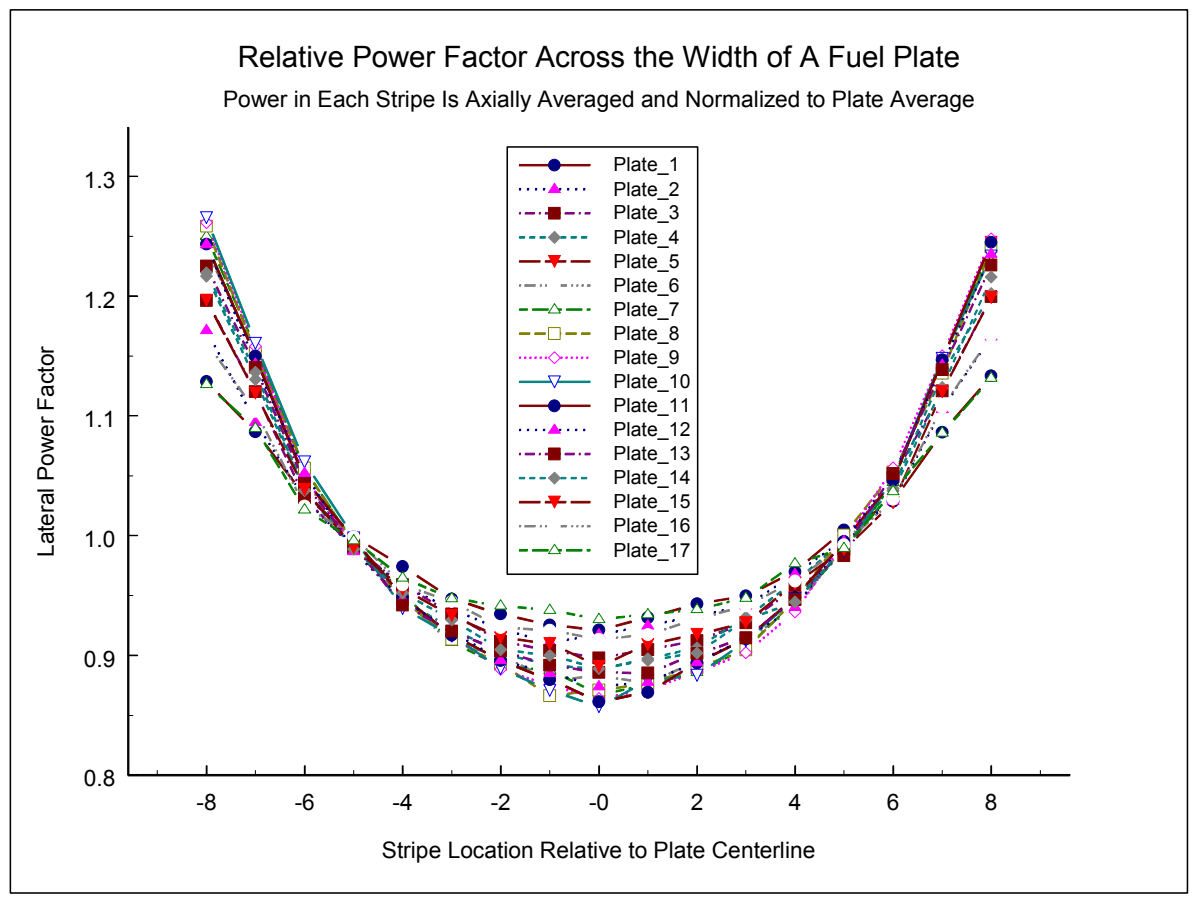

Figure 4-13. Lateral Power Distribution Across a Fuel Plate. 


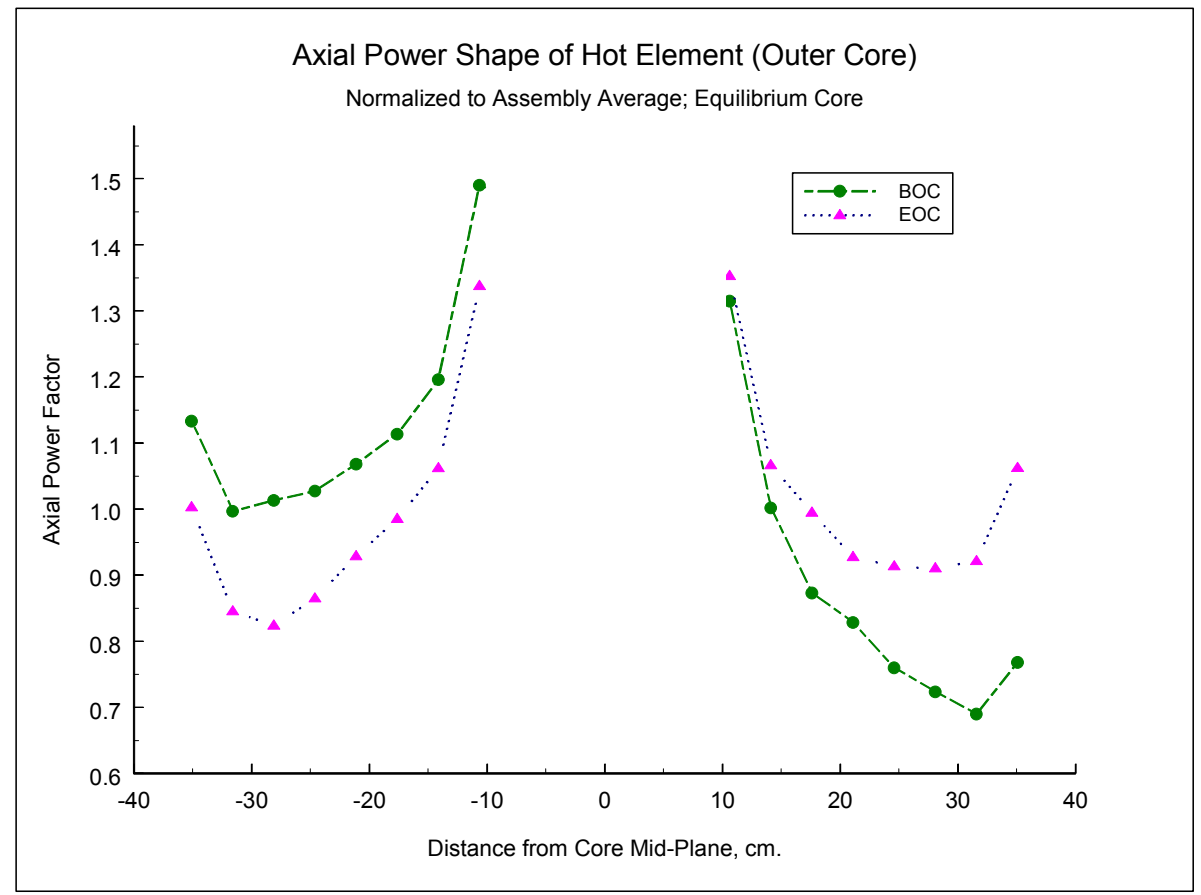

Figure 4-14. Relative Axial Power of Hot Fuel Element.

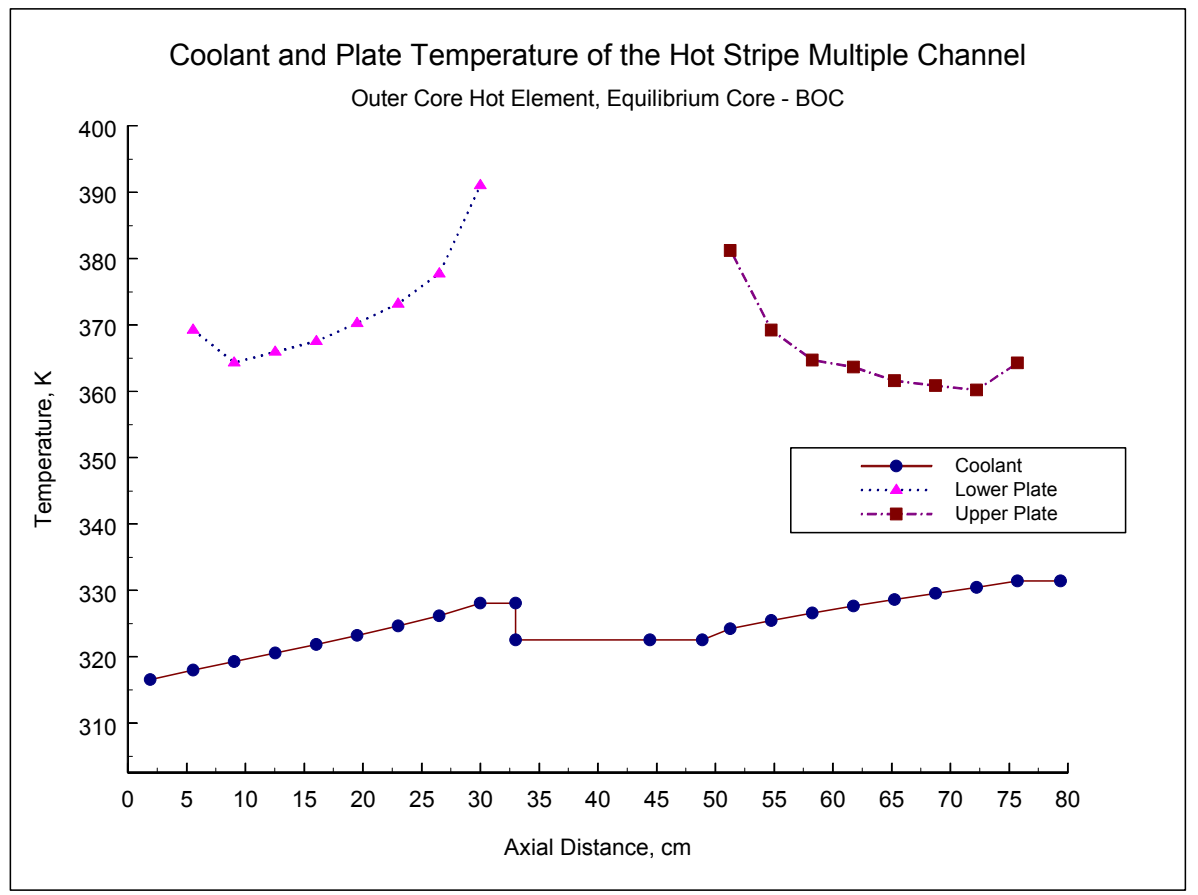

Figure 4-15. Coolant and Plate Temperature for Hot Channel in BOC Equilibrium Core. 


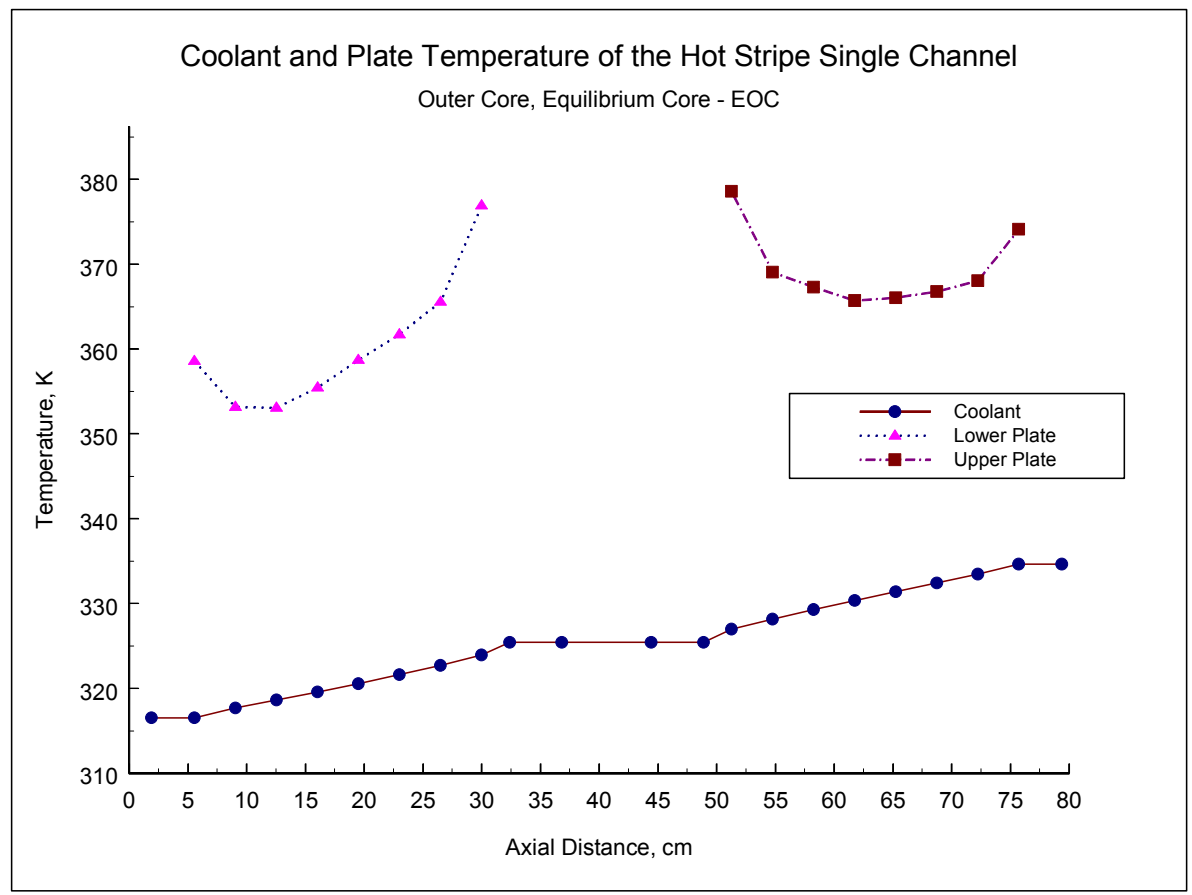

Figure 4-16. Coolant and Plate Temperature for Hot Channel in EOC Equilibrium Core. 
Table 4-1. Dimensions of NBSR Fuel Element

\begin{tabular}{|c|c|c|c|c|c|}
\hline & \multirow[b]{2}{*}{$\begin{array}{l}\text { Height, } \\
\text { m (in) }\end{array}$} & \multicolumn{2}{|c|}{ Single Element } & \multicolumn{2}{|c|}{ Single Hot Channel } \\
\hline & & $\begin{array}{l}\text { Flow Area, } \\
\text { m }^{2}\left(\text { in }^{2}\right)\end{array}$ & $\begin{array}{c}\text { Hydraulic } \\
\text { Diameter, } \\
\text { m (in) }\end{array}$ & $\begin{array}{l}\text { Flow Area, } \\
\text { m }^{2}\left(\text { in }^{2}\right)\end{array}$ & $\begin{array}{c}\text { Hydraulic } \\
\text { Diameter, } \\
\text { m (in) }\end{array}$ \\
\hline \multirow{2}{*}{$\begin{array}{l}\text { Upper End } \\
\text { Adapter }\end{array}$} & $\begin{array}{c}0.1274 \\
(5.0156)\end{array}$ & $\begin{array}{c}0.006154 \\
(9.538)\end{array}$ & $\begin{array}{l}0.0781 \\
(3.073)\end{array}$ & $\begin{array}{c}0.0003211 \\
(0.4977)\end{array}$ & $\begin{array}{l}0.0781 \\
(3.073)\end{array}$ \\
\hline & $\begin{array}{l}0.0572 \\
(2.25)\end{array}$ & $\begin{array}{c}0.004153 \\
(6.438)\end{array}$ & $\begin{array}{l}0.0643 \\
(2.533)\end{array}$ & $\begin{array}{c}0.0002167 \\
(0.3359)\end{array}$ & $\begin{array}{l}0.0643 \\
(2.533)\end{array}$ \\
\hline $\begin{array}{l}\text { Upper Box } \\
\text { Section }\end{array}$ & $\begin{array}{c}0.4632 \\
(18.2344)\end{array}$ & $\begin{array}{c}0.004974 \\
(7.709)\end{array}$ & $\begin{array}{l}0.0701 \\
(2.760)\end{array}$ & $\begin{array}{c}0.0002596 \\
(0.4023)\end{array}$ & $\begin{array}{l}0.0701 \\
(2.760)\end{array}$ \\
\hline $\begin{array}{l}\text { Upper Plated } \\
\text { Section }\end{array}$ & $\begin{array}{l}0.3302 \\
(13.0)\end{array}$ & $\begin{array}{c}0.003520 \\
(5.456)\end{array}$ & $\begin{array}{l}0.00557 \\
(0.2193)\end{array}$ & $\begin{array}{c}0.0001837 \\
(0.2847)\end{array}$ & $\begin{array}{l}0.00525 \\
(0.2066)\end{array}$ \\
\hline $\begin{array}{l}\text { Un-plated } \\
\text { Section }\end{array}$ & $\begin{array}{c}0.1524 \\
(6.0)\end{array}$ & $\begin{array}{c}0.004974 \\
(7.709)\end{array}$ & $\begin{array}{l}0.0701 \\
(2.760)\end{array}$ & $\begin{array}{c}0.0002596 \\
(0.4023)\end{array}$ & $\begin{array}{l}0.0701 \\
(2.760)\end{array}$ \\
\hline $\begin{array}{l}\text { Lower Plated } \\
\text { Section }\end{array}$ & $\begin{array}{c}0.3302 \\
(13.0)\end{array}$ & $\begin{array}{c}0.003520 \\
(5.456)\end{array}$ & $\begin{array}{l}0.00557 \\
(0.2193)\end{array}$ & $\begin{array}{c}0.0001837 \\
(0.2847)\end{array}$ & $\begin{array}{l}0.00525 \\
(0.2066)\end{array}$ \\
\hline $\begin{array}{l}\text { Lower Box } \\
\text { Section }\end{array}$ & $\begin{array}{l}0.1111 \\
(4.375)\end{array}$ & $\begin{array}{c}0.004974 \\
(7.709)\end{array}$ & $\begin{array}{l}0.0701 \\
(2.760)\end{array}$ & $\begin{array}{c}0.0002596 \\
(0.4023)\end{array}$ & $\begin{array}{l}0.0701 \\
(2.760)\end{array}$ \\
\hline \multirow{2}{*}{$\begin{array}{l}\text { Lower End } \\
\text { Adapter }\end{array}$} & $\begin{array}{c}0.0776 \\
(3.0541)\end{array}$ & $\begin{array}{c}0.004974 \\
(7.709)\end{array}$ & $\begin{array}{l}0.0701 \\
(2.760)\end{array}$ & $\begin{array}{c}0.0002596 \\
(0.4023)\end{array}$ & $\begin{array}{l}0.0701 \\
(2.760)\end{array}$ \\
\hline & $\begin{array}{c}0.1034 \\
(4.0709)\end{array}$ & $\begin{array}{c}0.002027 \\
(3.142)\end{array}$ & $\begin{array}{c}0.0508 \\
(2.0)\end{array}$ & $\begin{array}{c}0.0001058 \\
(0.1639)\end{array}$ & $\begin{array}{c}0.0508 \\
(2.0)\end{array}$ \\
\hline
\end{tabular}

Dimensions of coolant channel between fuel plates:

\begin{tabular}{|c|c|c|}
\hline & Width, $\mathrm{m}$ (in) & Gap, m (in) \\
\hline Average Channel & $0.06729(2.6493)$ & $0.002906(0.1144)$ \\
\hline Hot Channel & $0.06729(2.6493)$ & $0.002730(0.1075)$ \\
\hline
\end{tabular}

Notes:

There are 18 coolant channels in the plated region per fuel element.

Channel flow area is the area between two curved fuel plates and two straight side plates.

Channel width is the average of the two curved plates when flattened.

Channel gap is the flow area divided by the width.

Average channel has a centerline gap of $0.002946 \mathrm{~m}(0.116 \mathrm{in})$.

Hot channel has a centerline gap of $0.002769 \mathrm{~m}$ (0.109 in). 
Table 4-2. Delayed Neutron Groups

\begin{tabular}{|c|l|l|l|}
\hline Group & $\beta_{\mathrm{i}}, \%$ & $\beta_{\mathrm{i}} / \beta$ & Decay Constant, $\mathrm{s}^{-1}$ \\
\hline 1 & 0.0276 & 0.03644 & 0.0127 \\
\hline 2 & 0.1546 & 0.2041 & 0.0317 \\
\hline 3 & 0.1364 & 0.1801 & 0.115 \\
\hline 4 & 0.2954 & 0.3900 & 0.311 \\
\hline 5 & 0.0929 & 0.1227 & 1.40 \\
\hline 6 & 0.0189 & 0.02495 & 3.87 \\
\hline & & 0.02680 & 0.278 \\
\hline 7 & 0.0203 & 0.008582 & 0.0169 \\
\hline 8 & 0.0065 & 0.002944 & 0.00490 \\
\hline 9 & 0.00223 & 0.001413 & 0.00152 \\
\hline 10 & 0.00107 & $8.714 \times 10^{-4}$ & $4.27 \times 10^{-4}$ \\
\hline 11 & 0.00066 & $9.770 \times 10^{-4}$ & $1.16 \times 10^{-4}$ \\
\hline 12 & 0.00074 & $1.320 \times 10^{-4}$ & $4.41 \times 10^{-5}$ \\
\hline 13 & 0.00010 & $0.4357 \times 10^{-4}$ & $3.65 \times 10^{-6}$ \\
\hline 14 & 0.000033 & \multicolumn{3}{|l}{} \\
\hline
\end{tabular}

$\beta=\sum \beta_{\mathrm{i}}=0.007574(0.7574 \%)$

$\Lambda=$ neutron lifetime $=400 \mu \mathrm{s}$

$\beta / \Lambda=18.935 \mathrm{~s}^{-1}$ 


\section{Table 4-3. Dimensions of Various Coolant Channel Types in the Plated Region}

\begin{tabular}{|c|c|c|c|}
\hline & $\begin{array}{l}\text { Flow Area } \\
\text { m }^{2}\left(\text { in }^{2}\right)\end{array}$ & $\begin{array}{c}\text { Hydraulic } \\
\text { Diameter } \\
\text { m (in) }\end{array}$ & $\begin{array}{l}\text { Heated Diameter } \\
\text { m (in) }\end{array}$ \\
\hline \multicolumn{4}{|c|}{ Inner Core Group } \\
\hline Hot Stripe Channel & $\begin{array}{l}0.0007347 \\
(1.139)\end{array}$ & $\begin{array}{c}0.00525 \\
(0.207)\end{array}$ & $\begin{array}{l}0.006094 \\
(0.240)\end{array}$ \\
\hline $\begin{array}{l}\text { Multi-Channel Hot Stripe in Hot } \\
\text { Element }\end{array}$ & $\begin{array}{l}0.0001837 \\
(0.2847)\end{array}$ & $\begin{array}{c}0.00525 \\
(0.207)\end{array}$ & $\begin{array}{c}0.006094 \\
(0.240)\end{array}$ \\
\hline Average Channel in Hot Element & $\begin{array}{l}0.003336 \\
(5.17)\end{array}$ & $\begin{array}{c}0.00557 \\
(0.219)\end{array}$ & $\begin{array}{l}0.006918 \\
(0.272)\end{array}$ \\
\hline Average Fuel Element & $\begin{array}{l}0.0169 \\
(26.14)\end{array}$ & $\begin{array}{r}0.00557 \\
(0.219)\end{array}$ & $\begin{array}{l}0.006907 \\
(0.272)\end{array}$ \\
\hline \multicolumn{4}{|c|}{ Outer Core Group } \\
\hline Hot Stripe Channel & $\begin{array}{l}0.0007347 \\
(1.139)\end{array}$ & $\begin{array}{c}0.00525 \\
(0.207)\end{array}$ & $\begin{array}{l}0.006094 \\
(0.240)\end{array}$ \\
\hline $\begin{array}{l}\text { Multi-Channel Hot Stripe in Hot } \\
\text { Element }\end{array}$ & $\begin{array}{l}0.0001837 \\
(0.2847)\end{array}$ & $\begin{array}{c}0.00525 \\
(0.207)\end{array}$ & $\begin{array}{c}0.006094 \\
(0.240)\end{array}$ \\
\hline Average Channel in Hot Element & $\begin{array}{l}0.003336 \\
(5.17)\end{array}$ & $\begin{array}{l}0.00557 \\
(0.219)\end{array}$ & $\begin{array}{l}0.006918 \\
(0.272)\end{array}$ \\
\hline Average Fuel Element \#1 & $\begin{array}{l}0.0169 \\
(26.14)\end{array}$ & $\begin{array}{r}0.00557 \\
(0.219)\end{array}$ & $\begin{array}{c}0.006907 \\
(0.272)\end{array}$ \\
\hline Average Fuel Element \#2 & $\begin{array}{l}0.0211 \\
(32.73)\end{array}$ & $\begin{array}{r}0.00557 \\
(0.219)\end{array}$ & $\begin{array}{c}0.006869 \\
(0.270)\end{array}$ \\
\hline Average Fuel Element \#3 & $\begin{array}{l}0.0211 \\
(32.73)\end{array}$ & $\begin{array}{r}0.00557 \\
(0.219)\end{array}$ & $\begin{array}{l}0.006869 \\
(0.270)\end{array}$ \\
\hline Average Fuel Element \#4 & $\begin{array}{l}0.0211 \\
(32.73)\end{array}$ & $\begin{array}{l}0.00557 \\
(0.219)\end{array}$ & $\begin{array}{c}0.006869 \\
(0.270)\end{array}$ \\
\hline
\end{tabular}


Table 4-4. Setpoints for Reactor Scram

\begin{tabular}{|c|c|c|}
\hline Reactor Trip & Setpoint & Instrument Delay Time,s \\
\hline Total Primary Flow & $\begin{array}{c}372 \ell / \mathrm{s} \\
(5900 \mathrm{gpm})\end{array}$ & 0.4 \\
\hline Outer Plenum Fow & $\begin{array}{c}297 \mathrm{~s} / \mathrm{s} \\
(4700 \mathrm{gpm})\end{array}$ & 0.4 \\
\hline Inner Plenum Flow & $\begin{array}{c}75.7 \mathrm{~s} / \mathrm{s} \\
(1200 \mathrm{gpm})\end{array}$ & 0.4 \\
\hline Reactor Power & $30 \mathrm{MW}$ & 0.05 \\
\hline Outside Power & $\pm 10 \mathrm{~V}$ & 0.1 \\
\hline
\end{tabular}

Notes:

The LSSS value for reactor power is $130 \%$.

Scram initiation is delayed by the amount indicated in the table. 
Table 4-5. Steady State Operating Conditions

\begin{tabular}{|c|c|c|c|}
\hline Parameter & Alarm & Normal Operating Range & $\begin{array}{c}\text { Design Basis } \\
\text { Value }\end{array}$ \\
\hline \multirow{3}{*}{ Reactor Power $^{1}$} & High & $102 \%$ (Alarm - servo deviation) & \multirow{3}{*}{$\begin{array}{c}20.4 \mathrm{MW} \\
(102 \%)\end{array}$} \\
\hline & Normal & $100 \%$ (Normal servo deviation: $\pm 0.5 \%$ ) & \\
\hline & Low & 98\% (Alarm - servo deviation) & \\
\hline \multirow{3}{*}{$\begin{array}{l}\text { Reactor Water } \\
\text { Level }^{2}\end{array}$} & High & 164 in (Alarm) & \multirow{3}{*}{$\begin{array}{l}3.81 \mathrm{~m} \\
(150 \mathrm{in})\end{array}$} \\
\hline & Normal & 158 in (Normal) & \\
\hline & Low & 150 in (Alarm) & \\
\hline \multirow{3}{*}{$\begin{array}{l}\text { Core Inlet Tem- } \\
\text { perature }\end{array}$} & High & $110^{\circ} \mathrm{F}$ (Alarm) & \multirow{3}{*}{$\begin{array}{l}316.5 \mathrm{~K} \\
\left(110^{\circ} \mathrm{F}\right)\end{array}$} \\
\hline & Normal & $100^{\circ} \mathrm{F}$ (Normal) & \\
\hline & Low & $80^{\circ} \mathrm{F}$ (Alarm) & \\
\hline \multirow{3}{*}{ Primary Flow ${ }^{3}$} & High & $9000 \mathrm{gpm}$ & \multirow{3}{*}{$\begin{array}{c}549 \text { U/s } \\
(8700 \mathrm{gpm})\end{array}$} \\
\hline & Normal & 8800 gpm(Normal) & \\
\hline & Low & $8700 \mathrm{gpm}$ & \\
\hline \multirow{3}{*}{$\begin{array}{c}\text { Pressure Above } \\
\text { Core }^{4}\end{array}$} & High & $0.37 \mathrm{psig}$ & \multirow{3}{*}{$\begin{array}{c}1.01 \mathrm{kPa} \\
(0.0 \mathrm{psig})\end{array}$} \\
\hline & Normal & $0.15 \mathrm{psig}$ & \\
\hline & Low & $0.00 \mathrm{psig}$ & \\
\hline
\end{tabular}

Notes:

1 Rated reactor power is $20 \mathrm{MW}$.

2 Reactor water level is referenced to the bottom of the lower grid plate.

3 There is no alarm on primary flow. The range of flow is defined by different combinations of main pumps.

4 This is the pressure of the helium cover gas. 


\section{Table 4-6. Steady State Core Thermal Analysis Results}

Equilibrium Core - Beginning of Cycle

$$
\text { Reactor Power }=20.4 \mathrm{MW}
$$

Core Inlet Temperature $=316.5 \mathrm{~K}\left(110^{\circ} \mathrm{F}\right)$

Inner Plenum Flow $=145 \mathrm{l} / \mathrm{s}$ (2300 gpm)

Outer Plenum Flow $=404$ l/s (6400 gpm)

\begin{tabular}{|c|c|c|c|c|}
\hline & \multirow{2}{*}{$\begin{array}{c}\text { Maximum } \\
\text { Fuel Center- } \\
\text { line Tempera- } \\
\text { ture, } \mathrm{K} \\
\end{array}$} & \multirow{2}{*}{$\underset{\text { CHFR }^{\#}}{\text { Minimum }}$} & \multicolumn{2}{|c|}{ Coolant Temperature, $\mathrm{K}$} \\
\hline & & & Mid Core & Core Exit \\
\hline \multicolumn{5}{|c|}{ Inner Core Group } \\
\hline $\begin{array}{l}\text { Hot Stripe } \\
(100)^{*}\end{array}$ & 363.8 & 4.90 & 323.1 & $328.1(107)^{* *}$ \\
\hline $\begin{array}{l}\text { Multi-Channel Hot Stripe in } \\
\text { Hot Element (200) }\end{array}$ & 364.1 & 4.87 & \multirow{2}{*}{320.4} & $325.5(207)$ \\
\hline $\begin{array}{l}\text { Average Plate in Hot Element } \\
(210)\end{array}$ & 348.2 & 7.51 & & $323.3(217)$ \\
\hline $\begin{array}{l}\text { Plate in Average Element } \\
(\mathbf{3 0 0})\end{array}$ & 345.4 & 8.30 & 319.9 & $322.5(307)$ \\
\hline \multicolumn{5}{|c|}{ Outer Core Group } \\
\hline $\begin{array}{l}\text { Hot Stripe } \\
(400)\end{array}$ & 390.6 & 3.01 & 328.0 & $336.8(407)$ \\
\hline $\begin{array}{l}\text { Multi-Channel Hot Stripe in } \\
\text { Hot Element (500) }\end{array}$ & 391.2 & 2.98 & \multirow{2}{*}{322.5} & $331.4(507)$ \\
\hline $\begin{array}{l}\text { Average Plate in Hot Element } \\
(510)\end{array}$ & 360.6 & 5.52 & & $326.9(517)$ \\
\hline $\begin{array}{l}\text { Plate in Average Element \#1 } \\
(600)\end{array}$ & 358.8 & 5.78 & 322.0 & $326.2(607)$ \\
\hline $\begin{array}{l}\text { Plate in Average Element \#2 } \\
(700)\end{array}$ & 357.2 & 6.05 & 321.8 & $325.9(707)$ \\
\hline $\begin{array}{l}\text { Plate in Average Element \#3 } \\
(800)\end{array}$ & 355.1 & 6.42 & 321.5 & $325.4(807)$ \\
\hline $\begin{array}{l}\text { Plate in Average Element \#4 } \\
(900)\end{array}$ & 352.9 & 6.87 & 321.2 & $324.8(907)$ \\
\hline
\end{tabular}

* Heat structure numbers as defined in RELAP5 input.

** Volume number as defined in RELAP5 input.

\# For all channels the hot node is located at the top of the lower core. 


\section{Table 4-7. Steady State Core Thermal Analysis Results}

Equilibrium Core - End of Cycle

$$
\text { Reactor Power }=20.4 \mathrm{MW}
$$

Core Inlet Temperature $=316.5 \mathrm{~K}\left(110^{\circ} \mathrm{F}\right)$

Inner Plenum Flow $=145$ /s (2300 gpm)

Outer Plenum Flow $=404$ /s (6400 gpm)

\begin{tabular}{|c|c|c|c|c|}
\hline & \multirow{2}{*}{$\begin{array}{c}\text { Maximum Fuel } \\
\text { Centerline } \\
\text { Temperature, K }\end{array}$} & \multirow{2}{*}{$\begin{array}{l}\text { Minimum } \\
\text { CHFR }\end{array}$} & \multicolumn{2}{|c|}{ Coolant Temperature, $\mathrm{K}$} \\
\hline & & & Mid Core & Core Exit \\
\hline \multicolumn{5}{|c|}{ Inner Core Group } \\
\hline $\begin{array}{l}\text { Hot Stripe } \\
(100)^{*}\end{array}$ & 359.2 & 5.58 & 322.0 & $327.7(107)^{* *}$ \\
\hline $\begin{array}{l}\text { Multi-Channel Hot Stripe in } \\
\text { Hot Element (200) }\end{array}$ & 358.1 & $5.68^{\#}$ & \multirow{2}{*}{319.8} & $325.6(207)$ \\
\hline $\begin{array}{l}\text { Average Plate in Hot Element } \\
(210)\end{array}$ & 345.1 & 8.50 & & $323.1(217)$ \\
\hline $\begin{array}{l}\text { Plate in Average Assembly } \\
(300)\end{array}$ & 343.0 & 9.20 & 319.5 & $322.5(307)$ \\
\hline \multicolumn{5}{|c|}{ Outer Core Group } \\
\hline $\begin{array}{l}\text { Hot Stripe } \\
(400)\end{array}$ & 378.6 & 3.76 & 325.4 & $334.7(407)$ \\
\hline $\begin{array}{l}\text { Multi-Channel Hot Stripe in } \\
\text { Hot Element (500) }\end{array}$ & 377.3 & $3.86^{\#}$ & \multirow{2}{*}{321.5} & $330.8(507)$ \\
\hline $\begin{array}{l}\text { Average Plate in Hot Element } \\
(510)\end{array}$ & 355.9 & 6.31 & & $326.5(517)$ \\
\hline $\begin{array}{l}\text { Plate in Average Assembly \#1 } \\
(600)\end{array}$ & 355.2 & 6.44 & 321.2 & $326.1(607)$ \\
\hline $\begin{array}{l}\text { Plate in Average Assembly \#2 } \\
\text { (700) }\end{array}$ & 354.4 & 6.61 & 321.2 & $326.0(707)$ \\
\hline $\begin{array}{l}\text { Plate in Average Assembly \#3 } \\
(800)\end{array}$ & 352.8 & 6.93 & 321.0 & $325.5(807)$ \\
\hline $\begin{array}{l}\text { Plate in Average Assembly \#4 } \\
(900)\end{array}$ & 350.7 & 7.42 & 320.7 & $325.0(907)$ \\
\hline
\end{tabular}

* Heat structure numbers as defined in RELAP5 input.

** Volume number as defined in RELAP5 input.

\# In multi-channel hot stripe the hot node is located at the top of the lower core. All other channels have the hot node at the bottom of the upper core. 


\section{ACCIDENT ANALYSIS}

\subsection{Introduction}

This section presents the analysis performed for postulated NBSR accidents. The consequences of each accident are analyzed to the extent necessary to determine the degree of potential hazard. The analyses show that the design is very conservative, owing to the inherent characteristics of this reactor and the redundancy of systems and defense-in-depth designs that have been employed.

The self-regulating characteristics of the reactor core are similar to those of other enriched uranium reactors. The temperature and void coefficients are everywhere negative and similar to those in other research and test reactors. In addition, the NBSR has a very large negative reflector temperature coefficient which, although delayed a few seconds, would serve to mitigate all but the most rapid transients. The NBSR also has the long neutron lifetime characteristic of heavy water moderated reactors. Thus, it would respond more slowly to a given reactivity insertion than a light water reactor.

Any light water leakage into the reactor vessel would act as a poison, reducing the reactivity of the core and lessening the magnitude of any positive reactivity excursion.

The hypothetical accidents analyzed have been selected to represent a wide range of frequency of occurrence, as well as to span a range of probability of core damage and potential releases of radioactive isotopes to the environment. For all of these accident scenarios, the reactor is assumed to be operating with all critical parameters at the most unfavorable extreme value of their normal range. This assures that the analysis for each accident scenario uses the worst case initial conditions that might be anticipated, within the normal limits of operation. These conditions are:

\begin{tabular}{lcl}
\multicolumn{1}{c}{ Parameter } & Limit & \multicolumn{1}{c}{ Value } \\
\hline Reactor Power & 102\% of Nominal Rating & $20.4 \mathrm{MW}$ \\
Reactor $\mathrm{D}_{2} \mathrm{O}$ Level & Low & $3.81 \mathrm{~m}(150 \mathrm{in})$ \\
Core Inlet Temperature & High & $43.3^{\circ} \mathrm{C}\left(110^{\circ} \mathrm{F}\right)$ \\
Main Primary Coolant Flow & Low & $549 \mathrm{l} / \mathrm{s} \quad(8700 \mathrm{gpm})$
\end{tabular}

Statistical analyses have been performed using a thermal hydraulic model of the reactor with conservative but realistic assumptions for the values of the various parameters needed to describe the behavior of the coolant flow during these accident scenarios. It will be shown that these analyses provide high statistical assurance that the fuel plates will not be damaged due to reaching CHF during the postulated accident scenarios. 


\subsection{Startup Accident}

A startup accident model was developed using assumptions that were selected to maximize the reactivity insertion. The reactor is assumed to be initially critical at a power level of $10^{-4} \mathrm{MW}$. Contrary to operating procedures and all previous training and experience, the operator is then assumed to withdraw the shim arms steadily without any pause, until the reactor is scrammed by a high power level trip. The accident model uses a reactivity insertion rate for the shim arm withdrawal equal to $5 \times 10^{-4} \Delta \mathrm{k}$ per second. This rate is greater than the maximum measured and calculated (from the results shown in Figure 4-11) rate at any shim arm position.

The power excursion is analyzed by using the RELAP5 point kinetics model discussed previously in Section 4.2.3.5. Upon reactor scram, shim arm insertion is determined by this model. The shim arms are assumed to remain at the initial critical position of $19^{\circ}$ before the reactor trips. The positive reactivity ramp is terminated once a high power scram is initiated. For conservatism the calculation does not consider any fuel or moderator reactivity feedback. A delay of $0.05 \mathrm{~s}$ is assumed between the time of high power trip and reactor scram. This delay is to account for the time lag in the response of the power range detectors and their associated scram circuits. The high power level trip is set to $30 \mathrm{MW}$ (150\% of full power). This is very conservative because the setting is actually at $130 \%$ of power.

The transient reactor power and the excursion energy above $20 \mathrm{MW}$ are plotted in Figure 5-1 and tabulated in Table 5-1. Reactor power exceeds $30 \mathrm{MW}$ at $16.198 \mathrm{~s}$ and a power scram is initiated at $16.248 \mathrm{~s}$. Though shim arms start to insert into the reactor at $16.347 \mathrm{~s}$ the reactor power continues to escalate and reaches a peak of $51.8 \mathrm{MW}$ at $16.371 \mathrm{~s}$. It takes $0.071 \mathrm{~s}$ for the power to subsequently decay below $20 \mathrm{MW}$. The total excursion energy above $20 \mathrm{MW}$, i.e., during the time when reactor power is above $20 \mathrm{MW}$, is $5.60 \mathrm{MJ}$. The same transient was analyzed for the end of cycle condition, i.e., using end of cycle axial power distribution and having the shim arms initially at the full out position. For the EOC startup accident, the peak reactor power is 56.0 MW and the total excursion energy above $20 \mathrm{MW}$ is $8.09 \mathrm{MJ}$. The results are shown in Figure 5-2 and Table 5-2.

\subsection{Maximum Reactivity Insertion Accident}

The maximum reactivity accident power excursion is analyzed by using the RELAP5 point kinetics model discussed previously in Section 4.2.3.5. For conservatism the calculation does not consider any fuel or moderator reactivity feedback. A delay of $0.05 \mathrm{~s}$ is assumed between the time of high power trip (30 MW) and reactor scram. This delay is to account for the time lag in the response of the power range detectors and their associated scram circuits.

The transient reactor power and the excursion power above $20 \mathrm{MW}$ are plotted in Figure 5-3 and tabulated in Table 5-3 for the beginning of cycle equilibrium core. Reactor power exceeds 30 $\mathrm{MW}$ at $0.164 \mathrm{~s}$ and a power scram is initiated at $0.214 \mathrm{~s}$. Though shim arms start to insert into the reactor at $0.313 \mathrm{~s}$ the reactor power continues to escalate and reaches a peak of $83.58 \mathrm{MW}$ at $0.36 \mathrm{~s}$. It then takes $0.07 \mathrm{~s}$ for the power to decay below $20 \mathrm{MW}$. The total excursion energy above $20 \mathrm{MW}$, i.e. during the time when reactor power is above $20 \mathrm{MW}$, is $9.68 \mathrm{MJ}$. 
Also calculated during the transient is the reactor period. It is seen from Table 5-3 that $0.03 \mathrm{~s}$ into the transient the reactor period falls below $1 \mathrm{~s}$. A short period trip, not assumed in this analysis, would normally have occurred before the high power trip and would result in a less severe power excursion.

Results of the maximum reactivity insertion accident for the EOC conditions are summarized in Table 5-4. Two parameters were varied for this analysis: the prompt neutron lifetime and the high power trip setpoint. A longer lifetime or a lower trip setpoint has the effect of mitigating the consequences of this transient.

\subsection{Loss Of Flow Accidents}

\subsubsection{Loss of Offsite Power}

The accident scenario assumes all three primary pumps trip upon loss of offsite power and a reactor scram will initiate after a $100 \mathrm{~ms}$ delay. The three primary coolant pumps will begin to coast down, and eventually the primary coolant flow will drop to a value where one or more of the primary coolant flow monitors will generate a delayed scram signal.

This is a relatively mild transient because of the short time interval between flow trip and reactor scram. Since the power decays faster than flow, the transient is over as soon as the shim arms start to move into the core. Table 5-5 summarizes the results of this accident. The BOC conditions are more limiting, and the hot spot is in the outer core. The minimum CHFR at the hot spot during the transient is 2.95 , only a fraction below the steady-state value of 2.98 . During the transient the fuel centerline temperature at the hot spot only rises by $1.3 \mathrm{~K}$.

\subsubsection{Loss of Electrical Power Feed to Primary Pumps}

In this case, no scram signal will be generated directly by the loss of electrical power to the primary pumps. Coastdown of all three pumps will begin, and when the flow has decreased to the trip point, one or more of the primary coolant flow monitors will generate a scram. For the purposes of this model, it is assumed that the scram occurs $400 \mathrm{~ms}$ after flow has reached the trip value to allow for instrumentation sensing and scram actuation delays.

The transient analysis shows that the earliest flow trip is from the outer plenum flow. The flow trips are initiated at $0.883 \mathrm{~s}$ for the outer plenum flow, $1.080 \mathrm{~s}$ for the total flow and $1.761 \mathrm{~s}$ for the inner plenum flow. After a $0.4 \mathrm{~s}$ delay a reactor scram is initiated at $1.286 \mathrm{~s}$. The results of the analysis are summarized in Table 5-6. The progression of this accident is similar to the one analyzed in the previous section. The minimum CHFR at the hot spot is 2.14 and the corresponding fuel centerline temperature is $409.9 \mathrm{~K}$. These extreme values for the two parameters are reached just before the shim arms begin to move into the core, terminating the transient. 


\subsubsection{Seizure of One Primary Coolant Pump}

It is assumed that through some failure, such as a faulty bearing, the rotor of one pump suddenly becomes locked. Since the RELAP5 model lumps all three pumps into one effective pump, the seizure of one of the pumps is modeled by an instantaneous step reduction in the pump speed to $2 / 3$ of full speed. This is conservative since the flow with only two pumps operating would actually be more than $2 / 3$ of the full flow with all three pumps in operation.

Because of its momentum, coolant flow through the primary loop will decrease over a finite time interval until the $1 / 3$ flow reduction is achieved. The detailed behavior of this flow reduction is modeled by the thermal hydraulic code over a time span that has arbitrarily been set at $3.5 \mathrm{~s}$. This time span is conservatively chosen to be long enough to assure that the flow reduction transient is over and the discharge valve on the seized pump is closed ( $3 \mathrm{~s}$ closure time). At this time ( $3.5 \mathrm{~s}$ after the pump locks) it is assumed that a scram is initiated by flow sensing instrumentation.

The flow transient in a pump seizure differs from that caused by a normal pump trip in two aspects. First, instead of continuing to pump water while coasting down, a locked pump impeller acts as a flow resistance and the primary flow diminishes more quickly than a normal pump trip. Second, with two out of three pumps running, the primary flow decays to a value close to, but somewhat higher than the $2 / 3$ value assumed here. Results of the transient analysis are summarized in Tables 5-7 and 5-8. The results indicate that the flow coastdown for the pump seizure simulated by a step reduction in the rotational velocity of the RELAP5 effective pump model is faster than a normal pump trip (see Table 5-6 for comparison). In a little over one second after initiation of the transient, the primary flow decays from 549 /s ( $8700 \mathrm{gpm})$ to a new steady state value of $365 \mathrm{l} / \mathrm{s}(5790 \mathrm{gpm})$. In response to the reduced flow, the fuel plates rapidly assume higher temperatures. The minimum CHFR (at the hot spot in the outer plenum) decreases from an initial value of 2.98 to a new minimum value of 2.22 . The corresponding fuel centerline temperature increases by 17.3 degrees to $408.5 \mathrm{~K}$.

The conditions at the hot spot in the inner plenum are less limiting because the fuel elements there receive more flow than those in the outer plenum. The results show that the minimum CHFR and fuel temperatures remain constant until power decay starts at $3.6 \mathrm{~s}$. Thereafter, the power falls, fuel temperatures fall, and the minimum CHFR rises.

Although the analysis predicts that the inner plenum flow remains at a value above the low flow trip, in reality a flow trip could have been generated within the first second of the transient due to either a low outer plenum flow signal or a low total flow signal while the primary flow is still coasting down. However, the present analysis conservatively assumes that the reactor remains at full $(102 \%)$ power until the primary flow has decreased to the $2 / 3$ full flow value and has remained there for some time.

The analysis also assumes that it is justifiable to neglect the possibility of some backflow through the seized pump. This is a consequence of the effects of fluid inertia and the slow closure of the discharge valve, which assures that the combined flow to the inner and outer plenums will not drop below the $2 / 3$ full flow value during the transient. 


\subsubsection{Throttling of Coolant Flow to the Outer Plenum}

In this accident scenario, the flow control valve DWV-1 is assumed to close, reducing the flow through the outer plenum, with a scram completed $400 \mathrm{~ms}$ after the flow reaches the low flow trip point of $4700 \mathrm{gpm}(297 \mathrm{l} / \mathrm{s})$. The consequences of this flow transient are bounded by the pump trip analyzed in Section 5.4.2. The closure of the flow control valve is expected to result in slower flow decay than a pump trip. This is because the reduction in flow due to a partial valve closure is offset somewhat by a corresponding increase in local pressure drop. It is therefore unnecessary to perform an additional RELAP5 calculation for this postulated accident.

The complete closure of the flow control valve isolates the lower plenum of the reactor and at the same time cuts off the supply of forced coolant flow. The RELAP5 calculation shows that since all coolant channels in the fuel elements in the outer core share the same inlet and outlet plenums, closed loop recirculation flow paths are established between the two plenums via the heated coolant channels in the core. Buoyancy induces upflow through the hotter coolant channels, while downflow through the cooler channels completes the closed flow loop. The recirculation flow removes heat from the core region by natural convection.

When the buoyancy head is insufficient to induce closed loop recirculation, boiling by itself is sufficient to remove decay heat from the core region. As a limiting condition, it can be assumed that no coolant enters the fuel assemblies from the lower plenum (a blocked channel scenario). The makeup for the boiloff is from coolant draining down the upper end of the fuel assemblies. The ability for the liquid coolant to drain downward in a counter-current flow situation is limited by the flooding condition. Flooding is related to the phenomenon of levitation, whereby the steam upflow is at a speed high enough that the interfacial drag begins to impede the downward flow of liquid from the top end of a flow channel. The imbalance in upward steam flow and downward liquid flow would lead eventually to the dryout of a coolant channel (assuming the bottom of the channel is blocked). A flooding-limited power is defined as the maximum power of a blocked channel such that heat removal by steam generation is sustainable under the counter-current flow limitation (CCFL) condition. The flooding-limited power for the NBSR coolant channels is calculated in Appendix E to be $3.58 \mathrm{~kW}$. The hottest coolant channel in the outer core region is estimated to be 1.5 times the power of an average channel. With the hottest channel at the flooding-limited power the corresponding core power is $1.2 \mathrm{MW}$. It would be less than $30 \mathrm{~s}$ after a reactor scram that the core power would fall below $1 \mathrm{MW}$. It is then concluded that the throttling of a flow control valve would not lead directly to fuel overheating as long as the core is covered by coolant.

\subsubsection{Throttling of Coolant Flow to the Inner Plenum}

In this accident scenario, the flow control valve DWV-2 is assumed to close, decreasing the flow through the inner plenum, with a scram completed $400 \mathrm{~ms}$ after the flow reaches the low flow trip point of $1200 \mathrm{gpm}(75.7 \mathrm{l} / \mathrm{s})$. The 8 " flow control valve is known to have a stroke time of 30 s. It is conservatively assumed in the transient analysis that the flow control valve will stroke from full open to full closed in $15 \mathrm{~s}$. The valve aperture is assumed to be circular in shape with its radius varying linearly with time during the closure. The results of the transient analysis are 
shown in Table 5-9. In a beginning of cycle equilibrium core, the minimum CHFR at the hot spot (in the inner plenum) decreases from an initial value of 4.87 to a new low of 2.86. The corresponding fuel centerline temperature increases by 34.1 degrees to $398.2 \mathrm{~K}$. The transient is over once the shim arms begin to move in at $9.99 \mathrm{~s}$. A comparison of the beginning and end of cycle results indicate that the former imposes more limiting conditions for this transient. The discussions in Section 5.4.4 of heat removal by natural convection and steam generation are applicable to the present flow transient. The conclusion again is that no fuel overheating occurs in the throttling of coolant flow to the inner plenum.

\subsubsection{Loss of Both Shutdown Coolant Pumps}

This accident begins with a loss of offsite power, which initiates a scram after a $100 \mathrm{~ms}$ delay and the primary pumps coast down, as described in Section 5.4.1 above. In addition, it is assumed that both the shutdown primary coolant pumps and all of the secondary coolant pumps also coast down, since there has been a failure of all backup power sources. The primary coolant then circulates by natural convection as the water heats up. A RELAP5 simulation of this process is followed until the fuel reaches a relatively stable temperature, where it is being cooled by convective flow of water up through the fuel elements and down around the outside of the core. The entire inventory of water in the vessel will then be involved in a very gradual warmup. It can be expected to take a much longer time ( several hours) for the bulk water temperature to reach the boiling point, allowing time for shutdown cooling to be restored.

The RELAP5 simulation of a complete loss of shutdown cooling transient is essentially an extension of the loss of offsite power transient described in Section 5.4.1. In addition to losing all of the primary pumps, it is assumed that all of the secondary cooling pumps are lost also. Any flow through the primary system is then by natural circulation and core heat removal is by natural convection. Heat transfer from the primary side to the secondary will continue at a decreasing rate due to the heatup of the secondary coolant in the heat exchangers. The core bypass flow paths between the two flow plenums and the holdup pan region are assumed lost due to the settling of fuel assemblies into the lower grid plate upon loss of forced upward flow.

The transient conditions of the primary flow are summarized in Table 5-10. It is observed that during the course of the transient ( 0 to $500 \mathrm{~s}$ ), the vessel outlet temperature actually decreased a small amount. This is because the decay heat load has decreased significantly (from full power) while the primary loop temperature remains relatively unchanged (due to slow convection of natural circulation). The calculation shows that early in the transient (less than $200 \mathrm{~s}$ ), internal circulation flow paths are established inside the reactor vessel. Buoyancy induces flow upward in warmer coolant channels in the core and downward through cooler channels. The downward flow brings warmer coolant from the upper plenum to the lower inner and outer plenums and this is reflected in the transient increase of coolant temperatures in these flow plenums. As the transient progresses, the external recirculation (flow between the vessel and the primary loop) dominates over the internal circulation and all flow through the core becomes upward only.

Table 5-11 summarizes the temperature response of the fuel plates. Listed in the table are the centerline temperatures of the top node in the lower and upper heat structures (representing the lower and upper core) for the hot channel. Also listed are the temperatures of the coolant 
adjacent to the heat structures. It is noted that the lower heat structures in Table 5-11 have the highest heat flux in their respective core region. At full power and full flow (time zero conditions) the temperature difference between the heat structure and the coolant is much higher than the core temperature rise in the coolant. Consequently, the maximum plate temperature then occurs in the node with the highest heat flux.

The situation changes when forced flow is lost and the structures are heated by decay heat. At reduced flow under natural circulation and reduced heat generation, the core temperature rise in the coolant is much higher than the temperature difference between the heat structure and the coolant. It is observed in Table 5-11 that the location of the maximum plate temperature moves upward towards the exit. Hence the location of the position of the maximum plate temperature is not fixed and can vary as the transient conditions change over time.

At the end of 500 seconds the reactor system has reached a quasi-steady state and beyond this point, the thermal-hydraulic conditions of the coolant and the fuel elements vary slowly with time owing to the declining decay power.

\subsection{Misloading of Fuel Accident}

\subsubsection{Assumptions}

Under equilibrium core conditions the NBSR refueling plan calls for the discharge of four spent fuel elements from the inner core and the installation of four fresh fuel elements in the periphery of the outer core. Fresh elements are loaded only after fuel shuffling is complete. The misloading of fuel accident postulates an error in the placement of a fresh fuel element in the core during refueling. Loading a fresh element into the wrong position in the core creates the potential for a more reactive core configuration, thus leading to more peaking in the radial power distribution. The accident scenario assumes that an error occurred in the rotation of fuel elements and an irradiated fuel element was left in the M-4 location (refer to Figure 3-4 for the designation of core locations), which is normally to be filled by a fresh fuel element. Instead, it is assumed that the fresh fuel element was placed in the remaining empty position in the core.

\subsubsection{Radial Power Distributions}

Power distributions that would be expected to result from a misloading of the fuel have been determined for a set of 26 different postulated cases in which the positions of two elements were exchanged. Each of the cases examined starts with the selection of one of the 26 different irradiated elements in the startup (SU) core. The selected fuel element is swapped with the fresh fuel element that was supposed to be loaded into core position M-4. This is accomplished in MCNP by interchanging the material number of the selected irradiated element with that of the fresh M-4 element. The resulting radial power distribution is then calculated and compared with the nominal power distribution where all fuel elements are placed in the correct core positions. The calculations for the misloaded fuel are for the SU core conditions while the nominal power distributions are calculated for a BOC equilibrium core. 
The radial power distributions for the two cases that resulted in the highest power peaking in the inner and outer core regions respectively are depicted in Figure 5-4. For each case analyzed the figure shows two sets of numbers. The upper set of numbers shows the fuel loading designation, which is to be compared to Figure 3-4. The lower set of numbers shows the calculated fission energy power distributions (on the left) and the statistical uncertainties of the MCNP calculations (on the right). It is noted that the placement of a fresh fuel in the inner core results in a higher maximum fuel element power than the placement of a fresh fuel in the outer core region. The relative power of the misloaded fresh fuel is shown in Table 5-12 for all 26 cases. The overall effect of the misloaded fuel on the core-wide power distribution is noted by identifying in the table the fuel elements having the highest power in the inner and outer core respectively. The tabulated results indicate that the radial power distributions for the misloading of fuel accident have peak values of 1.68 and 1.51 in the inner and outer core regions respectively.

\subsubsection{Safety Implications of a Misloaded Fuel Accident}

The minimum CHFRs for the worst cases of the misloading of fuel accident can be inferred from the peak wall heat fluxes and the CHFs calculated previously in Section 4.3.2 for the equilibrium core in the beginning of cycle conditions. From the analysis discussed in Section 4.3.2, the minimum CHFR is at the location of the peak heat flux. Assuming the BOC and the SU core have the same axial power distribution, the axial location of the minimum CHFR is then known for the misloaded fuel. The nominal radial power distributions for a BOC equilibrium core (see Section 3.4.1) have peak values of 1.07 and 1.16 for fuel elements in the inner and outer core, respectively. The corresponding values for the misloaded fuel (worst cases) are 1.68 and 1.51 for elements in the inner and outer core respectively. The peak wall heat fluxes of the misloaded fuel elements are calculated by noting that wall heat flux is proportional to fuel element power. Determining the peak heat flux takes care of half of the equation for the evaluation of the minimum CHFR.

The next step is to determine the CHF. Assuming identical coolant velocities in the misloaded fuel and the limiting coolant channel identified in Section 4.3.2 for the equilibrium core, the burnout heat transfer coefficient and the wall temperature according to the Bernath correlation (see Section 4, Appendix D for the CHF analysis) remain unchanged. The only variable that needs to be adjusted for the calculation of the CHF is the coolant temperature at the location of the peak heat flux. That temperature is known for the equilibrium core condition. The corresponding coolant temperature for the misloaded fuel is calculated by noting that the coolant temperature rise (from core inlet to the location of peak heat flux) is also proportional to element power.

The results of the calculations are summarized in Table 5-13. The minimum CHFRs are 2.94 and 2.18 for the misloaded fuel (worst case) in the inner and outer core, respectively. The minimum CHFRs for the misloaded fuel are above the limiting value of 1.911 (99.9\% probability) and therefore no fuel damage is anticipated for the misloading of fuel accident. 


\subsection{Heat Removal by Flow from the Inner Emergency Cooling Tank}

In the unlikely event that a break occurred in the inlet pipe between the reactor inlet valves and the inlet plena, coolant will drain from the interior of the fuel elements. Coolant exterior to the fuel elements will continue to provide some cooling. Another source of cooling is by flow from the inner emergency cooling tank. Nozzles in the distribution pan direct flow from the inner emergency cooling tank to each individual fuel element.

Assuming heat removal is by boiloff, the makeup flow rate is determined from the decay power calculated by the RELAP5 model of the NBSR for a 20.4 MW core (allowing for a $2 \%$ uncertainty in core power). Within the first second after shutdown the core makeup flow rate drops below $1 \mathrm{~kg} / \mathrm{s}$. The required makeup flow rate for boiloff is shown in Figure 5-5. The flow from the inner emergency cooling tank is calculated as a function of time, using the analytical model described in Section 4.2.3.4, and is shown in Figure 5-5. The coolant in the fuel element is assumed to have drained out of the break and the tank flow is a result of the hydrostatic head. The flow from the inner emergency cooling tank decreases linearly in time as the water level drops in the tank. For at least 20 minutes after shutdown the tank flow is more than adequate to cool the fuel elements by boiloff. Coolant inventory in the inner emergency cooling tank would be replenished from the 3000 gallon main emergency cooling tank. Thus there is ample time for the operators to assess the situation and initiate additional emergency cooling as needed. 


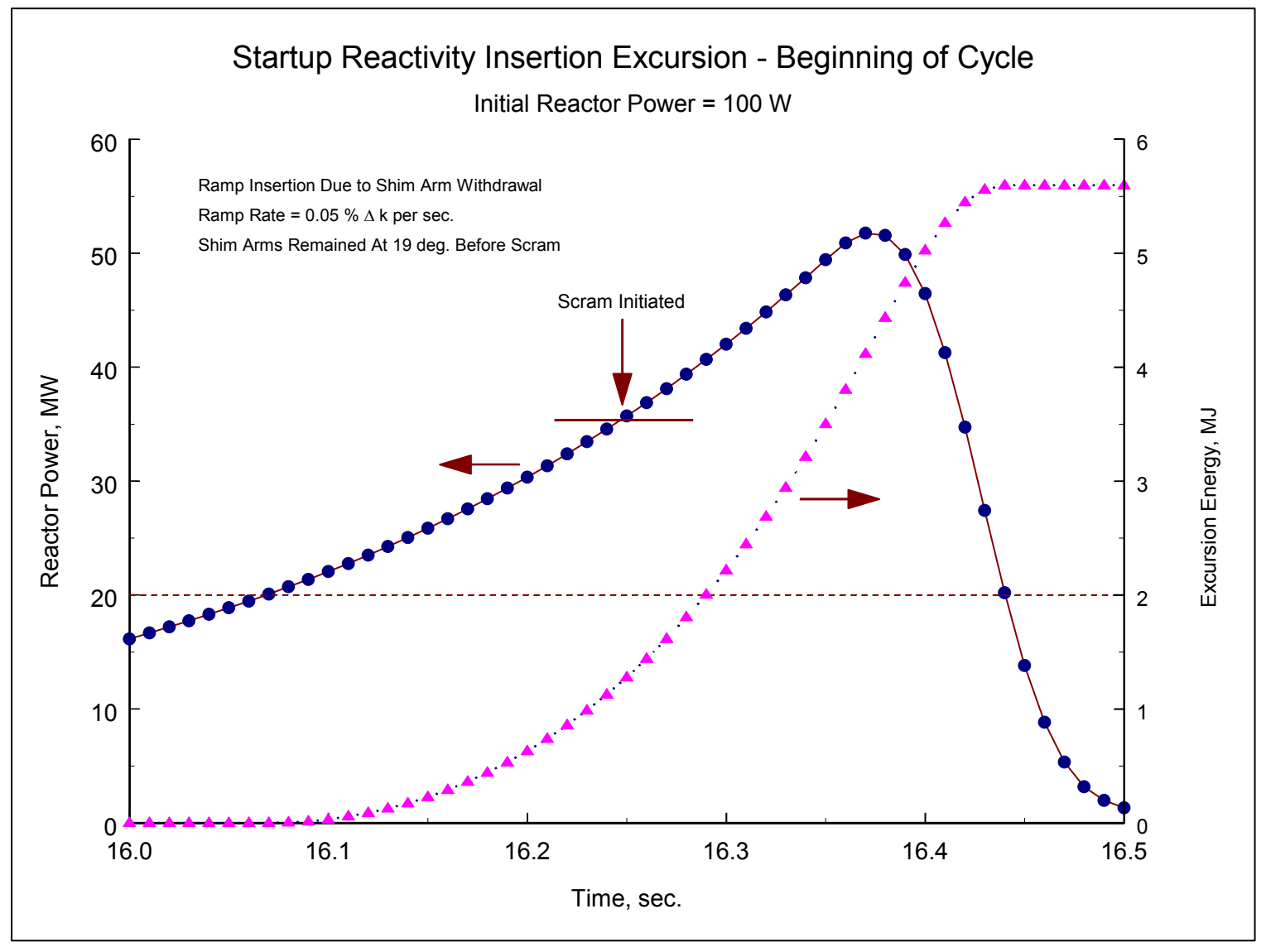

Figure 5-1. Startup Reactivity Insertion Excursion - BOC. 


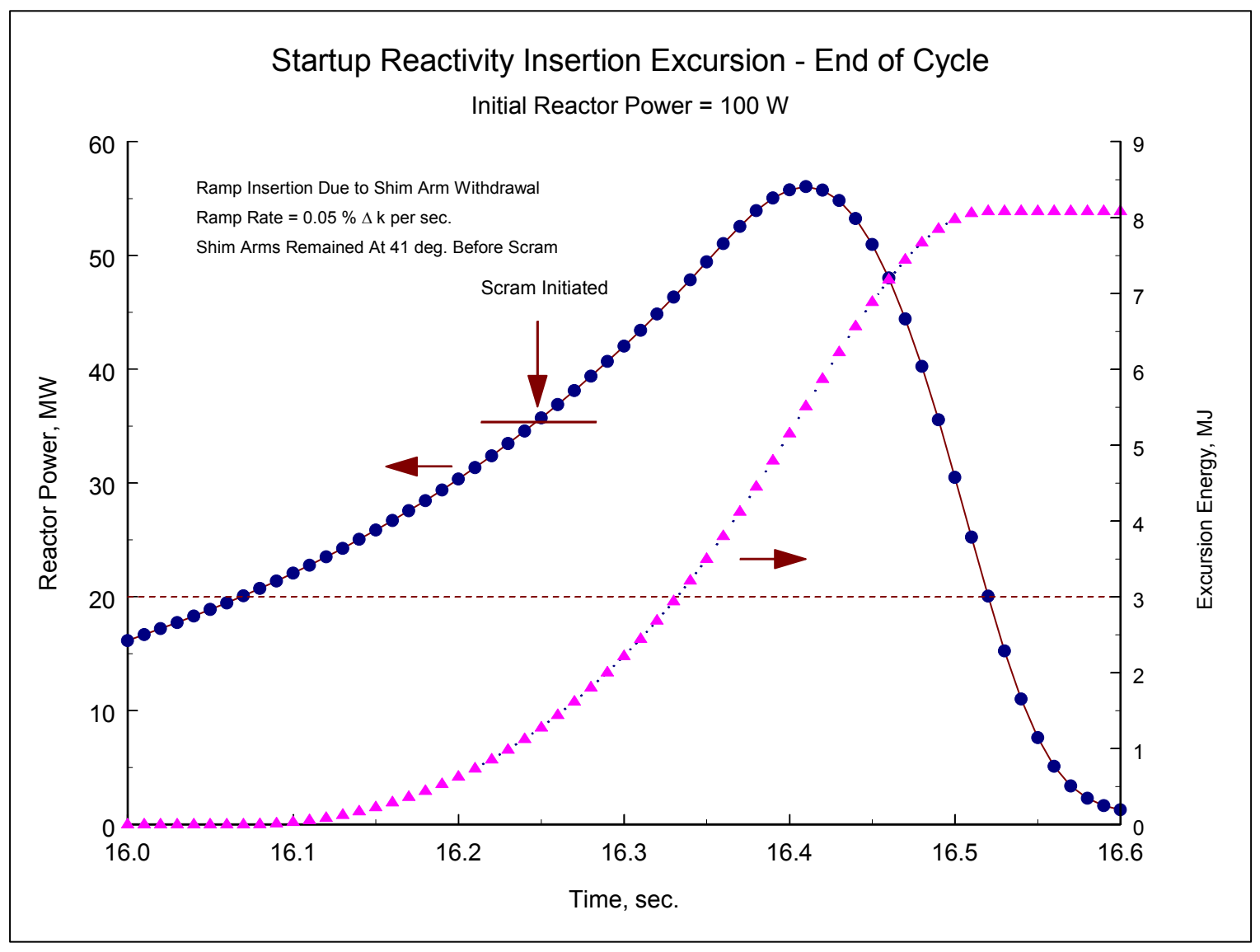

Figure 5-2. Startup Reactivity Insertion Excursion - EOC. 


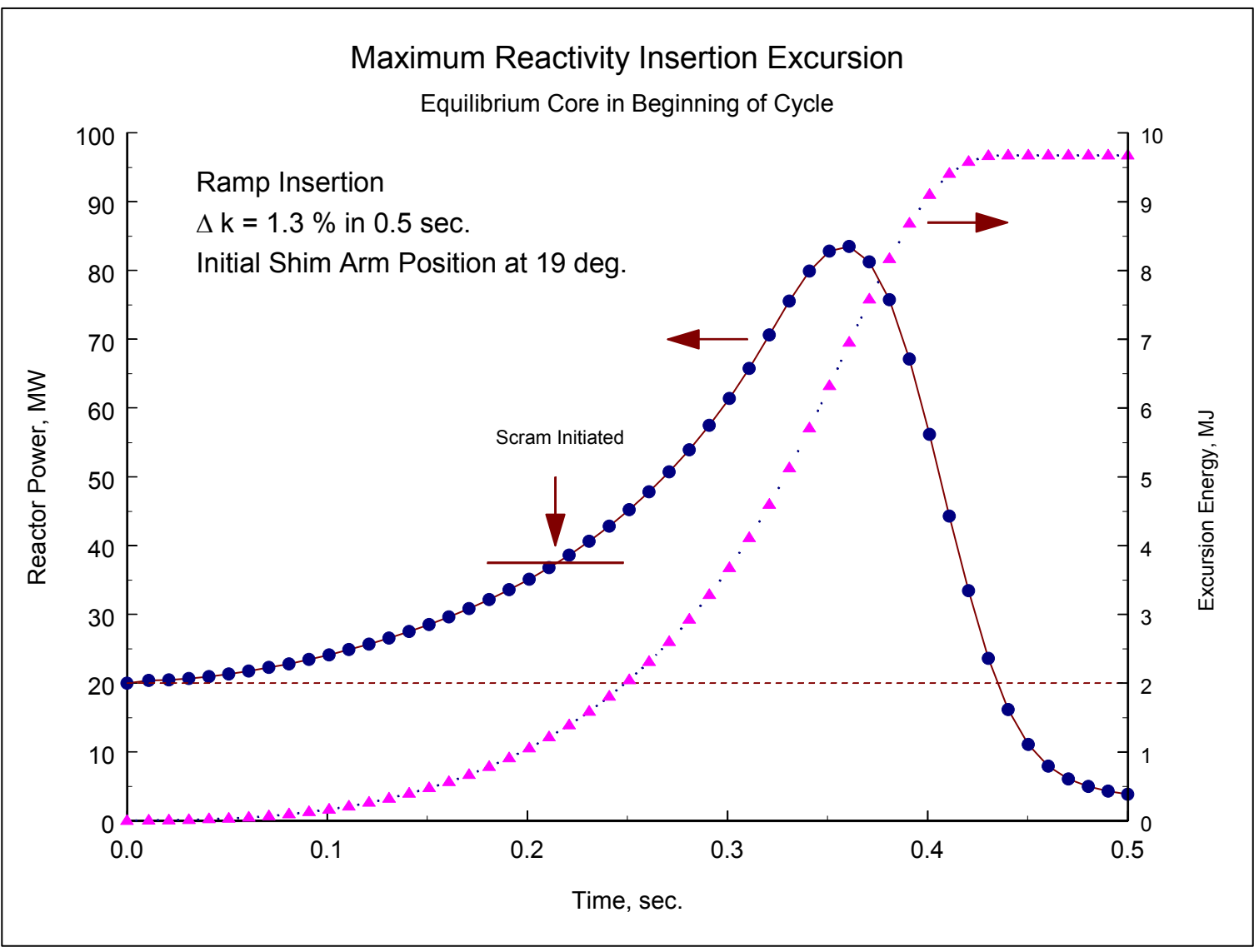

Figure 5-3. Maximum Reactivity Insertion Excursion - Equilibrium Core in Beginning of Cycle. 


\section{Misloaded Fuel in Inner Core}

Exchange elements M-4 and F-3 (7-1 with 8-7)

$$
\begin{aligned}
& \text { Misload Scheme } \\
& \begin{array}{llll}
8-1 & 7-2 & 7-2 & 8-1
\end{array}
\end{aligned}
$$

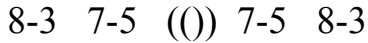

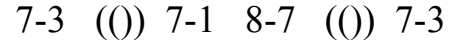

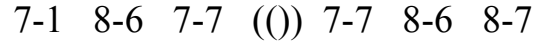

$$
\begin{aligned}
& \text { 8-4 (()) 8-8 8-8 (()) 8-4 } \\
& \begin{array}{lllll}
7-4 & 7-6 & (()) & 7-6 & 7-4
\end{array} \\
& 8-2 \quad 8-5 \quad 8-5 \quad 8-2 \\
& \text { NORTH } \quad \text { D-1 } \quad \text { F-1 } \quad \text { H-1 J-1 }
\end{aligned}
$$

NBSR Loading$$
\text { C-2 E-2 (()) I-2 K-2 }
$$$$
\text { B-3 (()) F-3 H-3 (()) L-3 }
$$

\begin{tabular}{|c|}
\hline Fission Energy Deposition \\
\hline $\begin{array}{llll}1.08 & 1.17 & 1.21 & 1.05\end{array}$ \\
\hline $\begin{array}{llll}1.16 & 1.22(0) & 1.10 & .95\end{array}$ \\
\hline $1.04(()) \quad 1.68 \quad 1.10(()) \quad .88$ \\
\hline 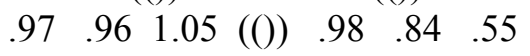 \\
\hline $.91 \quad(()) \quad .89 \quad .87 \quad(()) \quad .81$ \\
\hline 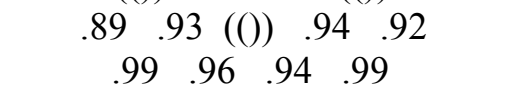 \\
\hline
\end{tabular}$$
\text { A-4 C-4 E-4 (()) I-4 K-4 M-4 }
$$$$
\text { B-5 (()) F-5 H-5 (()) L-5 }
$$$$
\text { C-6 E-6 (()) I-6 K-6 }
$$$$
\text { D-7 } \quad \text { F-7 } \quad \text { H-7 J-7 }
$$

$$
\begin{gathered}
+/-(\%) \\
\text { NORTH } \quad .77 \quad .72 \quad .72 \quad .79 \\
.72 \quad .67(()) \quad .70 \quad .79 \\
.76(()) \quad .62 \quad .66(()) \quad .82 \\
.82 .72 \quad .67(()) .69 \quad .78 \quad .92 \\
.79(()) \quad .69 \quad .70(()) \quad .84 \\
.80 \quad .74(()) \quad .73 \quad .79 \\
.79 \quad .75 \quad .75 \quad .79
\end{gathered}
$$

\section{Misloaded Fuel in Outer Core}

Exchange elements M-4 and E-2 (7-1 with 7-5)

$$
\begin{aligned}
& \text { Misload Scheme } \\
& \text { NBSR Loading } \\
& \begin{array}{lllllllll}
8-1 & 7-2 & 7-2 & 8-1 & \text { NORTH } & \text { D-1 } & \text { F-1 } & \text { H-1 } & \text { J-1 }
\end{array} \\
& \text { 8-3 7-1 (()) 7-5 8-3 } \quad \text { C-2 } \quad \text { E-2 (()) I-2 K-2 } \\
& \text { 7-3 (()) 8-7 8-7 } \quad(()) \text { 7-3 } \quad \text { B-3 } \quad(()) \text { F-3 H-3 (()) L-3 }
\end{aligned}
$$

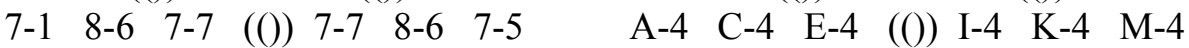

$$
\begin{aligned}
& \text { 8-4 (()) 8-8 8-8 (()) 8-4 } \quad \text { B-5 } \quad(()) \text { F-5 H-5 (()) L-5 }
\end{aligned}
$$

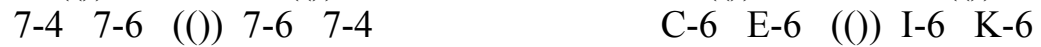

$$
\begin{aligned}
& \begin{array}{llllllll}
8-2 & 8-5 & 8-5 & 8-2 & \text { D-7 } & \text { F-7 } & \text { H-7 } & \text { J-7 }
\end{array} \\
& +/-(\%) \\
& \begin{array}{llll}
1.10 & 1.19 & 1.21 & 1.08
\end{array} \\
& 1.151 .51(()) 1.11 \quad .95 \\
& 1.01(()) \quad 1.09 \quad 1.07 \quad(()) \quad .90 \\
& \begin{array}{lllllll}
.96 & .94 & 1.01 & (()) & .96 & .85 & .68
\end{array} \\
& \begin{array}{llllll}
.89 & (()) & .88 & .88 & (()) & .85
\end{array} \\
& \begin{array}{lllll}
.90 & .93 & (0) & .97 & .95
\end{array} \\
& \begin{array}{llll}
1.00 & .98 & .98 & 1.02
\end{array}
\end{aligned}
$$

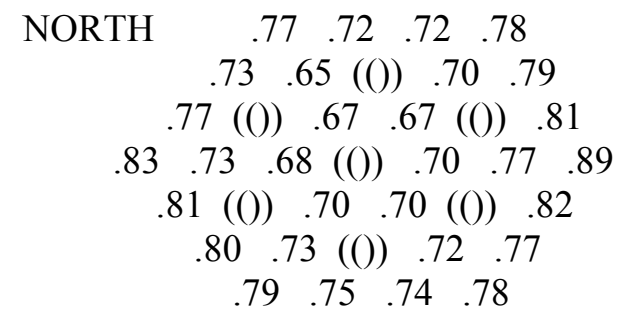

Figure 5-4. Fission Power Distribution Resulting from a Misloaded Fresh Fuel. 


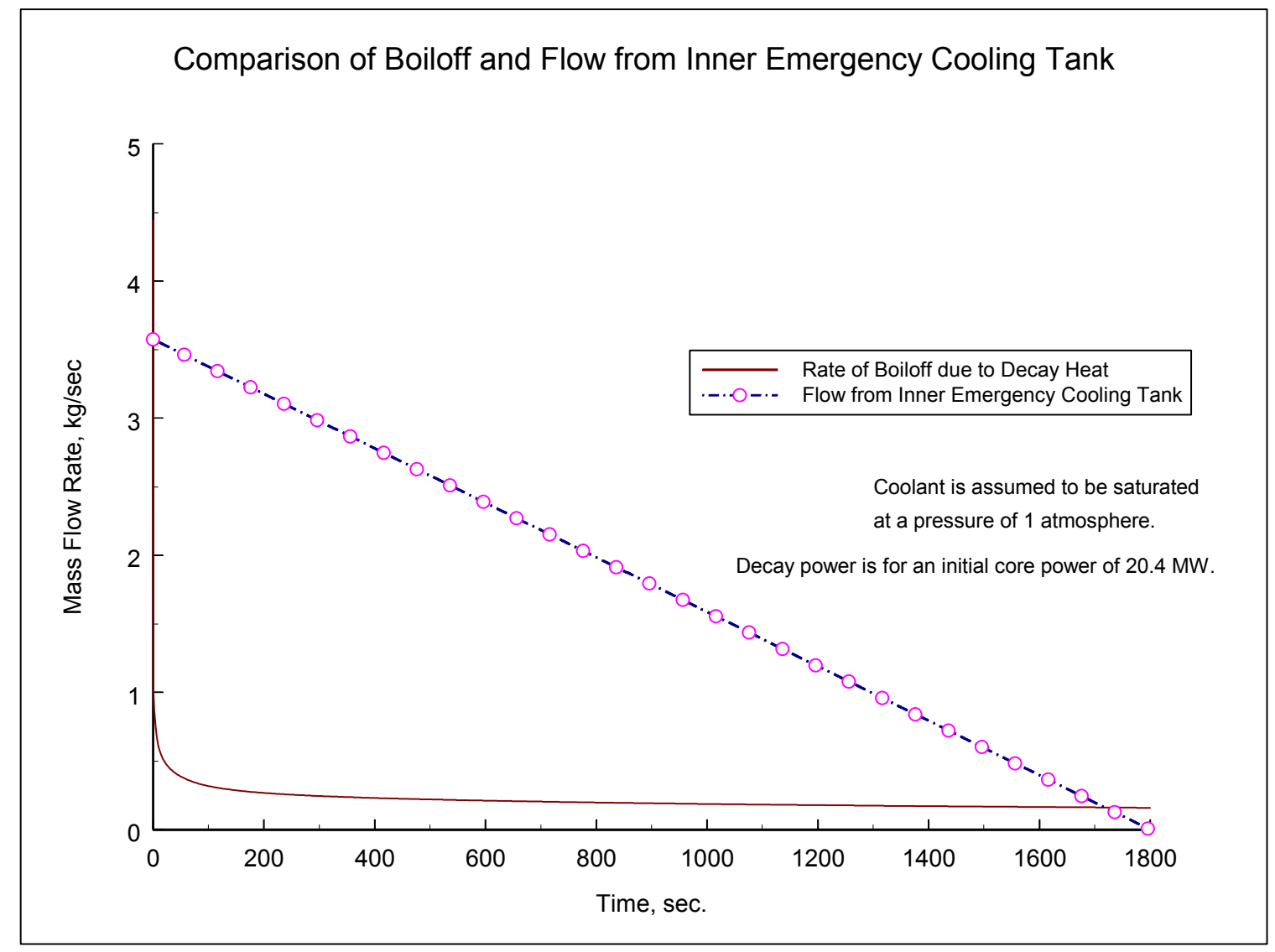

Figure 5-5. Comparison of Boiloff and Flow from Inner Emergency Cooling Tank. 
Table 5-1. Reactor Response to Startup Accident Equilibrium Core - Beginning of Cycle

\begin{tabular}{|c|c|c|}
\hline $\begin{array}{c}\text { Time } \\
\text { s }\end{array}$ & $\begin{array}{c}\text { Reactor } \\
\text { Power } \\
\text { MW }\end{array}$ & $\begin{array}{c}\text { Excursion } \\
\text { Energy } \\
\text { MJ }\end{array}$ \\
\hline 16.0. & 16.1 & 0. \\
\hline 16.02 & 17.2 & 0.0 \\
\hline 16.04 & 18.3 & 0.0 \\
\hline 16.06 & 19.5 & 0.0 \\
\hline 16.08 & 20.7 & 0.0042 \\
\hline 16.10 & 22.1 & 0.0322 \\
\hline 16.12 & 23.5 & 0.0879 \\
\hline 16.14 & 25.1 & 0.173 \\
\hline 16.16 & 26.7 & 0.291 \\
\hline 16.18 & 28.5 & 0.442 \\
\hline 16.20 & 30.4 & 0.630 \\
\hline 16.22 & 32.4 & 0.858 \\
\hline 16.24 & 34.6 & 1.13 \\
\hline 16.26 & 36.9 & 1.44 \\
\hline 16.28 & 39.4 & 1.80 \\
\hline 16.30 & 42.0 & 2.22 \\
\hline 16.32 & 44.9 & 2.69 \\
\hline 16.34 & 47.9 & 3.21 \\
\hline 16.36 & 50.9 & 3.80 \\
\hline 16.37 & 51.8 & 4.12 \\
\hline 16.38 & 51.6 & 4.43 \\
\hline 16.40 & 46.5 & 5.03 \\
\hline 16.42 & 34.7 & 5.45 \\
\hline 16.44 & 20.2 & 5.60 \\
\hline 16.46 & 8.85 & 5.60 \\
\hline 16.48 & 3.19 & 5.60 \\
\hline 16.50 & 1.35 & 5.60 \\
\hline
\end{tabular}

Initial reactor power $=100 \mathrm{~W}$ (equilibrium core $-\mathrm{BOC}$ ) Reactivity insertion rate $=0.05 \% \Delta \mathrm{k}$ per s Initial shim arm position $=19^{\circ}$

Power scram delay $=0.05 \mathrm{~s}$ 
Table 5-2. Reactor Response to Startup Accident

\section{Equilibrium Core - End of Cycle}

\begin{tabular}{|c|c|c|}
\hline $\begin{array}{c}\text { Time } \\
\text { S }\end{array}$ & $\begin{array}{c}\text { Reactor } \\
\text { Power } \\
\text { MW }\end{array}$ & $\begin{array}{c}\text { Excursion } \\
\text { Energy } \\
\text { MJ }\end{array}$ \\
\hline 16.0. & 16.1 & 0. \\
\hline 16.02 & 17.2 & 0.0 \\
\hline 16.04 & 18.3 & 0.0 \\
\hline 16.06 & 19.5 & 0.0 \\
\hline 16.08 & 20.7 & 0.0042 \\
\hline 16.10 & 22.1 & 0.0322 \\
\hline 16.12 & 23.5 & 0.0879 \\
\hline 16.14 & 25.1 & 0.173 \\
\hline 16.16 & 26.7 & 0.291 \\
\hline 16.18 & 28.5 & 0.442 \\
\hline 16.20 & 30.4 & 0.630 \\
\hline 16.22 & 32.4 & 0.858 \\
\hline 16.24 & 34.6 & 1.13 \\
\hline 16.26 & 36.9 & 1.44 \\
\hline 16.28 & 39.4 & 1.80 \\
\hline 16.30 & 42.0 & 2.22 \\
\hline 16.32 & 44.9 & 2.69 \\
\hline 16.34 & 47.9 & 3.21 \\
\hline 16.36 & 51.0 & 3.80 \\
\hline 16.38 & 53.9 & 4.45 \\
\hline 16.40 & 55.8 & 5.15 \\
\hline 16.41 & 56.0 & 5.51 \\
\hline 16.42 & 55.8 & 5.87 \\
\hline 16.44 & 53.2 & 6.57 \\
\hline 16.46 & 48.0 & 7.18 \\
\hline 16.48 & 40.3 & 7.67 \\
\hline 16.50 & 30.5 & 7.98 \\
\hline 16.52 & 20.1 & 8.09 \\
\hline 16.54 & 11.0 & 8.09 \\
\hline 16.56 & 5.10 & 8.09 \\
\hline 16.58 & 2.30 & 8.09 \\
\hline 16.60 & 1.28 & 8.09 \\
\hline & & \\
\hline
\end{tabular}

Initial reactor power $=100 \mathrm{~W}$ (equilibrium core $-\mathrm{EOC}$ )

Reactivity insertion rate $=0.05 \% \Delta \mathrm{k}$ per s

Initial shim arm position $=41^{\circ}$

Power scram delay $=0.05 \mathrm{~s}$ 
Table 5-3. Reactor Response to Maximum Reactivity Insertion

Equilibrium Core - Beginning of Cycle

\begin{tabular}{|c|c|c|c|}
\hline $\begin{array}{c}\text { Time } \\
\mathbf{s}\end{array}$ & $\begin{array}{c}\text { Reactor } \\
\text { Power } \\
\text { MW } \\
\end{array}$ & $\begin{array}{c}\text { Excursion } \\
\text { Energy } \\
\text { MJ } \\
\end{array}$ & $\begin{array}{c}\text { Reactor } \\
\text { Period } \\
\text { s } \\
\end{array}$ \\
\hline 0. & 20.0 & 0. & $\infty$ \\
\hline 0.01 & 20.4 & 0.00303 & 4.25 \\
\hline 0.02 & 20.5 & 0.00756 & 1.27 \\
\hline 0.04 & 21.0 & 0.0221 & 0.608 \\
\hline 0.06 & 21.8 & 0.0494 & 0.442 \\
\hline 0.08 & 22.8 & 0.0952 & 0.366 \\
\hline 0.10 & 24.1 & 0.165 & 0.321 \\
\hline 0.12 & 25.7 & 0.262 & 0.289 \\
\hline 0.14 & 27.5 & 0.394 & 0.265 \\
\hline 0.16 & 29.7 & 0.565 & 0.244 \\
\hline 0.18 & 32.2 & 0.783 & 0.227 \\
\hline 0.20 & 35.1 & 1.06 & 0.210 \\
\hline 0.22 & 38.6 & 1.39 & 0.196 \\
\hline 0.24 & 42.8 & 1.81 & 0.182 \\
\hline 0.26 & 47.8 & 2.31 & 0.169 \\
\hline 0.28 & 53.9 & 2.93 & 0.157 \\
\hline 0.30 & 61.4 & 3.68 & 0.145 \\
\hline 0.32 & 70.6 & 4.59 & 0.139 \\
\hline 0.34 & 80.0 & 5.70 & 0.208 \\
\hline 0.36 & 83.5 & 6.95 & -1.16 \\
\hline 0.38 & 75.8 & 8.17 & -0.104 \\
\hline 0.40 & 56.2 & 9.10 & -0.0472 \\
\hline 0.42 & 33.4 & 9.58 & -0.0293 \\
\hline 0.44 & 16.2 & 9.68 & -0.0239 \\
\hline 0.46 & 7.94 & 9.68 & -0.0273 \\
\hline 0.48 & 5.00 & 9.68 & -0.0435 \\
\hline 0.50 & 3.86 & 9.68 & -0.0606 \\
\hline
\end{tabular}

Initial reactor power $=20 \mathrm{MW}$ (equilibrium core $-\mathrm{BOC}$ )

Reactivity insertion rate $=1.3 \% \Delta \mathrm{k}$ in $0.5 \mathrm{~s}$

Initial shim arm position $=19^{\circ}$

Power scram delay $=0.05 \mathrm{~s}$ 
Table 5-4. Maximum Reactivity Insertion Equilibrium Core - End of Cycle

\begin{tabular}{|c|c|c|c|}
\hline $\begin{array}{c}\text { Power Trip } \\
\text { Setpoint } \\
\text { MW }\end{array}$ & $\begin{array}{c}\text { Prompt Neutron } \\
\text { Lifetime } \\
\mu \mathbf{s}\end{array}$ & $\begin{array}{c}\text { Peak } \\
\text { Power } \\
\text { MW }\end{array}$ & $\begin{array}{c}\text { Excursion } \\
\text { Energy } \\
\text { MJ }\end{array}$ \\
\hline 30 & 400 & 129.0 & 21.0 \\
\hline 26 & 400 & 86.8 & 12.9 \\
\hline 30 & 1000 & 93.3 & 16.7 \\
\hline 26 & 1000 & 67.1 & 10.6 \\
\hline
\end{tabular}


Table 5-5. Transient Conditons at Hot Spot Following Loss of Commercial Power to Plant (Loss of Flow Due to Power Outage)

\begin{tabular}{|c|c|c|c|c|}
\hline \multirow[b]{2}{*}{$\begin{array}{c}\text { Time } \\
s\end{array}$} & \multirow{2}{*}{$\begin{array}{c}\text { Reactor } \\
\text { Power } \\
\text { MW }\end{array}$} & \multirow{2}{*}{ 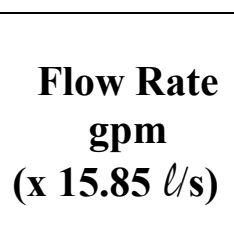 } & \multicolumn{2}{|c|}{$\begin{array}{c}\text { BOC - Equilibrium } \\
\text { Core }\end{array}$} \\
\hline & & & CHFR & $\begin{array}{c}\text { Fuel } \\
\text { Centerline } \\
\text { Temp., K }\end{array}$ \\
\hline 0. & 20.4 & 8700 & 2.98 & 391.2 \\
\hline 0.1 & 20.4 & 8550 & 2.98 & 391.3 \\
\hline 0.2 & 20.4 & 8270 & 2.95 & 392.5 \\
\hline 0.3 & 9.22 & 7940 & 3.65 & 380.4 \\
\hline 0.4 & 2.81 & 7620 & 8.60 & 348.3 \\
\hline 0.5 & 2.20 & 7320 & 16.7 & 334.1 \\
\hline
\end{tabular}

\begin{tabular}{|c|c|c|c|c|}
\hline \multirow{2}{*}{$\underset{s}{\text { Time }}$} & \multirow{2}{*}{$\begin{array}{c}\text { Reactor } \\
\text { Power } \\
\text { MW }\end{array}$} & \multirow{2}{*}{ 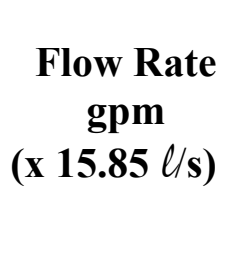 } & \multicolumn{2}{|c|}{$\begin{array}{c}\text { EOC - Equilibrium } \\
\text { Core }\end{array}$} \\
\hline & & & CHFR & $\begin{array}{c}\text { Fuel } \\
\text { Centerline } \\
\text { Temp., K }\end{array}$ \\
\hline 0. & 20.4 & 8700 & 3.76 & 378.6 \\
\hline 0.1 & 20.4 & 8550 & 3.75 & 378.8 \\
\hline 0.2 & 20.4 & 8270 & 3.71 & 379.7 \\
\hline 0.3 & 17.4 & 7940 & 3.83 & 378.4 \\
\hline 0.4 & 7.66 & 7620 & 5.49 & 363.3 \\
\hline 0.5 & 2.69 & 7320 & 11.5 & 343.0 \\
\hline
\end{tabular}

Initial power $=20.4 \mathrm{MW}$

Primary pump tripped at time zero.

Reactor scram delay $=0.1 \mathrm{~s}$

For BOC the hot spot is in the multi-channel hot stripe at the top of the lower core.

For EOC the hot spot is in the single-channel hot stripe at the bottom of the upper core. 


\section{Table 5-6. Transient Conditons at Hot Spot Following \\ Loss of Primary Pumps (Loss of Flow Due to Primary Pump Trip)}

\begin{tabular}{|c|c|c|c|c|c|c|c|c|}
\hline \multirow{2}{*}{ Time } & \multirow{2}{*}{$\begin{array}{c}\text { Primary } \\
\text { Flow Rate } \\
\text { gpm } \\
(x) 15.85 \ell / s)\end{array}$} & \multirow{2}{*}{$\begin{array}{c}\begin{array}{c}\text { Outer } \\
\text { Plenum Flow } \\
\text { gpm }\end{array} \\
(\times 15.85 \ell / \text { s) }\end{array}$} & \multicolumn{3}{|c|}{ BOC - Equilibrium Core } & \multicolumn{3}{|c|}{ EOC - Equilibrium Core } \\
\hline & & & $\begin{array}{c}\text { Reactor } \\
\text { Power } \\
\text { MW }\end{array}$ & CHFR & $\begin{array}{c}\text { Fuel } \\
\text { Centerline } \\
\text { Temp., K }\end{array}$ & $\begin{array}{c}\text { Reactor } \\
\text { Power } \\
\text { MW }\end{array}$ & CHFR & $\begin{array}{c}\text { Fuel } \\
\text { Centerline } \\
\text { Temp., K }\end{array}$ \\
\hline 0 & 8700 & 6380 & 20.4 & 2.98 & 391.2 & 20.4 & 3.76 & 378.6 \\
\hline 0.1 & 8550 & 6290 & 20.4 & 2.98 & 391.3 & 20.4 & 3.75 & 378.8 \\
\hline 0.2 & 8270 & 6100 & 20.4 & 2.95 & 392.5 & 20.4 & 3.71 & 379.7 \\
\hline 0.3 & 7940 & 5870 & 20.4 & 2.88 & 394.2 & 20.4 & 3.64 & 381.1 \\
\hline 0.4 & 7620 & 5650 & 20.4 & 2.81 & 396.1 & 20.4 & 3.55 & 382.8 \\
\hline 0.5 & 7320 & 5430 & 20.4 & 2.73 & 398.0 & 20.4 & 3.46 & 384.6 \\
\hline 0.6 & 7030 & 5220 & 20.4 & 2.65 & 399.9 & 20.4 & 3.37 & 386.5 \\
\hline 0.7 & 6760 & 5020 & 20.4 & 2.57 & 401.6 & 20.4 & 3.29 & 388.5 \\
\hline 0.8 & 6510 & 4840 & 20.4 & 2.50 & 403.1 & 20.4 & 3.20 & 390.5 \\
\hline 0.9 & 6280 & 4670 & 20.4 & 2.43 & 404.5 & 20.4 & 3.12 & 392.3 \\
\hline 1.0 & 6060 & 4510 & 20.4 & 2.37 & 405.8 & 20.4 & 3.04 & 394.0 \\
\hline 1.1 & 5860 & 4360 & 20.4 & 2.31 & 407.0 & 20.4 & 2.96 & 395.6 \\
\hline 1.2 & 5660 & 4210 & 20.4 & 2.25 & 408.0 & 20.4 & 2.89 & 397.0 \\
\hline 1.3 & 5480 & 4080 & 20.4 & 2.20 & 409.0 & 20.4 & 2.82 & 398.3 \\
\hline 1.4 & 5310 & 3950 & 20.3 & 2.14 & 409.9 & 20.4 & 2.76 & 399.5 \\
\hline 1.5 & 5150 & 3830 & 6.98 & 3.12 & 393.7 & 16.6 & 2.93 & 396.9 \\
\hline 1.6 & 5000 & 3720 & 2.57 & 6.44 & 362.3 & 6.32 & 4.29 & 378.8 \\
\hline 1.7 & 4850 & 3610 & 2.19 & 11.2 & 345.2 & 2.44 & 8.29 & 356.0 \\
\hline
\end{tabular}

Initial reactor power $=20.4 \mathrm{MW}$

Primary pump tripped at time zero.

Reactor tripped on low outer plenum flow (4700 gpm).

Flow scram delay $=0.4 \mathrm{~s}$

For BOC the hot spot is in the multi-channel hot stripe at the top of the lower core.

For EOC the hot spot is in the single-channel hot stripe at the bottom of the upper core. 
Table 5-7. Transient Conditions at Hot Spot Following Pump Seizure (Loss of Flow Due to Loss of One Pump)

\section{Equilibrium Core - Beginning of Cycle}

\begin{tabular}{|c|c|c|c|c|c|c|c|c|}
\hline \multirow{3}{*}{$\begin{array}{l}\text { Time } \\
\text { s }\end{array}$} & \multirow{3}{*}{$\begin{array}{c}\text { Reactor } \\
\text { Power } \\
\text { MW }\end{array}$} & \multirow{3}{*}{$\begin{array}{c}\text { Primary } \\
\text { Flow Rate } \\
\text { gpm } \\
(x \quad 15.85 \ell / s)\end{array}$} & \multirow{3}{*}{ 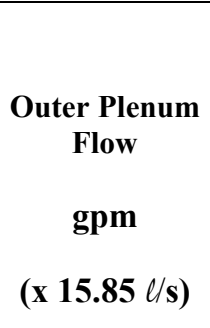 } & \multirow{2}{*}{\multicolumn{2}{|c|}{$\begin{array}{c}\text { Outer Plenum } \\
\text { Hot Spot }\end{array}$}} & \multirow{3}{*}{$\begin{array}{c}\text { Inner } \\
\text { Plenum } \\
\text { Flow } \\
\text { gpm } \\
\text { (x } 15.85 \% / \mathrm{s})\end{array}$} & \multirow{2}{*}{\multicolumn{2}{|c|}{$\begin{array}{c}\text { Inner Plenum } \\
\text { Hot Spot }\end{array}$}} \\
\hline & & & & & & & & \\
\hline & & & & $\underset{\mathbf{R}}{\mathbf{C H F}}$ & $\begin{array}{c}\text { Fuel } \\
\text { Centerline } \\
\text { Temp.,K }\end{array}$ & & CHFR & $\begin{array}{c}\text { Fuel } \\
\text { Centerline } \\
\text { Temp.,K }\end{array}$ \\
\hline 0 & 20.4 & 8700 & 6380 & 2.98 & 391.2 & 2290 & 4.87 & 364.1 \\
\hline 0.2 & 20.4 & 6570 & 4960 & 2.64 & 400.6 & 1600 & 4.06 & 374.9 \\
\hline 0.4 & 20.4 & 6050 & 4540 & 2.39 & 405.5 & 1500 & 3.68 & 380.4 \\
\hline 0.6 & 20.4 & 5880 & 4370 & 2.29 & 407.3 & 1490 & 3.60 & 381.6 \\
\hline 0.8 & 20.4 & 5820 & 4300 & 2.25 & 408.0 & 1500 & 3.61 & 381.5 \\
\hline 1.0 & 20.4 & 5800 & 4270 & 2.23 & 408.3 & 1500 & 3.62 & 381.2 \\
\hline 1.2 & 20.4 & 5790 & 4260 & 2.23 & 408.4 & 1510 & 3.63 & 381.0 \\
\hline 1.4 & 20.4 & 5790 & 4250 & 2.22 & 408.5 & 1510 & 3.64 & 380.8 \\
\hline 1.6 & 20.4 & 5790 & 4250 & 2.22 & 408.5 & 1520 & 3.65 & 380.8 \\
\hline 1.8 & 20.4 & 5790 & 4250 & 2.22 & 408.5 & 1520 & 3.65 & 380.7 \\
\hline 2.0 & 20.4 & 5790 & 4250 & 2.22 & 408.5 & 1520 & 3.65 & 380.7 \\
\hline 2.2 & 20.4 & 5790 & 4250 & 2.22 & 408.5 & 1520 & 3.65 & 380.7 \\
\hline 2.4 & 20.4 & 5790 & 4250 & 2.22 & 408.5 & 1520 & 3.65 & 380.7 \\
\hline 2.6 & 20.4 & 5790 & 4250 & 2.22 & 408.5 & 1520 & 3.65 & 380.7 \\
\hline 2.8 & 20.4 & 5790 & 4250 & 2.22 & 408.5 & 1520 & 3.65 & 380.7 \\
\hline 3.0 & 20.4 & 5790 & 4250 & 2.22 & 408.5 & 1520 & 3.65 & 380.7 \\
\hline 3.2 & 20.4 & 5790 & 4250 & 2.22 & 408.5 & 1520 & 3.65 & 380.7 \\
\hline 3.4 & 20.4 & 5790 & 4250 & 2.22 & 408.5 & 1520 & 3.65 & 380.7 \\
\hline 3.5 & 20.4 & 5790 & 4250 & 2.22 & 408.5 & 1520 & 3.65 & 380.7 \\
\hline 3.6 & 20.4 & 5790 & 4250 & 2.22 & 408.5 & 1520 & 3.65 & 380.7 \\
\hline 3.7 & 9.23 & 5790 & 4250 & 2.91 & 396.1 & 1520 & 4.57 & 369.5 \\
\hline 3.8 & 2.77 & 5790 & 4250 & 6.32 & 361.2 & 1520 & 11.0 & 341.7 \\
\hline 3.9 & 2.20 & 5790 & 4250 & 11.8 & 342.6 & 1520 & 21.8 & 329.8 \\
\hline 4.0 & 2.16 & 5780 & 4250 & 17.4 & 334.6 & 1520 & 31.1 & 325.9 \\
\hline
\end{tabular}

Initial reactor power $=20.4 \mathrm{MW}$

Initial primary pump velocity $=161.49 \mathrm{rad} / \mathrm{s}$

Step decrease in pump velocity to $2 / 3$ of initial value at time zero.

Reactor tripped at $3.5 \mathrm{~s}$, some time after flow has reached new steady state.

For BOC the hot spot is in the multi-channel hot stripe at the top of the lower core. 
Table 5-8. Transient Conditons at Hot Spot Following Pump Seizure (Loss of Flow Due to Loss of One Pump)

\section{Equilibrium Core - End of Cycle}

\begin{tabular}{|c|c|c|c|c|c|c|c|c|}
\hline \multirow{2}{*}{$\begin{array}{c}\text { Time } \\
\text { s }\end{array}$} & \multirow{2}{*}{$\begin{array}{c}\text { Reactor } \\
\text { Power } \\
\text { MW }\end{array}$} & \multirow{2}{*}{$\begin{array}{c}\text { Primary } \\
\text { Flow Rate } \\
\text { gpm } \\
\text { (x } 15.85 \ell / \text { s) }\end{array}$} & \multirow{2}{*}{$\begin{array}{c}\begin{array}{c}\text { Outer } \\
\text { Plenum } \\
\text { Flow }\end{array} \\
\text { gpm } \\
(\mathbf{x} 15.85 / / \text { s) }\end{array}$} & \multicolumn{2}{|c|}{$\begin{array}{c}\text { Outer Plenum } \\
\text { Hot Spot }\end{array}$} & \multirow{2}{*}{$\begin{array}{c}\text { Inner } \\
\text { Plenum } \\
\text { Flow, } \\
\text { gpm } \\
\text { (x } 15.85 \ell / \text { s) }\end{array}$} & \multicolumn{2}{|c|}{$\begin{array}{c}\text { Inner Plenum } \\
\text { Hot Spot }\end{array}$} \\
\hline & & & & CHFR & $\begin{array}{c}\text { Fuel } \\
\text { Centerline } \\
\text { Temp.,K }\end{array}$ & & CHFR & $\begin{array}{c}\text { Fuel } \\
\text { Centerline } \\
\text { Temp., K }\end{array}$ \\
\hline 0 & 20.4 & 8700 & 6380 & 3.76 & 378.6 & 2290 & 5.58 & 359.0 \\
\hline 0.2 & 20.4 & 6570 & 4960 & 3.41 & 386.8 & 1600 & 4.69 & 368.3 \\
\hline 0.4 & 20.4 & 6050 & 4540 & 3.08 & 393.3 & 1500 & 4.24 & 373.5 \\
\hline 0.6 & 20.4 & 5880 & 4370 & 2.93 & 396.0 & 1490 & 4.14 & 374.7 \\
\hline 0.8 & 20.4 & 5820 & 4300 & 2.87 & 397.1 & 1500 & 4.13 & 374.7 \\
\hline 1.0 & 20.4 & 5800 & 4270 & 2.84 & 397.6 & 1500 & 4.15 & 374.4 \\
\hline 1.2 & 20.4 & 5790 & 4260 & 2.83 & 397.8 & 1510 & 4.17 & 374.2 \\
\hline 1.4 & 20.4 & 5790 & 4250 & 2.82 & 397.9 & 1510 & 4.17 & 374.1 \\
\hline 1.6 & 20.4 & 5790 & 4250 & 2.82 & 397.9 & 1520 & 4.18 & 374.0 \\
\hline 1.8 & 20.4 & 5790 & 4250 & 2.82 & 398.0 & 1520 & 4.18 & 374.0 \\
\hline 2.0 & 20.4 & 5790 & 4250 & 2.82 & 398.0 & 1520 & 4.18 & 374.0 \\
\hline 2.2 & 20.4 & 5790 & 4250 & 2.82 & 398.0 & 1520 & 4.18 & 374.0 \\
\hline 2.4 & 20.4 & 5790 & 4250 & 2.82 & 398.0 & 1520 & 4.18 & 374.0 \\
\hline 2.6 & 20.4 & 5790 & 4250 & 2.82 & 398.0 & 1520 & 4.19 & 374.0 \\
\hline 2.8 & 20.4 & 5790 & 4250 & 2.82 & 398.0 & 1520 & 4.19 & 374.0 \\
\hline 3.0 & 20.4 & 5790 & 4250 & 2.82 & 398.0 & 1520 & 4.19 & 374.0 \\
\hline 3.2 & 20.4 & 5790 & 4250 & 2.82 & 398.0 & 1520 & 4.19 & 374.0 \\
\hline 3.4 & 20.4 & 5790 & 4250 & 2.82 & 398.0 & 1520 & 4.19 & 373.9 \\
\hline 3.5 & 20.4 & 5790 & 4250 & 2.82 & 398.0 & 1520 & 4.19 & 373.9 \\
\hline 3.6 & 20.4 & 5790 & 4250 & 2.82 & 398.0 & 1520 & 4.19 & 373.9 \\
\hline 3.7 & 17.4 & 5790 & 4250 & 2.97 & 395.4 & 1520 & 4.40 & 371.6 \\
\hline 3.8 & 7.70 & 5790 & 4250 & 4.15 & 378.5 & 1520 & 6.41 & 357.2 \\
\hline 3.9 & 2.66 & 5790 & 4250 & 8.43 & 353.6 & 1520 & 14.1 & 338.2 \\
\hline 4.0 & 1.86 & 5780 & 4250 & 15.2 & 339.6 & 1520 & 26.3 & 328.7 \\
\hline
\end{tabular}

Initial reactor power $=20.4 \mathrm{MW}$

Initial primary pump velocity $=161.49 \mathrm{rad} / \mathrm{s}$

Step decrease in pump velocity to $2 / 3$ of initial value at time zero.

Reactor tripped at $3.5 \mathrm{~s}$, some time after flow has reached new steady state.

For EOC the hot spot is in the single-channel hot stripe at the bottom of the upper core. 
Table 5-9. Transient Conditions at Hot Spot Following Inner Plenum Flow Control Valve Throttling

\begin{tabular}{|c|c|c|c|c|c|c|c|c|}
\hline \multirow[b]{2}{*}{ Time } & \multirow{2}{*}{$\begin{array}{c}\text { Primary } \\
\text { Flow Rate } \\
\text { gpm } \\
\left(\begin{array}{ccc}1 & 15.85 \ell / s)\end{array}\right.\end{array}$} & \multirow{2}{*}{ 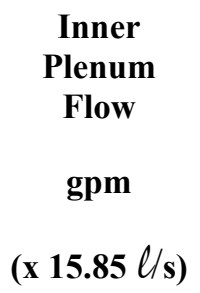 } & \multicolumn{3}{|c|}{ BOC - Equilibrium Core } & \multicolumn{3}{|c|}{ EOC - Equilibrium Core } \\
\hline & & & $\begin{array}{c}\begin{array}{c}\text { Reactor } \\
\text { Power }\end{array} \\
\text { MW }\end{array}$ & CHFR & $\begin{array}{c}\text { Fuel } \\
\text { Centerline } \\
\text { Temp., K }\end{array}$ & $\begin{array}{c}\begin{array}{c}\text { Reactor } \\
\text { Power }\end{array} \\
\text { MW }\end{array}$ & CHFR & $\begin{array}{c}\text { Fuel } \\
\text { Centerline } \\
\text { Temp., K }\end{array}$ \\
\hline 0.0 & 8700 & 2290 & 20.4 & 4.87 & 364.1 & 20.4 & 5.58 & 359.0 \\
\hline 1.0 & 8700 & 2290 & 20.4 & 4.87 & 364.1 & 20.4 & 5.58 & 359.0 \\
\hline 2.0 & 8700 & 2280 & 20.4 & 4.85 & 364.3 & 20.4 & 5.56 & 359.2 \\
\hline 3.0 & 8690 & 2250 & 20.4 & 4.82 & 364.6 & 20.4 & 5.52 & 359.5 \\
\hline 4.0 & 8680 & 2210 & 20.4 & 4.76 & 365.3 & 20.4 & 5.45 & 360.1 \\
\hline 5.0 & 8670 & 2140 & 20.4 & 4.66 & 366.4 & 20.4 & 5.34 & 361.0 \\
\hline 6.0 & 8650 & 2030 & 20.4 & 4.49 & 368.3 & 20.4 & 5.15 & 362.7 \\
\hline 7.0 & 8610 & 1880 & 20.4 & 4.25 & 371.3 & 20.4 & 4.88 & 365.4 \\
\hline 8.0 & 8560 & 1650 & 20.4 & 3.90 & 376.5 & 20.4 & 4.47 & 370.1 \\
\hline 9.0 & 8490 & 1350 & 20.4 & 3.43 & 385.4 & 20.4 & 3.94 & 378.1 \\
\hline 9.4 & 8470 & 1230 & 20.4 & 3.22 & 390.3 & 20.4 & 3.70 & 382.5 \\
\hline 9.5 & 8460 & 1200 & 20.4 & 3.16 & 391.6 & 20.4 & 3.64 & 383.6 \\
\hline 9.6 & 8450 & 1160 & 20.4 & 3.11 & 392.9 & 20.4 & 3.58 & 384.9 \\
\hline 9.7 & 8450 & 1130 & 20.4 & 3.05 & 394.2 & 20.4 & 3.52 & 386.2 \\
\hline 9.8 & 8440 & 1100 & 20.4 & 2.99 & 395.6 & 20.4 & 3.46 & 387.7 \\
\hline 9.9 & 8430 & 1070 & 20.4 & 2.93 & 396.9 & 20.4 & 3.39 & 389.2 \\
\hline 10.0 & 8420 & 1030 & 20.4 & 2.86 & 398.2 & 20.4 & 3.32 & 390.7 \\
\hline 10.1 & 8410 & 995 & 7.78 & 3.67 & 385.5 & 16.9 & 3.45 & 389.1 \\
\hline 10.2 & 8400 & 959 & 2.65 & 7.59 & 355.9 & 6.82 & 4.86 & 372.8 \\
\hline 10.3 & 8400 & 922 & 2.20 & 13.6 & 340.6 & 2.52 & 9.41 & 351.7 \\
\hline 10.4 & 8390 & 885 & 2.16 & 19.4 & 333.8 & 1.86 & 16.2 & 339.8 \\
\hline 10.5 & 8380 & 846 & 2.13 & 23.9 & 330.9 & 1.83 & 22.3 & 333.7 \\
\hline
\end{tabular}

Initial reactor power $=20.4 \mathrm{MW}$

Flow control valve throttling started at time zero.

Reactor tripped on low inner plenum flow (1200 gpm).

Flow scram delay $=0.4 \mathrm{~s}$

For BOC the hot spot is in the multi-channel hot stripe at the top of the lower core.

For EOC the hot spot is in the single-channel hot stripe at the bottom of the upper core. 
Table 5-10. Transient Conditions of Coolant Following Loss of Shutdown Cooling (Loss of Both Shutdown Coolant Pumps)

\begin{tabular}{|c|c|c|c|c|c|c|c|}
\hline \multirow{2}{*}{$\begin{array}{c}\text { Time } \\
\text { s }\end{array}$} & \multirow{2}{*}{$\begin{array}{c}\text { Reactor } \\
\text { Power } \\
\text { MW }\end{array}$} & \multirow{2}{*}{$\begin{array}{c}\text { Primary } \\
\text { Flow Rate } \\
\text { gpm } \\
(x 15.85 \ell / / s)\end{array}$} & \multirow{2}{*}{$\begin{array}{c}\begin{array}{c}\text { Inner Plenum } \\
\text { Flow } \\
\text { gpm }\end{array} \\
\left(\begin{array}{cc}\mathbf{x} & 15.85 \ell / \mathrm{s})\end{array}\right.\end{array}$} & \multirow{2}{*}{$\begin{array}{c}\begin{array}{c}\text { Outer } \\
\text { Plenum Flow }\end{array} \\
\text { gpm } \\
\left(\begin{array}{cc}\text { x } 15.85 \ell / s)\end{array}\right.\end{array}$} & \multicolumn{3}{|c|}{ Coolant Temperature, $\mathrm{K}$} \\
\hline & & & & & $\begin{array}{c}\text { Reactor } \\
\text { Outlet }\end{array}$ & $\begin{array}{c}\text { Inner } \\
\text { Plenum }\end{array}$ & $\begin{array}{l}\text { Outer } \\
\text { Plenum }\end{array}$ \\
\hline 0.0 & 20.40 & 8699.45 & 2288.20 & 6382.21 & 316.56 & 316.56 & 324.66 \\
\hline 20.0 & 1.04 & 133.08 & 3.27 & 127.79 & 316.57 & 316.57 & 324.57 \\
\hline 40.0 & 0.86 & -7.72 & -5.41 & -2.99 & 326.57 & 316.57 & 324.56 \\
\hline 60.0 & 0.76 & 10.76 & -19.40 & 29.91 & 353.19 & 327.68 & 324.56 \\
\hline 80.0 & 0.70 & 11.36 & 4.08 & 7.15 & 340.43 & 329.22 & 324.56 \\
\hline 100.0 & 0.66 & 43.44 & 28.88 & 14.43 & 337.67 & 333.49 & 324.55 \\
\hline 120.0 & 0.63 & 63.11 & 10.38 & 52.53 & 322.61 & 331.43 & 324.53 \\
\hline 140.0 & 0.61 & 67.10 & 11.21 & 55.66 & 320.39 & 322.89 & 324.51 \\
\hline 160.0 & 0.59 & 57.06 & 11.38 & 45.45 & 318.40 & 319.61 & 324.49 \\
\hline 180.0 & 0.57 & 43.54 & 8.11 & 35.23 & 317.89 & 318.22 & 324.47 \\
\hline 200.0 & 0.56 & 39.39 & 8.31 & 30.91 & 317.56 & 317.60 & 324.45 \\
\hline 220.0 & 0.55 & 41.74 & 8.07 & 33.50 & 317.39 & 317.20 & 324.44 \\
\hline 240.0 & 0.53 & 41.51 & 8.44 & 32.90 & 317.25 & 316.95 & 324.42 \\
\hline 260.0 & 0.53 & 37.73 & 7.56 & 30.00 & 317.16 & 316.80 & 324.41 \\
\hline 280.0 & 0.52 & 35.65 & 7.29 & 28.21 & 317.09 & 316.71 & 324.39 \\
\hline 300.0 & 0.51 & 36.20 & 7.26 & 28.78 & 317.03 & 316.65 & 324.38 \\
\hline 320.0 & 0.50 & 36.38 & 7.33 & 28.90 & 316.98 & 316.61 & 324.37 \\
\hline 340.0 & 0.50 & 34.91 & 7.03 & 27.72 & 316.94 & 316.58 & 324.35 \\
\hline 360.0 & 0.49 & 33.47 & 6.77 & 26.55 & 316.90 & 316.56 & 324.34 \\
\hline 380.0 & 0.49 & 33.19 & 6.68 & 26.35 & 316.87 & 316.54 & 324.33 \\
\hline 400.0 & 0.48 & 33.20 & 6.67 & 26.38 & 316.84 & 316.52 & 324.32 \\
\hline 420.0 & 0.48 & 32.59 & 6.55 & 25.89 & 316.81 & 316.51 & 324.32 \\
\hline 440.0 & 0.47 & 31.67 & 6.38 & 25.14 & 316.78 & 316.50 & 324.31 \\
\hline 460.0 & 0.47 & 31.13 & 6.26 & 24.72 & 316.76 & 316.49 & 324.30 \\
\hline 480.0 & 0.46 & 30.92 & 6.21 & 24.56 & 316.74 & 316.48 & 324.30 \\
\hline 500.0 & 0.46 & 30.57 & 6.14 & 24.29 & 316.72 & 316.47 & 324.30 \\
\hline
\end{tabular}


Table 5-11. Transient Conditions of Fuel Plate Following

Loss of Shutdown Cooling

(Loss of Both Shutdown Coolant Pumps)

\begin{tabular}{|r|c|c|c|c|c|c|c|c|}
\hline \multirow{2}{*}{ Time } & \multicolumn{4}{|c|}{$\begin{array}{c}\text { Inner Core } \\
\text { Hot Stripe in Hot Element }\end{array}$} & \multicolumn{3}{c|}{$\begin{array}{c}\text { Outer Core } \\
\text { Hot Stripe in Hot Element }\end{array}$} \\
\cline { 2 - 9 } s & $\begin{array}{c}\text { Lower Core } \\
\text { Temperature, K }\end{array}$ & $\begin{array}{c}\text { Upper Core } \\
\text { Temperature, K }\end{array}$ & $\begin{array}{c}\text { Lower Core } \\
\text { Temperature, K }\end{array}$ & $\begin{array}{c}\text { Upper Core } \\
\text { Temperature, K }\end{array}$ \\
\cline { 2 - 9 } & Plate & Coolant & Plate & Coolant & Plate & Coolant & Plate & Coolant \\
\hline 0.0 & 364.1 & 323.1 & 346.8 & 325.5 & 391.2 & 328.1 & 364.3 & 331.4 \\
\hline 20.0 & 368.3 & 348.4 & 359.0 & 344.5 & 363.1 & 336.9 & 357.2 & 339.2 \\
\hline 40.0 & 366.2 & 346.2 & 382.5 & 373.1 & 381.2 & 363.8 & 380.2 & 368.4 \\
\hline 60.0 & 374.1 & 358.4 & 366.7 & 355.3 & 372.7 & 355.7 & 382.2 & 371.7 \\
\hline 80.0 & 366.3 & 349.4 & 364.4 & 353.3 & 372.2 & 354.8 & 370.1 & 358.2 \\
\hline 100.0 & 371.7 & 356.5 & 371.2 & 361.0 & 374.2 & 357.3 & 383.3 & 373.4 \\
\hline 120.0 & 364.1 & 348.2 & 371.9 & 361.8 & 371.0 & 354.2 & 374.9 & 363.9 \\
\hline 140.0 & 372.0 & 357.1 & 379.7 & 370.4 & 370.2 & 353.4 & 379.7 & 369.5 \\
\hline 160.0 & 359.0 & 342.5 & 369.7 & 359.4 & 365.6 & 348.3 & 375.3 & 364.7 \\
\hline 180.0 & 365.8 & 350.8 & 372.2 & 362.8 & 365.4 & 348.4 & 374.4 & 364.0 \\
\hline 200.0 & 361.5 & 346.0 & 375.3 & 366.3 & 367.2 & 350.8 & 377.6 & 367.6 \\
\hline 220.0 & 363.6 & 348.6 & 375.1 & 366.1 & 365.3 & 348.7 & 378.6 & 368.8 \\
\hline 240.0 & 360.9 & 345.6 & 374.6 & 365.5 & 364.5 & 348.0 & 376.7 & 366.9 \\
\hline 260.0 & 362.1 & 347.2 & 373.7 & 364.7 & 364.7 & 348.4 & 376.3 & 366.5 \\
\hline 280.0 & 362.3 & 347.5 & 374.8 & 366.0 & 365.5 & 349.5 & 377.5 & 368.0 \\
\hline 300.0 & 362.4 & 347.8 & 375.7 & 367.1 & 365.1 & 349.1 & 378.4 & 368.9 \\
\hline 320.0 & 361.7 & 347.1 & 375.5 & 366.9 & 364.5 & 348.6 & 378.0 & 368.5 \\
\hline 340.0 & 361.8 & 347.4 & 375.2 & 366.6 & 364.6 & 348.8 & 377.6 & 368.2 \\
\hline 360.0 & 362.2 & 347.9 & 375.6 & 367.1 & 365.1 & 349.4 & 378.0 & 368.8 \\
\hline 380.0 & 362.3 & 348.1 & 376.2 & 367.8 & 365.0 & 349.5 & 378.7 & 369.5 \\
\hline 400.0 & 362.0 & 347.9 & 376.4 & 368.1 & 364.7 & 349.3 & 378.8 & 369.7 \\
\hline 420.0 & 362.0 & 347.9 & 376.4 & 368.1 & 364.7 & 349.3 & 378.7 & 369.6 \\
\hline 440.0 & 362.1 & 348.2 & 376.5 & 368.3 & 364.8 & 349.6 & 378.8 & 369.8 \\
\hline 460.0 & 362.3 & 348.4 & 376.9 & 368.7 & 364.9 & 349.8 & 379.2 & 370.3 \\
\hline 480.0 & 362.2 & 348.4 & 377.2 & 369.1 & 364.9 & 349.8 & 379.5 & 370.6 \\
\hline 500.0 & 362.2 & 348.4 & 377.3 & 369.3 & 364.8 & 349.8 & 379.6 & 370.8 \\
\hline
\end{tabular}

Notes:

Temperatures are for the top node in the lower and upper core.

Plate temperature is the centerline temperature. 
Table 5-12. Relative Assembly Power Due to Misloading of Fresh Fuel

\begin{tabular}{|c|c|c|c|c|}
\hline \multirow{2}{*}{$\begin{array}{c}\text { Core Location of Fuel } \\
\text { Assembly }\end{array}$} & \multicolumn{2}{|c|}{$\begin{array}{c}\text { Assembly Power in the } \\
\text { Core Location }\end{array}$} & $\begin{array}{c}\text { Maximum Assembly Power } \\
\text { With Misloaded Fresh Fuel }\end{array}$ \\
\cline { 2 - 5 } & $\begin{array}{c}\text { With } \\
\text { Irradiated } \\
\text { Fuel }\end{array}$ & $\begin{array}{c}\text { With } \\
\text { Fresh Fuel }\end{array}$ & $\begin{array}{c}\text { Inner } \\
\text { Core }\end{array}$ & $\begin{array}{c}\text { Outer } \\
\text { Core }\end{array}$ \\
\hline F-1 & 1.11 & 1.17 & $1.07(\mathrm{~F}-3)$ & $1.17(\mathrm{~F}-1)$ \\
\hline H-1 & 1.15 & 1.24 & $1.07(\mathrm{~F}-3)$ & $1.24(\mathrm{H}-1)$ \\
\hline C-2 & 1.08 & 1.23 & $1.06(\mathrm{~F}-3)$ & $1.23(\mathrm{C}-2)$ \\
\hline E-2 & 1.13 & 1.51 & $1.09(\mathrm{~F}-3)$ & $1.51(\mathrm{E}-2)$ \\
\hline I-2 & 1.08 & 1.4 & $1.09(\mathrm{~F}-3)$ & $1.40(\mathrm{I}-2)$ \\
\hline K-2 & 0.98 & 1.12 & $1.07(\mathrm{H}-3)$ & $1.21(\mathrm{H}-1)$ \\
\hline B-3 & 0.99 & 1.12 & $1.06(\mathrm{~F}-3)$ & $1.16(\mathrm{H}-1)$ \\
\hline F-3 & 1.07 & 1.68 & $1.68(\mathrm{~F}-3)$ & $1.22(\mathrm{E}-2)$ \\
\hline H-3 & 1.05 & 1.63 & $1.63(\mathrm{H}-3)$ & $1.22(\mathrm{H}-1)$ \\
\hline L-3 & 0.94 & 1.07 & $1.06(\mathrm{~F}-3)$ & $1.16(\mathrm{H}-1)$ \\
\hline C-4 & 0.93 & 1.35 & $1.07(\mathrm{~F}-3)$ & $1.35(\mathrm{C}-4)$ \\
\hline E-4 & 1.0 & 1.59 & $1.59(\mathrm{E}-4)$ & $1.18(\mathrm{E}-2)$ \\
\hline I-4 & 0.99 & 1.53 & $1.53(\mathrm{I}-4)$ & $1.17(\mathrm{H}-1)$ \\
\hline K-4 & 0.9 & 1.25 & $1.07(\mathrm{H}-3)$ & $1.25(\mathrm{~K}-4)$ \\
\hline B-5 & 0.9 & 1.1 & $1.06(\mathrm{~F}-3)$ & $1.18(\mathrm{H}-1)$ \\
\hline F-5 & 0.89 & 1.57 & $1.57(\mathrm{~F}-5)$ & $1.13(\mathrm{E}-2)$ \\
\hline H-5 & 0.89 & 1.6 & $1.60(\mathrm{H}-5)$ & $1.10(\mathrm{H}-1)$ \\
\hline L-5 & 0.91 & 1.1 & $1.06(\mathrm{~F}-3)$ & $1.14(\mathrm{H}-1)$ \\
\hline C-6 & 0.92 & 1.09 & $1.07(\mathrm{~F}-3)$ & $1.16(\mathrm{H}-1)$ \\
\hline E-6 & 0.95 & 1.4 & $1.06(\mathrm{~F}-3)$ & $1.40(\mathrm{E}-6)$ \\
\hline I-6 & 1.01 & 1.48 & $1.05(\mathrm{~F}-3)$ & $1.48(\mathrm{I}-6)$ \\
\hline K-6 & 1.02 & 1.26 & $1.06(\mathrm{~F}-3)$ & $1.26(\mathrm{~K}-6)$ \\
\hline D-7 & 1.04 & 1.09 & $1.06(\mathrm{~F}-3)$ & $1.18(\mathrm{H}-1)$ \\
\hline F-7 & 1.01 & 1.36 & $1.03(\mathrm{~F}-3)$ & $1.36(\mathrm{~F}-7)$ \\
\hline H-7 & 1.03 & 1.41 & $1.04(\mathrm{~F}-3)$ & $1.41(\mathrm{H}-7)$ \\
\hline J-7 & 1.08 & 1.15 & $1.06(\mathrm{~F}-3)$ & $1.15(\mathrm{~J}-7)$ \\
\hline
\end{tabular}

Notes:

Relative assembly power is normalized to the core-wide average assembly power. Assembly power with irradiated fuel in the specified core location and fresh fuel in location M-4 is for an equilibrium core at the beginning of cycle.

Assembly power with fresh fuel in the specified core location and irradiated fuel in location M-4 is for an equilibrium startup core.

Maximum assembly power refers to the power and location (in parenthesis) of the hottest assembly in the inner and outer core, as a result of the misloaded fresh fuel. 
Table 5-13. Minimum Critical Heat Flux Ratio for the Misloaded Fresh Fuel

\begin{tabular}{|c|c|c|c|c|}
\hline & \multicolumn{2}{|c|}{ Inner Core } & \multicolumn{2}{|c|}{ Outer Core } \\
\hline & EQ-BOC & Fresh Fuel & EQ-BOC & Fresh Fuel \\
\hline $\begin{array}{c}\text { Relative } \\
\text { Radial } \\
\text { Power }\end{array}$ & 1.07 & 1.68 & 1.16 & 1.51 \\
\hline $\begin{array}{l}\text { Peak Heat Flux } \\
\qquad\left(\mathrm{W} / \mathrm{m}^{2}\right)\end{array}$ & $1.395 \times 10^{6}$ & $2.189 \times 10^{6}$ & $1.715 \times 10^{6}$ & $2.232 \times 10^{6}$ \\
\hline $\begin{array}{c}\text { Coolant } \\
\text { Temperature } \\
\text { (K) }\end{array}$ & 323.11 & 326.85 & 328.09 & 331.57 \\
\hline $\begin{array}{c}\text { Critical Heat } \\
\text { Flux } \\
\left(\mathbf{W} / \mathbf{m}^{2}\right)\end{array}$ & $6.793 \times 10^{6}$ & $6.441 \times 10^{6}$ & $5.116 \times 10^{6}$ & $4.857 \times 10^{6}$ \\
\hline $\begin{array}{l}\text { Minimum } \\
\text { Critical Heat } \\
\text { Flux Ratio }\end{array}$ & 4.87 & 2.94 & 2.98 & 2.18 \\
\hline
\end{tabular}

Notes:

'EQ-BOC' refers to the equilibrium core beginning of cycle conditions.

'Fresh Fuel' refers to misloaded fuel in startup core.

Core inlet temperature is $316.56 \mathrm{~K}$. 


\section{REFERENCES}

1. "FSAR on the National Bureau of Standards Reactor," NBSR 9, The National Bureau of Standards, U. S. Department of Commerce, 1966.

2. “Addendum 1, Final Safety Analysis Report," NBS Research Reactor Radiation Division, November, 1980.

3. “DRAFT Final Safety Analysis Report on the NBS Reactor,” NBSR 9 Revision 1994.

4. "DRAFT Final Safety Analysis Report on the NBS Reactor," NBSR 9 Revision 1998.

5. J. F. Breismeister (Ed.), "MCNP - A General Monte Carlo N-Particle Transport Code, Version 4b," LA-12625, Los Alamos National Laboratory, March 1997.

6. H. R. Trellue, "Development of MONTEBURNS: A Code that Links MCNP and ORIGEN in an Automated Fashion for Burnup Calculations," Los Alamos National Laboratory, LA-13514-T, December 1998.

7. “RELAP5/MOD3 Code Manual,” NUREG/CR-5535, INEL-95/0174, August 1995.

8. R. Williams, NIST, private communication.

9. L. Bernath, "A Theory of Local Boiling Burnout and Its Application to Existing Data," Chem. Eng. Prog. Symp. Series, Vol. 56, No. 30, 1960.

10. J. M. Hendrie, "FSAR on the Brookhaven High Flux Beam Research Reactor," Section 4.7.7, BNL 7661, Brookhaven National Laboratory, 1964.

11. P. Tichler, "Addendum to the HFBR FSAR for 60 MW Operation," BNL Reactor Division Report, Brookhaven National Laboratory, 1982.

12. L.S. Tong and J. Weisman, Thermal Analysis of Pressurized Water Reactors, p. 239, ANS Publication, 1970.

13. D.B. Owen, "Factors for One-Sided Tolerance Limits and for Variable Sampling Plans," SCR-607, March 1963.

14. J.M. Hammersley and D.C. Handscomb, Monte Carlo Methods, p. 39, Methuen \& Co. Ltd., 1967. 


\section{APPENDIX A}

\section{COMPONENTS OF THE THERMAL-HYDRAULIC MODEL OF THE VESSEL}

\section{Components V65 and V66 - Setting the Boundary Conditions}

These two time-dependent volumes are used to simulate the pressure boundary condition of the primary system. The NBSR is non-pressurized except for a small pressure of about $10.2 \mathrm{~cm}$ (4 in) of water maintained by a helium cover gas blanket. The normal water level is maintained at about $2.97 \mathrm{~m}$ (117 in) above the top of the core by a $7.62 \mathrm{~cm}$ (3 in) overflow pipe. In the RELAP5 model these two volumes are assumed to contain heavy water at a pressure of one atmosphere and at a temperature equal to the steady state temperature in the upper plenum. The water level is maintained constant by connecting these two volumes to the upper plenum and the inner emergency cooling tank via two separate junctions, J77 and J76 respectively.

\section{Component V75 - Inner Emergency Cooling Tank}

The inner emergency cooling tank is represented by a pipe component. Normally the tank is filled and submerged under water. However for conservatism, the reactor water level is set below the top of the tank. Thus the height of the tank is adjusted to coincide with the set water level.

\section{Component V64 - Upper Plenum}

The upper plenum occupies the region above the elevation of the distribution pan and below the reactor water level. The height of this pipe component is again adjusted to the set water level. It is connected to the reflector region via junction $\mathrm{J} 63$.

Junction J74 - Inner Emergency Cooling Tank Orifice

This junction is modeled as an orifice through which water from the inner emergency tank empties into the distribution pan. The size of the orifice is determined from a side calculation described in Section 4.2.3.4.

\section{Component V72 - Distribution Pan}

The distribution pan volume is modeled to receive flow normally from the fuel elements and redirect the flow to the upper plenum volume via junction J73. The bottom of the pan is connected to all the fuel elements via two multiple junction components, MJ70 and MJ71.

\section{$\underline{\text { Components MJ70 and MJ71 - Upper Exit of Fuel Elements }}$}

The upper exits of the fuel elements in the inner and outer group are represented by the multiple junction components MJ70 and MJ71 respectively. 


\section{Components 101 through 109 - Inner Hot Stripe}

These components represent the hottest coolant channel in the inner group fuel elements. The single channel hot stripe characterizes the local peaking of heat generation in the lateral direction, i.e. across the width of a fuel plate. A more detailed description of the various channel types in the core region is given in Section 4.2.3.8. A schematic of the single channel hot stripe is shown in Figure 4-3.

\section{Components 201 through 209 and 212 Through 218 - Inner Hot Element}

The hot element is the fuel element that contains the hot stripe. There are two parallel coolant channels in the lower core and upper core. The parallel channels share the same non-plated regions in the fuel element. One of the parallel channels represents the hot stripe channel and the other channel represents the rest of coolant channels in the hot element. This arrangement of parallel flow channels is to simulate the effect of a common unfueled center section in a fuel element. A schematic of the hot element is also shown in Figure 4-3.

Components 301 through 309 - Average Inner Fuel Elements

These components represent the rest of coolant channels in the inner group fuel elements that are not part of the inner hot stripe and the inner hot element.

Components 401 through 409 - Outer Single-channel Hot Stripe

These components represent the coolant channel of the hot stripe in the outer group fuel elements. A schematic of the hot stripe channel is shown in Figure 4-13.

Components 501 through 509 and 512 Through 518 - Outer Hot Element

The hot element is the fuel element that contains the hot stripe and it also has the highest heat generation rate in the group. The set up is identical with the hot element for the inner group of fuel elements.

Components 601 through 609,701 through 709, 801 through 809, 901 through 909 - Average Outer Fuel Elements

The 24 fuel elements in the outer group are ranked by their heat generation rate. In decreasing order of their power ranking the elements are separated into four groups of six elements each. Components 601 through 609 represent the first group minus the hot strip and the hot element. This channel type is identical with the average fuel element for the inner group. The next three groups of fuel elements in the outer group are represented by the 700, 800 and 900 series of components respectively. 


\section{Component V60 - Hold Up Pan}

This volume surrounds the lower core of the reactor external to the fuel elements. It is connected to the reflector volume through junction $\mathrm{J} 61$.

\section{Component V62 - Reflector}

This volume represents the coolant outside the fuel elements and between the elevations of the top of the hold up pan and the bottom of the upper plenum. It is connected to the lower reflector through junction J67.

\section{Component V68 - Lower Reflector}

This volume represents the region of the reflector that is outside the hold up pan. It is connected to the lower head of the vessel through junction J56.

\section{Component V57 - Lower Head of Reactor Vessel}

This volume occupies the region outside the inlet funnel and is below the bottom of the lower grid plate. The coolant leaves the reactor via the outlet nozzle represented by junction J58. The two outlet nozzles are modeled as one single junction.

\section{Components MJ54 and MJ55 - Inlets to Fuel Elements and Core Bypass}

The inlets to the fuel elements in the inner and outer group are represented by the multiple junction components MJ54 and MJ55 respectively. One of the branches of the multiple junction components is used to represent the core bypass flow that ends up in the holdup pan.

\section{Component V52 - Inner Plenum}

This volume receives flow from the primary coolant pipe via the inlet nozzle J50 and supplies flow to the central six fuel elements.

\section{Component V53 - Outer Plenum}

This volume receives flow from the primary coolant pipe via the inlet nozzle $\mathrm{J} 51$ and supplies flow to the outer 24 fuel elements. 


\section{APPENDIX B \\ COMPONENTS OF THE PRIMARY AND SECONDARY COOLING LOOP THERMAL-HYDRAULIC MODELS}

\section{Primary Loop Components}

Component 10 - Primary Piping

This piping component represents the primary loop between the reactor outlet and the primary pump.

Component 20 - Primary Pump

This pump component represents the three primary pumps combined.

Component 25 - Primary Piping

This pipe component runs between the primary pump and the primary heat exchanger.

Component 30 - Primary Heat Exchanger

The two primary heat exchangers are combined into one. A flat plate heat structure separates the primary and secondary flow. This component represents the primary side of the heat exchangers.

Component 40 - Primary Piping

This pipe component goes from the outlet of the primary heat exchanger to the inlet to the inner plenum.

Component 41 - Primary Piping

This pipe component branches off Component 40 and runs to the inlet to the outer plenum of the vessel.

\section{Secondary Cooling Loop Components}

Component 16 - Source of Secondary Coolant

This time-dependent volume defines the thermodynamic state of the secondary cooling water.

Component 17 - Controls Flow of Secondary Coolant

This is a time-dependent junction component and it defines the flow rate of the secondary coolant as a function of time. 


\section{Component 15 - Secondary Side of Primary Heat Exchanger}

The rectangular coolant channels on the secondary side of the primary heat exchangers are represented by this pipe component.

Component $19-$ Sink for the Secondary Cooling Water

Once out of the primary heat exchangers the secondary cooling water flows to a sink via junction J18. This component represents the sink. 


\section{APPENDIX C \\ CONTROL VARIABLES AND REACTOR TRIPS IN THE THERMAL-HYDRAULIC MODEL}

\section{Control Variables}

1 Initial shim arm position in degrees from full in (the zero position).

10-800 These are all related to the shim arm motion, scram and withdrawal. The reactivity of shim arms is determined from their position.

$600 \quad$ Reactivity insertion of the shim arms in $\$$.

$800 \quad$ Initial bias to zero out reactivity.

$900 \quad$ Reactivity ramp insertion.

901 Total energy release above $20 \mathrm{MW}$, i.e. reactor power integrated over time.

907 Total primary flow (gpm) in the reactor outlet pipe.

$908 \quad$ Flow to the inner plenum (gpm).

$909 \quad$ Flow to the outer plenum (gpm).

923

924

933

CHF (Bernath correlation) for the hot node in the inner group of fuel elements. CHFR (CHF/local heat flux) for the hot node in the inner group.

934 CHFR (CHF/local heat flux) for the hot node in the outer group.

\section{Reactor Trips}

$501 \quad$ Pump trip.

$502 \quad$ Isolating core bypass flow paths.

$510 \quad$ Trip on low primary flow.

$511 \quad$ Trip on low inner plenum flow.

$512 \quad$ Trip on low outer plenum flow.

$521-523$ Conditions to be satisfied to initiate a reactor scram, e.g. a time delay, highpower,low flow, etc. Open flow control valve (for both inner and outer plenum). Close inner plenum flow control valve.

599 Trip to start inserting shim arms in a scram (i.e. after the time delay has expired). 601 Scram initiation. 


\section{APPENDIX D \\ PROBABILISTIC HOT CHANNEL ANALYSIS IN SUPPORT \\ OF THE NIST RESEARCH REACTOR}

\section{D1. INTRODUCTION}

\section{D1.1 Purpose}

The purpose of this analysis is to provide a probabilistic characterization of the hot channel variables and to determine their limiting values with high confidence for safe power operation of the NBSR. The hot channel variables analyzed in this study include: 1) critical heat flux ratio (CHFR), 2) coolant temperature rise, 3) fuel plate temperature drop and 4) fuel plate local heat flux. The computational model for the analysis employed a full statistical treatment for the hot channel factors. The statistical distributions for the hot channel factors were constructed by performing a Monte Carlo simulation in which each factor was randomly assigned a value according to its assumed distribution. The method used to combine these various hot channel factors to arrive at the frequency distribution of the hot channel variables such as: CHFR, coolant temperature rise and other parameters of interest are described and the analysis results are provided in terms of cumulative distribution functions (CDFs).

\section{D1.2 Core Thermal Design Bases}

The core thermal design is based on the requirement that no damage occurs to the fuel during normal operation. The term fuel damage refers to overheating of a fuel plate leading to leakage of fission products.

The critical heat flux (CHF) analysis presented here establishes a specific criterion for insuring that no fuel damage occurs during normal operation of the NBSR. The criterion sets a limit on the critical heat flux ratio to insure a large margin between normal operation and the point where film boiling occurs. Under normal operating conditions, the fuel plates are cooled by forced convection. If the critical heat flux were to be reached, heat transfer coefficients become small and fuel temperatures rise rapidly to the melting point. However, since the uncertainty in the correlation that predicts the CHF is statistical in nature and has an inherent statistical distribution, it is not possible to state categorically that the CHF will never be reached under normal operation. For practical purposes, it is possible to establish a limiting CHFR (ratio of critical heat flux to local heat flux at the surface of a fuel plate) such that the probability of fuel overheating is acceptably small. This limiting CHFR is set at a value that assures that the likelihood of the hottest region of the core reaching the $\mathrm{CHF}$ is exceedingly small. This requirement is quantified by establishing a limiting CHFR value such that the probability of not reaching CHF in the hottest region of the core is high, e.g., $95 \%$ or $99.9 \%$. To determine whether the criterion is satisfied for the operating conditions at the NBSR, it is necessary to compute the probability distributions of the CHFR as well as other channel variables of interest by statistically combining all the hot channel factors that affect these parameters. The hot channel factors are for channel gap, power density and fuel loading, etc. In the following sections, the treatment for the uncertainty 
and variability in the hot channel factors is first described, followed by a description of the probabilistic method to combine the various factors to arrive at the CDFs for the hot channel variables.

\section{D2. Statistical Treatment of Hot Channel Factors}

Uncertainties in operating conditions, fuel element fabrication, and modeling will affect the accuracy of the computation of core temperatures and critical heat flux ratios. In the original NBSR safety analysis [1], these uncertainties were taken into account by assuming that they occur simultaneously in the most unfavorable way at the core location of maximum temperature or heat flux. In the present analysis, account is taken of the low probability associated with this worst case approach and instead, each factor is considered to be a random variable with a defined probability distribution. A Monte-Carlo method is then used to combine these individual distributions to arrive at the probability distributions of interest, i.e., for temperature, critical heat flux ratio, etc.

The statistical distribution of an individual random variable is characterized mathematically by its probability density function (pdf). Many of the variables of interest have mean or nominal values and maximum deviations from the mean. Generally, there is not sufficient information available to precisely define the shape of the pdf within these limits. It is assumed that all the hot channel factors will have normal distribution.

To simplify the manipulation of these individual variables in the analysis, they are converted to dimensionless form and normalized so that their mean value is one. Generally, this is done by dividing the random value of the variable by its mean or nominal value. The only exception to this is in the case of the CHF correlation: because of the way the statistical data is presented, the normalization is inverted; that is, the nominal value is divided by the random value.

All the hot channel factors of interest, and their pdf characteristics are summarized in Table D-1. The uncertainty limits in Table D-1 represent one standard deviation $(1 \sigma)$. These values were either derived from the available information in the NBSR safety analysis or obtained through communication with the NIST project manager. The uncertainties associated with the Bernath correlation for the prediction of CHF will be described in detail in the next section. Not included in the statistical analysis is the uncertainty in the core inlet water temperature and the effect of coolant velocity variation within a channel. The uncertainty in inlet temperature is small, less than $1{ }^{\circ} \mathrm{C}$. To simplify the analysis the core inlet temperature is increased by $1^{\circ} \mathrm{C}$ in the computation of the pdfs of temperature, $\mathrm{CHF}$, etc. The coolant velocity factor reflects the reduction of coolant velocity near the narrow sides of the channel and is not a random variable. This effect has been incorporated in the analysis by assuming that the coolant velocity is 0.94 of the value that would have been calculated using the nominal primary flow rate.

\section{D3. Uncertainties Associated with Critical Heat Flux Correlation}

The primary reason for choosing the Bernath correlation [9] for the calculation of CHF is its applicability to plate-type fuel assemblies. The Bernath correlation had been used in the thermal design of the HFBR [10], a research reactor that is similar to the NBSR in fuel design. By using 
the same CHF correlation the previously determined uncertainties for the Bernath correlation can be applied directly to the current CHF analysis. A secondary reason for adopting the Bernath correlation is its relative ease of use as compared to several other correlations that all predict CHFs which are reasonably close to each other [10]. The functional form of the Bernath correlation is summarized in Table D-2.

An analysis [11] of the data used to develop the Bernath correlation indicates that the ratio $\mathrm{q}$ (predicted)/q(measured) has a normal distribution with sample mean, $\mathrm{m}$, equal to 1 and standard deviation, $s$, equal to \pm 0.165 . Since the data sample is finite $(n=250)$ the value of $s$ is only an estimate of the true value, $\sigma$. To account for this in the analysis in a conservative way the following expression is used to obtain a limiting estimate of $\sigma$ [12]

$$
\sigma \approx \frac{\mathrm{k}}{\mathrm{k}_{\infty}} \mathrm{s}
$$

where $\mathrm{k}$ is the one-sided tolerance parameter defined such that a percentage $\mathrm{P}$ of the population is less than $\mathrm{m}+\mathrm{k} \mathrm{s}$ with probability equal to $\gamma$. The values of $\mathrm{k}$ are listed in Reference 13 for various values of $P, \gamma$ and $n$. $k_{\infty}$ is the value of $k$ when $n$ is infinite. At the $95 / 95 \%$ confidence limits $(\mathrm{P}=95, \gamma=.95) \mathrm{k}$ and $\mathrm{k}_{\infty}$ are found to be 1.815 and 1.645 , respectively. With these values in hand the upper limit estimate of $\sigma$ is found to be \pm 0.182 .

\section{D4. Formulation of Hot Channel Variables}

To compute the pdf of the parameters of interest, (critical heat flux ratio, temperature rise, etc.), these parameters must be expressed in terms of the individual hot channel factors in Table D-1. These relationships are developed below. The subscripts $r$ refers to the random value of the variable and $\mathrm{n}$ refers to the nominal or calculated value.

\section{D4.1 Channel Velocity and Mass Flow Rate}

Referring to Table D-1, it is seen that the coolant velocity is proportional to $F_{5}$ and $F_{6}$. $F_{4}$, the channel dimensional tolerance factor, affects the velocity because of the dependence of frictional loss on channel equivalent diameter. For a given pressure loss and channel length, the average velocity in a channel in turbulent flow can be shown to be related to the average equivalent diameter as follows:

$$
\bar{V} \propto \bar{D}^{2 / 3}
$$

Because of the large aspect ratio (width to gap) in the channel, the flow area, A, and channel gap, $\mathrm{d}$, are approximately proportional to equivalent diameter. Thus the following relationships hold:

$$
\begin{gathered}
\bar{V} \propto \bar{d}^{2 / 3} \\
M \propto \bar{V} \bar{A} \propto \bar{V} \bar{d} \propto \bar{d}^{5 / 3}
\end{gathered}
$$


where $\mathrm{M}$ is the mass flow rate and a bar over a symbol refers to the average value over the axial length of a flow channel. $\mathrm{F}_{4}$ is defined as $\bar{d}_{r} / \bar{d}_{n}$. These relationships can be combined to yield

$$
\begin{aligned}
& \frac{\overline{V_{r}}}{\overline{V_{n}}}=F_{5} F_{6} F_{4}^{2 / 3} \\
& \frac{M_{r}}{M_{n}}=F_{5} F_{6} F_{4}^{5 / 3}
\end{aligned}
$$

The local velocity is important in the evaluation of the heat transfer coefficient. The local velocity is related to the average velocity as follows:

$$
M \propto \bar{V} \bar{d}=V d
$$

Combining relationships (4) and (6) and noting that $\overline{\mathrm{d}}_{\mathrm{n}}=\mathrm{d}_{\mathrm{n}}$, we obtain

$$
\frac{V_{r}}{V_{n}}=F_{5} F_{6} F_{4}^{2 / 3} \frac{\overline{d_{r}}}{d_{r}}
$$

Since $F_{3}$ is defined as $d_{r} / \bar{d}_{r}$, equation (7) simplifies to

$$
\frac{V_{r}}{V_{n}}=\left(F_{5} F_{6} F_{4}^{2 / 3}\right) / F_{3}
$$

\section{D4.2 Bulk Temperature Rise - $\Delta \mathbf{T}_{\mathrm{b}}$}

The bulk temperature rise is directly proportional to $F_{1}, F_{2}$ and $F_{8}$ and inversely proportional to the mass flow rate.

Using the mass flow rate relationship expressed in equation (5), the normalized value of $\Delta \mathrm{T}_{\mathrm{b}}$ is given by

$$
\left(\Delta T_{b}\right)_{r} /\left(\Delta T_{b}\right)_{n}=\left(F_{1} F_{2} F_{8}\right) /\left(F_{5} F_{6} F_{4}^{5 / 3}\right)
$$




\section{D4.3 Local Heat Flux}

The local heat flux at the surface of a fuel plate is directly proportional to factors $F_{1}, F_{2}$ and $F_{7}$, thus

$$
q_{r} / q_{n}=F_{1} F_{2} F_{7}
$$

\section{D4.4 Heat Transfer Coefficient}

The heat transfer coefficient is directly proportional to the correlation factor $F_{10}$. The coefficient is also a function of local channel dimensions, local coolant velocity and bulk temperature. However, the sensitivity to bulk temperature is small and can be ignored. This approximation is conservative in that increases in bulk temperature result in a higher coefficient and a lower film temperature drop. From the Dittus-Boelter correlation,

$$
h \propto V^{0.8} d^{-0.2}
$$

where $\mathrm{h}$ is the local coefficient.

Combining relationships (8) and (11) with the definition for $\mathrm{F}_{3}$ and $\mathrm{F}_{4}$ and including the correlation factor $\mathrm{F}_{10}$ we obtain

$$
h_{r} / h_{n}=F_{10}\left(F_{5} F_{6} F_{4}^{2 / 3} / F_{3}\right)^{0.8}\left(F_{3} F_{4}\right)^{-0.2}
$$

Simplifying, this becomes

$$
h_{r} / h_{n}=F_{10} F_{4}^{1 / 3} F_{5}^{0.8} F_{6}^{0.8} / F_{3}
$$

\section{D4.5 Film Temperature Rise}

The temperature difference between the fuel plate surface and bulk coolant temperature is defined as

$$
\Delta T_{f}=q / h
$$

Combining equations (10) and (13), $\Delta \mathrm{T}_{\mathrm{f}}$ can be expressed as

$$
\left(\Delta T_{f}\right)_{r} /\left(\Delta T_{f}\right)_{n}=F_{1} F_{2} F_{7} F_{3} / F_{10} F_{4}^{1 / 3} F_{5}^{0.8} F_{6}^{0.8}
$$

\section{D4.6 Critical Heat Flux}

The Bernath correlation (see Table D-2) indicates that the CHF is a function of coolant temperature $\left(T_{b}\right)$, coolant velocity $(V)$, equivalent diameter $(D)$, and pressure $(P)$. The CHF is also a function of the "heated" diameter $\left(\mathrm{D}_{\mathrm{i}}\right)$ but this parameter is essentially constant and will not be considered in the uncertainty analysis. 
It is not possible to express the normalized CHF in such a way that only $\mathrm{F}$ factors appear in the expression. Nominal values have to be assumed for $\mathrm{T}_{\mathrm{b}}, \mathrm{V}, \mathrm{D}$ and $\mathrm{P}$. Define the CHF as computed by the Bernath correlation as

$$
C H F=\psi\left(T_{b}, V, D, P\right)
$$

Then

$$
C H F_{n}=\psi\left(\left(T_{b}\right)_{n}, V_{n}, D_{n}, P_{n}\right) \equiv \psi_{n}
$$

and

$$
C H F_{r}=\psi\left(\left(T_{b}\right)_{r}, V_{r}, D_{r}, P_{r}\right) / F_{11} \equiv \psi_{r} / F_{11}
$$

The critical heat flux is inversely proportional to the correlation factor $F_{11}$. The random values of the variable within the brackets are given by

$$
\begin{gathered}
V_{r}=V_{n} F_{5} F_{6} F_{4}^{2 / 3} / F_{3} \\
D_{r}=D_{n} F_{3} F_{4} \\
P_{r}=P_{n} F_{5} \\
\left(T_{b}\right)_{r}=\left(T_{0}\right)_{n}+1.0+\left(\Delta T_{b}\right)_{n} F_{1} F_{2} F_{8} / F_{5} F_{6} F_{4}^{5 / 3}
\end{gathered}
$$

$\left(\mathrm{T}_{\mathrm{o}}\right)_{\mathrm{n}}$ is the nominal value of the core inlet temperature. As was discussed in Section $\mathrm{D}-2,1^{\circ} \mathrm{C}$ $\left(1.8^{\circ} \mathrm{F}\right)$ is added as a fixed value to the nominal value of the bulk inlet temperature to account for the uncertainty in inlet temperature measurement.

The normalized random value of the CHF is

$$
(C H F)_{r} /(C H F)_{n}=\psi_{r} / \psi_{n} F_{11}
$$

\section{D4.7 Critical Heat Flux Ratio}

The CHFR is defined as

$$
C H F R=C H F / q
$$

In normalized form this becomes

$$
(C H F R)_{r} /(C H F R)_{n}=\psi_{r} /\left(\psi_{n} F_{11} F_{1} F_{2} F_{7}\right)
$$




\section{D5. Computation of Distribution Functions for the Hot Channel Variables}

\section{D5.1 Monte Carlo Method}

A Monte Carlo simulation is used to compute the CDF of the channel variables with full statistical treatment of the hot channel factors listed in Table D-1. In a Monte Carlo analysis, the values of a variable are picked randomly according to the assumed statistical distribution for the variable. In the current analysis, all $\mathrm{F}$ factors are assumed to have a normal distribution. Since the F factor is defined as normal with mean equal to 1 and standard deviation equal to $\sigma$, the BoxMuller $\left.{ }^{[} 14\right]$ simulation is utilized to sample the hot channel variables.

A random value of each of the $\mathrm{F}$ factors of interest is obtained as follows. First, two pseudo-random numbers, $Z_{1}$ and $Z_{2}$, are generated using a random number generator with uniform distribution in the interval $(0,1)$, and it can be proved that $X_{1}$ and $X_{2}$ computed using the following expressions:

$$
\begin{aligned}
& X_{1}=\left(-2 \ln Z_{1}\right)^{1 / 2} \cos \left(2 \pi Z_{2}\right) \\
& X_{2}=\left(-2 \ln Z_{1}\right)^{1 / 2} \sin \left(2 \pi Z_{2}\right)
\end{aligned}
$$

are two independent random variables having normal distribution with zero mean and a unit standard deviation. A random number $X$ generated with the Box-Muller method can then be converted to a normally distributed $\mathrm{F}$ factor with the following relation

$$
F=1+X \sigma
$$

When a set of random $\mathrm{F}$ values for a particular normalized parameter (e.g., CHFR) is obtained, the parameter is evaluated. A new set of random $\mathrm{F}$ values is obtained and the parameter evaluated again. This process is repeated until a large sample size (e.g., 100,000) of parameter values is computed. The statistically sampled values of the parameters are sorted in ascending order and the CDF is determined as follows:

$$
F(y)=N_{y} / N_{T}
$$

where

$$
\begin{aligned}
& \mathrm{F}(\mathrm{y})=\text { CDF of random variable } \mathrm{y} \\
& \mathrm{N}_{\mathrm{y}}=\begin{array}{l}
\text { number of parameter values which are } \\
\text { equal to or less than } \mathrm{y} .
\end{array} \\
& \mathrm{N}_{\mathrm{T}}=\text { sample size }
\end{aligned}
$$

To address the accuracy associated with the sample size used in the Monte Carlo process, the CDFs of the hot channel variables were computed with two sample sizes, namely, 100,000 and 200,000 , respectively. The results of the variable values corresponding to the $95 \%$ probability (in 
the case of CHFR, both $95 \%$ and $99.9 \%$ values were computed) are tabulated in Table D-3. As indicated in this table, the error due to the sample size is equal to or less than $0.52 \%$.

\section{D5.2 Results and Analysis of Distribution Functions}

An in-house computer program was developed at BNL to compute the CDF for the hot channel variables using a Monte Carlo method. Two approaches were used to validate the program. In the first approach, an extremely small value was assumed for the uncertainties associated with the hot channel factors, and the distribution calculated this way resembles a delta function about the mean value. Therefore, the ratio of the random to nominal values should approach unity. The program was validated with this approach using BNL HFBR data.

The second approach is to validate the program against existing results. The BNL HFBR SAR [11] documented the results of the hot channel analysis, which includes the CDFs of all channel variables as well as the input parameters utilized to derive these distributions. The newly developed program was used to repeat the HFBR hot channel analysis. A comparison of the calculated distributions with the HFBR SAR data showed practically identical results. This exercise also serves to verify and validate the in-house program.

The nominal values of input parameters for the NBSR analysis are provided in Table D-4. The parameter values in this table were calculated based on the information provided by NIST. The nominal parameters, together with the distributions for the hot channel factors as listed in Table D-2, were used to perform the probabilistic hot channel analysis for the NBSR. The following subsections provide a detailed description of the probability statements and the analysis of results in terms of CDFs for each of the hot channel variables.

\section{D5.2.1 Coolant Bulk Temperature Rise}

The CDF of the normalized bulk temperature rise (equation (9)) is shown in Figure D-1. The curve expresses the relation

or equivalently

$$
\operatorname{Pr}\left(\left(\Delta T_{b}\right)_{r} /\left(\Delta T_{b}\right)_{n} \leq Z\right)=p
$$

$$
\operatorname{Pr}\left(\left(\Delta T_{b}\right)_{r} \leq Z\left(\Delta T_{b}\right)_{n}\right)=p
$$

For example, the value of $Z$ corresponding to $p=0.95$ is 1.167 . Thus, the nominal value of the bulk temperature that is calculated at a particular core location is multiplied by 1.167 to obtain the upper limit value such that the probability is $95 \%$ that this value will not be exceeded.

\section{D5.2.2 Local Heat Flux}

The CDF of the normalized heat flux (equation (10)) is shown in Figure D-2. The curve expresses the relation

$$
\operatorname{Pr}\left(q_{r} / q_{n} \leq Z\right)=p
$$


The value of $Z$ corresponding to the $95 \%$ probability level is 1.333 .

\section{D5.2.3 Film Temperature Rise}

The CDF of the normalized film temperature rise (equation (15)) is shown in Figure D-3. The curve expresses the relation

$$
\operatorname{Pr}\left(\left(\Delta T_{f}\right)_{r} /\left(\Delta T_{f}\right)_{n} \leq Z\right)=p
$$

The value of $Z$ corresponding to the $95 \%$ probability level is 1.281 .

\section{D5.2.4 Critical Heat Flux Ratio}

Because of the way the fuel damage criterion is expressed, the normalized critical heat flux ratio (equation (25)) is plotted in inverted form as shown in Figure D-4. The curve expresses the relation

$$
\left.\operatorname{Pr}\left((C H F R)_{n} /(C H F R)_{r}\right) \leq Z\right)=p
$$

In order to satisfy the criterion of no fuel damage stated in Section D.1.2, it is first necessary to develop a probability statement of no fuel damage for an arbitrary subregion of the core. Given the CHFR for a subregion of the core, the probability statement,

$$
\operatorname{Pr}\left((C H F R)_{r}>1.0\right)=p_{o}
$$

defines the probability, $p_{o}$, of no fuel damage in that subregion. Multiplying both terms in the above probability statement by the ratio $(\mathrm{CHFR})_{\mathrm{n}} /(\mathrm{CHFR})_{\mathrm{r}}$ and rearranging we obtain,

$$
\operatorname{Pr}\left((C H F R)_{n} /(C H F R)_{r}<(C H F R)_{n}\right)=p_{o}
$$

which has the same form as equation (34). For $p_{o}=0.999$, the value of $Z$ from Figure D-4 is 1.911, which means that the nominal value of the critical heat flux ratio (CHFR) must be at least 1.911 in order for a subregion of the core to have a 0.999 probability of no fuel damage. It can also be stated that if the minimum critical heat flux ratio $(\mathrm{CHFR})_{\mathrm{n}}$ for the whole core is equal to 1.911 , there is a $99.9 \%$ probability that no overheating in the hottest node of the fuel plates will occur.

The CDF of CHFR shown in Figure D-4 implies that the subregion or node with the minimum $(\mathrm{CHFR})_{\mathrm{n}}$ in the core will have the highest probability of fuel failure. The no fuel damage criterion can be extended further to define a CHFR value that corresponds to a $99.9 \%$ probability that there is no overheating in any subregion of the core. This is done by taking into account the contribution to the probability of fuel damage by subregions of the core other than the one with the minimum CHFR. The extension of the CHF analysis to cover nodes other than the hottest one in the core requires additional calculations to provide detailed power distribution throughout the core. 
Table D-1. Hot Channel Uncertainties

\begin{tabular}{|c|c|c|c|}
\hline Source of Uncertainty & $\begin{array}{l}\text { Normalized } \\
\text { Variable } \\
\text { Identification }\end{array}$ & Limits * & References \\
\hline Reactor Power Measurement & $\mathrm{F}_{1}$ & \pm 0.025 & $\begin{array}{l}\text { Table } 3.2-1 \text { of NBSR } \\
9 \text { Addendum } 1 .\end{array}$ \\
\hline Power Density Computation & $\mathrm{F}_{2}$ & \pm 0.05 & $\begin{array}{l}\text { Use BNL HFBR } \\
\text { SAR.value as } 2 \sigma\end{array}$ \\
\hline $\begin{array}{l}\text { Channel Dimensional Tolerance } \\
\text { (local) }\end{array}$ & $\mathrm{F}_{3}$ & \pm 0.045 & Dwg \# E-04-016 \\
\hline $\begin{array}{l}\text { Channel Dimensional Tolerance } \\
\text { (average) }\end{array}$ & $\mathrm{F}_{4}$ & \pm 0.03 & Dwg \# E-04-016 \\
\hline $\begin{array}{l}\text { Velocity Distribution Measure- } \\
\text { ment }\end{array}$ & $\mathrm{F}_{5}$ & \pm 0.04 & $\begin{array}{l}\text { NBSR 9, } \\
\text { 4.7.4.5, 4.7.4.6 }\end{array}$ \\
\hline $\begin{array}{l}\text { Primary Flow Rate Measure- } \\
\text { ment }\end{array}$ & $\mathrm{F}_{6}$ & \pm 0.015 & $\begin{array}{l}\text { email from NIST on } \\
7 / 31 / 02\end{array}$ \\
\hline Fuel Loading Tolerance (local) & $\mathrm{F}_{7}$ & \pm 0.12 & $\begin{array}{l}\text { Dwg \# 4-2002, rev. } \\
\text { C, 2-20-81 }\end{array}$ \\
\hline $\begin{array}{l}\text { Fuel Loading Tolerance (aver- } \\
\text { age) }\end{array}$ & $\mathrm{F}_{8}$ & \pm 0.035 & $\begin{array}{l}\text { Dwg \# 4-2002, rev. } \\
\text { C, 2-20-81 }\end{array}$ \\
\hline Pressure Measurement ${ }^{* *}$ & $\mathrm{~F}_{9}$ & \pm 0.0 & Assumed Constant \\
\hline Heat Transfer Correlation & $\mathrm{F}_{10}$ & \pm 0.075 & Use HFBR value \\
\hline Critical Heat Flux Correlation & $\mathrm{F}_{11}$ & \pm 0.182 & Use HFBR value \\
\hline
\end{tabular}

*Uncertainty limits represent $1 \sigma$ standard deviation assuming a normal distribution. When the referenced uncertainties are given as lower and upper limits, the range is assumed to represent a $2 \sigma$ value.

** $F_{9}$ is assigned a constant value of unity because the NBSR is an unpressurized reactor. 


\section{Table D-2. Bernath Correlation}

Bernath Sub-cooled Burnout Correlation:

where

$$
C H F=h_{b o}\left(T_{w}-T_{b}\right)
$$

$$
\begin{aligned}
& h_{b o}=61836 D_{e} /\left(D_{e}+D_{i}\right)+438.38 V / D_{e}^{0.6}, W / m^{2}-K \\
& T_{w}=57 \ln P-54 P /(P+103421)-0.82021 V-230.645, K \\
& O r \\
& h_{b o}=10890 D_{e} /\left(D_{e}+D_{i}\right)+48 V / D_{e}^{0.6}, B T U / h r-f t^{2}-{ }^{o} F \\
& T_{w}=102.6 \ln P-97.2 P /(P+15)-V / 2.22+32,{ }^{o} F
\end{aligned}
$$

Note: the above equations require the use of consistent units. If the result is to be in S.I. units then all variables in the equation have to be in S.I. units also.

Nomenclature

$$
\begin{array}{ll}
\mathrm{h}_{\mathrm{bo}} & =\text { burnout heat transfer coefficient, } \mathrm{W} / \mathrm{m}^{2}-\mathrm{K}\left(\mathrm{BTU} / \mathrm{hr}-\mathrm{ft}^{2}-{ }^{\circ} \mathrm{F}\right) . \\
\mathrm{D}_{\mathrm{e}} & =\text { equivalent diameter, } \mathrm{m}(\mathrm{ft}) . \\
\mathrm{D}_{\mathrm{i}} & =\text { heated perimeter } / \pi, \mathrm{m}(\mathrm{ft}) \\
\mathrm{T}_{\mathrm{w}} & =\text { surface temperature at burnout condition, } \mathrm{K}\left({ }^{\circ} \mathrm{F}\right) . \\
\mathrm{T}_{\mathrm{b}} & =\text { coolant temperature, } \mathrm{K}\left({ }^{\circ} \mathrm{F}\right) \\
\mathrm{P} & =\text { pressure, } \mathrm{Pa}(\mathrm{psia}) \\
\mathrm{V} & =\text { coolant velocity, } \mathrm{m} / \mathrm{s}(\mathrm{ft} / \mathrm{sec}) \\
\mathrm{CHF} & =\text { critical heat flux, } \mathrm{W} / \mathrm{m}^{2}\left(\mathrm{BTU} / \mathrm{hr}-\mathrm{ft}^{2}\right)
\end{array}
$$


Table D-3. Sensitivity of Sampling Size

\begin{tabular}{|c|c|c|c|c|c|c|}
\hline Probability Level & \multicolumn{2}{|c|}{$95 \%$} & \multirow{2}{*}{$\begin{array}{c}\text { Error } \\
(\%)\end{array}$} & \multicolumn{2}{|c|}{$99.9 \%$} & \multirow{2}{*}{$\begin{array}{c}\text { Error } \\
(\%)\end{array}$} \\
\hline Sampling Size & 100000 & 200000 & & 100000 & 200000 & \\
\hline Hot Channel Variable & & & & & & \\
\hline$(\mathrm{CHFR})_{\mathrm{n}} /(\mathrm{CHFR})_{\mathrm{r}^{*}}$ & 1.435 & 1.435 & 0.0 & 1.921 & 1.911 & 0.52 \\
\hline$\left(\Delta \mathrm{T}_{\mathrm{b}}\right)_{\mathrm{r}} /\left(\Delta \mathrm{T}_{\mathrm{b}}\right)_{\mathrm{n}}$ & 1.167 & 1.164 & 0.26 & & & \\
\hline$\left(\Delta \mathrm{T}_{\mathrm{f}}\right)_{\mathrm{r}} /\left(\Delta \mathrm{T}_{\mathrm{f}}\right)_{\mathrm{n}}$ & 1.281 & 1.283 & 0.16 & & & \\
\hline$(q)_{r} /(q)_{n}$ & 1.333 & 1.333 & 0.0 & & & \\
\hline
\end{tabular}

* This ratio defines the limiting minimum $(\mathrm{CHFR})_{\mathrm{n}}$

Table D-4. Nominal Values of Input Parameters Full Power Operation

\begin{tabular}{|l|l|}
\hline Variable & Nominal Value \\
\hline Equivalent Diameter ${ }^{1}\left(\mathrm{D}_{\mathrm{e}}\right)$ & $0.0055702 \mathrm{~m}(0.2193 \mathrm{in})$. \\
${\text { Heated Diameter }\left(\mathrm{D}_{\mathrm{i}}\right)}^{\text {Pressure }(\mathrm{P})}$ & $0.0064897 \mathrm{~m}(0.2555 \mathrm{in})$. \\
Coolant Velocity $^{2}(\mathrm{~V})$ & $1.0132 \times 10^{5} \mathrm{~Pa}(14.7 \mathrm{psia})$ \\
${\text { Core Inlet Temperature }\left(\mathrm{T}_{0}\right)}^{\text {Bulk Temperature Rise }}{ }^{3}\left(\Delta \mathrm{T}_{\mathrm{b}}\right)$ & $4.0843 \mathrm{~m} / \mathrm{s}(13.4 \mathrm{ft} / \mathrm{sec})$ \\
& $19.48 \mathrm{~K}\left(110^{\circ} \mathrm{F}\right)$ \\
\hline
\end{tabular}

1) Nominal hydraulic diameter of coolant channel in the plated region.

2) Coolant velocity includes a 0.94 multiplier for variation across the width of a coolant channel and a 0.95 multiplier for channel-to-channel variation.

3) The bulk temperature rise varies with core position and core power. It is set conservatively at $19.4 \mathrm{~K}\left(35^{\circ} \mathrm{F}\right)$, a value two to three times the average bulk temperature rise at full power (20 MW). 


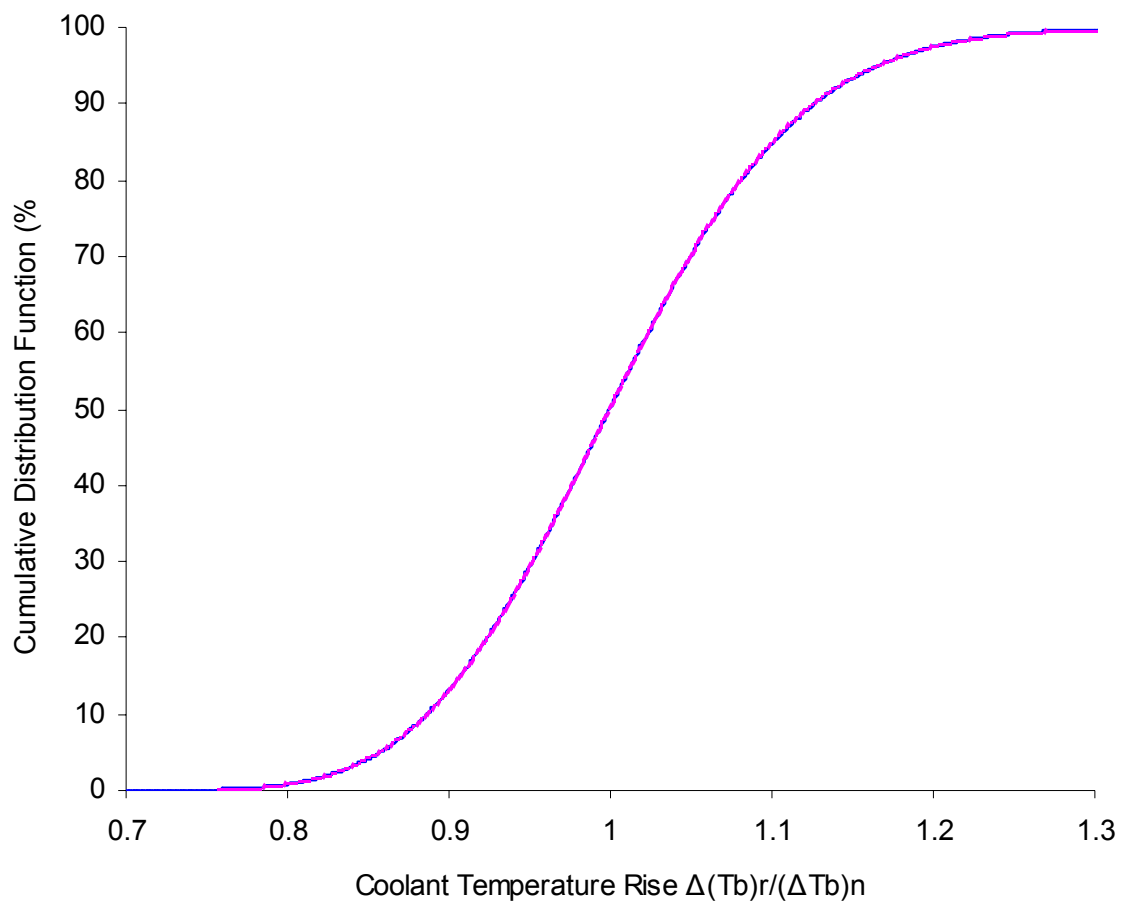

100000 samples

200000 samples

Figure D- 1. Cumulative Distribution Function of $(\Delta T b)_{r} /(\Delta T b)_{n}$ for NBSR

D - 13 


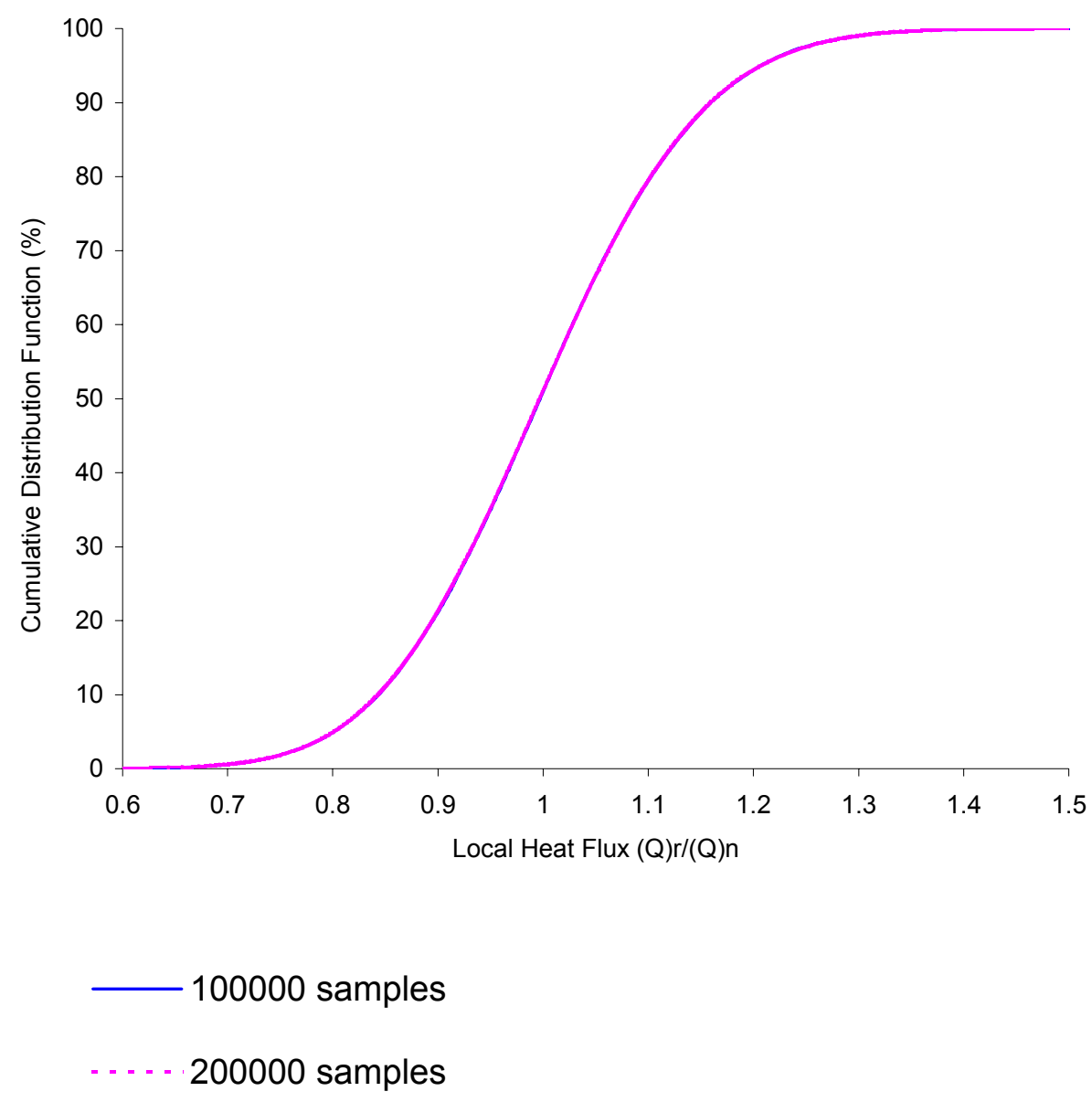

Figure D- 2. Cumulative Distribution Function of $(Q) r /(Q) n$ for NBSR

D - 14 


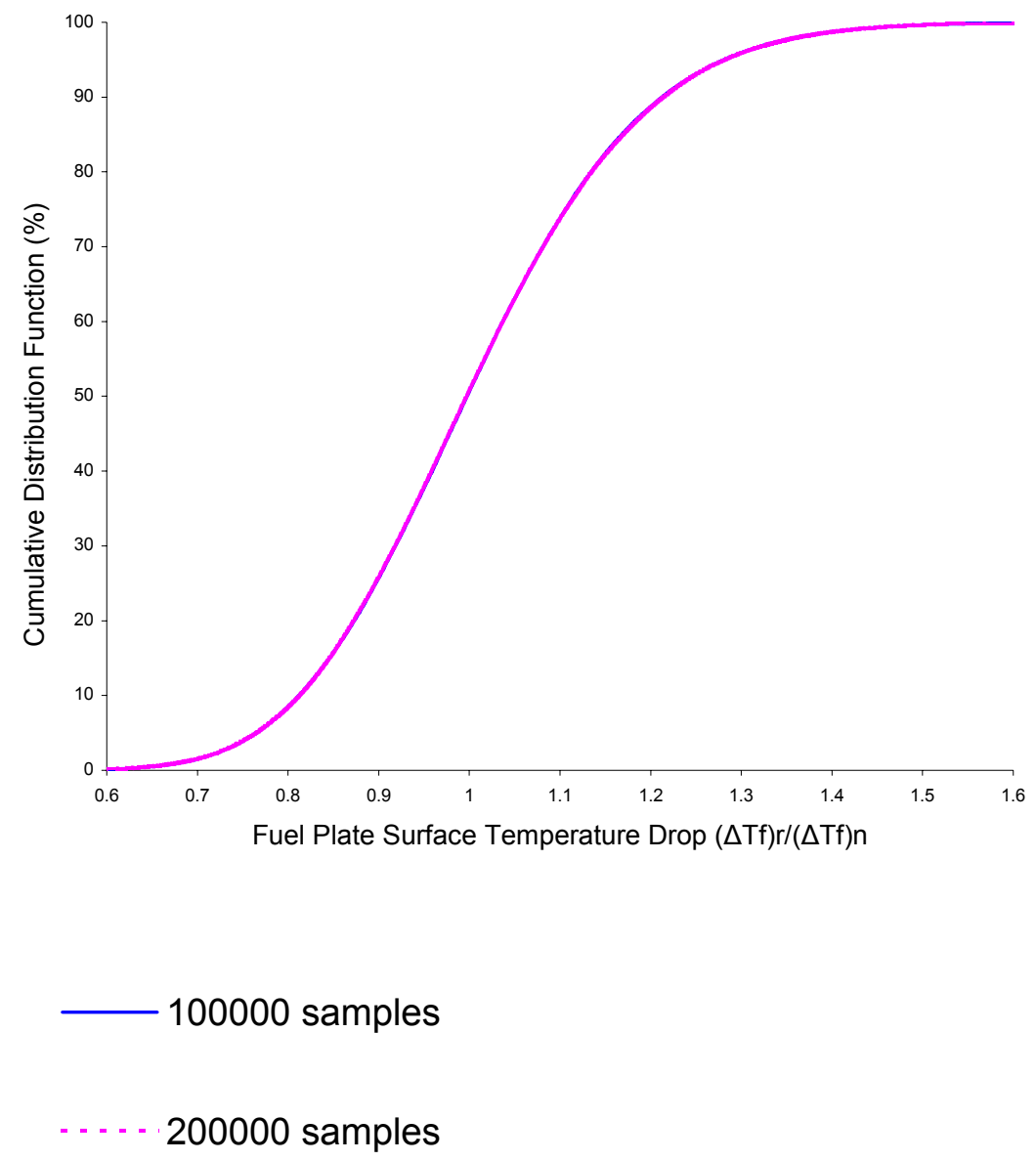

Figure D- 3 Cumulative Distribution Function of $(\Delta T f) r /(\Delta T f) n$ for NBSR 


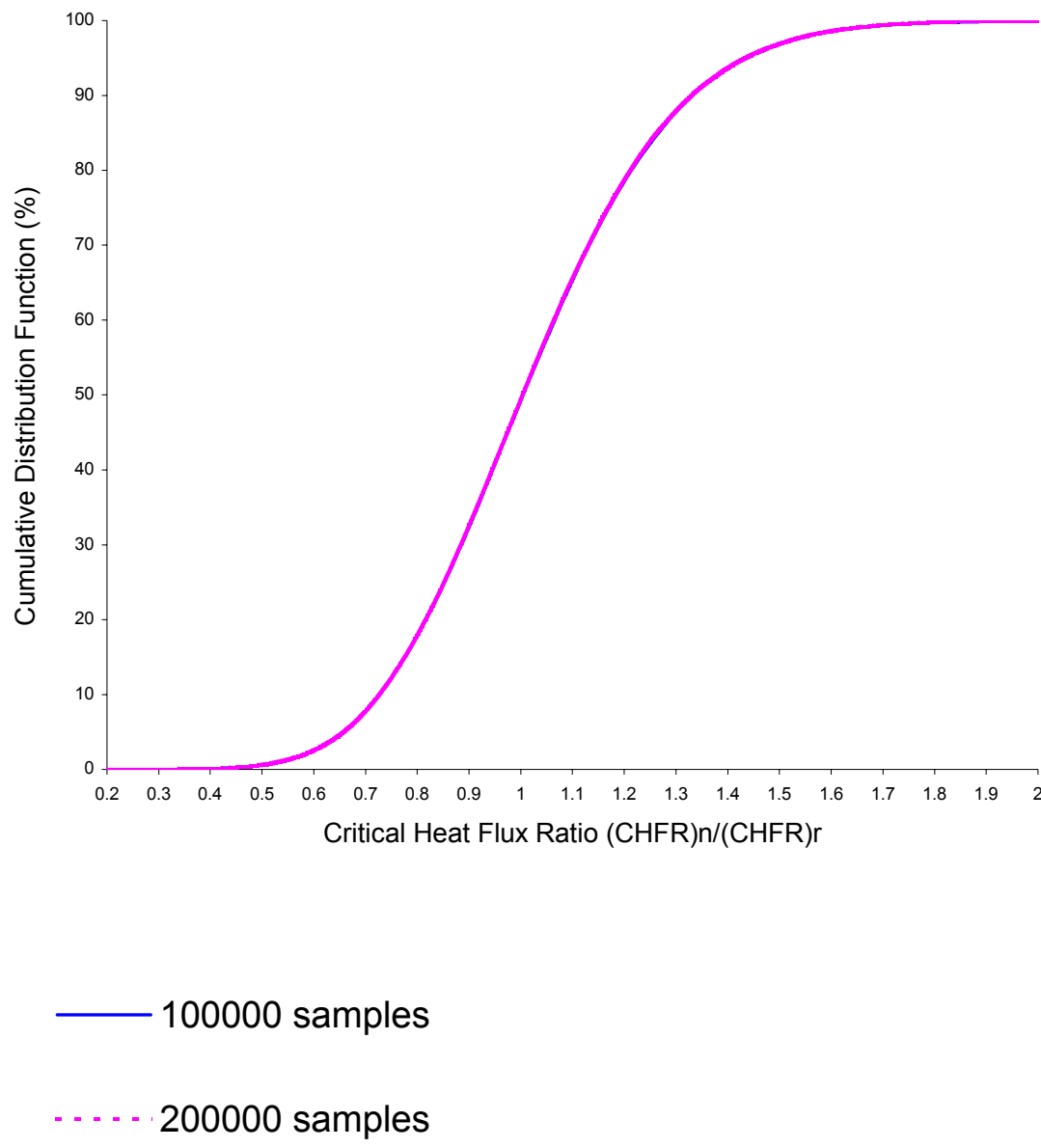

Figure D-4. Cumulative Distribution Function of CHFR for NBSR

D - 16 


\section{APPENDIX E}

\section{FLOODING-LIMITED CRITICAL POWER}

Flooding is a two-phase flow phenomenon that occurs in counter-current gas-liquid flow. Imagine an annular film of liquid flowing down a heated vertical tube with a center core of vapor flowing in the opposite direction. The gas velocity will increase with the power applied to the flow channel. With increasing gas velocity, the shear force at the gas-liquid interface will eventually reach a value that is high enough to impede the downward flow of the liquid. At this point the liquid flow becomes counter-current flow limited. The slowing down of the liquid film velocity by the interfacial shear will cause the film thickness to increase. If the gas velocity continues to increase, the so-called flooding phenomenon may occur whereby the shear forces completely prevent the downward liquid flow and flood (block) the flow channel with the liquid. For a heated channel with a blocked bottom, coolant makeup is from liquid down flow at the open end on top. For a given flow of gas, generated by boiling in the blocked flow channel, the maximum flow of liquid is restricted by the phenomenon of counter-current flow limitation (CCFL). A critical power for the blocked channel is reached when the steam flow rate exceeds that of the liquid flow. This deficit in liquid flow would lead to the eventual dryout of the channel. The flooding-limited critical power is defined as the maximum power a blocked channel can sustain under the counter-current flow limitation.

Empirical correlations for CCFL are typically expressed in terms of the superficial velocities of the gas and liquid flow. The correlation developed by Sudo and Kaminaga [1] is based on test data that closely match the NBSR channel geometry and is thus applicable to the determination of the flooding-limited critical power for the NBSR. The following discussion follows essentially the derivation of the critical power in Reference 2 .

The CCFL data obtained by Sudo and Kaminaga [1] in thin rectangular channels are shown to be well-correlated by the following expression,

$$
\mathrm{X}^{0.7}+\mathrm{Y}^{0.7}=1.3^{0.7}
$$

where

$$
\begin{aligned}
& X=\frac{m}{C} j_{1}^{* 1 / 2} \\
& Y=\frac{1}{C} j_{g}^{* 1 / 2}
\end{aligned}
$$

and, 


$$
\begin{aligned}
& \mathrm{C}=0.66\left(\frac{\mathrm{W}}{\mathrm{S}}\right)^{0.25} \\
& \mathrm{~m}=0.5+0.0015 \mathrm{Bo}^{1.3}
\end{aligned}
$$

The Bond number, Bo, is given by,

$$
\mathrm{Bo}=\frac{\mathrm{WS}}{\lambda^{2}}
$$

where $\lambda$ a length scale associated with Taylor instability in stratified fluids is given by,

$$
\lambda=\left(\frac{\sigma}{\left(\rho_{1}-\rho_{\mathrm{g}}\right) g}\right)^{1 / 2}
$$

and $\mathrm{W}$ and $\mathrm{S}$ are the channel width and channel gap respectively.

The dimensionless superficial velocities of the upward gas flow $\left(\mathrm{j}_{\mathrm{g}}{ }^{*}\right)$ and downward liquid flow $\left(\mathrm{j}_{1} *\right)$ are expressed by using the channel gap $\mathrm{S}$ as the characteristic length scale.

$$
\begin{aligned}
& j_{g}^{*}=\left[\frac{\rho_{g}}{g S\left(\rho_{1}-\rho_{g}\right)}\right]^{1 / 2} j_{g} \\
& j_{1}^{*}=\left[\frac{\rho_{1}}{g S\left(\rho_{1}-\rho_{g}\right)}\right]^{1 / 2} j_{1}
\end{aligned}
$$

In the above equations $\sigma$ is the surface tension, $g$ is the gravitational acceleration and $\rho_{g}$ and $\rho_{\mathrm{f}}$ are the densities of the gas and liquid respectively.

The energy balance for counter-current flow in a heated channel with blocked bottom is given by,

$$
\mathrm{Q}=\mathrm{h}_{\mathrm{fg}} \rho_{\mathrm{g}} \mathrm{j}_{\mathrm{g}} \mathrm{A}+\rho_{1} \mathrm{j}_{\mathrm{l}} \mathrm{C}_{\mathrm{p}} \Delta \mathrm{T}_{\text {sub }} A
$$

In Equation (10) $Q$ is the power of the heated channel; $h_{f g}$ is the heat of vaporization; $C_{p}$ is the specific heat capacity of the liquid; $\Delta \mathrm{T}_{\text {sub }}$ is the liquid subcooling at the top of the channel, and $\mathrm{A}$ is the channel flow area. Under the flooding-limited power condition, the 
mass conservation requires that the net mass flux to the flow channel is zero, and this implies,

$$
\mathrm{G}_{\mathrm{c}}=\rho_{1} \mathrm{j}_{1}=\rho_{\mathrm{g}} \mathrm{j}_{\mathrm{g}}
$$

The critical power $\mathrm{Q}_{\mathrm{c}}$ corresponding to the critical mass flux $\mathrm{G}_{\mathrm{c}}$ is given by,

$$
\mathrm{Q}_{\mathrm{c}}=\mathrm{G}_{\mathrm{c}} \mathrm{A}\left(\mathrm{h}_{\mathrm{fg}}+\mathrm{C}_{\mathrm{p}} \Delta \mathrm{T}_{\mathrm{sub}}\right)
$$

The critical mass flux $\mathrm{G}_{\mathrm{c}}$ is obtained from Equations (1) and (11) and it has the form,

$$
\mathrm{G}_{\mathrm{c}}=\left[\frac{1.3 \mathrm{x} 0.66\left(\mathrm{~W} \rho_{\mathrm{g}}\left(\rho_{\mathrm{l}}-\rho_{\mathrm{g}}\right) \mathrm{g}\right)^{0.25}}{\left(1+\left\{\mathrm{m}\left(\frac{\rho_{\mathrm{g}}}{\rho_{\mathrm{l}}}\right)^{0.25}\right\}^{0.7}\right)^{1 / 0.7}}\right]^{2}
$$

The flooding-limited critical power becomes,

$$
\mathrm{Q}_{\mathrm{c}}=\mathrm{A}\left(\mathrm{h}_{\mathrm{fg}}+\mathrm{C}_{\mathrm{p}} \Delta \mathrm{T}_{\mathrm{sub}}\right)\left[\frac{0.858\left\{\mathrm{~W} \rho_{\mathrm{g}}\left(\rho_{\mathrm{l}}-\rho_{\mathrm{g}}\right) \mathrm{g}\right\}^{0.25}}{\left(1+\left\{\mathrm{m}\left(\frac{\rho_{\mathrm{g}}}{\rho_{\mathrm{l}}}\right)^{0.25}\right\}^{0.7}\right)^{1 / 0.7}}\right]^{2}
$$

Equation (14) is applied to calculate the flooding-limited critical power for the NBSR flow channel. The channel is assumed to have a channel gap, $\mathrm{S}$, of $2.73 \times 10^{-3} \mathrm{~m}(0.107 \mathrm{in})$ (corresponding to the minimum centerline gap of 0.109 in) and a span (flattened plates), $\mathrm{W}$, of $0.0673 \mathrm{~m}(2.65 \mathrm{in})$. The channel flow area, $\mathrm{A}$, is $1.84 \times 10^{-4} \mathrm{~m}^{2}\left(0.285 \mathrm{in}^{2}\right)$. At a pressure of 1 atmosphere $(0.101325 \mathrm{MPa})$, the following thermal properties for heavy water [3] are used in the calculation.

$$
\begin{gathered}
\rho_{\mathrm{f}}=1062.36 \mathrm{~kg} / \mathrm{m}^{3} \\
\rho_{\mathrm{g}}=0.6607 \mathrm{~kg} / \mathrm{m}^{3} \\
\mathrm{~h}_{\mathrm{fg}}=2073.4 \mathrm{~kJ} / \mathrm{kg} \\
\sigma=5.87 \times 10^{-2} \mathrm{~N} / \mathrm{m} \\
\mathrm{C}_{\mathrm{p}}=4.1613 \mathrm{~kJ} / \mathrm{kg}-\mathrm{K}
\end{gathered}
$$

From Equation (13) the critical flooding mass flux is,

$$
\mathrm{G}_{\mathrm{c}}=9.39 \mathrm{~kg} / \mathrm{m}^{2}-\mathrm{sec}
$$


Using Equation (14) and assuming zero liquid subcooling, the corresponding floodinglimited critical power, is,

$$
\mathrm{Q}_{\mathrm{c}}=3.58 \mathrm{~kW}
$$

Assume $\mathrm{Q}_{\mathrm{c}}$ is the hot channel power, i.e. the combined power from one fuel plate each in the lower and upper core. It has been noted in Section 4 of the main report that the power of the hottest channel is about 1.5 times the core average. For each fuel element there are 17 fuel plates each in the lower and upper core and the NBSR core has 30 elements. The corresponding core power when the hot channel reaches the flooding-limited power is estimated to be,

$$
\left(\mathrm{Q}_{d} 1.5\right) \times 17 \times 30=1.2 \mathrm{MW}
$$

For a $20 \mathrm{MW}$ core the decay power drops below $1 \mathrm{MW}$ in less than 30 seconds after reactor shutdown. Therefore power transferred to the coolant channels in the NBSR core would be below the flooding-limited critical power shortly after reactor shutdown. Even without any forced flow, decay power can be removed from the NBSR core simply by boiling, as long as the core is covered with coolant.

\section{References:}

1. Sudo, Y. and Kaminaga, M., "A CHF Characteristic for Downward Flow in a Narrow Vertical Rectangular Channel Heated from Both Sides," Int. J. Multiphase Flow, 15, No. 5, 1989.

2. Cheng, L. Y., "Flooding Limited Heating Rates in HFBR Coolant Channels," BNL Reactor Division Calculation No. SE-09, Rev. 2, Brookhaven National Laboratory, December 2, 1990.

3. Crabtree, A., Siman-Tov, M., "Thermophysical Properties of Saturated Light and Heavy Water for Advanced Neutron Source Applications," ORNL/TM-12322, Oak Ridge National Laboratory, May 1993. 